\author{
Universidade de São Paulo \\ Instituto de Astronomia, Geofísica e Ciências Atmosféricas \\ Departamento de Ciências Atmosféricas
}

Felipe Vemado

Dinâmica das tempestades sobre o Lago Vitória, África

Impacto da temperatura da superfície do lago na gênese desenvolvimento e dissipação dos eventos convectivos

São Paulo 
Felipe Vemado

\section{Dinâmica das tempestades sobre o Lago Vitória, África}

Impacto da temperatura da superfície do lago na gênese, desenvolvimento e dissipação dos eventos convectivos

Tese apresentada ao Departamento de Ciências Atmosféricas do Instituto de Astronomia, Geofísica e Ciências Atmosféricas da Universidade de São Paulo como requisito parcial para a obtenção do título de doutor em Ciências.

Área de Concentração: Ciências Atmosféricas Orientador: Prof. Dr. Augusto J. Pereira Filho Versão Corrigida. $O$ original encontra-se disponível na Unidade

São Paulo 
Aos meus pais e a minha vó 


\section{Agradecimentos}

A minha vó, Valderez pela paciência e convívio e pela força desprendida durante esses longos anos de convivência desde a graduação. Seu apoio foi de fundamental importância para a conclusão do presente projeto de pesquisa.

Aos meus pais, João e Antonia por todo amor, compreensão apoio e confiança por eles depositadas em mim. Aos meus irmãos Guilherme Vemado e Artur Vemado pelo companheirismo.

Ao Prof. Dr. Augusto José Pereira Filho, pelo apoio moral, acadêmico e de suporte durante o período da pesquisa, pela orientação desde o período de iniciação científica, além da amizade e das palavras sinceras e positivas que foram muito importantes para a conclusão desse projeto de pesquisa.

Aos Prof. Dr. Hugo Abi Karam e Prof. Dr. Ricardo Hallak, pelas importantes sugestões, dicas e ensinamentos no uso do modelo ARPS e métodos de análise do mesmo desde o período da graduação.

Aos amigos e colegas da pós-graduação do Departamento de Ciências Atmosféricas do IAG-USP , Msc. Angélica Tavares, Dr. José Flores, Msc. Lucas lima, Dr. Ivon Wilson da Silva Júnior e Msc. Aliton Oliveira da Silva pelo bom e agradável convívio social. Aos amigos que me acompanham Otavio Vieira Asquino, Fabricio Cristiano Souza, Marcelo Barbosa, Luciana Eto, Simone Valarini, Camila Ferrari, José Ricardo Costa, Thaissa Santana entre muitos outros por todos os bons momentos.

A todos os professores e funcionários do IAG pelo bom funcionamento da instituição e pelo compartilhamento dos seus conhecimentos.

Ao Conselho Nacional de Desenvolvimento Científico e Tecnológico (CNPQ) do Brasil, pela concessão da bolsa de Doutorado e pelo apoio financeiro para a realização desta pesquisa. 
Quanto mais aumenta nosso conhecimento, mais evidente fica nossa ignorância

[John F. Kennedy] 


\section{Resumo}

As circulações locais tem sido alvo de diversos estudos, pois em muitos locais exercem forte influência no disparo de convecção profunda com impactos significativos para a população. Particularmente, no presente trabalho, estudou-se o impacto da interação entre as circulações locais produzidas pelo Lago Vitória (LV) e a circulação de vale-montanha no disparo da convecção noturna com alta intensidade da precipitação e forte impacto para as populações locais. O mecanismo de disparo de tempestades sobre o Lago Vitória foi simulado por meio da modelagem numérica com o modelo The Advanced Regional Prediction System (ARPS) e sensoriamento remoto por meio de técnica que combina diferentes canais do satélite para a estimativa de precipitação denominada de CPC Morphing Technique (CMORPH). Utilizaramse as análises do modelo Global Forecast System (GFS), como condição inicial e de fronteira, para a modelagem numérica com o sistema ARPS. Os dados de satélite METEOSAT Segunda Geração (MSG) e a técnica CMORPH foram utilizados nos estudos. As estimativas de TSL obtidas por Anyah [2005] foram utilizadas em conjunto com as estimativas do MODIS nas simulações ARPS que auxiliaram na análise do mecanismo de disparo da convecção noturna sobre o LV. Obteve-se o campo tridimensional destas tempestades e as respectivas circulações associadas, assim como a estimativa de fluxos de calor sensível e latente. Por meio das simulações numéricas, estimou-se o efeito da topografia no entorno do LV sobre o escoamento predominantemente de leste (alísios) e sua interação na formação das circulações locais de brisa lacustre-terrestre e vale-montanha no disparo dessas intensas células convectivas, que se formam preferencialmente no período noturno. O mecanismo de geração de vorticidade vertical foi estimado por meio da equação de tendência de vorticidade. As estimativas com o CMORPH foram utilizadas para uma melhor caracterização climática dos eventos que se propagam pela África Equatorial entre $3^{\circ} \mathrm{S}-1^{\circ} \mathrm{N}$ e $24^{\circ} \mathrm{E}-42^{\circ} \mathrm{E}$ para o período entre 2000 e 2014 . Essa região incluí o Vale do Rift, metade leste da floresta do Congo e a bacia do Lago Vitória (LV). Diagramas Hovmoller foram utilizados para identificar todos os eventos convectivos que se 
deslocaram sobre a região e resultou num total de 33,189 eventos no período. Os resultados mostram que os sistemas se propagam de Leste para Oeste com velocidade de fase, duração e período médios de $10.3 \mathrm{~m} \mathrm{~s}^{-1}, 10.7 \mathrm{~h}$ e $332 \mathrm{~km}$, respectivamente. Para os eventos que se propagam por uma distância superior a $600 \mathrm{~km}$, a velocidade e duração média foram de $12 \mathrm{~m}$ $\mathrm{s}^{-1}$ e $19 \mathrm{~h}$, respectivamente. A maioria dos sistemas convectivos apresenta velocidade de fase entre $8 \mathrm{~m} \mathrm{~s}^{-1}$ e $16 \mathrm{~m} \mathrm{~s}^{-1}$ e duração entre 8 e 16 horas com três regiões preferenciais de disparo da convecção inicial: 1) a leste do LV sobre as montanhas, 2) metade oeste do LV e 3) sobre as montanhas a leste da floresta do Congo. As simulações com o sistema ARPS auxiliaram na análise dos processos dinâmicos e termodinâmicos associados às tempestades noturnas, que mostraram forte correlação com a TSL do lago Vitória. Assim, a sua estimativa é de fundamental importância para a previsão dessas tempestades na região. O padrão de TSL, obtido por meio dos estudos de Anyah [2005] de modelos hidrodinâmicos, foram os que melhor caracterizaram as chuvas convectivas noturnas sobre a região do Lago Vitória. Uma diferença de $2^{\circ} \mathrm{C}$ produz uma diferença de seis a oito vezes no fluxo de vapor de água entre o lago e a atmosfera e, na presença da cadeia de montanhas à leste do LV, age para reduzir os alísios de leste. As simulações sem montanhas indicam, em média, ventos com magnitude entre 1,5 a 2,0 $\mathrm{m} \mathrm{s}^{-1}$ acima do indicado na simulação com topografia realística e geram um fluxo de calor latente de $20 \mathrm{~W} \mathrm{~m}^{-2}$ superior, que favorece o disparo da convecção $1 \mathrm{~h}$ antes e volume de chuva de duas a três vezes acima da condição real. Espera-se que os resultados deste trabalho e de futuras publicações incentivem o estabelecimento de uma rede de monitoramento da TSL e tempestades convectivas que se formam na região para uma melhor previsibilidade desses eventos. 


\begin{abstract}
The local circulation has been targeted from several works due to high influence on triggering deep convection with significant impacts to the population. Particularly, in the present work it's been verified the impact of the interaction between lake breeze and valleymountain breeze on the deep convection over Victoria lake, during night, with high winds e heavy rainfall on it and impact to the population around it. The triggering mechanism of storms over Victoria lake it has been simulated with numerical model The Advanced Regional Prediction System (ARPS) and remote sensing through technique that combine different satellite channel to estimate precipitation. The analyses from Global Forecast system (GFS) it's been used as boundary and initial conditions in ARPS simulations. Observations from the METEOSAT second generation (MSG) and the CPC morphing technique (CMORPH) was used to investigate deep convection. The surface lake temperature (TSL) has been estimated from MODIS and Anyah [2005] hydrodynamical simulations and assimilated with ARPS system as initial conditions, that aided on the understanding of deep night convection over the lake. The three-dimensional field was obtained from these storms and its respective circulations and heating and latent fluxes. Also, the numerical simulations it's been useful to better understand the impact of topography around the lake in the synoptic fluxes from the east (trade winds), lake and valley-mountains breeze and the deep convection during night. The tilting, divergence and advection terms from the vorticity tendency equation was calculated to better understand the vertical vorticity generation.

Through CMORH technique it was possible to explore the climate behavior of the convection all long the year. It's been used data between 2000-2014 over most part of equatorial Africa that include Victoria lake. In this period, it's been obtained the statistics for 33,189 convection episodes as phase speed, duration, span and distance. The hovmoller diagram has been used as tool to obtain the statistics from these rain streaks. Results show precipitation episodes move westward across Rift Valley and Congo forest with average speed, span and duration of $10.3 \mathrm{~m} \mathrm{~s}^{-1}, 10.7 \mathrm{hr}$ and $332 \mathrm{~km}$, respectively and the ones longer than $600 \mathrm{~km}$ move at $12.1 \mathrm{~m} \mathrm{~s}^{-1}$ with duration of $19 \mathrm{hrs}$ on average. These systems tend to increase rainfall rates
\end{abstract}


hundreds of kilometers all to way to the Congo Forest region. About $50 \%$ of the 33,189 episodes of organized convection have phase speed between $8 \mathrm{~m} \mathrm{~s}^{-1}$ and $16 \mathrm{~m} \mathrm{~s}^{-1}$ and duration between $8 \mathrm{hr}$ and $16 \mathrm{hr}$. Furthermore, most precipitation system have less than $400 \mathrm{~km}$ in span and start east of LV and west of Rift Valley between afternoon and early morning. Hourly rainfall and lightning fields show three preferable regions to initiate convection: 1) LV mountain range; 2) LV mid-west and; 3) Congo Forest mountain range.

The ARPS system was capable to simulated the dynamics and thermodynamics process that trigger deep convection and it have shown the high correlation between the TSL from Victoria lake. Thus, it's highly important an accurate evaluation of TSL to obtain a better forecast of storms over the lake. The pattern obtained from Anyah [2005] through hydrodynamic model has been the one that better characterized the deep convection over Victoria lake. The simulations indicated that a difference of $2{ }^{\circ} \mathrm{C}$ produced difference on water vapor flux of 6 to 8 times between lake and atmosphere and the mountain range east of LV reduced the trade winds. Without the mountain range, ARPS simulation has been indicated wind velocity 1.5 to $2 \mathrm{~m} \mathrm{~s}^{-1}$ higher than real condition simulation and produced latent heat flux $\sim 20 \mathrm{~W} \mathrm{~m}^{-2}$ higher that triggered the initial convection 1 hour before and produced 2 to 3 times more rainfall.

Through these work and future publication is expected to encourage the establishment of a monitoring network of TSL and deep convection that have been triggered over the lake to increase the accuracy forecast of these events. 


\section{LISTA DE FIGURAS}

1.1 Nível do lago Vitória no período de 1900 até 2006. As barras vermelhas representam o mínimo e máximo histórico de 10,13 m e 13,33 metros, respectivamente. Eixo x representa ano.

1.2 Mapa topográfico e domínio/configuração das grades com o ARPS. A resolução espacial das grades do retângulo maior para o menor é de $12 \mathrm{~km}, 4 \mathrm{~km}$ e $500 \mathrm{~m}$, respectivamente. A barra de cores indica altitude em metros. Contorno do LV e geopolítico estão indicados 34

1.3 Distribuição espacial da climatologia da precipitação interpolado pelos métodos (a) IDW (método em que o peso é inversamente proporcional a distância) e (b) UK (método de variograma exponencial) para o período de 1960 a 2004 interpolados de 223 estações. O autor ressalta que como inexistem pluviômetros no interior do lago, a estimativa acima está longe de ser acurada. Fonte do mapa: Kizza et al., [2012]. .34

1.4 Ciclo diurno da convecção por meio da fração de nuvens frias com temperatura de brilho $<210 \mathrm{~K}$ em intervalos de 3 horas de (a) $0300 \mathrm{LT}$ até (h) $0000 \mathrm{LT}$ obtidas do canal infravermelho da base de dados GridSat [Knapp et al., 2011] para o ano de 2009. Contorno do LV e geopolítico está indicado. Barra de cores indica frequência. Fonte: Chamberlain et al., [2013].

1.5 Vento médio horário simulado em $850 \mathrm{hPa}\left(\mathrm{m} \mathrm{s}^{-1}\right)$ para o mês de dezembro de 1988: (a) 0600 UTC; (b) 1200 UTC; (c) 1800 UTC e (d) 2400 UTC. Fonte: Song et al., [2004]. Contornos do LV e geopolíticos estão indicados.

1.6 Vento médio horário no nível de $850 \mathrm{hPa}\left(\mathrm{m} \mathrm{s}^{-1}\right)$ para o mês de dezembro de 1988. Barra

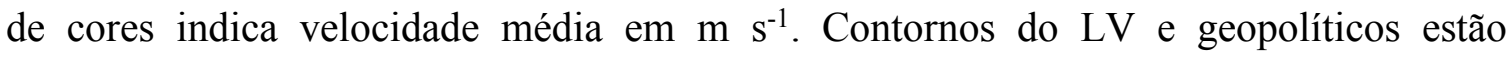
indicados. Fonte: Reanálise do NCEP/NCAR 
1.7 Circulação hidrodinâmica do LV e TSL média $\left({ }^{\circ} \mathrm{C}\right)$ para o mês de dezembro simulada pelo modelo acoplado RegCM2-POM. Contorno do LV está indicado. Fonte: Song et al., $[2004]$

1.8 Série temporal de chuva anual $(\mathrm{mm})$ sobre o lago Vitória para o período de 1956-1978. Linha sólida [Yin e Nicholson, 1998]; Linha tracejada [Sutcliffe, 1988]. Setas em vermelho indicam anos de ENSO positivo. Fonte: Sharon et al., [2000].

1.9 Secção vertical da circulação de brisa média na direção y 8 horas após o início da simulação para regiões com (a) baixa e (b) alta intensidade de radiação solar para brisa marítima e (c) baixa e (d) alta intensidade da radiação solar sobre lago (25 km de diâmetro). A barra de cores representa velocidade do vento $\mathrm{u}\left(\mathrm{m} \mathrm{s}^{-1}\right)$ e as linhas sólidas representam temperatura potencial (K). Regiões de movimento vertical maior que $0.5 \mathrm{~m} \mathrm{~s}^{-1}$ estão demarcadas por linhas pontilhadas em azul. A superfície do mar ou do lago está representada por uma linha sólida em azul. Fonte: Crosman e Horel, 2012

1.10 Secção vertical da circulação de brisa média na y 8 horas após o início da simulação para estabilidade (a) baixa e (b) alta no oceano e (c) baixa e (d) alta para um lago com $25 \mathrm{~km}$ de diâmetro. A barra de cores representa velocidade do vento $\mathrm{u}\left(\mathrm{m} \mathrm{s}^{-1}\right)$ e as linhas sólidas representam temperatura potencial $(\mathrm{K})$. Regiões de movimento vertical acima de $0.5 \mathrm{~m} \mathrm{~s}^{-1}$ estão demarcadas por linhas pontilhadas em azul. A superfície do mar ou do lago está representada por uma linha sólida em azul. Fonte: Crosman e Horel, 2012

1.11 Razão entre a distância propagada pela frente de brisa e a espessura da CBL e CBM na costa observada 8 horas após o início da simulação para baixos e altos índices de fluxo de calor sensível e estabilidade inicial atmosférica. Fonte: Crosman e Horel, 2012. .44

1.12 Velocidade do vento da CBL e CBM a 30 metros acima da superfície na linha de costa com o tempo (a), distância propagada da costa com o tempo em quilômetros (b) e profundidade em metros da CBL e CBM para lagos com diâmetro de 10, 25, 50 e $100 \mathrm{~km}$ e mar. O eixo horizontal refere-se ao tempo após o início da simulação idealizada. A sensibilidade para a componente $u$ do vento (d), distância propagada da costa (e) e profundidade da CBL (f) como função do diâmetro do lago 8 horas após o início da simulação para baixo, médio e altos valores de fluxo de calor sensível na superfície e estabilidade atmosférica inicial. Fonte: Crosman e Horel, 2012. 
1.13 Simulação com o modelo numérico ARPS para o evento de precipitação na região metropolitana de Tóquio no dia 21/08/2013 às 1330 UTC para o campo de diferença de temperatura do ar (a) entre as simulações com e sem ambiente urbano (tTEB) e (b) direção e intensidade do vento para a simulação com o ambiente urbano. Contornos geográficos estão indicados. Barra de cores indica diferença de temperatura em ${ }^{\circ} \mathrm{C}$ e magnitude do vento em $\mathrm{km} \mathrm{h}^{-1}$, respectivamente. Fonte: Pereira filho et al., [2018]. .51

1.14 Similar a figura 1.13, mas para os campos diferença de direção e intensidade do vento a 10 metros de altura no mesmo horário e chuva acumulado total para o dia 21/08/2013. Contornos geográficos estão indicados. Barra de cores indica diferença de magnitude do vento e precipitação em $\mathrm{km} \mathrm{h}^{-1}$ e mm, respectivamente. Fonte: Pereira filho et al., [2018].52

1.15 Esquema de ambiente dinâmico no plano horizontal a $0.5 \mathrm{~km}$ de altura de (a) duas frentes de rajadas ou duas frentes de brisa geradas por sistemas precipitantes ou mesmo por um lago ou oceano separadas em $20 \mathrm{~km}$ e que se movem uma em direção a outra. O retângulo em A define á região de colisão das 2 frentes que enquanto se movem força a saída do ar pelas laterais do mesmo, enquanto o retângulo diminuí de tamanho (b) e a convergência de massa aumenta. Linha sólida espessa com barbela indica as frentes de rajadas ou de brisa. Fonte: Hallak, 2007. .52

2.1 Precipitação média anual obtida com CMORPH $(\mathrm{mm})$ sobre a África Equatorial para o período de 2000 a 2014. Longitudes, latitudes, contornos geográficos e geopolíticos estão indicados. Escala de cores indica precipitação em $\mathrm{mm} \mathrm{ano}^{-1}$. O domínio da análise Hovmoller é indicado pelo retângulo em negrito.

2.2 Distribuição da temperatura $\left({ }^{\circ} \mathrm{C}\right)$ climatológica na superfície do Lago Vitória. Fonte: WWRP, A Nowcasting Project for Lake Victoria. .66

2.3 Distribuição espacial de temperatura superficial do lago (TSL) utilizado em três experimentos para os eventos de 01 de Novembro de 2010 e 03 de Novembro de 2014. Contorno geográficos, geopolíticos do lago Vitória estão indicado. Barra de cores indica TSL em $\left({ }^{\circ} \mathrm{C}\right)$. 
2.4 Velocidade vertical omega média, para o período da tarde anterior $(31 / 10 / 2010$ às $18 Z)$ ao disparo da convecção noturna sobre o LV para o nível de $500 \mathrm{hPa}$. Contornos geopolíticos e do LV estão indicados. Barra de cores indica omega em $\mathrm{Pa} \mathrm{s}^{-1}$. Fonte: Reanálise do NCEP.

2.5 Velocidade vertical omega média, para o período da tarde anterior (02/11/2014) ao disparo da convecção noturna sobre o LV para o nível de $500 \mathrm{hPa}$. Contornos geopolíticos e do LV estão indicados. Barra de cores indica omega em $\mathrm{Pa} \mathrm{s}^{-1}$. Fonte: Reanálise do NCEP

3.1 Campo médio mensal da precipitação com estimativa CMORPH (mm) sobre a África Equatorial para o período entre 2000 e 2014. Longitudes, latitudes, contornos geográficos e geopolíticos estão indicados. Escala de cores indica precipitação acumulada média mensal em mm mês ${ }^{-1}$

3.2 Frequência de precipitação horária superior a $1 \mathrm{~mm} \mathrm{~h}^{-1}$ obtida com CMORPH sobre a África Equatorial para o período entre 2000 e 2014. Titulo da figura indica abreviação de mês e hora UTC de referência para o calculo da frequência horária. Longitudes, latitudes, contornos geográficos e geopolíticos estão indicados. Escala de cores indica frequência de

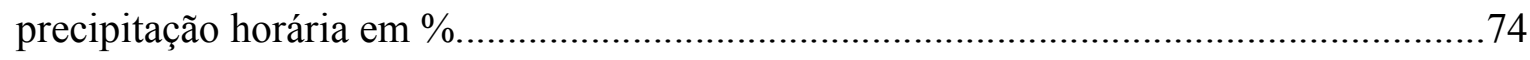

3.3 Similar a figura 3.2 mas para horários específicos nos meses de maio, julho e novembro. Longitudes, latitudes, contornos geográficos e escala de cores (\%) estão indicados. .75

3.4 Similar a figura 3.3, mas para limiar de $20 \mathrm{~mm}$. Latitudes, longitudes e limites geográficos estão indicados. Escala de cores indica frequência (\%).

3.5 Diagrama hovmoller de chuva média horária entre $3^{\circ} \mathrm{S}$ e $1^{\circ} \mathrm{N}$ entre 28 de Abril de 2010 e 7 de Maio de 2010. Eixo x indica longitude da média de precipitação e eixo y indica a data. Barra de cores indica taxa de precipitação média na latitude $\left(\mathrm{mm} \mathrm{hr}^{-1}\right)$..... .77

3.6 Diagrama hovmoller do ciclo diurno médio da precipitação entre $3^{\circ} \mathrm{S}$ e $1^{\circ} \mathrm{N}$ para o período entre 2000 e 2014. As 3 setas da esquerda para direita indicam, floresta do Congo, LV e motanhas a leste do LV, respectivamente. Eixo x indica longitude e y indica horário UTC. Barra de cores indica taxa de chuva média $\left(\mathrm{mm} \mathrm{hr}^{-1}\right)$ 
3.7 Similar a figura 3.6, mas média horária para cada mês do ano. Barra de cores indica taxa de chuva média $\left(\mathrm{mm} \mathrm{hr}^{-1}\right)$

3.8 Densidade média de descarga atmosférica sobre a África equatorial para o período de 2000 a 2013. Longitude, latitude e limites geográficos estão indicados. A escala de cores indica densidade de raios (número de raios $\mathrm{km}^{-2} \mathrm{ano}^{-1}$ ). Horário em UTC. Fonte dos dados brutos: NASA, http://lightning.nsstc.nasa.gov/data/data_lis-vhr-climatology.html .82

3.9 Frequência da distribuição de duração (a), velocidade de fase (b) e propagação longitudinal (c) dos eventos de leste de convecção organizada sobre a África equatorial entre $1^{\circ} \mathrm{N}$ e $3^{\circ} \mathrm{S}$ para 33,189 eventos no período 2000 a 2014. Eixo x indica (a) duração dos episódios, (b) velocidade de fase e (c) distância propagada e o eixo y indica número de episódios. As unidades estão indicadas.

3.10 Frequência da distribuição de longitude inicial e final para todos os eventos (a) de leste da convecção organizada entre as latitudes $1^{\circ} \mathrm{S}$ e $3^{\circ} \mathrm{N}$ para os eventos com propagação superior a $600 \mathrm{~km}$ (b) e respectiva hora de início (c) e distribuição de frequência de propagação (d). Eixo x indica longitude de início e fim para todos os episódios (a) e os que se propagam por mais que $600 \mathrm{~km}$ (b), horário de início para todos os episódios (c) e distância propagada dos episódios que se propagam por mais que $600 \mathrm{~km}$ (d). Eixo y indica número de episódios. Unidade de tempo está em (x100) UTC. .86

3.11 Frequência horária de precipitação com limiar superior a $1.5 \mathrm{~mm} \mathrm{~h}^{-1}$ sobre a na área descrita pelo retângulo da figura 2.1. Eixo x representa hora UTCx100 e eixo y frequência de pontos de grade média horária para cada mês.

3.12 Frequência horária de precipitação com limiar superior a $1.5 \mathrm{~mm} \mathrm{~h}^{-1}$ sobre a na área descrita pelo retângulo da figura 2.1. Eixo x representa hora UTCx100 e eixo y frequência de pontos de grade média horária para cada mês. .89

3.13 Campo de direção e intensidade do vento no nível de $850 \mathrm{hPa}$ (a) e $500 \mathrm{hPa}$ (b). Contornos geopolíticos e do LV estão indicados. Barra de cores indica intensidade do vento em $\mathrm{m} \mathrm{s} \mathrm{s}^{-}$ ${ }^{1}$ as 0000 UTC do dia $01 / 11 / 2010$. 90 
3.14 Campo de direção e intensidade do vento no nível de $250 \mathrm{hPa}$ (a) e velocidade vertical ômega em $500 \mathrm{hPa}$ (b). Contornos geopolíticos e do LV estão indicados. Barra de cores indica intensidade do vento em $\mathrm{m} \mathrm{s}^{-1}$ (a) e velocidade vertical omega em $\mathrm{Pa} \mathrm{s}^{-1}$ (b) as 0000

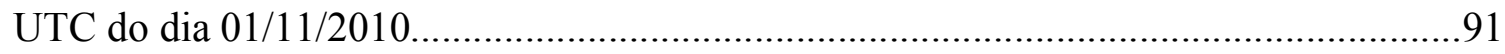

3.15 Campo de direção e intensidade do vento no nível de $850 \mathrm{hPa}$ (a) e $500 \mathrm{hPa}$ (b). Contornos geopolíticos e do LV estão indicados. Barra de cores indica intensidade do vento em $\mathrm{m} \mathrm{s}^{-}$ ${ }^{1}$ as 0000 UTC do dia $03 / 11 / 2014$

3.16 Campo de direção e intensidade do vento no nível de $250 \mathrm{hPa}$ (a) e velocidade vertical ômega em $500 \mathrm{hPa}$ (b). Contornos geopolíticos e do LV estão indicados. Barra de cores indica intensidade do vento em $\mathrm{m} \mathrm{s}^{-1}$ (a) e velocidade vertical omega em $\mathrm{Pa} \mathrm{s}^{-1}$ (b) as 0000

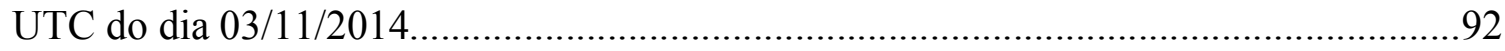

3.17 Simulação numérica com o sistema ARPS para o evento convectivo de 01 de novembro de 2010. Barbela de vento indica direção e intensidade do vento em $\mathrm{m} \mathrm{s}^{-1}$ e barra de cores indica intensidade da chuva em $\mathrm{mm} \mathrm{h}^{-1}$. Resolução espacial da simulação com 500 metros. Contorno do LV e horário estão indicados.

3.18 Imagens do Satélite METEOSAT realçada do canal infravermelho, para o evento de tempestade de 01 de novembro de 2010, com início no meio da madrugada. Horário UTC está indicado no canto inferior da figura. Está indicado contorno do LV .95

3.19 Simulação numérica com o modelo ARPS para o evento de 01 de novembro de 2010 . Barbelas indicam direção e intensidade do vento (10 $\mathrm{m}$ da superfície) e barra de cores indica temperatura do ar em ${ }^{\circ} \mathrm{C}$ no mesmo nível. Resolução espacial da simulação é de 500 m. Título da figura indica horário UTC. Contorno do LV está indicado .96

3.20 Simulação numérica com o modelo ARPS para o evento de 01 de novembro de 2010. Barbelas indicam direção e intensidade do vento (10 $\mathrm{m}$ da superfície) e barra de cores indica fluxo de umidade em $\mathrm{g}^{*} 100 / \mathrm{m}^{2} \mathrm{~s}$. A letra g indica grama de vapor de água. Resolução espacial da simulação é de $500 \mathrm{~m}$. Título da figura indica horário UTC. Contorno do LV está indicado. 
3.21 Simulação numérica com o modelo ARPS para o evento de 01 de novembro de 2010 . Barbelas indicam direção e intensidade do vento (10 $\mathrm{m}$ da superfície) e barra de cores indica intensidade em $\mathrm{km} \mathrm{h}^{-1}$. Resolução espacial da simulação é de $500 \mathrm{~m}$. Título da figura indica horário UTC

3.22 Simulação numérica com o modelo ARPS para o evento de 01 de novembro de 2010 . Barbelas indicam direção e intensidade do vento (10 $\mathrm{m}$ da superfície) e barra de cores indica temperatura potencial equivalente $(\mathrm{K})$. Resolução espacial da simulação é de 500 m. Título da figura indica horário UTC. Contorno do LV está indicado. .98

3.23 Campo de vorticidade vertical da simulação numérica com o modelo ARPS para o evento de 01 de novembro de 2010. Resolução espacial da simulação é de $500 \mathrm{~m}$. Barra de cores indica vorticidade relativa $\mathrm{em} \mathrm{s}^{-1} 10^{-5}$. Título da figura indica horário UTC. 100

3.24 Secção vertical de componente zonal e vertical do vento e magnitude para a simulação numérica com o modelo ARPS do evento de 01 de novembro de 2010. Vetor indica direção e intensidade do vento e a barra de cores indica intensidade do vento vertical em $\mathrm{m} \mathrm{s}^{-1}$. Corte vertical foi feito em $1.7^{\circ} \mathrm{S}$ de latitude. Da esquerda para a direita, o horário do corte foi as 0300 e $0400 \mathrm{UTC}$, respectivamente. 101

3.25 Similar a figura 3.24, mas com zoom sobre a região de máxima velocidade vertical da tempestade. Barra de cores indica intensidade da componente vertical do vento em $\mathrm{m} \mathrm{s}^{-1}$ as $0300 \mathrm{UTC}$

3.26 Campo de CAPE e vento para a simulação numérica com o modelo ARPS para o evento de 01 de novembro de 2010. A barbela indica direção e intensidade do vento e a barra de cores indica energia disponível para a convecção (CAPE) em $\mathrm{J} \mathrm{kg}^{-1}$. Simulação realizada com 500 metros de resolução. Título da figura indica horário UTC

3.27 Chuva acumulada para o período entre 0000 e 0900 HL (hora local) para as configurações de TSL da figura 2.3a, b e c com a, b e c, respectivamente. Simulação com 500 metros de resolução espacial. Contorno do LV está indicado. Barra de cores indica chuva acumulada em $\mathrm{mm}$ .106 
3.28 Perfil vertical de $\theta_{\mathrm{e}}$ para a latitude de $1.7^{\circ} \mathrm{S}$. Utilizou-se a média dos 50 cortes mais a norte e mais a sul para remoção de ruído ocasionado por células convectivas muito localizadas. Simulação com 500 metros de resolução espacial. Barra de cores indica $\theta_{\mathrm{e}}$ em K 107

3.29 Distribuição horizontal de $\theta_{\mathrm{e}}$ à 29 metros acima da superfície. Contorno do LV está indicado. Simulação numérica realizada com 500 metros de resolução espacial. Barra de cores indica $\theta_{\mathrm{e}}$ em $\mathrm{K}$. 108

3.30 Perfil vertical médio entre as latitudes $1.6^{\circ} \mathrm{S}$ e $1.8^{\circ} \mathrm{S}$ da somatória de Qc+Qr+Qi (água de nuvem + água de chuva + gelo em g kg-1, respectivamente). Simulação com 500 metros de resolução espacial, com corte entre as longitudes $31.6^{\circ} \mathrm{E}$ e $32.5^{\circ} \mathrm{E}$. Barra de cores em g $\mathrm{kg}^{-1}$

3.31 Esquema da geração de vorticidade vertical através da inclinação de vórtice horizontal. O eixo X representa direção tangencial e y a radial. Movimentos ascendentes inclinam o rolo em ambos os lados e produz rotação ciclônica de um lado e anticiclônica do outro. Fonte: Franklin et al., [2006]. 112

3.32 Campo horizontal dos termos da equação de tendência da vorticidade vertical (3) à 116 metros acima da superfície às 2130 UTC. Os termos calculados foram os de advecção horizontal e vertical, termo de divergência e inclinação, indicados no titulo da figura. Contorno do LV está indicado. Simulação numérica realizada com 500 metros de resolução espacial. Barra de cores indica contribuição de cada termo em s ${ }^{-2} 10^{-6}$. 113

3.33 Similar a figura 3.32, mas para o horário das 2350 UTC. 114

3.34 Similar a figura 3.33, com zoom na região da CBL para os termos de advecção horizontal e de inclinação. 114

3.35 Similar a figura 3.32, mas para o horário das 0200 UTC. 115

3.36 Similar a figura 3.32, mas para o horário das 0430 UTC, pouco antes do disparo das primeiras células convectivas. 
3.37 Esquema de atuação do termo de inclinação na produção de vorticidade vertical. As setas horizontais representam a variação da velocidade do vento com a altura. O símbolo + representa vorticidade vertical positiva. Setas verticais indicam regiões onde se produzem movimentos de ascensão do ar e inclinação dos rolos horizontais..

3.38 Campo de precipitação acumulada para o período da madrugada com a configuração de TSL da figura $2.3 \mathrm{c}$ e remoção das montanhas no entorno do lago Vitória. Simulação numérica com 500 metros de resolução horizontal. Contorno do LV está indicado. Barra de cores indica chuva acumulada em mm.

3.39 Campo de diferença de direção e magnitude do vento para as simulações com e sem topografia no entorno. Simulações com 500 metros de resolução horizontal. Contorno do $\mathrm{LV}$ está indicado. A barra de cores indica diferença de magnitude em $\mathrm{m} \mathrm{s}^{-1}$..... 119

3.40 Campo de intensidade da precipitação para as grades (a) com topografia e (b) sem topografia. Para a grade (a), início da ocorrência das chuvas e para a grade (b) 40 minutos após o disparo das primeiras células convectivas. Simulações com 500 metros de resolução horizontal. A barra de cores indica intensidade da precipitação $\left(\mathrm{mm} \mathrm{h}^{-1}\right)$......

3.41 Intensidade média do vento sobre o LV para as simulações com o sistema ARPS com topografia (vermelho) e sem topografia (azul) no entorno para o evento de 01/11/2010. Eixo $\mathrm{x}$ representa o horário e eixo y vento médio sobre a área do lago em $\mathrm{m} \mathrm{s}^{-1}$

3.42 Fluxo de calor latente médio sobre o LV para as simulações com (vermelho) e sem topografia (azul) no entorno do LV para o evento de 01/11/2010. Eixo x representa o horário e eixo y o vento fluxo de calor latente em $\mathrm{W} \mathrm{m}^{-2}$. 121

3.43 Perfil vertical do gradiente vertical de temperatura potencial equivalente para a latitude central de $1.7^{\circ} \mathrm{S}$ em (a) grade sem topografia (terreno plano) e (b) grade com topografia normal. Utilizou-se a média dos 50 cortes mais a norte e 50 cortes mais a sul para remoção de ruído, ocasionado por células convectivas localizadas.

3.44 Campo horizontal de $\theta_{\mathrm{e}}$ a 29 metros acima da superfície para a grade (a) terreno plano e (b) com topografia real para o evento de 01/11/2010. Contorno do LV e horário está indicado. Barra de cores indica temperatura potencial equivalente em $\mathrm{K}$ 123 
3.45 Chuva acumulada simulada com o sistema ARPS para o período entre 2100 e 1200 UTC do evento do dia $03 / 11 / 2014$ com a TSL do GFS que de $\sim 21.5^{\circ} \mathrm{C}$ (a) e TSL da figura $2.3 \mathrm{~b}$ (b). que apresenta média aproximada sobre o LV de $24.5^{\circ} \mathrm{C}$. Simulação numérica realizada com 500 metros de resolução. Barra de cores indica precipitação acumulada em mm.....124

3.46 Campo de direção e magnitude do vento para a simulação com o ARPS para o evento de 03/11/2014 com TSL de $21.5^{\circ}$ C. Contorno do LV e hora UTC está indicado. Simulação com $500 \mathrm{~m}$ de resolução horizontal. Barra de cores indica velocidade do vento em $\mathrm{m} \mathrm{s}^{-1}$

3.47 Campo de intensidade da precipitação para o evento de 03/11/2014 com TSL de $21.5^{\circ} \mathrm{C}$ simulada com o modelo ARPS. Contorno do LV e hora UTC está indicado. Simulação realizada com $500 \mathrm{~m}$ de resolução horizontal. Barra de cores indica intensidade $\mathrm{em} \mathrm{mm} \mathrm{h}^{-}$ 1

3.48 Campo de fluxo de vapor de água entre a superfície e o ar acima para o evento de 03/11/2014 com TSL de $21.5^{\circ} \mathrm{C}$ simulada com o ARPS. Simulação realizada com $500 \mathrm{~m}$ de resolução horizontal. Contorno do LV e hora UTC está indicado. Barra de cores indica intensidade fluxo em $\mathrm{g}^{*} 100 \mathrm{~m}^{-2}$ $\mathrm{s}^{-1}$

3.49 Campo de intensidade da precipitação para o evento de $03 / 11 / 2014$ com TSL de $24.5^{\circ} \mathrm{C}$ da simulação com o ARPS com 500 m de resolução espacial. Contorno do LV e hora UTC

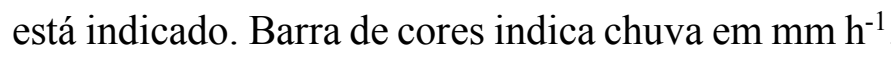
130

3.50 Campo do fluxo de vapor de água entre a superfície e o ar acima para o evento de 03/11/2014 com TSL de $24.5^{\circ} \mathrm{C}$ (Fig. 2.3b) simulado com o ARPS. Contorno do LV e hora UTC está indicado. Simulação realizada com 500 m de resolução horizontal. Barra de cores indica intensidade do fluxo em $\mathrm{g} * 100 \quad \mathrm{~m}^{-2} \mathrm{~s}^{-1}$

3.51 Campo de $\theta_{\mathrm{e}}$ para o evento de 03/11/2014 com TSL de $24.5^{\circ} \mathrm{C}$ (Fig. 2.3b). Barra de cores indica ThetaE em K. Simulação realizada com 500 m de resolução horizontal. Contorno do LV e hora UTC está indicado. 


\section{LISTA DE TABELAS}

2.1 Variáveis simuladas explicitamente pelo ARPS

.64

2.2 Variáveis calculadas no pós-processamento. .65

2.3 Características gerais do experimento sobre o LV. .66 


\section{Sumário}

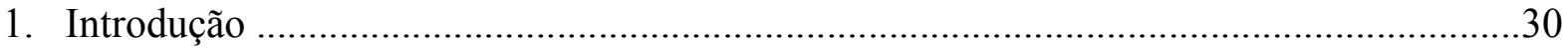

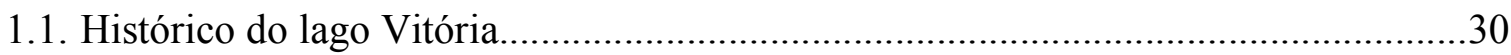

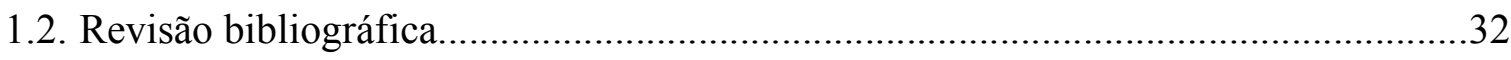

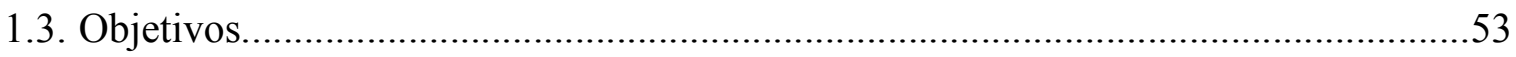

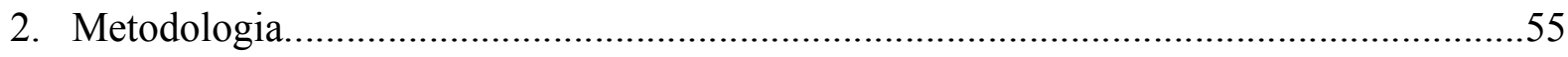

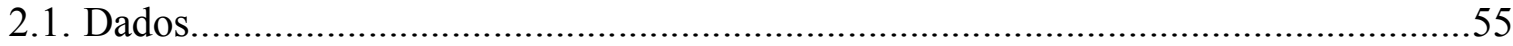

2.1.1. Precipitação estimada com o CMORPH..........................................................55

2.1.2. Densidade de descargas atmosféricas com o sistema LIS..............................56

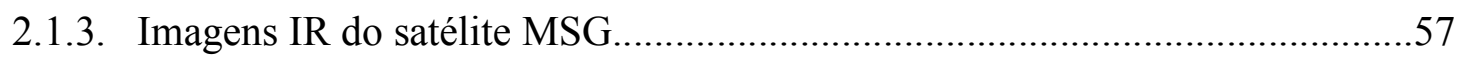

2.1.4. Temperatura de superfície estimada com o MODIS......................................57

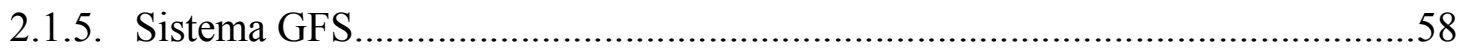

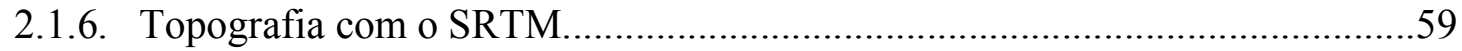

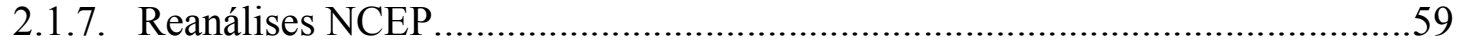

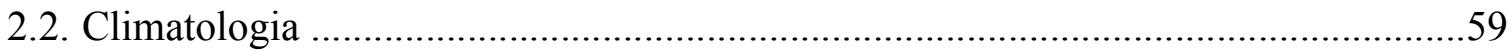

2.2.1. Análise dos ciclos diurno, mensal, sazonal e anual da convecção....................60

2.2.2. Diagramas longitude-tempo de Hovmoller....................................................61

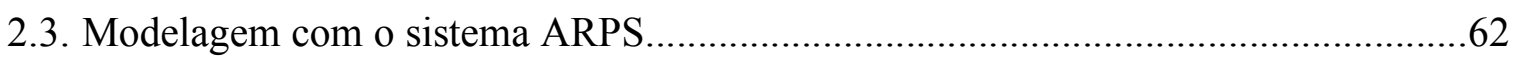

2.3.1. Descrição do sistema ARPS...........................................................................63

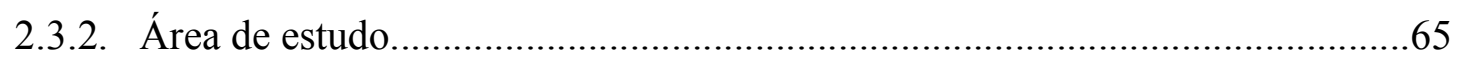

2.3.3. Configuração de grade e parametrizações.........................................................65

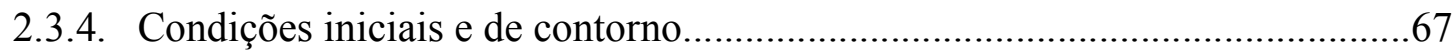

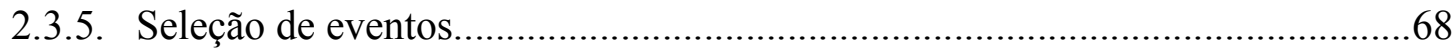

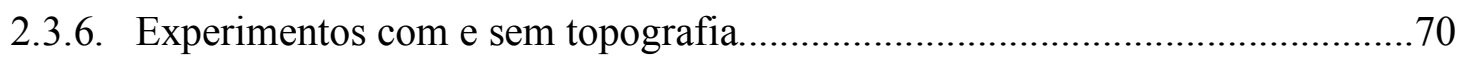

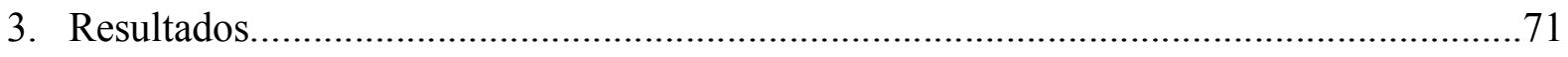

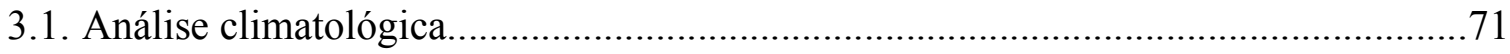

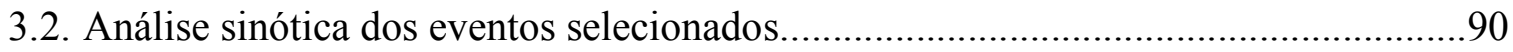




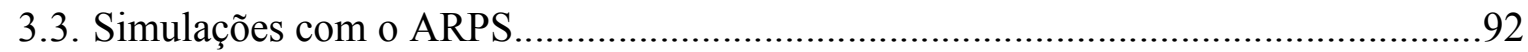

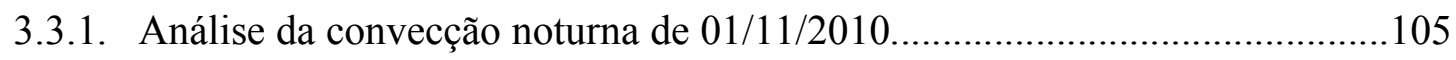

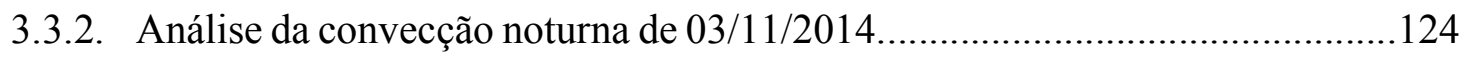

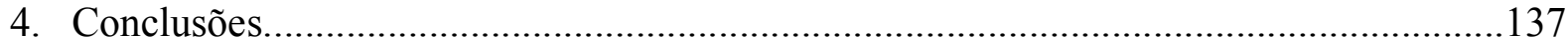

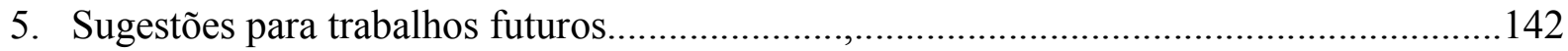

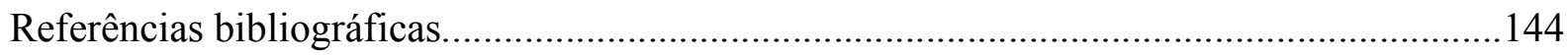




\section{Lista de Siglas}

ARPS: Advance Regional Prediction System

CAPE: Convective Available Potential Energy

CINE: Convective Inhibition Energy

CBL: Circulação de brisa lacustre

CBM: Circulação de brisa marítima

CBVM: Circulação de brisa vale-montanha

CBT: Circulação de brisa terrestre

CLP: Camada limite planetária

CMORPH: CPC Morphing technique

CPC: Climate Prediction Center

$\mathrm{Cb}$ : Cumulunimbus

ENSO: El Niño Oscilação Sul

FBM: Frente de brisa marítima

FBL: Frente de brisa Lacustre

FGP: Força do Gradiente de Pressão

GFS: Global Forecast System

GPM: Global Precipitation Measuring

HI_H: High heat flux

HI_N: High stability

LIS: Lightning Imaging Sensor

LO_H: Low heat flux

LO_N: Low stability

LV: Lago Vitória

MODIS: Moderate Resolution Imaging Spectroradiometer

MSG: Satélite METEOSAT Segunda Geração (MSG)

NASA: National Aeronautics and Space Administration

NCEP: National Centers for Environmental Prediction

NDVI: Normalized Difference Vegetation Index 
NOAA: National Oceanic and Atmospheric Administration

RMSP: Região Metropolitana de São Paulo

SSM/I: Special Sensor Microwave Imager

ICU: Ilha de calor Urbano

TBM: Topo da brisa marítima

TBL: Topo da brisa lacustre

TRMM: Tropical Rainfall Measuring Mission

TSL: Temperatura da superfície do lago

TSM: Temperatura da superfície do mar

WRF: Weather Research and Forecasting

ZCIT: Zona de Convergência Intetropical 


\section{Capítulo 1}

\section{Introdução}

\subsection{Histórico do lago Vitória}

O lago Vitória (LV) é o maior lago Africano e está localizado em uma região de planalto na parte ocidental do Vale do Rift na África oriental a 1133 metros de altitude e está sob domínio da Tanzânia, Uganda e Quênia. O lago possui área de aproximadamente $68,870 \mathrm{~km}^{2}$ e é considerado o segundo maior lago do mundo e o maior localizado na região tropical do planeta em área. Em termos de volume ele possui $2760 \mathrm{~km}^{3}$ e fica na sétima posição mundial devido a baixa profundidade média do mesmo (média de 40 metros e máxima de 83 metros). Sua principal afluência é o Nilo branco, uma das nascentes do rio Nilo. O lago possui mais de 3000 ilhas localizadas no seu interior com parte delas habitadas e é cortado pela linha do equador, a parte nordeste do lago pertence ao Quênia (6\%), norte e noroeste a Uganda (45\%) e a Tanzânia (49\%) ao sul possui a maior parte do lago. Estudos geológicos mostram que o lago foi formado a 4 milhões de anos atrás e ocupa uma depressão formada por movimentos tectônicos, com aproximadamente $320 \mathrm{~km}$ de comprimento norte a sul, $275 \mathrm{~km}$ de largura leste a oeste e 4828 $\mathrm{km}$ de linha de costa quando somado com as ilhas em seu interior que correspondem a 3,7\% do total.

A bacia hidrográfica do LV possui diversos afluentes, o mais importante deles é o rio Kagera da Tanzânia, outras nascentes menores têm nascente na Ruanda, Quênia e Burundi, apesar disso, a afluência corresponde a apenas $20 \%$ das águas do lago, $80 \%$ é proveniente das chuvas [Hickling, 1961). A única defluência é o Nilo branco que desce para norte e abastecem os lagos Kyoga e Albert e posteriormente o rio Nilo. Estima-se que o a região entre os lagos Kyoga e Albert surgiu entre 12000 a.C. e 14000 a.C. Até a década de 60 o lago era bem equilibrado e sem grandes variações no seu nível, no entanto, em 1962 o lago sofreu forte variação positiva após um período de chuvas intensas, com ligeira diminuição nos anos seguintes. Desde 2004 o 
lago sofre forte redução com uma queda de aproximada 1 metro por ano devido principalmente a falta de chuvas que atuam tanto sobre o lago quanto sobre seus afluentes.

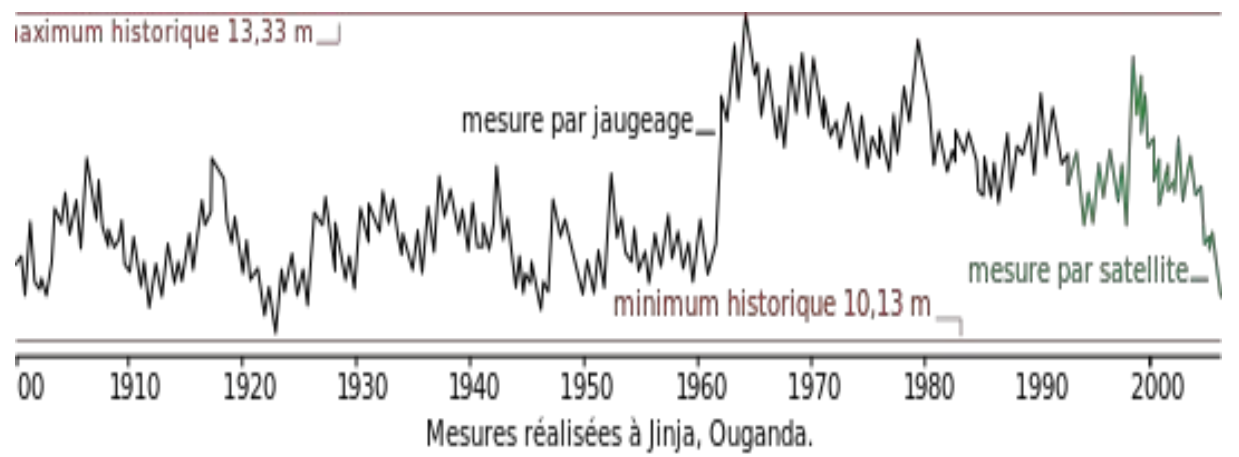

Figura 1.1: Nível do lago Vitória no período de 1900 até 2006. As barras vermelhas representam o mínimo e máximo histórico de 10,13 m e 13,33 metros, respectivamente. Eixo x representa ano.

Os primeiros povos a explorarem o LV que se tem registro datam do século $\mathrm{X}$ a procura de marfim, ouro, escravos e artigos preciosos, também nessa época atribuiu-se a ele a nascente do rio Nilo. O britânico John Hanning Speke, em expedição encontrou o LV em julho de 1856 e em batizou o lago de Vitória em homenagem a rainha. Em 1902 foi inaugurada uma ferrovia ligando Mombaça ao LV que foi utilizada para ocupação europeia causou forte destruição da floresta no local, boa parte dela substituída por lavouras de açúcar, tabaco, chá, café e algodão. A população cresceu em ritmo acelerado e a pesca de subsistência foi substituída pela pesca comercial para abastecer centros urbanos que cresciam rapidamente [Linch, 1997]. Os britânicos foram responsáveis pela intensa exploração no local por meio da rede de pesca que foi reduzindo gradativamente o tamanho dos peixes capturados, e os pescadores tendo que adotar redes cada vez menores. Na década de 50, a espécie mais popular do lago, a ngege, estava extinta e em tentativa de recuperação do lago os britânicos introduziram novas espécies no lago.

Os britânicos introduziram a espécie não nativa perca-do-nilo ainda nos anos 1950, na tentativa de melhorar os rendimentos de pesca, no entanto, esse peixe é um voraz predador e temia-se que a falta de um predador natural desencadeasse a destruição do ecossistema local. Sem isso, a espécie se proliferou e nos anos de 1970 já era encontrada em todo o lago com peso acima dos $250 \mathrm{~kg}$. Em menos de 40 anos foram extintas diversas populações locais, o que inclui aproximadamente 400 espécies endêmicas. Com a redução maior do alimento no lago, a percado-nilo tornou-se canibal e os indivíduos adultos passaram a se alimentar dos mais jovens, assim sua própria população começou a sofrer redução, deste modo, a indústria da pesca entrou 
em colapso. Mais de 70 cientistas se reuniram nos anos de 1990 para discutirem um plano de ação para recuperação do ecossistema do lago. Desde então, a perca-do-nilo é retirada do lago e algumas espécies nativas aumentaram novamente, com cerca de 200 espécies atualmente que abastecem aproximadamente 30 milhões de pessoas que vivem no entorno do LV. Outros problemas ecológicos resultante da introdução de espécies não nativas ocorreram sobre o LV, como por exemplo a introdução de uma planta conhecida como Jacinto-da-água que encobriu a maior parte do litoral de Uganda, além do aumento da poluição e perda de oxigênio que tornaram a água turva.

O transporte entre Uganda, Tanzânia e Quênia é feita por balsas dos portos de Mwanza, Kisumu, Bukoba, Entebbe, Jinja e Port Bell desde 1900, encomendadas e construídas pelo Reino Unido. O LV é palco de constantes naufrágios que são causados principalmente por más condições meteorológicas.

A energia elétrica da região é proveniente de 2 barragens a primeira proveniente de um estudo de 1954 sobre as cataratas Owen do Nilo Vitória em Jinja, Uganda conhecida como barragem Nalubaale e a segunda construída em 2000 de nome Kira construída a aproximadamente $1 \mathrm{~km}$ da barragem anterior.

\subsection{Revisão Bilbliográfica}

Aproximadamente 30 milhões de pessoas vivem no entorno do LV, população essa que basicamente vive da pesca de subsistência. Devido ao alto índice de tempestades sobre o lago, naufrágios são comuns na região, além disso, boa parte da convecção ocorre entre o período da madrugada e início da manhã, período em que os pescadores saem de barco. Existem estudos sobre as formações convectivas sobre o LV, no entanto, não houveram estudos no sentido de avaliar a frequência, velocidade média de fase da convecção, período climatológico dos eventos convectivos sobre o LV, além de estudos mais detalhados do disparo da convecção por meio de simulação numérica de altíssima resolução espacial, que no caso da presente tese foi com 500 metros de resolução e permitiram avaliar a dinâmica e cinemática da convecção e motivaram esse trabalho.

Um dos fatores que está associado ao disparo da convecção sobre o LV é a circulação de brisa, que basicamente ocorre em todas as regiões do mundo na interface terra-água, em que a superfície de água seja suficientemente grande para gerar gradientes de temperatura do ar, devido a diferença de calor específico entre as diferentes superfícies água e terra, que faz com 
que o ar sobre a última, aqueça mais rápido que o ar sobre a água. Essas circulações ocorrem em escala local, com grandeza espacial da ordem de centenas de quilômetros e segundo Orlanski [1975] se enquadram na mesosescala.

A incidência de radiação solar é a principal fonte de energia no disparo dos processos de circulação local que geram as circulações de brisa marítima (CBM), circulações de brisa lacustre (CBL) e circulações de brisa vale-montanha (CBVM). No caso particular do LV verifica-se que a frente de brisa que se forma entre a terra e o lago converge sobre o último e dispara a convecção no período da madrugada [Flohn e Fraedrich, 1966, Nicholson e Yin, 2000] com graves consequências e comum registro de mortes naquela região, já que ela é dominada por pescadores, que tem seus barcos atingidos por ondas e ventos gerados por essas tormentas. A complexa topografia no entorno do lago acelera a circulação de brisa terrestre (CBT), com disparo de convecção pela convergência da brisa terrestre [Laing et al., 2011, Anyah et al., 2006]. A instabilidade resulta de uma diferença média de temperatura em torno de $3{ }^{\circ} \mathrm{C}$ entre o ar sobre o lago e o ar sobre a terra [Ba e Nicholson, 1998]. A topografia é de extrema complexidade, com picos de até 2100 metros próximos a borda do lago e em torno de 3400 metros a $200 \mathrm{~km}$ a leste do mesmo (Fig. 1.2), e sugere que a CBL noturna acopla com a CBVM acelera em direção ao meio do lago e favorece o disparo da convecção noturna.

Chamberlain et al., [2013] obteve média anual horária de temperatura de brilho do topo das nuvens para todo o ano de 2009 da base de dados do GridSat [Knap et al., 2011], onde notouse o efeito das circulações locais na convecção diurna, com nuvens verticalmente desenvolvidas no período da madrugada e início da manhã no meio do lago e entre o meio da tarde e início da noite na borda do mesmo, conforme Fig 1.4. Outros estudos como os de Datta [1981] e Piper et al., [1986] mostram comportamento semelhante de maior volume de chuva sobre o lago quando comparado com a região no entorno. Além disso, observações realizadas em uma ilha dentro do lago mostram acumulação anual de $2000 \mathrm{~mm}$ enquanto que estações no entorno registram acumulados anuais de $1200 \mathrm{~mm}$ (Fig. 1.3) [Kizza et al., 2012]. Kizza et al., [2012] também apresenta em seu trabalho a baixa qualidade dos dados disponíveis na região do LV, deste modo, o sensoriamento remoto se torna importante para uma avaliação mais acurada da precipitação no local. 


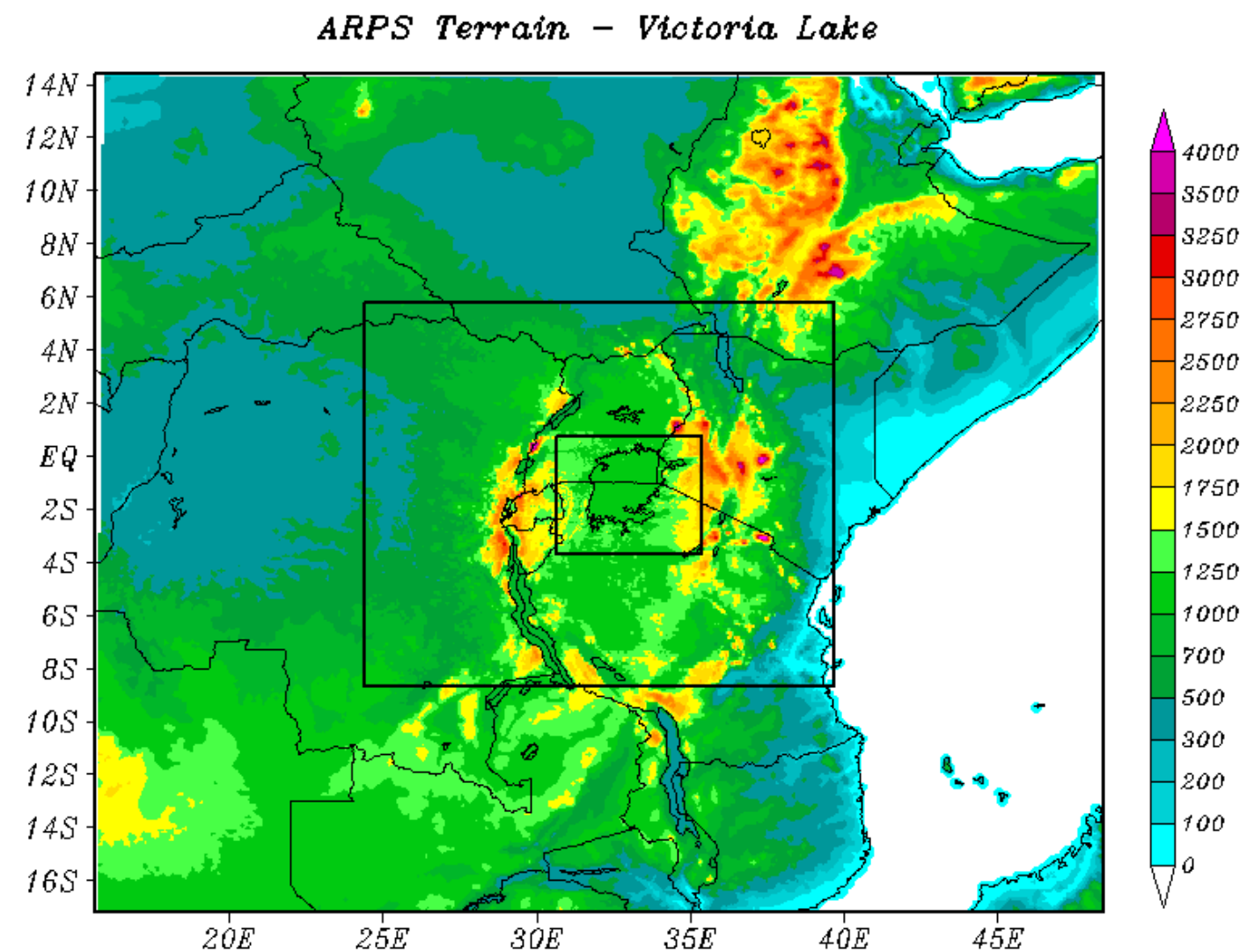

Figura 1.2: Mapa topográfico e domínio/configuração das grades com o ARPS. A resolução espacial das grades do retângulo maior para o menor é de $12 \mathrm{~km}, 4 \mathrm{~km}$ e $500 \mathrm{~m}$, respectivamente. A barra de cores indica altitude em metros. Contorno do LV e geopolítico estão indicados.

(a) IDW

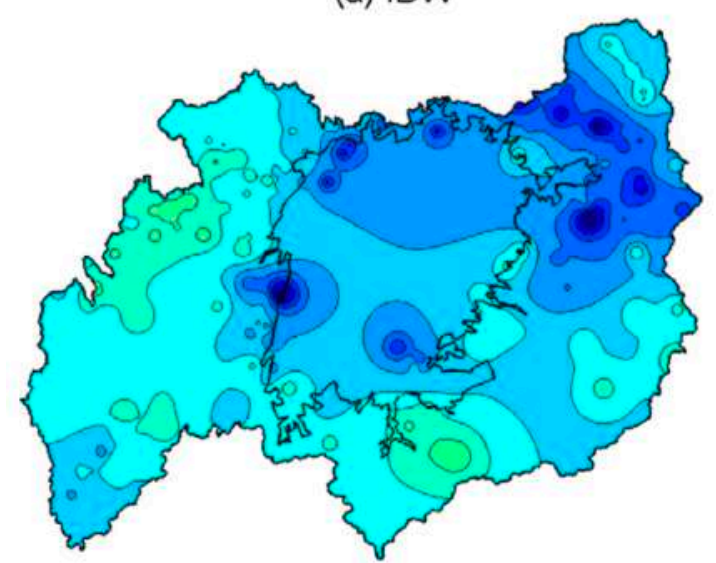

(b) UK

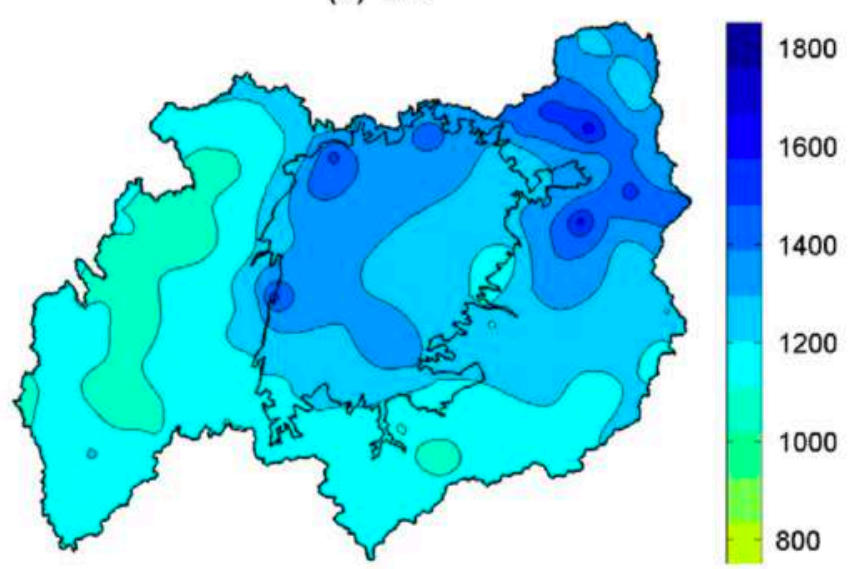

Figura 1.3: Distribuição espacial da climatologia da precipitação interpolado pelos métodos (a) IDW (método em que o peso é inversamente proporcional a distância) e (b) UK (método de variograma exponencial) para o período de 1960 a 2004 interpolados de 223 estações. O autor ressalta que como inexistem pluviômetros no interior do lago, a estimativa acima está longe de ser acurada. Fonte do mapa: Kizza et al., [2012].

O sensoriamento remoto é utilizado como ferramenta para estudo mais detalhado dessa região da África dada a escassa distribuição e inconsistência das estações meteorológicas nessa região [Kizza et al., 2012]. Com o avanço do poder computacional, modelos numéricos são 
utilizados para tentar explicar o comportamento diurno da convecção sobre a África, no entanto, dada a falta e a baixa qualidade dos dados na região, é difícil obter acurácia na condição inicial.

(a) $0300 \mathrm{LT}$

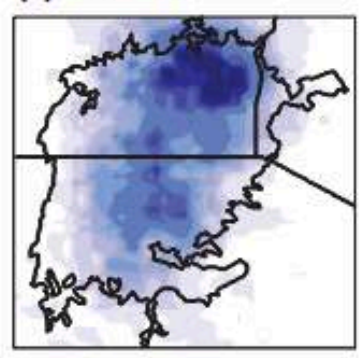

(e) $1500 \mathrm{LT}$

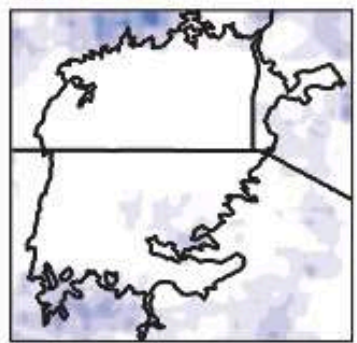

(b) 0600 LT

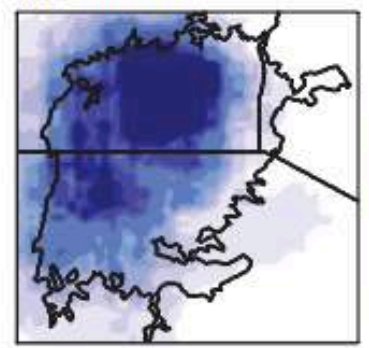

(f) 1800 LT

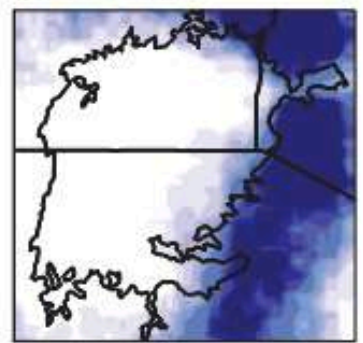

(c) 0900 LT

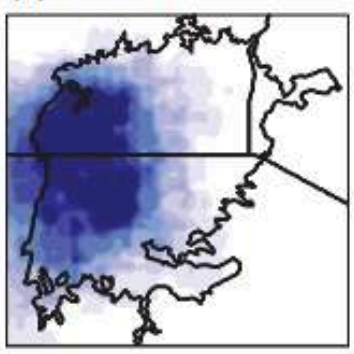

(g) $2100 \mathrm{LT}$

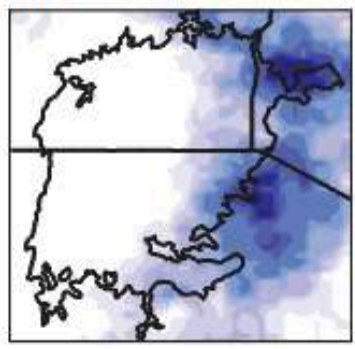

(d) $1200 \mathrm{LT}$

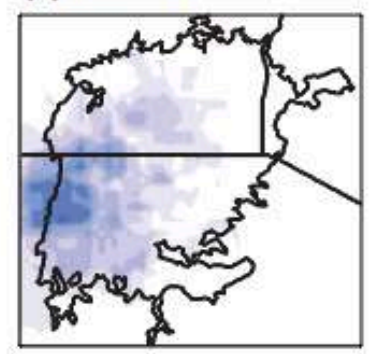

(h) 0000 LT

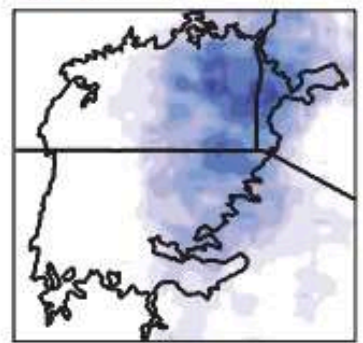

\section{$\begin{array}{lllllllllll}0.005 & 0.01 & 0.015 & 0.02 & 0.025 & 0.03 & 0.035 & 0.04 & 0.045 & 0.05 & 0.055\end{array}$}

Figura 1.4: Ciclo diurno da convecção por meio da fração de nuvens frias com temperatura de brilho < $210 \mathrm{~K}$ em intervalos de 3 horas de (a) $0300 \mathrm{LT}$ até (h) $0000 \mathrm{LT}$ obtidas do canal infravermelho da base de dados GridSat [Knapp et al., 2011] para o ano de 2009. Contorno do LV e geopolítico está indicado. Barra de cores indica frequência. Fonte: Chamberlain et al., [2013]

Nota-se que a maior parte da convecção ocorre na porção norte e oeste do lago, com formação por volta das 1500 HL e propagação para oeste, até a total dissipação na costa oeste do lago, por volta das $1200 \mathrm{HL}$, com máximo as $1800 \mathrm{HL}$ na borda leste do lago e entre 0300 HL e 0900 HL sobre o lago. (Fig. 1.4).

O lago Vitória (LV) é o segundo maior lago do mundo em área e o maior lago de água doce, com aproximadamente $400 \mathrm{~km}$ de extensão Norte-Sul, $250 \mathrm{~km}$ Leste-Oeste, $68800 \mathrm{~km}^{2}$ de área, profundidade média e máxima de 40 e 83 metros, respectivamente [Spigel e Coulter, 1996] e altitude de 1133 metros. A área do LV é compartilhada por 3 países: $4100 \mathrm{~km}^{2}, 33700 \mathrm{~km}^{2} \mathrm{e}$ $31000 \mathrm{~km}^{2}$ pertencem ao Kenya, Tanzania e Uganda, respectivamente. Ele recebe afluência de 17 tributários, sendo que o maior de todos é o Kegera em uma área total da bacia de 193000 $\mathrm{km}^{2}$. Seu único fluxo de saída é via Nilo Branco, próximo a Jinja e Uganda, na borda norte do lago. Yin e Nicholson [1998] e Okonga [2001] confirmam que o fluxo de carga e descarga dos rios são comparativamente muito menores que a contribuição devido a evaporação $(80 \%)$ e precipitação (86\%) para a hidrologia do LV e faz com que o nível do lago aumente muito em 
situações atípicas de chuvas muito acima da média como as que ocorreram entre 1961 e 1962 [Flohn, 1987].

O lago é usado por grande número de botes para transportes de pescadores. Ventos intensos e ondas associadas com os ventos intensos gerados pelas tempestades sobre o lago expõe os usuários do lago a sérios riscos. Todos os anos a mídia local reporta diversos naufrágios devido as fortes tempestades, com a morte de centenas de pessoas em cada um. O número exato de fatalidades é desconhecido.

O clima sobre a África equatorial é primariamente governado pela passagem da zona de convergência intertropical (ZCIT) 2 vezes por ano, uma entre Março e Abril e outra entre Outubro e Dezembro [Nicholson, 1996]. A estação chuvosa de Março a Maio é normalmente conhecida por chuvas de longa duração, já a estação chuvosa entre Outubro e Dezembro, onde se concentra a maior parte dos eventos de tempestade localizadas e é conhecido por chuvas intensas e de curta duração [Song et al., 2004]. O clima na bacia do LV varia desde o equatorial até o semiárido que é caracterizado por secas intermitentes sobre algumas regiões localizados até mesmo a menos de $100 \mathrm{~km}$ da linha de costa do lago. Diversos estudos observacionais [Alusa, 1976, Asnani e Kinuthia, 1979] e estudos numéricos [Mukabana e Pielke, 1996; Indeje e Anyamba, 1998; William et al., 2014; Karina et al., 2015] associaram a atividade de tempestades sobre a parte oeste das montanhas do Kenya com a interação entre o fluxo de leste e a circulação diurna de mesosescala da região. Poucos estudos foram desenvolvidos no âmbito da interação entre o clima regional e os lagos na identificação da frequência dos eventos convectivos sobre a região.

Song et al., [2004] focou seus estudos na estação de chuvas de curta duração de 1988, segundo o autor, o ano de 1988 foi escolhido, pois apresentou comportamento próximo a climatologia na África leste [Sun et al., 1999]. Song utilizou o sistema acoplado dos modelos NCSU-RegCM2 e o POM (RegCM2-POM) para simular as condições atmosféricas e hidrodinâmicas do LV. Em seu estudo, Song adotou temperatura inicial constante de $24^{\circ} \mathrm{C}$ e o modelo do lago foi integrado de um estado inicial sem movimento, três simulações foram realizadas, com início nos meses de setembro a dezembro de 1988. Somente os resultados de dezembro foram considerados, o que permitiu um período de 3 meses de "Spin-Up" para o modelo. Os resultados foram obtidos com resolução espacial de $20 \mathrm{~km}$ onde fica evidente o ciclo diurno da circulação de brisa sobre o LV (Fig 1.5), com divergência/convergência sobre o LV durante o período da tarde/noite, respectivamente.

Nota-se o forte desenvolvimento da brisa terrestre as 2400 UTC (fig 1.5), quando a convergência sobre o lago é predominante. A cadeia de montanhas presente a leste do LV, 
exerce efeito de bloqueio na circulação sinótica de leste em torno de $36^{\circ} \mathrm{E}$ (Fig 1.6) e a máxima convergência do período da tarde ocorre a norte do lago, com divergência sobre o LV. O efeito de bloqueio dos alísios de leste fica evidente na figura 1.6, onde nota-se uma redução média do vento de aproximadamente 5 para menos de $2 \mathrm{~m} \mathrm{~s}^{-1}$ após a oeste das montanhas. As 1800 UTC, a linha de confluência associada a CBL diurna também fica bloqueada pelas montanhas a leste. Song et al. [2004] destaca que o efeito desse padrão de circulação associado ao lago proporciona chuvas mais intensas a oeste do mesmo (sobre terra) e que o efeito do lago se estende por mais de $200 \mathrm{~km}$ de distância, e resulta em uma área total de influência comparável a toda a área de Uganda. O padrão de chuva associado a circulação encontrada por Song et al., [2004], é semelhante ao padrão de temperatura de nuvens frias encontrado por Knapp et al., [2011].
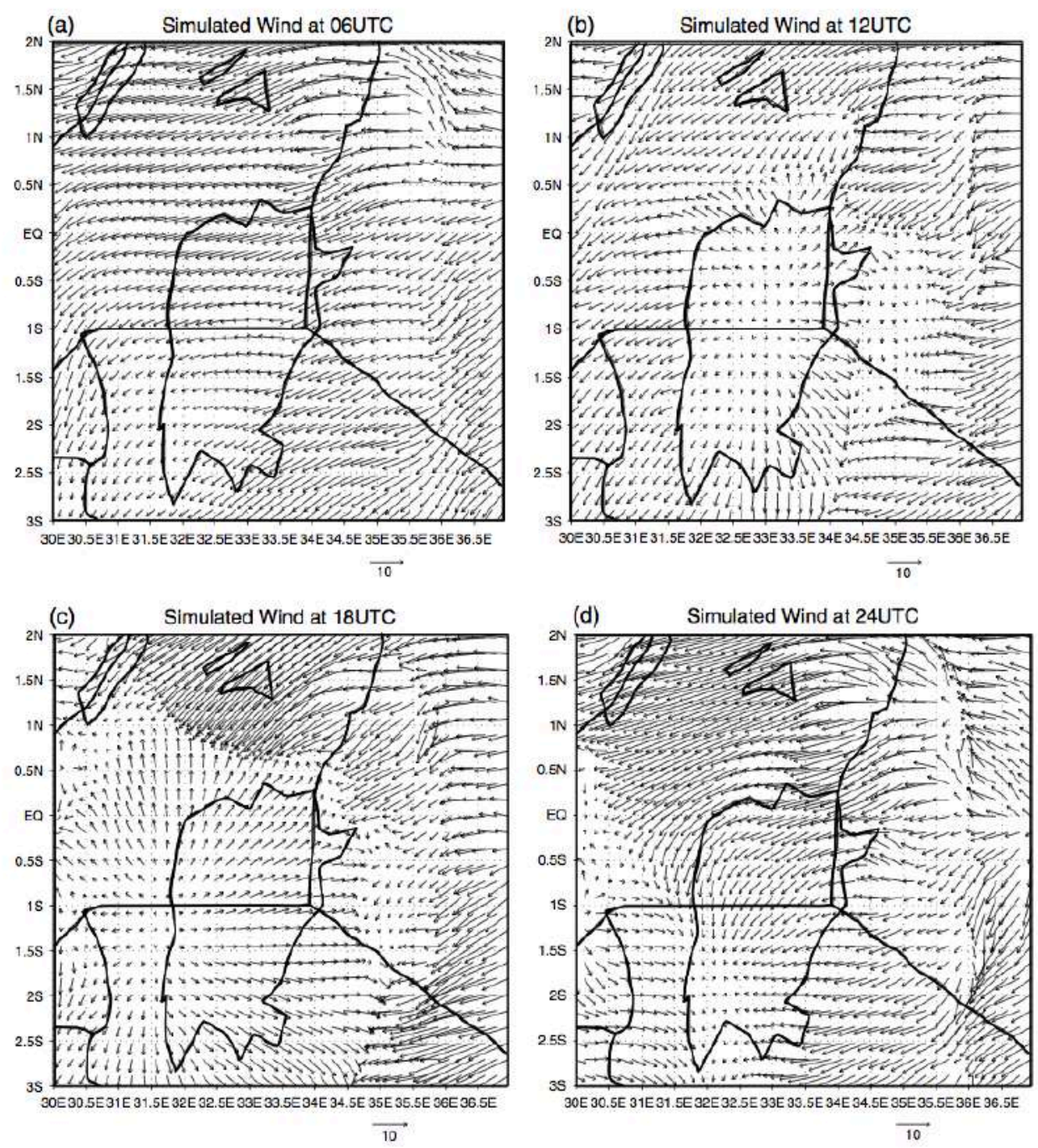

Figura 1.5: Vento médio horário simulado em $850 \mathrm{hPa}\left(\mathrm{m} \mathrm{s}^{-1}\right)$ para o mês de dezembro de 1988: (a) 0600 UTC; (b) 1200 UTC; (c) 1800 UTC e (d) 2400 UTC. Fonte: Song et al., [2004]. Contornos do LV e geopolíticos estão indicados. 

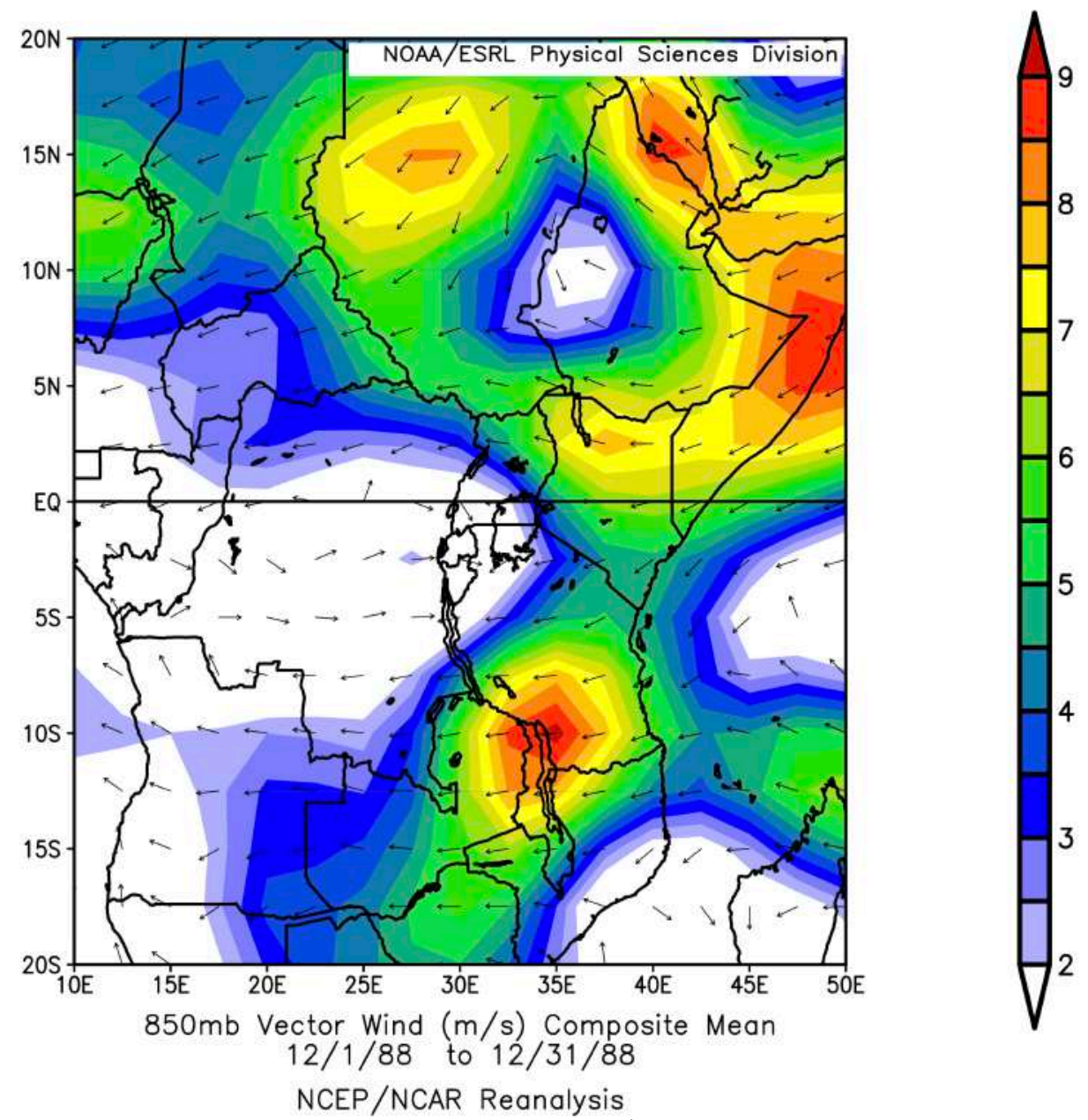

Figura 1.6: Vento médio horário no nível de $850 \mathrm{hPa}\left(\mathrm{m} \mathrm{s}^{-1}\right)$ para o mês de dezembro de 1988. Barra de cores indica velocidade média em $\mathrm{m} \mathrm{s}^{-1}$. Contornos do LV e geopolíticos estão indicados. Fonte: Reanálise do NCEP/NCAR.

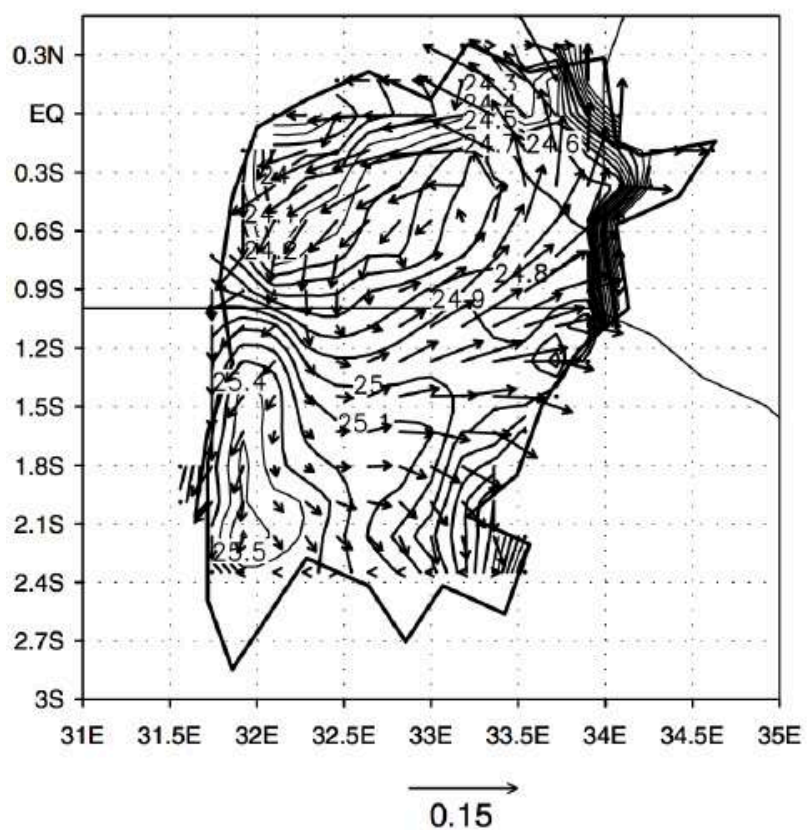

Figura 1.7: Circulação hidrodinâmica do LV e TSL média $\left({ }^{\circ} \mathrm{C}\right)$ para o mês de dezembro simulada pelo modelo acoplado RegCM2-POM. Contorno do LV está indicado. Fonte: Song et al., [2004]. 
Nota-se na figura 1.7 o padrão de circulação e a TSL média do lago para o mês de dezembro de 1988 obtido pelo estudo de Song et al., [2004]. As correntes são dominadas por um padrão espiral horizontal com um dipolo no campo de TSL, água mais quentes sobre a região mais rasa (setor sudoeste) e águas mais frias no setor nordeste, onde o lago é mais fundo. O conjunto de simulações obtidas por Song et al., [2004], obteve as maiores acumulações na região com os maiores valores de TSL. As simulações do modelo acoplado obtiveram TSL mais próximas à observada do que as simulações sem o acoplamento com o modelo de circulação do lago (POM), isso é explicado pela alta eficiência hidrodinâmica do POM em transportar calor das regiões mais rasas no sudoeste via advecção de calor sensível e transporte de água. O modelo RegCM2, mais simples, somente transporta calor horizontal indiretamente, através da transferência de calor sensível do ar e lateralmente pelo movimento do vento. O resultado do modelo mais simples, sem a circulação do lago, indicou temperatura em torno de $2^{\circ} \mathrm{C}$ abaixo do observado, de acordo com Song et al., [2004] mostra a importância da circulação hidrodinâmica do lago para o clima local.

Ba e Nicholson [1998] estimaram a precipitação por meio de dados de satélite na região do LV, e obtiveram acumulação entre $25 \%$ a $30 \%$ maior sobre o lago $\left(1791 \mathrm{~mm}^{-1}\right.$ ano $\left.{ }^{-1}\right)$ do que no entorno do mesmo. Birkett et al., [1999] sugere forte correlação entre o fenômeno El Niño oscilação sul (ENSO) e a precipitação sobre a bacia do LV, com um aumento de 15 a $20 \%$ na precipitação durante a fase positiva do ENSO. A figura 1.8, mostra a chuva anual estimada sobre o lago entre 1956-1978, por Sutcliffe [1988] e Yin e Nicholson [1998]. Sutcliffe [1988] baseou sua estimativa por meio de manipulação estatística de dados de 8 estações na linha da costa (Jinba, Entebbe, Bukoba, Kagondo, Mwanza, Musoma and Kisumu), Yin e Nicholson [1998] usaram 18 estações localizadas no entorno do lago mais um fator peso derivado de dados de satélite para calcular a precipitação anual sobre o mesmo. As estimativas de precipitação através do satélite MSG possuem alta correlação com os dados medidos em superfície na região do LV, conforme mostrou Sharon et al., [2000].

Diversos autores corroboram a influência da topografia na amplificação ou atenuação da velocidade de propagação e áreas de convergência/divergência. Estudo feito por Vemado e Pereira Filho, [2016] corroboraram a importância da serra do mar na aceleração da frente de brisa em direção a Região Metropolitana de São Paulo (RMSP), com disparo de convecção no meio da tarde, o oposto do que ocorre na região do Lago Vitória. No caso da RMSP, a ilha de calor urbano (IC) amplifica o desenvolvimento das tempestades sobre a mesma. De maneira análoga, a TSL do LV, superior à temperatura do ar no período da noite, age no sentido de favorecer a formação de tempestades, mas nesse caso, no meio da madrugada. 


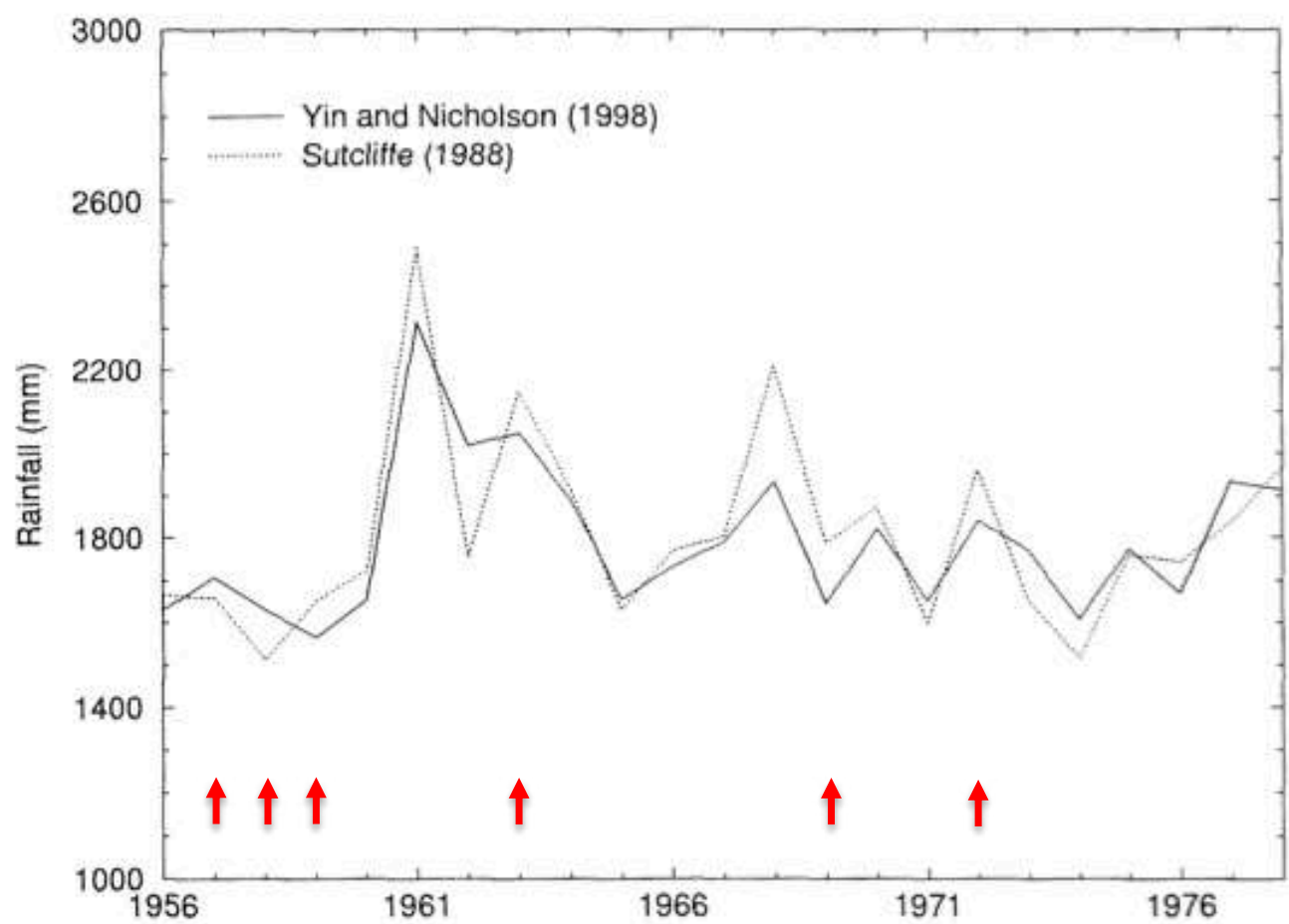

Figura 1.8: Série temporal de chuva anual (mm) sobre o lago Vitória para o período de 1956-1978. Linha sólida [Yin e Nicholson, 1998]; Linha tracejada [Sutcliffe, 1988]. Setas em vermelho indicam anos de ENSO positivo. Fonte: Sharon et al., [2000].

Chamberlain et al., [2013] analisou 2 configurações operacionais das saídas do modelo UM com previsão de tempestades sobre o lago. A primeira, com $40 \mathrm{~km}$ de resolução e a segunda, com $4 \mathrm{~km}$ de resolução, ambas centradas sobre o LV no período da primavera de 2012. As grades foram configuradas com 70 níveis verticais e previsão para 7 e 2 dias seguintes a inicialização com as grades de $40 \mathrm{~km}$ e $4 \mathrm{~km}$, respectivamente. A configuração utilizada para a primavera de 2012 foi a GA3.1 descrita por Walters et al., [2011]. Por dia foram realizadas 4 simulações $(0000,0600,1200,1800$ UTC). A condição inicial de TSL foi baseada na climatologia mensal do ARCLake da Universidade de Edinburgh [MacCallum e Merchant, 2011]. Os resultados das simulações foram comparados com as observações de superfície do departamento meteorológico de Uganda. Notou-se melhora na distribuição da velocidade do vento e precipitação com aumento da resolução do modelo, ainda, o máximo desempenho do modelo ocorre com simulações iniciadas 06 a 12 horas antes das tempestades que ocorrem no período da tarde e menor performance para as tempestades que ocorreram no período noturno. Essas últimas são de interesse do presente trabalho.

A circulação de brisa associada a lagos se desenvolve em lagos tão pequenos quanto $5 \mathrm{~km}$ de largura [Segal et al., 1997]. Muitos estudos foram realizados em lagos com extensão entre 5 
e $50 \mathrm{~km}$ de comprimento e todos identificaram uma circulação induzida pelo aquecimento diferencial entre a superfície do lago e a terra no entorno. Lagos com comprimento superior a $50 \mathrm{~km}$ apresentaram circulação de brisa com intensidade, duração e extensão similares as circulações de brisa marítima [Crosman e Horel, 2012]. No caso do LV, a mesma apresenta estrutura e intensidade similar à CBM devido à sua extensão.

A configuração topográfica na região do LV ainda favorece que a CBT também seja intensa dado o acoplamento entre a CBVM e a frente de brisa gerada por uma diferença de temperatura em torno de $3^{\circ} \mathrm{C}$ entre o ar sobre o LV e o ar sobre a terra [Ba e Nicholson, 1998] com disparo da convecção noturna.

Crosman e Horel, [2012] resumiram em 2 figuras a secção vertical da formação e propagação da frente de brisa para um estudo idealizado de um lago com $25 \mathrm{~km}$ de diâmetro e para brisa do mar ou brisa lacustre em lagos com diâmetro acima de $50 \mathrm{~km}$, que no caso apresentam comportamento similar (Fig. 1.9 e Fig. 1.10). Os resultados indicam que a espessura da frente de brisa do mar e lacustre, aumenta com o aumento da intensidade da radiação solar, ou seja, regiões tropicais apresentam frente de brisa mais espessas, conforme figuras 1.9a,c e $1.9 \mathrm{~b}, \mathrm{~d}$ que apresentam regiões com baixa e alta intensidade da radiação solar, respectivamente. Além disso, a intensidade da mesma é maior e a distância propagada para longe da linha de costa é maior e gera movimentos verticais mais intensos, quanto maior for a intensidade do fluxo de calor sensível proporcionado pela radiação solar. Seu estudo corroborou o fato de que lagos menores, nesse caso com diâmetro de $25 \mathrm{~km}$ apresentam espessura, intensidade e distancia propagada da frente de brisa menores que o mar e lagos maiores que $50 \mathrm{~km}$. A dependência da intensidade da radiação solar permanece a mesma que a obtida em regiões oceânicas. A estabilidade atmosférica também é um fator que afeta diretamente a intensidade, duração e espessura da CBM e CBL (figura 1.10), quanto menor a estabilidade, (figuras 1.10 a e c) maior é o desenvolvimento de ambas as circulações locais. Basicamente, a estabilidade está relacionada com o perfil vertical de temperatura potencial virtual, quanto maior a diminuição da temperatura potencial virtual com a altura, mais instável está o ambiente.

Outro ponto importante identificado por Crosman e Horel, [2012] é que, quanto maior o fluxo de calor sensível $(\mathrm{H})$ maior é o diâmetro no qual a CBL do lago passa a ter intensidade e duração semelhantes à CBM (Fig. 1.11). A figura 1.12 resume a dependência entre intensidade, duração e espessura da frente de brisa com o diâmetro do lago. 


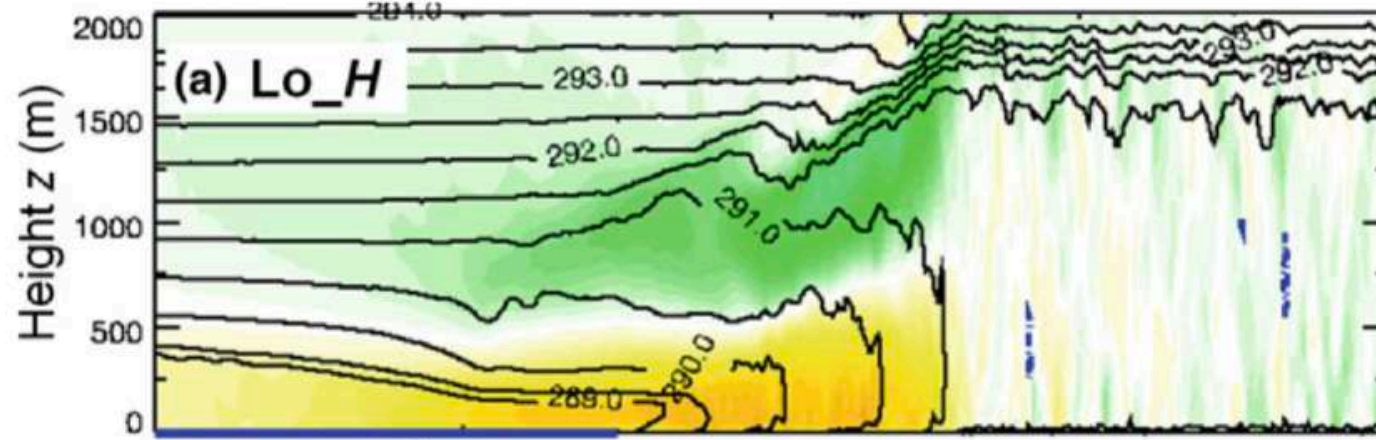

SEA

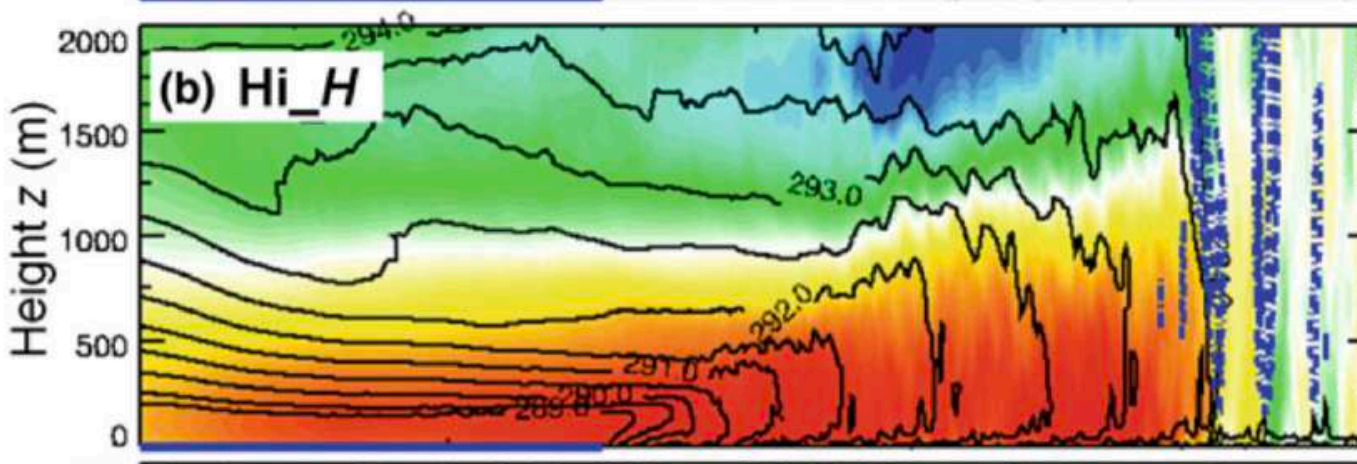

SEA

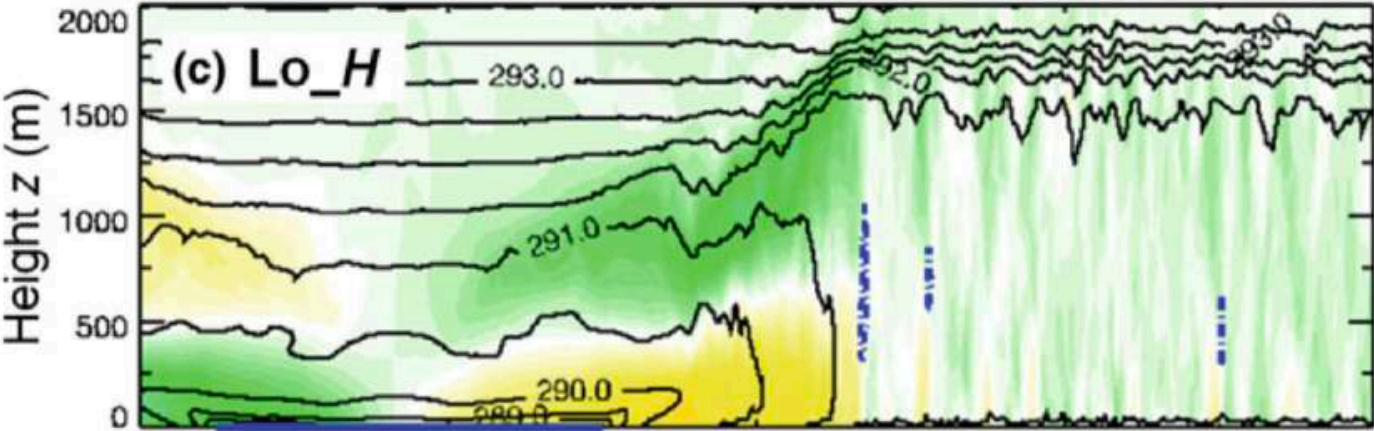

\section{LAKE}

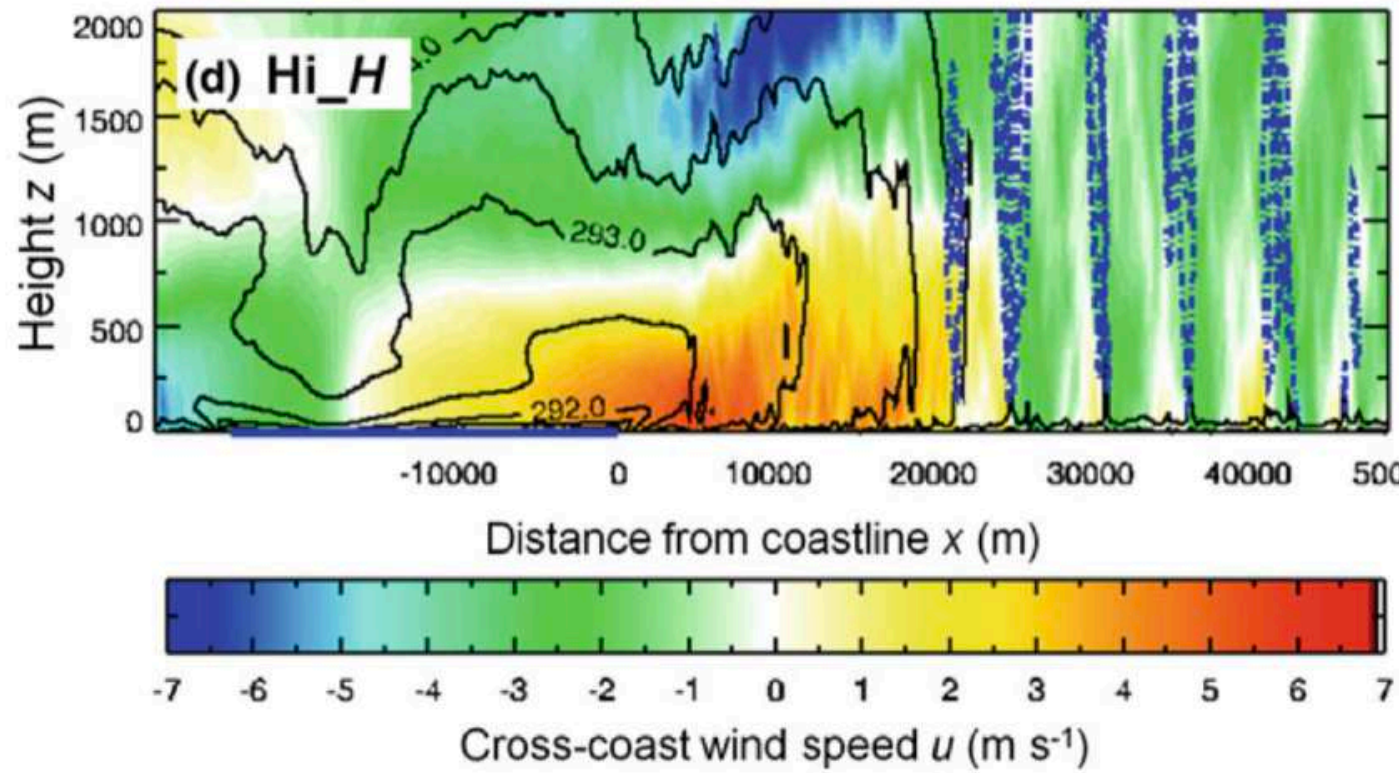

Figura 1.9: Secção vertical da circulação de brisa média na direção y 8 horas após o início da simulação para regiões com (a) baixa e (b) alta intensidade de radiação solar para brisa marítima e (c) baixa e (d) alta intensidade da radiação solar sobre lago ( $25 \mathrm{~km}$ de diâmetro). A barra de cores representa velocidade do vento $\mathrm{u}\left(\mathrm{m} \mathrm{s}^{-1}\right)$ e as linhas sólidas representam temperatura potencial $(\mathrm{K})$. Regiões de movimento vertical maior que $0.5 \mathrm{~m} \mathrm{~s}^{-1}$ estão demarcadas por linhas pontilhadas em azul. A superfície do mar ou do lago está representada por uma linha sólida em azul. Fonte: Crosman e Horel, 2012. 

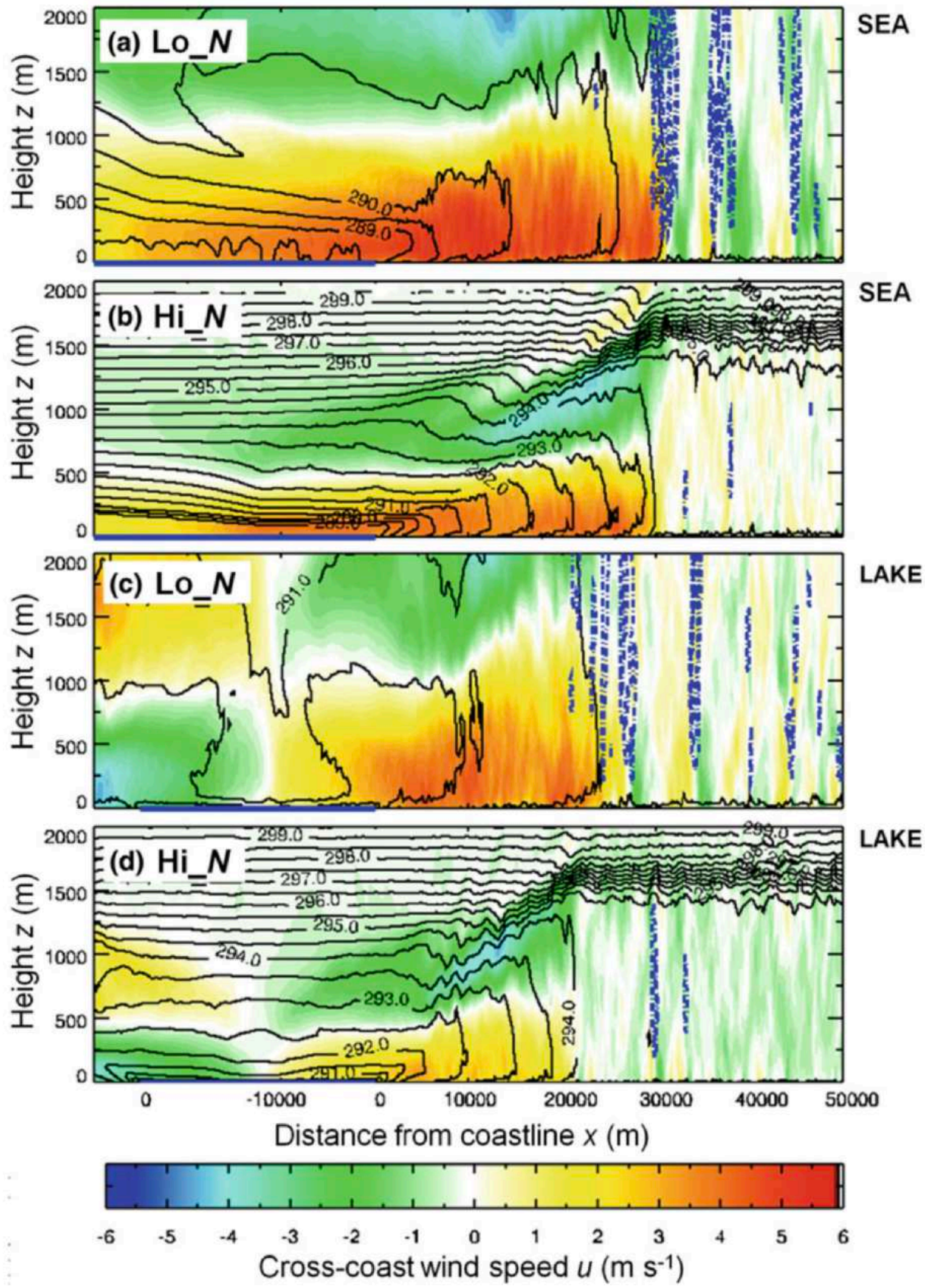

Figura 1.10: Secção vertical da circulação de brisa média na y 8 horas após o início da simulação para estabilidade (a) baixa e (b) alta no oceano e (c) baixa e (d) alta para um lago com $25 \mathrm{~km}$ de diâmetro. A barra de cores representa velocidade do vento $\mathrm{u}\left(\mathrm{m} \mathrm{s}^{-1}\right)$ e as linhas sólidas representam temperatura potencial $(\mathrm{K})$. Regiões de movimento vertical acima de $0.5 \mathrm{~m} \mathrm{~s}^{-1}$ estão demarcadas por linhas pontilhadas em azul. A superfície do mar ou do lago está representada por uma linha sólida em azul. Fonte: Crosman e Horel, 2012. 


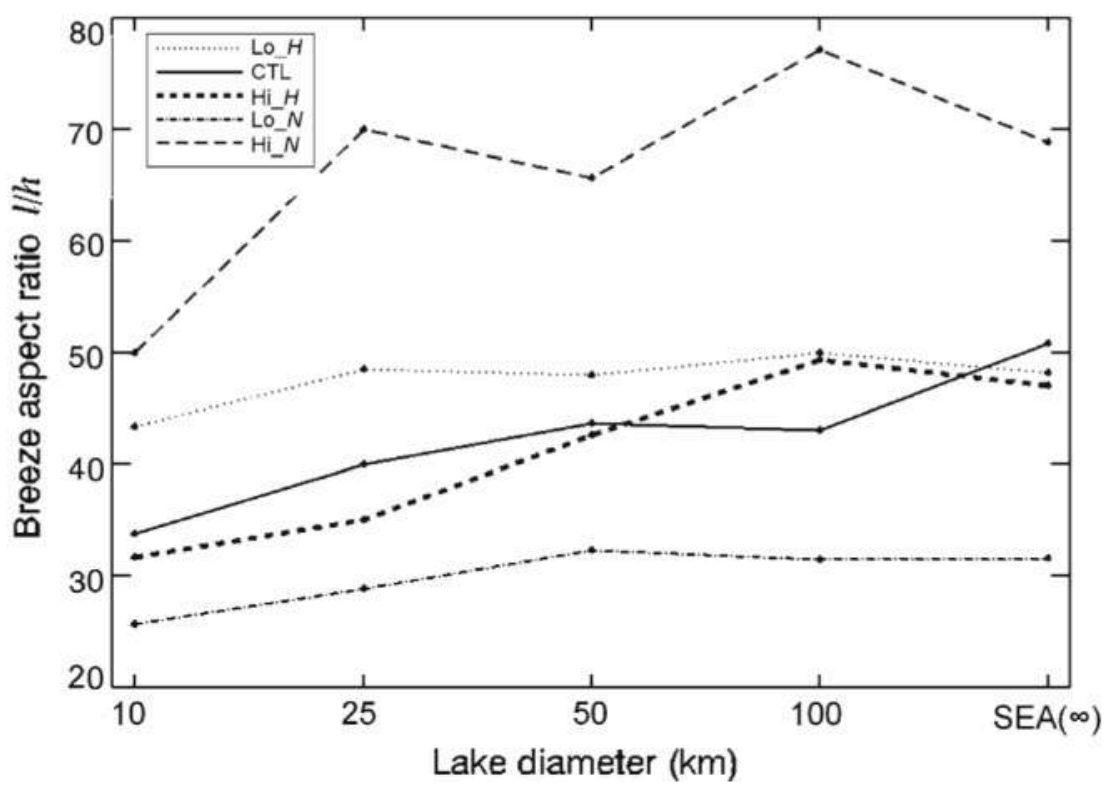

Figura 1.11: Razão entre a distância propagada pela frente de brisa e a espessura da CBL e CBM na costa observada 8 horas após o início da simulação para baixos e altos índices de fluxo de calor sensível e estabilidade inicial atmosférica. Fonte: Crosman e Horel, 2012.

A figura 1.9 e 1.10 indicam o perfil vertical simulado de velocidade zonal do vento 8 horas após o início das simulações com baixa $\left(\mathrm{Lo}_{-} \mathrm{H}\right)$ e alta intensidade $\left(\mathrm{Hi} \_\mathrm{H}\right)$ da radiação solar e baixa (Lo_N) e alta (Hi_N) estabilidade atmosférica, a condição de estabilidade pode ser verificada pelas linhas de temperatura potencial que estão muito próximas e com elevação com a altura na condição de alta estabilidade (Hi_N) e estão distantes na condição de baixa estabilidade (Lo_N). A figura 1.11 apresentam a razão entre a distância propagada pela frente de brisa e a espessura da CBL e CBM na costa, 8 horas após o início das simulações apresentadas nas figuras 1.9 e 1.10, com baixa e alta intensidade da radiação solar e estabilidade, no entanto, para diferentes diâmetros do lago. A maior razão entre distância e espessura da CBL e CBM ocorrem para a condição de alta estabilidade, devido a baixa espessura da brisa, enquanto que a menor razão ocorre para baixa estabilidade atmosférica devido a maior espessura da brisa, ou seja, a estabilidade atmosférica afeta muito mais a espessura da CBL e CBM do que a distância propagada pela mesma. O mesmo ocorre para intensidade da radiação solar que é inversamente proporcional a razão entre distância propagada e espessura e também afeta mais a espessura da CBL e CBM. As figuras 1.12(a,b,c) apresenta a evolução temporal do vento zonal, distância propagada e espessura da CBL e CBM na linha de costa para diferentes diâmetros do lago. As figuras 1.12(d,e,f) apresenta vento zonal, distância propagada e espessura da CBL e CBM na linha de costa 8 horas após o início das simulações para diferentes diâmetros do lago. 

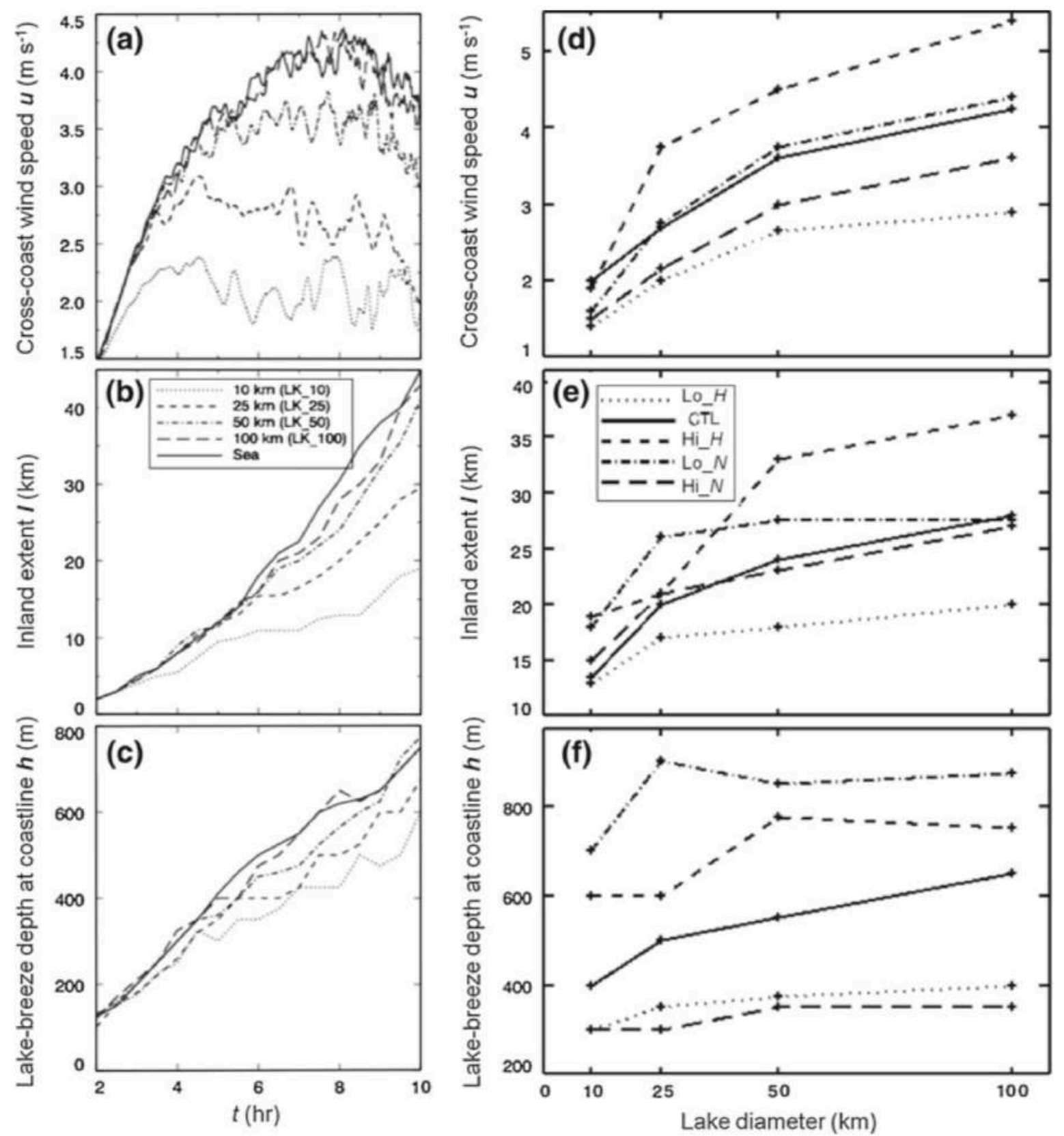

Figura 1.12: Velocidade do vento da CBL e CBM a 30 metros acima da superfície na linha de costa com o tempo (a), distância propagada da costa com o tempo em quilômetros (b) e profundidade em metros da CBL e CBM para lagos com diâmetro de 10, 25, 50 e $100 \mathrm{~km}$ e mar. O eixo horizontal refere-se ao tempo após o início da simulação idealizada. A sensibilidade para a componente u do vento (d), distância propagada da costa (e) e profundidade da CBL (f) como função do diâmetro do lago 8 horas após o início da simulação para baixo, médio e altos valores de fluxo de calor sensível na superfície e estabilidade atmosférica inicial. Fonte: Crosman e Horel, 2012. 
Os fluxos sinóticos de grande escala são conhecidos por apresentarem um importante papel em modular o comportamento das circulações de mesoescala sobre superfícies heterogêneas. Os efeitos dos fluxos de escala sinótica na circulação de brisa do mar são estudados e bem conhecidos desde o século 17 [Jehn, 1973] e de maneira geral não apresentam tantas variações quanto às circulações formadas pelas diferentes configurações e forma de lagos associadas à variabilidade nos padrões de linha de costa. Os modelos numéricos são uma importante ferramenta no estudo dessa complexa interação entre as circulações locais de diversos tipo. Por exemplo, na interação entre a entre a frente de brisa do mar na Índia com a frente de brisa formada pela presença do rio Banana com forte convergência em superfície [Zhong et al., 1991]. Nos estudos de Zhong et al., [1991] a direção, intensidade e duração das circulações locais na Índia apresentaram forte sensibilidade à intensidade dos fluxos sinóticos de grande escala. Outros estudos mostraram a convergência entre as frentes de brisa na região do cabo Canaveral na Florida, que são geradas em ambos os lados da costa, além da brisa gerada pelo lago Mosquito [Zhong e Takle, 1992], que gera uma complexa interação e frequentemente está associada ao disparo da convecção no período da tarde.

Os estudos sugerem que a forçante térmica se desenvolve basicamente sobre fraca circulação sinótica [Arrit, 1993; Reible et al., 1993; Stivari et al., 2003, 2005], também mostra que essas circulações geralmente são inibidas se a circulação sinótica ultrapassa os $4 \mathrm{~m} \mathrm{~s}^{-1}$ [Wang et al., 1996; Liu et al., 1999]. Por outro lado, Weaver e Avissar [2001] identificaram a formação de circulação local com ventos sinóticos de superfície tão intensos quanto $8-10 \mathrm{~m} \mathrm{~s}^{-1}$ na condição em que o fluxo sinótico era paralelo ao gradiente de temperatura em superfície. Nessa condição verificou-se a advecção da circulação local para longe da sua região de formação.

A CBL para lagos com diâmetros entre 3 e $10 \mathrm{~km}$ são suprimidas quando essas agem contra o vento sinótico, no entanto, estas são amplificadas se atuam na mesma direção do fluxo de grande escala, basicamente devido ao acoplamento entre as circulações de escala local e sinótica [Segal et al., 1997]. No caso da CBM, quando a direção do vento sinótico é da terra para o oceano, a CBM é mais intensa do que na situação de circulação sinótica na mesma direção da frente de brisa [Estoque, 1961 e 1962]. Esse comportamento ocorre em situações de vento sinótico fraco/moderado contra a direção da propagação da frente e criam as circulações de brisa mais intensas em termos de duração e intensidade [Arrit, 1993], por outro lado, em situações de forte circulação sinótica, nenhuma circulação local de brisa é formada, independente da direção do fluxo e a máxima intensidade da frente de brisa ocorre com a 
circulação sinótica na direção oposta à propagação de frente de brisa e com velocidade próxima à velocidade de propagação da brisa [Bechtold et al., 1991].

Observações com radar meteorológico mostram que as frentes de brisa mais intensas frequentemente aparecem como linhas finas com baixa refletividade com o vento sinótico contra a direção preferencial da frente de brisa, ao passo que para ventos sinóticos no sentido oposto, a frente de brisa não era observada no campo de refletividade do radar [Atkins e Wakimoto, 1997]. Para o caso de circulação sinótica paralela ao gradiente de aquecimento diferencial a linha tênue com máxima refletividade da frente de convergência da brisa era menos evidente. As frentes de convergência das CBM e CBL são capazes de alterar as condições atmosféricas localmente, pois frequentemente disparam o processo de convecção e chuvas, como, por exemplo, no entorno do lago Okeechobee no sul da Florida [Pielke, 1974] e durante o verão no entorno dos Grandes Lagos [Harman e Hebr, 1972].

O entendimento dos padrões de circulações gerados por lagos pequenos sob o efeito de uma circulação sinótica predominante também podem ser utilizados para o entendimento do efeito da circulação sinótica em circulações geradas por superfícies heterogêneas que não necessariamente precisam ser terra e água, já que superfícies distintas apresentam diferenças nos valores de capacidade térmica e, portanto, apresentam aquecimento diferencial com a formação de circulações locais, como no caso da circulação da ilha de calor urbano gerada pela diferença no aquecimento entre o ambiente urbano e rural [Asefi-Njafabady et al., 2010].

Estudos mais recentes por meio de radar meteorológico indicaram a formação da frente de brisa lacustre em lagos tão pequenos quanto $2 \mathrm{~km}$ de comprimento com a identificação de uma fina linha estacionária de convergência entre a CBL e a circulação sinótica de até $\sim 5 \mathrm{~m} \mathrm{~s}^{-1}$. Acima dos 5-6 $\mathrm{m} \mathrm{s}^{-1}$, a célula da circulação de brisa perde intensidade ou é advectada para longe [Asefi-Najafabady et al., 2012]. Por exemplo, Asefi-Najafabady et al. [2012] identificou que a intensidade dos ventos geradas pela frente de brisa do lago Wheeler (comprimento $\sim 2 \mathrm{~km}$ ) geralmente não passa dos $4 \mathrm{~m} \mathrm{~s}^{-1}$.

As simulações numéricas mostram relações interessantes entre o fluxo de calor sensível e intensidade, duração e espessura da frente de brisa. A magnitude do vento horizontal e vertical, a distância propagada e a espessura da frente de brisa aumentam com o aumento do fluxo de calor sensível, ou seja, espera-se que as circulações de brisa sejam mais intensas nos trópicos onde a radiação solar é maior. Em latitudes médias são mais intensas no verão e mais fracas no inverno. A turbulência convectiva leva à frontólise da frente de brisa e a distância de propagação da CBL e CBM é menor [Yan e Anthes, 1988; Sha et al., 2004; Shen, 1998; Tijm et al., 1999b; Miao et al., 2003; Marshall et al., 2004; Antonelli e Rotunno, 2007; Porson et al., 2007, Kala 
et al., 2010; Rotunno, 1983]. A distância propagada pela frente de brisa, espessura e intensidade do vento horizontal e vertical também aumentam com o aumento da área da superfície aquecida até a ordem de 50 a 100 km [Savijarvi e Matthews, 2004; Lemonsu et al, 2006; Courault et al., 2007; Freitas et al, 2007; Thompson et al., 2007; Chen e Byun, 2008; Dandou et al., 2009].

A combinação entre aquecimento diferencial de superfícies heterogêneas e declividade do terreno também podem intensificar as frentes de brisa do mar e lacustre. $\mathrm{O}$ efeito combinado entre frente de brisa e a circulação vale-montanha aumenta a intensidade do vento horizontal e vertical e a espessura da frente de brisa, no entanto, para declividade muito alta esse efeito pode ser suprimido. A declividade ideal para máxima amplificação também depende de fatores como distância entre a linha de costa e a montanha, altura absoluta da montanha, comprimento da inclinação, aquecimento e instabilidade [Neumann e Savijarvi, 1986; Ramis e Romero, 1995; Miao et al., 2003; Porson et al., 2007]. Além disso, pode haver a canalização pelas montanhas da frente de brisa e proporcionar aumento de intensidade local da CBL e CBM.

A formação de tempo severo pode ocorrer devido a fatores puramente dinâmicos e de larga escala, como um grande transporte de umidade associado a cavado em nível superior e forte cisalhamento vertical impulsionados por uma forçante termodinâmica, mas também pode ocorrer de maneira local associado à convergência, por exemplo, entre a circulação local gerada pelo ambiente urbano (ilha de calor) e a CBM com disparo da convecção e acumulados pontuais acima dos $100 \mathrm{~mm}$ em poucas horas, a exemplo do que ocorre no verão na Região Metropolitana de São Paulo [Vemado e Pereira Filho, 2016].

Nos casos estudados por Vemado e Pereira Filho [2016], o disparo da convecção intensa ocorreu por conta da interação entre a CBM e a circulação gerada pela ICU, mas mesmo nesses casos sempre há uma certa condição de grande escala com um mínimo de propensão para o disparo de tempestades, como por exemplo, divergência em altitude, disponibilidade de energia potencial convectiva (CAPE), ar mais seco em níveis médios para manutenção da convecção por tempo mínimo necessário à produção de grandes volumes de chuva em curto período, assim como para a formação de microexplosões [Honda e Kawano, 2015]. Flores et al., [2017] mostrou a importância de descrever as características físicas da superfície para que a modelagem atmosférica simule com eficiência as circulações locais associadas à heterogeneidade da superfície. O mesmo utilizou o tTEB (tropical Town Energy Budget Scheme), desenvolvido por Karam et al., [2010] e acoplado com o modelo ARPS por Flores, [2018] para descrever e aprimorar a descrição física dos fluxos de calor em ambiente urbano, no caso, a RMSP, que com frequência produz tempestades severas e pontuais associadas às 
circulações produzidas pela IC. Em suma, o tTEB basicamente é um modelo que descreve os fluxos de calor sensível e latente associados a presença do ambiente urbano (prédios, casas, carros, indústrias e etc) e está associado com o desenvolvimento da IC.

Todo o tipo de heterogeneidade na superfície produz aquecimento diferencial ou mesmo diferentes rugosidade de superfície com a formação de circulações locais com regiões preferenciais de confluência/difluência dos ventos e impacto no clima local. Até mesmo a heterogeneidade produzida pelas ondas sobre o lago ou oceano interferem nos ventos acima, essas, no entanto, muito mais complexa de analisar por ser extremamente dinâmica, além de depender de mais dados para sua avaliação [Li et al., 2018]. Na região dos grandes lagos, a presença dos lagos eventualmente produz eventos de neve localmente elevados devido à interação de forte advecção de ar gélido do polo norte que, ao se deslocar sobre as águas mais aquecidas dos lagos, produz tempestade de neve corrente abaixo do mesmo. Por exemplo, Cairns et al., [2001] estudou um evento de tempestade que produziu mais de $53 \mathrm{~cm}$ de neve em Carson City, Nevada, durante 2 dias. Este evento esteve associado à advecção de ar muito frio sobre o lago Tahoe mais aquecido. Laird et al., [2009] estudou por meio de radar meteorológico o efeito do lago Champlain na formação de bandas de precipitação e neve na região no entorno. Alguns dos resultados encontrados foram:

- O desenvolvimento de bandas de precipitação associados a ventos de sul ocorrem sobre o lago, mas de maneira geral são mais fracos, no entanto, $25 \%$ da precipitação sobre o lago estiveram associados a ventos de sul;

- O efeito do lago Champlain na formação de precipitação ocorre tipicamente com uma grande diferença entre a TSL e a temperatura do ar, com uma média de diferença em torno de $14.4^{\circ} \mathrm{C}$, tal que $\sim 86 \%$ dos eventos ocorrem com uma diferença superior a $10^{\circ} \mathrm{C}$. Outros autores encontraram diferenças menores na distribuição de diferença de temperatura que produziram precipitação devido à influência do lago.

- Uma inversão térmica próximo à superfície estava presente nas sondagens durante os eventos que ocorrem sobre o lago, um resultado um pouco diferente do encontrado por outros autores como Steenburgh et al., [2000] e Niziol et al., [1995] que determinaram que frequentemente a presença de uma camada de inversão age no sentido de limitar ou mesmo impedir a convecção. Neste caso, a eficiência do lago Champlain em produzir bandas de precipitação dentro de um ambiente mais estável sugere a presença de uma forte forçante em superfície que pode ser a CBVM produzidas pelas montanhas a oeste do lago. 
- Quase todos os eventos de neve estiveram associados à temperatura do ar inferior a $0^{\circ} \mathrm{C}$ e a maior parte deles esteve associado a ventos de norte. Também foram os que apresentaram duração mais longa.

- Eventos associados a ventos de sul ficaram mais confinados dentro do lago, enquanto eventos associados a ventos de norte apresentaram uma banda com aumento de precipitação e intensidade, seguindo a direção do vento. Nessa situação, produziu-se neve a dezenas de quilômetros distante da linha de costa do lago.

O modelo numérico ARPS [Xue et al., 2000, 2001] tem sido utilizado com sucesso na simulação de circulações de mesosescala. Por exemplo, com o ARPS-tTEB estudou-se a circulação local associada à ilha de calor urbano sobre a RMSP e a interação com a CBM. No período de verão, a interação entre a CBL e a circulação gerada pela IC é responsável pela formação de chuvas intensas e acumulados maiores sobre a mancha urbana da RMSP do que no seu entorno [Vemado e Pereira Filho, 2016].

O ARPS tTEB foi utilizado também com sucesso sobre a região metropolitana de Tóquio, o esquema tTEB implementado no modelo permitiu simular o aquecimento muito maior sobre a região durante o período de verão com consequência na formação de tempestades localizadas sobre a mesma. A área mais aquecida favorece o aumento de convergência de massa que, com disponibilidade de umidade, intensifica a convecção e a formação de células de tempestade. Pereira Filho et al., [2018] mostraram o desenvolvimento da convecção induzida pela IC e a CBM para dias com fraca influência sinótica. No estudo, realizou-se simulações para 3 eventos de tempestades convectivas sobre Tóquio sem e com tTEB, de modo que foi possível identificar o impacto da presença da cidade nas circulações locais. No período da tarde, a diferença de temperatura do ar chegou a $4^{\circ} \mathrm{C}$ com relação à simulação controle, próximo aos valores medidos em superfície. A figura 1.13a mostra a diferença de temperatura do ar simulada com o modelo ARPS entre os casos com e sem ambiente urbano, vento simulado com o ambiente urbano (fig. 1.13b) e diferença de velocidade e intensidade do vento (figura 1.14), onde se nota a forte convergência sobre a região de Tóquio devido a formação da ICU promovida pela extensa área urbanizada. 

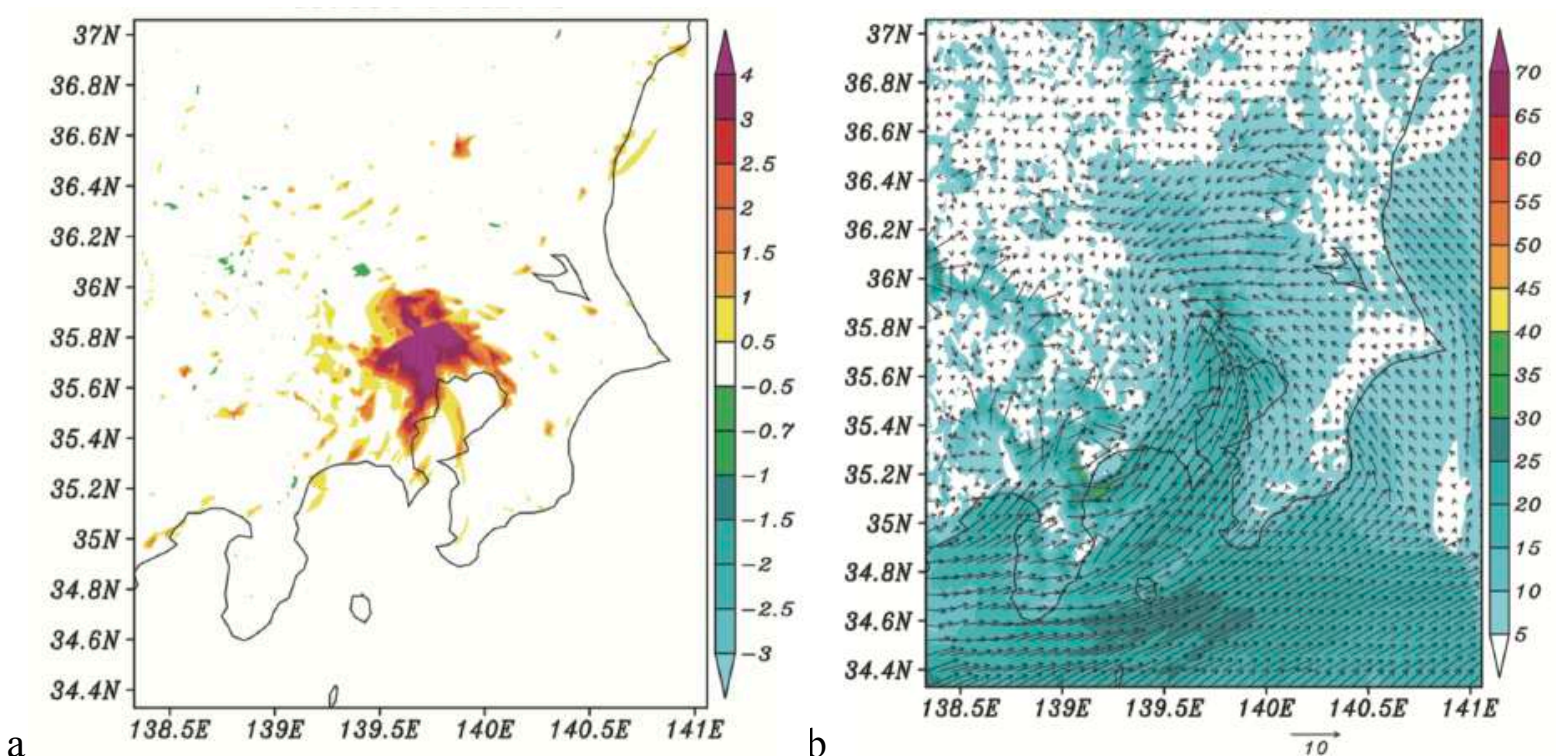

Figura 1.13: Simulação com o modelo numérico ARPS para o evento de precipitação na região metropolitana de Tóquio no dia 21/08/2013 às 1330 UTC para o campo de diferença de temperatura do ar (a) entre as simulações com e sem ambiente urbano (tTEB) e (b) direção e intensidade do vento para a simulação com o ambiente urbano. Contornos geográficos estão indicados. Barra de cores indica diferença de temperatura $\mathrm{em}^{\circ} \mathrm{C}$ e magnitude do vento $\mathrm{em} \mathrm{km} \mathrm{h}^{-1}$, respectivamente. Fonte: Pereira filho et al., [2018].

Os campos simulados com o ARPS mostram a forte influência das circulações locais geradas pelo aquecimento superficial na formação das chuvas sobre a área urbanizada. Além disso, mostram a eficiência da modelagem numérica com o ARPS em simular adequadamente os fluxos associados ao aquecimento diferencial. Analogamente, sobre o LV, não há ICU, mas o lago por, ser mais frio/aquecido no período da tarde/noite, produz circulação de brisa lacustre e terrestre, respectivamente, pela diferença de temperatura entre o ar sobre e no entorno do LV e o ARPS mostrou-se eficiente em produzir esses padrões atmosféricos, como será mostrado no capitulo 3.

Os estudos realizados acima no âmbito do grupo de trabalho no qual o presente autor participa indicam a eficiência do modelo numérico ARPS em simular as condições de circulações locais associadas ao microclima local, o que justifica o uso do mesmo para a realização dos estudos sobre a região do LV na África. Sobre essa região, não foi utilizado o tTEB devido a ausência de ambiente urbano típico e as circulações locais envolvidas basicamente referem-se à diferença de temperatura entre o lago e o entorno (brisa lacustre) e a presença de complexa região montanhosa (brisa vale-montanha). As características físicas e as principais parametrizações associadas ao modelo ARPS estão descritas no capitulo 2 deste trabalho. 

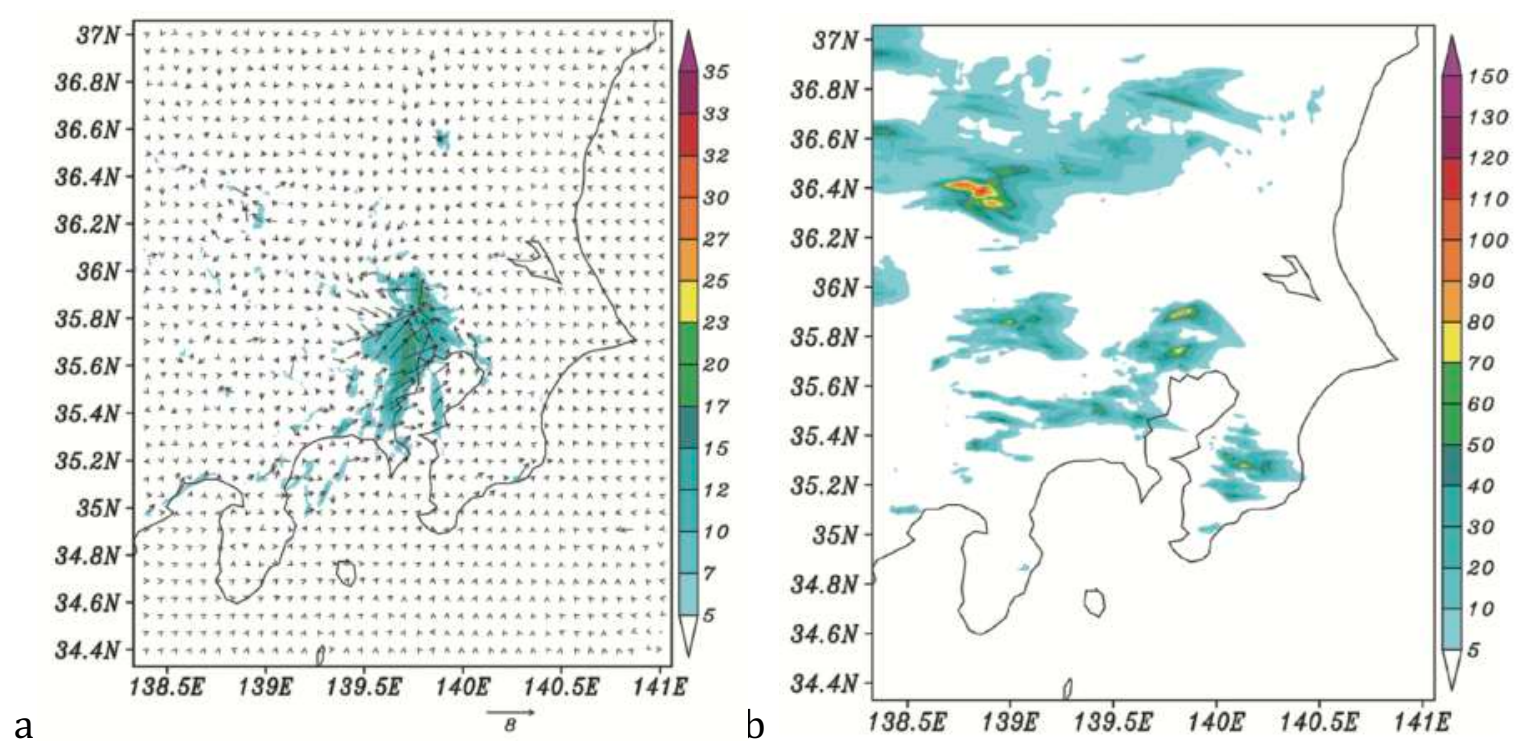

Figura 1.14: Similar a figura 1.13, mas para os campos diferença de direção e intensidade do vento a 10 metros de altura no mesmo horário e chuva acumulado total para o dia 21/08/2013. Contornos geográficos estão indicados. Barra de cores indica diferença de magnitude do vento e precipitação em $\mathrm{km} \mathrm{h}^{-1}$ e mm, respectivamente. Fonte: Pereira filho et al., [2018].

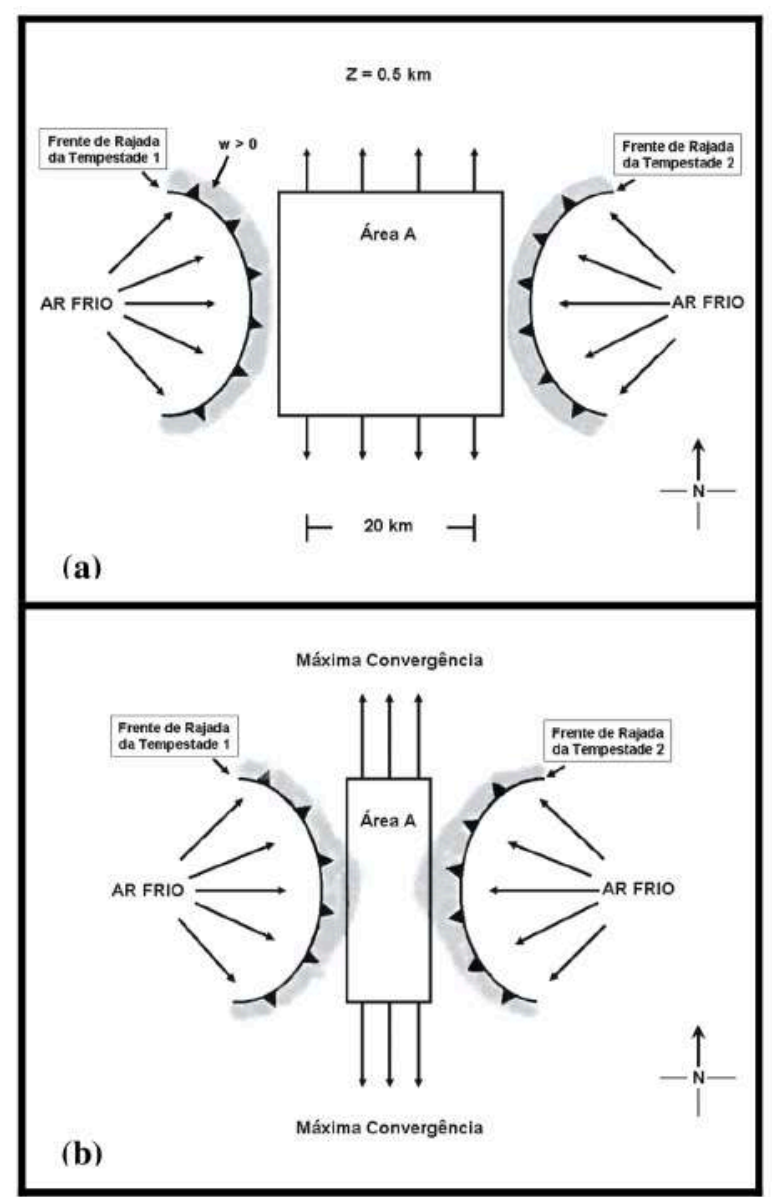

Figura 1.15: Esquema de ambiente dinâmico no plano horizontal a $0.5 \mathrm{~km}$ de altura de (a) duas frentes de rajadas ou duas frentes de brisa geradas por sistemas precipitantes ou mesmo por um lago ou oceano separadas em $20 \mathrm{~km}$ e que se movem uma em direção a outra. O retângulo em A define á região de colisão das 2 frentes que enquanto se movem força a saída do ar pelas laterais do mesmo, enquanto o retângulo diminuí de tamanho (b) e a convergência de massa aumenta. Linha sólida espessa com barbela indica as frentes de rajadas ou de brisa. Fonte: Hallak, 2007. 
$\mathrm{Na}$ figura $1.13 \mathrm{~b}$ existe um efeito combinado entre a colisão das frentes de brisa do mar de sul com a brisa oriunda da baía de Tóquio e o efeito da circulação gerada pela IC. A colisão entre essas frentes favorece o disparo da convecção conforme esquematizado na figura 1.15, que geram novas frentes de rajadas em uma complexa interação de mesoescala. De acordo com Droegemeier e Wihelmson, [1985], a máxima convergência ocorre a norte e a sul da área de colisão entre as frentes (figura 1.15b), tal que estas são as regiões preferenciais de provável levantamento das parcelas. Essas regiões surgem porque a velocidade horizontal de saída da massa de ar da área A não precisa trabalhar contra a força da gravidade e, portanto, é maior do que a velocidade vertical induzida pela aproximação das frentes.

\subsection{Objetivos}

O objetivo principal da tese foi o estudo das circulações locais na região do LV e o impacto da topografia na CBL e CBVM no disparo de células convectivas profundas. Particularmente, as tempestades mais intensas que se iniciam no período da madrugada e atingem a borda oeste do lago, o que torna essa região peculiar para os estudos. Os processos dinâmicos e termodinâmicos são estudados por meio do sistema ARPS e do sensoriamento remoto para estimativa de precipitação e TSL. Os processos na CLP foram ajustados com base em simulações realizadas no âmbito do projeto (TOMACS), Japão. Além disso, estudo climatológico de todos os eventos convectivos que atuaram na região do LV no período de 2000 a 2014.

Os objetivos específicos da tese são:

- Identificar a dinâmica associada as circulações locais CBL e CBVM com o ARPS, e como estas interagem para o disparo da convecção sobre o LV;

- Determinar a climatologia dos eventos convectivos que atuam sobre a África equatorial na região que compreende desde o LV até a floresta do Congo por meio das estimativas de precipitação com o CMORPH.;

- Estimar a frequência, velocidade de fase média, duração e distância propagada dos sistemas convectivos que atuam sobre a África equatorial e o LV por meio de diagramas Hovmoller; 
- Compreender como a complexa topografia no entorno do LV interfere na dinâmica das circulações locais e no disparo da convecção noturna com o sistema ARPS; 


\section{Capítulo 2}

\section{Metodologia}

\subsection{Dados}

\subsubsection{Precipitação estimada com o CMORPH}

O CMORPH [Joyce et al., 2004] tem sido usado com sucesso para o estudo de ondas de Rossby e de Kelvin na região intertropical, para o estudo da dinâmica da convecção na Amazônia, da convecção profunda sobre o lago Vitória, dentre outros. O conjunto de dados CMORPH permite amplo estudo da dinâmica das chuvas entre as latitudes $60^{\circ} \mathrm{S}$ a $60^{\circ} \mathrm{N}$, com resolução temporal de 30 minutos, espacial de $8 \mathrm{~km}$ e período que compreende desde 1998 até os dias atuais. Dado que a maior parte da região compreendida pelo CMORPH não apresenta medições in situ, essa estimativa se torna de fundamental importância na compreensão da dinâmica entre as latitudes baixas e médias, especialmente em áreas com baixa densidade ou nenhuma estação meteorológica disponível.

A técnica CMORPH utiliza do que cada sensor de diferentes satélites oferece de mais acurado. A mesma produz análise de precipitação global com resolução espacial e temporal muito alta. Essa técnica usa estimativa de precipitação derivada exclusivamente dos sensores de microondas de satélites de baixa órbita, com resolução temporal de 3 horas. Os sistemas precipitantes identificados são advectados por meio dos dados do canal infravermelho de satélites geoestacionário, com resolução de 15 minutos. As estimativas de precipitação são derivadas do sensor de microondas passivo a bordo do DMSP 13, 14 e 15 (SSM/I), o NOAA15, 16, 17 e 18 (AMSU-B) e AMSR-E e o TMI a bordo do satélite Aqua da NASA e o TRMM, respectivamente. São utilizados os algoritmos de Ferraro [1997] para o satélite SSM/I, Ferraro et al., [2000] para o AMSU-B e Kummerow et al., [2001] para o TMI. Note que esta técnica basicamente combina diferentes algoritmos para obtenção da precipitação, deste modo, é um método flexível na qual outras estimativas de precipitação de outras fontes de satélite podem 
ser combinadas. Em suma, essa técnica obtém estimativa de precipitação com o canal de microondas e usa dos canais de infravermelho para obter o deslocamento das chuvas, durante o intervalo de tempo na qual não há dados do canal microondas (menor resolução temporal). Essa estimativa produz resolução espacial e temporal no equador de $8 \mathrm{~km}$ e 30 minutos, respectivamente. A maior resolução, portanto, é obtida via interpolação.

As estimativas de precipitação com alta resolução espaço-temporal são importantes para muitas aplicações. Tal conjunto de dados pode fornecer informação útil para mitigação de desastres e podem ser utilizadas por modelos numéricos, tais como, modelos de superfície, resolvendo o ciclo da precipitação diurna e para validação de modelos de previsão de precipitação. Os mesmos são úteis na verificação de modelos numéricos de previsão. Em diversas áreas do globo os modelos numéricos globais apresentam baixa performance devido à modelagem inapropriada do ciclo diurno sobre essas regiões, conforme descrito por Yang e Slingo, [2001]. A maior parte do planeta apresenta baixa densidade de estações de superfície ou até mesmo nenhuma estação, principalmente sobre os oceanos. Deste modo, se torna essencial um método de estimativa de precipitação por meio de sensoriamento remoto baseado em satélite e que abrange todo o globo terrestre

Diversas técnicas podem obter estimativas de precipitação no globo terrestre. Vincente [1994] combinou observações de microondas com dados de infravermelho e radar na região do satélite GOES. Miller et al., [2001] desenvolveu um método de estimativa de precipitação por meio da regressão dos sensores de microondas pelas observações de temperatura de brilho de IR no mesmo ponto, de tal forma que foi possível obter estimativa de precipitação naquele ponto. Turk et al., [2003] conseguiu obter um limite de temperatura de brilho para o qual observava-se precipitação por meio de comparação entre temperatura de brilho da nuvem e estimativa de precipitação via microondas no mesmo ponto. Huffman et al., [2003] calibrou as estimativas via infravermelho por meio das estimativas com microondas.

\subsubsection{Densidade de descargas atmosféricas com o sistema LIS}

O ciclo diurno dos raios e o número total dos mesmos foram obtidos por meio dos dados do Lightning Imaging Sensor (LIS) [Albrecht et al., 2016]. Esse conjunto de dados, com resolução espacial de $0.1^{\circ}$, está disponível no período de 1998 a atual. Esse conjunto de dados foi utilizado de forma independente para verificação e validação das estimativas de precipitação obtidas com o CMORPH. Sobre a África equatorial, o horário de máxima precipitação e da atividade elétrica 
das tempestades estão em fase, mostrando forte correlação entre ambos [Vegunopal et al., 2015]. O LIS apresenta alta performance para detectar e avaliar a acurácia de outras redes de estimativas de queda de raios como o WWLLN [Rudlosky e Shea, 2013] e foi utilizado apenas como complemento para identificar se a climatologia de precipitação obtida com o CMORPH apresenta correlação com a climatologia de densidade de descargas atmosféricas na região do LV e no seu entorno. Nesse caso, a região de máxima precipitação deve ser aproximadamente coincidente com a região de máxima acumulação anual ou máximo no horário, já que boa parte da chuva sobre a região do LV é do tipo convectiva com forte atividade elétrica. O mesmo vale para a região da floresta do Conto.

\subsubsection{Imagens IR do satélite MSG}

As imagens do satélite meteorológico Meteosat Segunda Geração (MSG) foram utilizadas para identificação da convecção sobre a região do LV. Com resolução temporal e espacial de 15 minutos e $4 \mathrm{~km}$, respectivamente em doze canais que permitem estudos de nuvens por meio da radiação eletromagnética emitida na região do espectro visível e infravermelho. O canal visível permite a discriminação entre nuvens constituídas predominantemente por partículas de água ou gelo, por exemplo, Cirrus não precipitante. Os canais de vapor de água são destinados à observação da distribuição de vapor de água na atmosfera, o pico de banda dos canais disponíveis permite monitorar médios e altos níveis da troposfera. Nesse trabalho se utilizou do espectro infravermelho $(10.8 \mu \mathrm{m})$, janela atmosférica que permite estimar a temperatura de brilho do topo da nuvem, detecção de Cumulus Nimbus (Cb) que se forma sobre o LV no período da madrugada.

\subsubsection{Temperatura de superfície estimada com o MODIS}

O sensor MODIS a bordo dos satélites TERRA e AQUA da National Aeronautics and Space Administration (NASA) foi lançado em 2000. O primeiro fornece informações da superfície da Terra em 36 bandas que incluem os espectros visível e infravermelho-próximo. O satélite TERRA apresenta órbita polar e passa em um determinado ponto da terra 2 vezes por dia. $\mathrm{O}$ sensor MODIS térmico infravermelho mede a radiância no topo da atmosfera na qual a temperatura de brilho pode ser estimada por meio da lei de Planck. Essa temperatura de brilho é diferente da temperatura da superfície por uma diferença que pode variar entre $1 \mathrm{~K}$ e $5 \mathrm{~K}$, 
devido ao ângulo não vertical do satélite em relação ao ponto de interesse, variação subgrade da temperatura da superfície, variação na emissividade de superfície, além de outros efeitos atmosféricos [Dousset e Gourmelon, 2003].

Para remover os efeitos citados acima e estimar a temperatura da superfície do espaço, um método chamado de temperatura da superfície dia e noite do MODIS foi criado para tirar vantagem da capacidade do MODIS. Esse método basicamente combina os pares dia e noite dos dados do sensor térmico de infravermelho em sete bandas para simultaneamente recuperar a temperatura da superfície e a emissividade média da superfície com as bandas 20, 22, 23, 29, 31,32 e 33 sem precisar estimar o perfil vertical de vapor de água e temperatura atmosférica. Esse método apresenta alta acurácia de acordo com Wan e Li, [1997].

O MODIS tem estimativas de temperatura da superfície e emissividade nas resoluções espaciais de $1 \mathrm{~km}$ e $5 \mathrm{~km}$ no globo sobre condições de céu claro. Sobre a região do LV foram obtidas algumas estimativas de temperatura da superfície do lago (TSL), no entanto, para essa região em específico e para os eventos estudados 01/11/2010 e 03/11/2014 a estimativa de TSL estava com muitos ruídos. Deste modo, utilizou-se da TSL climatológica do lago obtidas por modelos hidrodinâmicos de Anyah, [2006]. Os dados MODIS foram úteis para verificação aproximada se os valores de TSL climatológico obtidos por outros autores eram aproximadamente próximos aos estimados pelo MODIS em alguns pontos.

\subsubsection{Sistema GFS}

As análises do modelo global Global Forecast System (GFS) são disponibilizadas em intervalos de $6 \mathrm{~h}$ em 6h, em 26 níveis de isobáricos de $1000 \mathrm{hPa}$ a $10 \mathrm{hPa}$, com os campos de componentes meridional e zonal $\left(\mathrm{m} \mathrm{s}^{-1}\right)$ velocidade vertical em $\left(\mathrm{Pa} \mathrm{s}^{-1}\right)$, temperatura do ar $\left({ }^{\circ} \mathrm{C}\right)$, umidade relativa do ar (\%), pressão atmosférica $(\mathrm{hPa})$, umidade absoluta $\left(\mathrm{g} \mathrm{Kg}^{-1}\right)$, temperatura do solo $\left({ }^{\circ} \mathrm{C}\right)$, além de diversas outras variáveis derivadas como CINI $\left(\mathrm{J} \mathrm{Kg}^{-1}\right), \mathrm{CAPE}\left(\mathrm{J} \mathrm{Kg}^{-1}\right)$, IL $\left({ }^{\circ} \mathrm{C}\right)$ e etc. As análises são disponibilizadas pelo National Center for Environmental Predicition (NCEP) dos EUA.

Os campos provenientes do sistema GFS são utilizados como condições iniciais e de contorno para a grade ARPS com menor resolução espacial. Com $1^{\circ}$ de resolução espacial, o sistema GFS basicamente fornece a condição sinótica para as simulações ARPS. 


\subsubsection{Topografia com o SRTM}

O modelo digital de elevação obtido por interferometria pela missão Shuttle Radar Topographic Mission (SRTM) foi uma missão conduzida pela NASA dos EUA durante o mês de Fevereiro de 2000 com o intuito de mapear a altitude da superfície terrestre continental entre as latitudes de $60^{\circ} \mathrm{N}$ e $58^{\circ} \mathrm{S}$. A missão durou 11 dias e realizou 159 órbitas em torno da terra a uma altitude de $233 \mathrm{~km}$. O sensor utilizado, desenvolvido em parceria com a NASA, é conhecido como Synthetic Aperture Radas (SAR) e obtém imagens da Terra usando sinais de micro-ondas nas bandas C e X. Duas antenas auxiliares permitiram a leitura interferométrica e possibilitou determinar a altitude de cada ponto, que culminou em um modelo de topografia de altíssima resolução [Hounam e Werner, 1999]. Para a região de interesse na África equatorial, os SRTM possuí 90 metros de resolução horizontal e foi como dado de entrada de topografia nas simulações com o sistema ARPS.

\subsubsection{Reanálises NCEP}

A reanálise NCEP é um sistema que assimila dados de superfície e altitude no passado para compor diversos campos instantâneos 4 vezes ao dia, nos horários sinóticos 0000 UTC, 0600 UTC, 1200 UTC e 1800 UTC desde 1979 até a atualidade. Essas composições são disponibilizadas pela NOAA e permitem uma avaliação sinótica dos principais campos atmosféricos, como vento zonal e meridional, temperatura do ar, pressão atmosférica, temperatura da superfície do mar entre outros.

Nesse trabalho os principais campos analisados na escala sinótica são os campos de vento nos baixos, médios e altos níveis, pressão atmosférica ao nível do mar e velocidade vertical ômega.

\subsection{Climatologia}

Utilizou-se de dados de estimativas do CMORPH no período de 2000 a 2014 para obter a climatologia de precipitação na região da África equatorial, que inclui o LV. Obteve-se estatísticas dos sistemas precipitantes que se desenvolveram na região por meio de climatologia horária, sazonal e mensal, além de uma avaliação obtida pela técnica Hovmoller. Para a 
avaliação desses sistemas utilizou-se os dados do CMORPH com resolução temporal e espacial de 30 min e $8 \mathrm{~km}$, respectivamente sobre a África Equatorial [Joyce et al., 2004; Janowiak et al., 2005; Kousky et al., 2006]. Esse método basicamente utiliza de chuva estimadas por sensores de microondas dos satélites (baixa resolução temporal) e que são propagadas pelos sensores de infravermelho (alta resolução temporal).

\subsubsection{Análise dos ciclos diurnos, mensal, sazonal e anual da convecção}

A análise do ciclo diurno mensal foi obtida por meio de médias simples para todos os meses de janeiro a dezembro para o período de 2000 a 2014. Deste modo, obteve-se o ciclo sazonal da precipitação sobre parte da África equatorial e o LV, com identificação dos períodos nas quais houveram os maiores/menores índices de precipitação. Estudos anteriores já indicavam maiores índices pluviométricos sobre o LV entre os meses de março e maio e um segundo ciclo entre outubro e dezembro, no entanto, utilizando-se de outras fontes de estimativa de precipitação e a validação dos dados CMORPH para essa região é necessária. No capítulo 3 será mostrado que o comportamento sazonal obtido com esse conjunto de dados segue o mesmo obtido por estudos anteriores.

A análise dos ciclos também foi utilizada para obter a frequência horária para uma determinada intensidade pluviométrica em $\mathrm{mm} \mathrm{h}^{-1}$. Os limiares utilizados foram $1.0 \mathrm{~mm}, 2.0$ $\mathrm{mm}, 5.0 \mathrm{~mm}, 10.0 \mathrm{~mm}$ e $20 \mathrm{~mm}$. A análise mostra, para um determinado horário e mês, a frequência em \%, de uma chuva com intensidade acima de cada limiar. Esse estudo identificou áreas preferencias de chuvas mais intensas de acordo com a época do ano e horário do dia e foi de suma importância para validação de estudos anteriores e para a identificação das chuvas mais intensas sobre o LV no período noturno e mais intensas sobre a floresta do Congo no período vespertino, conforme será mostrado no capítulo 3. A região de estudo compreende as latitudes $9^{\circ} \mathrm{S}$ a $5^{\circ} \mathrm{N}$ e entre $24^{\circ} \mathrm{E}$ a $42^{\circ} \mathrm{E}$, conforme figura 2.1 .

A análise de frequência também foi calculada pela média em toda a área do retângulo descrito na figura 2.1. Esse calculo foi utilizado para determinação do peso da influência do LV no clima da região entre as latitudes de $3^{\circ} \mathrm{S}$ e $1^{\circ} \mathrm{N}$, já que basicamente a convecção noturna ocorre, em grande parte das vezes apenas sobre o LV. 

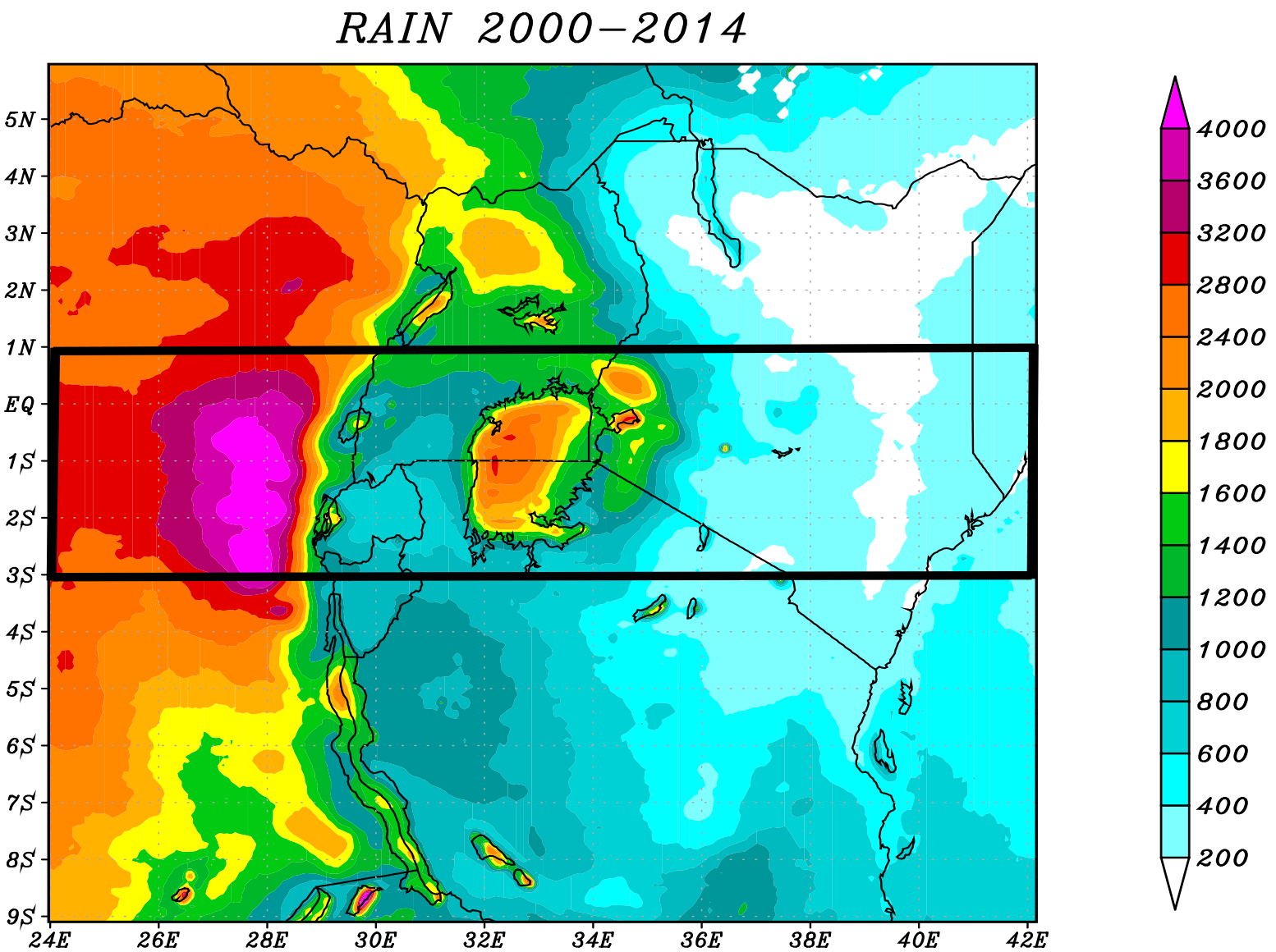

Figura 2.1: Precipitação média anual obtida com CMORPH $(\mathrm{mm})$ sobre a África Equatorial para o período de 2000 a 2014. Longitudes, latitudes, contornos geográficos e geopolíticos estão indicados. Escala de cores indica precipitação em $\mathrm{mm} \mathrm{ano}^{-1}$. O domínio da análise Hovmoller é indicado pelo retângulo em negrito.

\subsubsection{Diagramas longitude-tempo de Hovmoller}

O diagrama hovmoller é geralmente utilizado para plotar dados meteorológicos de tal forma que é possível identificar o comportamento de ondas atmosféricas e sistemas precipitantes no tempo e espaço. Os eixos do diagrama são geralmente longitude ou latitude e tempo nos eixos $\mathrm{x}$ e y, respectivamente, com valores de algum campo representado por uma palheta de cores. Diagramas hovmoller pode ser utilizado para plotar a evolução temporal de um perfil vertical de alguma quantidade escalar, umidade, temperatura dentre outras variáveis [Hovmoller, 1949].

O diagrama hovmoller também é utilizado para estudar a duração, propagação zonal e coerência dos sistemas atuantes. Pereira filho et al., [2015] utilizou este método para estudar os sistemas convectivos atuantes sobre a Amazônia e no trópico adjacente. O método possibilitou um estudo estatístico dos sistemas precipitantes que atuaram na região, no período entre 2002 a 2008, da sua velocidade de fase média, frequência e distância propagada dos episódios. De 
maneira análoga ao estudado por Pereira Filho et al., [2015] pretende-se utilizar do diagrama Hovmoller para um período de 15 anos de estimavas CMORPH (2000-2014) para obter a estatística dos sistemas que atuam na região da África equatorial e que incluem a região do LV. Por esse método, foi avaliado velocidade média de propagação da convecção, distancia média percorrida, tempo de duração e o ciclo diurno a fim de se entender o comportamento dos eventos que atuaram no maior lago tropical de água doce do mundo.

A área de estudo com o diagrama Hovmoller, descrita pelo retângulo da figura 2.1, compreende as latitudes $3^{\circ} \mathrm{S}-1^{\circ} \mathrm{N}$ e $24^{\circ} \mathrm{E}-42^{\circ} \mathrm{E}$, tal que o eixo $\mathrm{x}$ representa a longitude e o eixo y o tempo para a média da precipitação no intervalo de latitude citado acima.

Duração, velocidade de fase e distância propagada dos sistemas convectivos sobre a África equatorial e o LV foram estimados por meio de diagramas tempo versus longitude obtidos por esse método de maneira similar ao realizado por Pereira filho et al., [2015]. Uma função cosseno é correlacionada com cada sistema precipitante que aparece no diagrama Hovmoller para obter a estatística dos eventos. A função cosseno é retangular e é correlacionada com um dado evento que se propaga no tempo. Essa função é deslocada através de todas as posições tempo versus longitude a cada 30 minutos e $0.16^{\circ}$ para obter uma faixa de chuva contígua com correlação maior que 0.35 [Carbone et al., 2002, Pereira Filho et al., 2015 e Laing et al., 2008].

Através da inclinação dessas faixas de precipitação no diagrama foi possível obter as estatísticas. Por exemplo, o comprimento da faixa indica a distância propagada em $\mathrm{km}$, o coeficiente angular indica a velocidade de fase $\mathrm{em} \mathrm{km} \mathrm{h}^{-1}$ e o eixo y indica o tempo de duração do sistema precipitante. Foram consideradas as estatísticas de todos os episódios com taxa de precipitação média longitudinal acima de $0.1 \mathrm{~mm} \mathrm{~h}^{-1}$ entre as latitudes de $3^{\circ} \mathrm{S}$ e $1^{\circ} \mathrm{N}$ e com propagação em distância acima dos $275 \mathrm{~km}$. A área foi escolhida considerando a gênese da maioria dos sistemas convectivos disparados a leste do lago Vitória.

\subsection{Modelagem com o sistema ARPS}

O sistema ‘Advanced Regional Predicition System' (ARPS) foi desenvolvido pelo Centro de Análise e Previsão de tempestades (CAPS) pela Universidade de Oklahoma. O ARPS é um modelo tridimensional, compressível e não hidrostático formulado em coordenadas de altura que seguem o terreno. O modelo ARPS apresenta alta performance por ter seu desenvolvimento desde o início de maneira paralelizada [Xue et al., 2000]. Por utilizar equações dinâmicas e termodinâmicas com o mínimo de aproximação, apresenta alto desempenho para o estudo de 
movimentos de mesoescala e microescala. Hallak [2007] e Flores et al., [2018] utilizaram o modelo ARPS para estudo da dinâmica das células de tempestades sobre a RMSP. Flores [2017] implementou o esquema tTEB desenvolvido por Karam et al., [2010] para o estudo da IC e como essa intensifica as chuvas sobre o ambiente urbano.

\subsubsection{Descrição do sistema ARPS}

As principais características do sistema ARPS são descritas por [Xue et al., 1995, 2000, 2003]:

- Geometria 1D, 2D e 3D com coordenada vertical $\sigma_{z}$ que segue as variações de altura do terreno;

- As equações são não-hidrostáticas e compressíveis;

- Advecção de segunda e quarta ordem quadraticamente conservativas na grade do tipo C de Arakawa;

- Esquema 'leapfrog' e semiexplícito para os modos de gravidade e acústicos, respectivamente, com opção para filtro de Asselin;

- Diversos tipos de iniciação da modelagem (analítica, homogênea com sondagem, heterogênea tridimensional);

- Translação automatizada do domínio para seguir trajetórias de tempestades;

- Parametrizações de microfísica que englobam 6 fases da água com 3 categorias de gelo;

- Parametrização de cúmulos Kain-Fritsch entre outros;

- Parametrização de fluxos de calor, umidade e momento a partir das leis de arrasto aerodinâmico, com formulações dependentes da estabilidade atmosférica;

- Modelo de solo difusivo com múltiplas camadas e opção de inicialização usando o índice de precipitação antecedente;

- Iniciação do modelo em tempo real por meio de condições iniciais geradas pelo pacote de análise objetiva local;

- Assimilação de dados tridimensionais (3DVAR) para vários tipos de conjunto de dados, entre eles coordenadas esféricas de radar Doppler;

- Parametrização de microfísica para 3 categorias de gelo diferenciado em 6 fases da água (água de chuva, água de nuvem, gelo de nuvem, neve, granizo e graupel) [Lin et al., 1983]. 
Maior detalhamento das equações dinâmicas e termodinâmicas primitivas que são utilizadas pelo modelo ARPS podem ser encontradas nos apêndices A e B da tese do Hallak [2007].

O ARPS resolve explicitamente as variáveis da tabela 2.1, dependentes das coordenadas cartesianas $(\mathrm{x}, \mathrm{y}, \mathrm{z}, \mathrm{t})$ que em conjunto compõe as equações da dinâmica dos fluídos. A tabela 2.2 contém algumas das variáveis que são geradas no pós-processamento.

\begin{tabular}{|l|c|}
\hline \multicolumn{1}{|c|}{ Váriavel } & Unidades \\
\hline Temperatura Potencial ( $\boldsymbol{\theta})$ & $\mathrm{K}$ \\
\hline Pressão Atmosférica (p) & $\mathrm{Pa}$ \\
\hline Razão de Mistura do Vapor D'água (q) $\mathbf{v})$ & $\mathrm{g} \mathrm{kg}^{-1}$ \\
\hline Energia Cinética Turbulenta (tke) & $\mathrm{m}^{2} \mathrm{~s}^{-2}$ \\
\hline Componente Zonal do Vento (u) & $\mathrm{m} \mathrm{s}^{-1}$ \\
\hline Componente Meridional do Vento (v) & $\mathrm{m} \mathrm{s}^{-1}$ \\
\hline Componente Vertical do vento (w) & $\mathrm{m} \mathrm{s}^{-1}$ \\
\hline
\end{tabular}

Tabela 2.1: Variáveis simuladas explicitamente pelo ARPS.

Além das variáveis pós-processadas descritas na tabela 2.2, o ARPS apresenta pacotes para cálculo de outras variáveis como vorticidade horizontal e vertical, numero de Richardson, temperatura potencial equivalente, fluxo de calor sensível e latente em superfície entre outros. Essas variáveis foram calculadas com base m Bolton [1980] e Betts et al., [2002].

O sistema ARPS também possui um pacote de assimilação de dados denominado de ADAS (ARPS Data Assimilation System) que combina e interpola dados de medição na grade do modelo, além de realizar um controle de qualidade nos dados. Com o ADAS é permitido assimilar dados de estações e superfície, sondagem atmosféricas, satélite, campo de vento estimado por radar Doppler, campo de refletividade entre outros. O sistema ARPS considera os erros característicos de cada um do conjunto de dados no processo de assimilação.

O ADAS utiliza o esquema iterativo de correções sucessivas de Bratseth [1986], que reduz o processamento matricial e realiza os balanços dinâmicos e termodinâmicos necessários para garantir a estabilidade da análise. No fim de cada interação os dados podem ser inseridos de forma dinâmica com os passos de tempo no modelo e formar um processo de iniciação dinâmica. Esse processo garante uma inicialização do modelo mais estável e com menores chances de gerar instabilidade numérica. 


\begin{tabular}{|c|c|}
\hline Váriavel & Unidades \\
\hline Temperatura do ar (Celsius) & ${ }^{\circ} \mathrm{C}$ \\
\hline Pressão do vapor d’água (e) & $\mathrm{hPa}$ \\
\hline Umidade relativa (UR) & $\%$ \\
\hline Temperatura do ponto de orvalho $\left(\mathbf{T}_{\mathrm{D}}\right)$ & ${ }^{\circ} \mathrm{C}$ \\
\hline Temperatura de saturação do NCL $\left(T^{*}\right)$ & $\mathrm{K}$ \\
\hline Temperatura do NCL & $\mathrm{K}$ \\
\hline Umidade específica (s) & $\mathrm{g} \mathrm{kg}^{-1}$ \\
\hline Pressão do NCL $\left(\mathbf{P}_{\mathrm{NCL}}\right)$ & $\mathrm{hPa}$ \\
\hline Altitude do NCL $\left(\mathrm{Z}_{\mathrm{NCL}}\right)$ & $\mathrm{m}$ \\
\hline Energia de inibição de convecção (CINI) & $\mathrm{J} \mathrm{kg}^{-1}$ \\
\hline Energia potencial convectiva disponível (CAPE) & $\mathrm{J} \mathrm{kg}^{-1}$ \\
\hline Pressão ao nível do mar (slp) & $\mathrm{hPa}$ \\
\hline Vorticidade vertical e horizontal & $\mathrm{s}^{-1}$ \\
\hline Razão de Mistura da Água de Nuvem (qc) & $\mathrm{g} \mathrm{kg}^{-1}$ \\
\hline Razão de Mistura da Água de Chuva $\left(q_{r}\right)$ & $\mathrm{g} \mathrm{kg}^{-1}$ \\
\hline Razão de Mistura da Água em Forma de Cristais de Gelo $\left(q_{i}\right)$ & $\mathrm{g} \mathrm{kg}^{-1}$ \\
\hline Razão de Mistura da Água em Forma de Neve $\left(q_{s}\right)$ & $\mathrm{g} \mathrm{kg}^{-1}$ \\
\hline Razão de Mistura da Água em Forma de Granizo $\left(q_{h}\right)$ & $\mathrm{g} \mathrm{kg}^{-1}$ \\
\hline Componente Vertical do Vento (w) & $\mathrm{m} \mathrm{s}^{-1}$ \\
\hline
\end{tabular}

Tabela 2.2: Variáveis calculadas no pós-processamento.

\subsection{2 Área de estudo}

A área de estudo com o sistema ARPS compreende o retângulo menor descrito pela figura 1.2, onde está contido o LV. Para tal estudo foram realizadas simulações com 500 metros de resolução horizontal com condições de contorno proveniente das grades com menor resolução advindas dos 2 retângulos maiores da mesma figura. Os dados de topografia com 90 metros de resolução do SRTM foram interpolados para 500 metros com o objetivo de melhor descrever a complexa topografia no entorno do LV.

\subsubsection{Configuração de grade e parametrizações}

Os experimentos numéricos foram realizados com resoluções espaciais de $12 \mathrm{~km}, 4 \mathrm{~km}$ e $500 \mathrm{~m}$, descritos do retângulo maior para o menor da figura 1.2, respectivamente. A parametrização de Kain-Fritsch foi utilizada apenas nas grades de $12 \mathrm{~km}$ e $4 \mathrm{~km}$. Alguns testes 
iniciais foram realizados nessa região com a configuração de grade 32 km, 8 km, 2 km e 500 m (não apresentadas), no entanto, o resultado das simulações foi muito similar com o realizado com a primeira configuração e por questões de tempo computacional, optou-se pela primeira configuração citada. Os domínios estão centrados no LV na latitude de $1.5^{\circ} \mathrm{S}$ e longitude $33^{\circ} \mathrm{E}$ com projeção de Lambert [Xue et al., 1995]. A temperatura superficial do lago (TSL) utilizada foram as provenientes da condição de contorno do modelo Global Forecast System (GFS) e a climatológica da figura 2.2. De maneira geral, o GFS subestima a TSL do LV entre $2{ }^{\circ} \mathrm{C}$ e $3{ }^{\circ} \mathrm{C}$.

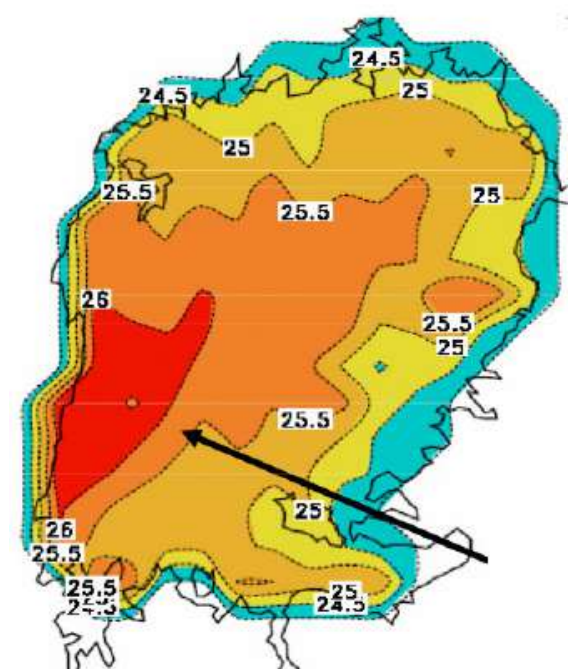

Figura 2.2: Distribuição da temperatura $\left({ }^{\circ} \mathrm{C}\right)$ climatológica na superfície do Lago Vitória. Fonte: WWRP, A Nowcasting Project for Lake Victoria.

\begin{tabular}{|c|c|c|c|}
\hline \multirow{2}{*}{ Característica dos experimentos } & \multicolumn{3}{|c|}{ Resolução horizontal das grades } \\
\cline { 2 - 4 } & $12 \mathrm{~km}$ & $4 \mathrm{~km}$ & $500 \mathrm{~m}$ \\
\hline Pontos x e y & $303 \times 297$ & $423 \times 402$ & $1053 \times 990$ \\
\hline Pontos verticais & 43 & 43 & 43 \\
\hline Primeiro nível & $30 \mathrm{~m}$ & $30 \mathrm{~m}$ & $30 \mathrm{~m}$ \\
\hline Tempo de integração & $24 \mathrm{~h}$ & $18 \mathrm{~h}$ & $18 \mathrm{~h}$ \\
\hline Passo de tempo & $30 \mathrm{~s}$ & $20 \mathrm{~s}$ & $3 \mathrm{~s}$ \\
\hline Cond. Iniciais & GFS $\left(1^{\circ}\right)$ & ARPS $12 \mathrm{~km}$ & ARPS $4 \mathrm{~km}$ \\
\hline Topografia SRTM & $90 \mathrm{~m}$ & $90 \mathrm{~m}$ & $90 \mathrm{~m}$ \\
\hline Parametrização de Kain-Fristch & Sim & Sim & Não \\
\hline Parametrização de Microfísica & Sim & Sim & Sim \\
\hline Modelo de Solo & 2 camadas & 2 camadas & 2 camadas \\
\hline Tipo de Solo/Vegeração & Realístico & Realístico & Realístico \\
\hline TSL & GFS & GFS e estimada & GFS e estimada \\
\hline
\end{tabular}

Tabela 2.3 Características gerais do experimento sobre o LV. 
A tabela 2.3 acima mostra as principais características dos experimentos numéricos realizados com o ARPS para todos os estudos de caso sobre a região da África.

\subsubsection{Condições iniciais e de contorno}

As condições iniciais e de contorno, conforme descrito na tabela 2.3, foram as provenientes das análises do modelo global GFS (Global Forecast System) com $1{ }^{\circ} \mathrm{C}$ de resolução. Um grande número de simulações foi realizado no decorrer deste trabalho em 2 sistemas computacionais, ambos em cluster SGI, o primeiro com 84 processadores Intel de $2.0 \mathrm{GHz}$ distribuídos em 21 nós. Esse sistema foi inicialmente configurado pelo presente autor para realizar simulações operacionais para a América do Sul e estados do Espirito Santo, Rio de Janeiro e Maranhão com o intuito de monitorar os portos de interesse da Vale do Rio Doce no âmbito de um projeto que implementou um sistema de previsão hidrometeorológica operacional [Pereira Filho et al., 2015]. Apenas parte do tempo era utilizado para as simulações já que o mesmo se encontrava em modo operacional.

As estimativas de TSL utilizadas nas simulações foram obtidas dos estudos de Anyah [2005], da climatologia da figura 2.2 da WWRP e da estimativa em alguns pontos obtidos pelo MODIS. Essas estimativas eram interpoladas por uma função seno com a TSL maior na borda oeste do lago e menor no leste do LV. Devido a falta de medições na região e as incertezas nos valores corretos de TSL. Um conjunto com 3 estimativas iniciais distintas de TSL foram realizados, conforme figuras 2.3 .

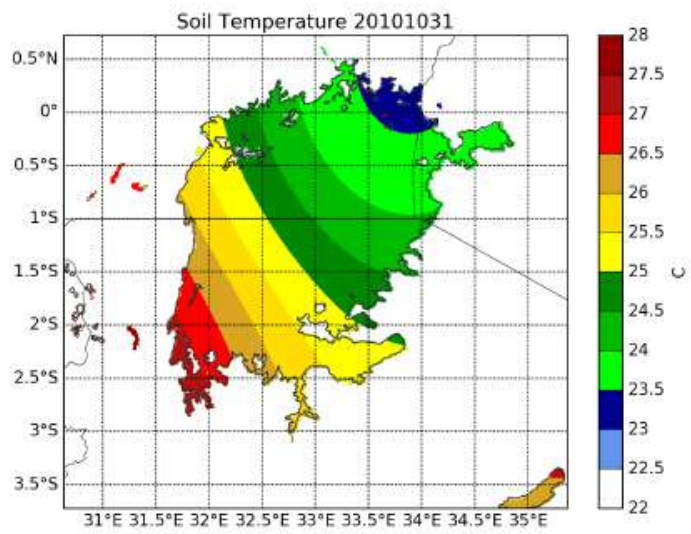

a

Figura 2.3: Distribuição espacial de temperatura superficial do lago (TSL) utilizado em três experimentos para os eventos de 01 de Novembro de 2010 e 03 de Novembro de 2014. Contorno geográficos, geopolíticos do lago Vitória estão indicado. Barra de cores indica TSL em $\left({ }^{\circ} \mathrm{C}\right)$. 
$\mathrm{b}$
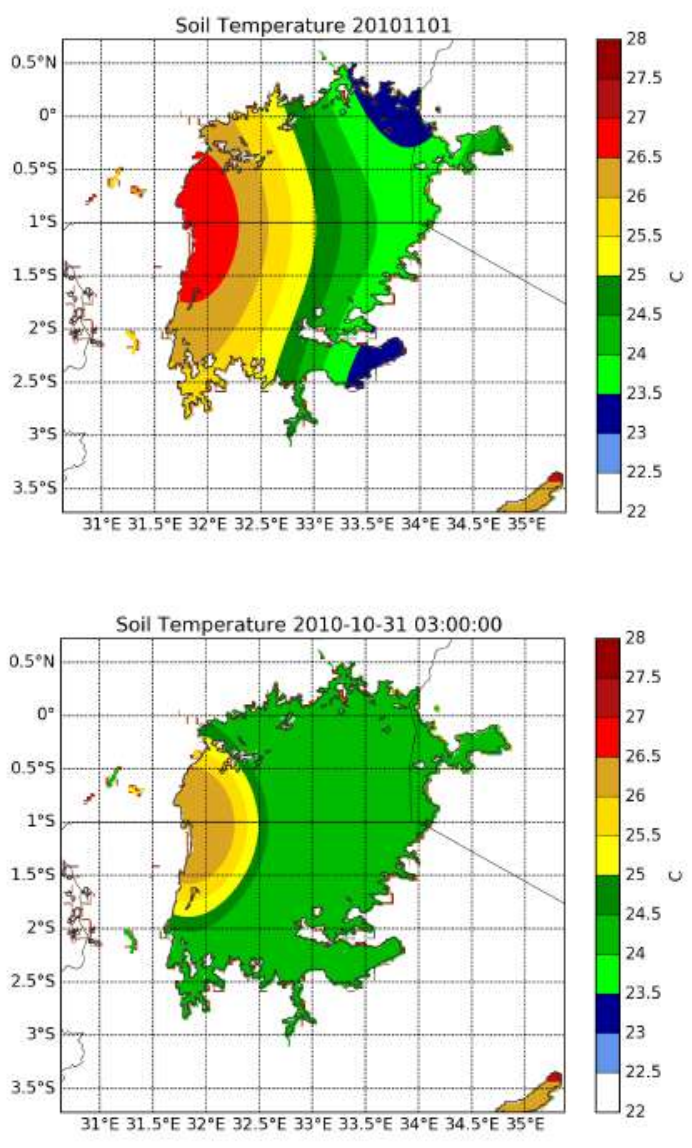

Figura 2.3: Continuação

\subsubsection{Seleção de eventos}

Foram realizados experimentos em diferentes datas, no entanto, nesse trabalho apresentouse os estudos de caso para o evento de 01/11/2010, este mais localizado, com disparo da convecção noturna sobre o LV e posterior deslocamento para oeste das instabilidades geradas. Esse primeiro evento representa aqueles na qual a maior parte da região tem estabilidade com céu claro e nenhuma formação no entorno do LV antes do disparo da convecção. Esse evento, por ser mais localizado, mostrou-se muito mais sensível a pequenas variações na TSL, tal que variações em torno e $2{ }^{\circ} \mathrm{C}$ eram suficientes entre um experimento com o disparo da convecção e a simulação que não houve disparo da tempestade. A figura 2.4 mostra a velocidade vertical ômega $\left(\mathrm{Pa} \mathrm{s}^{-1}\right)$ em $500 \mathrm{hPa}$ no período da tarde anterior a convecção noturna para o dia 01/11/2010, nota-se que os movimentos de subsidência a aproximadamente $500 \mathrm{~km}$ a leste e oeste do LV e leves movimentos convectivos a leste do LV, ou seja, instabilidades mais localizadas. 


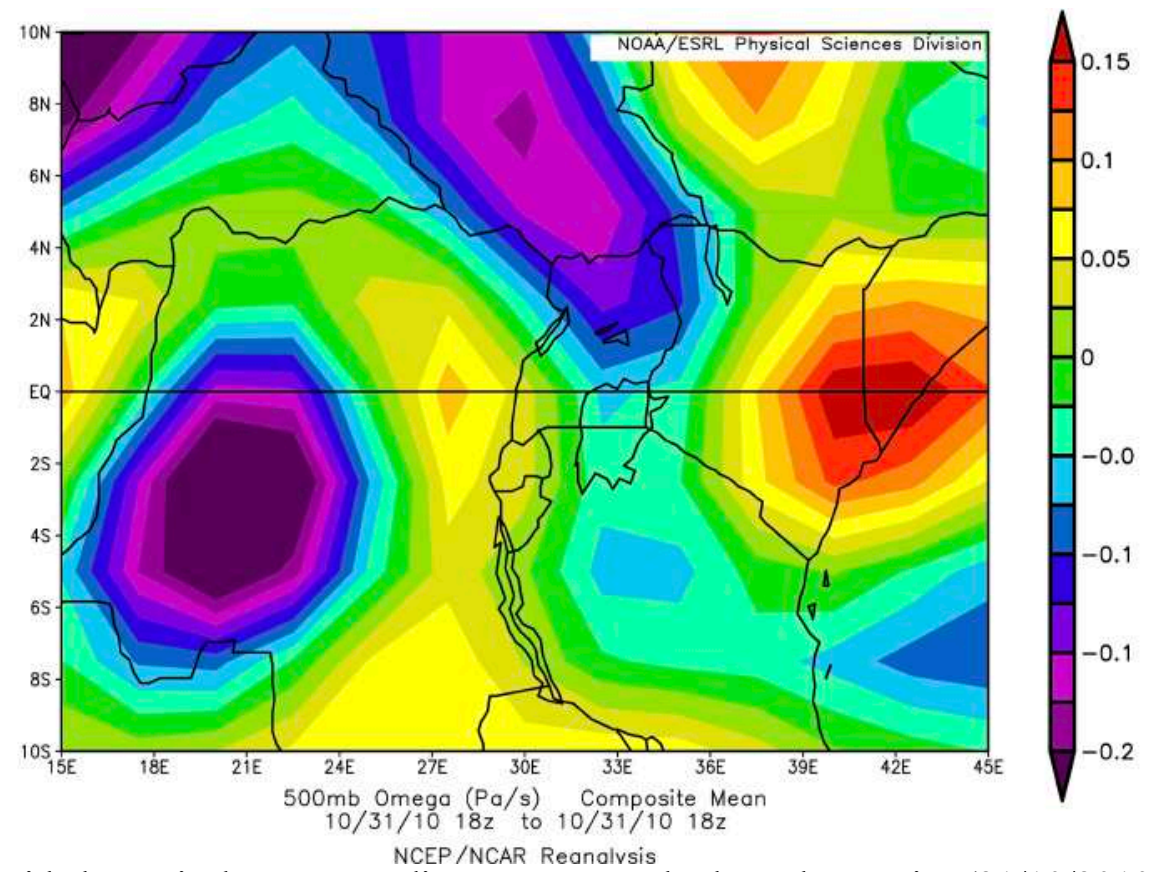

Figura 2.4: Velocidade vertical omega média, para o período da tarde anterior (31/10/2010 às $18 \mathrm{Z})$ ao disparo da convecção noturna sobre o LV para o nível de $500 \mathrm{hPa}$. Contornos geopolíticos e do LV estão indicados. Barra de cores indica omega em $\mathrm{Pa} \mathrm{s}^{-1}$. Fonte: Reanálise do NCEP.

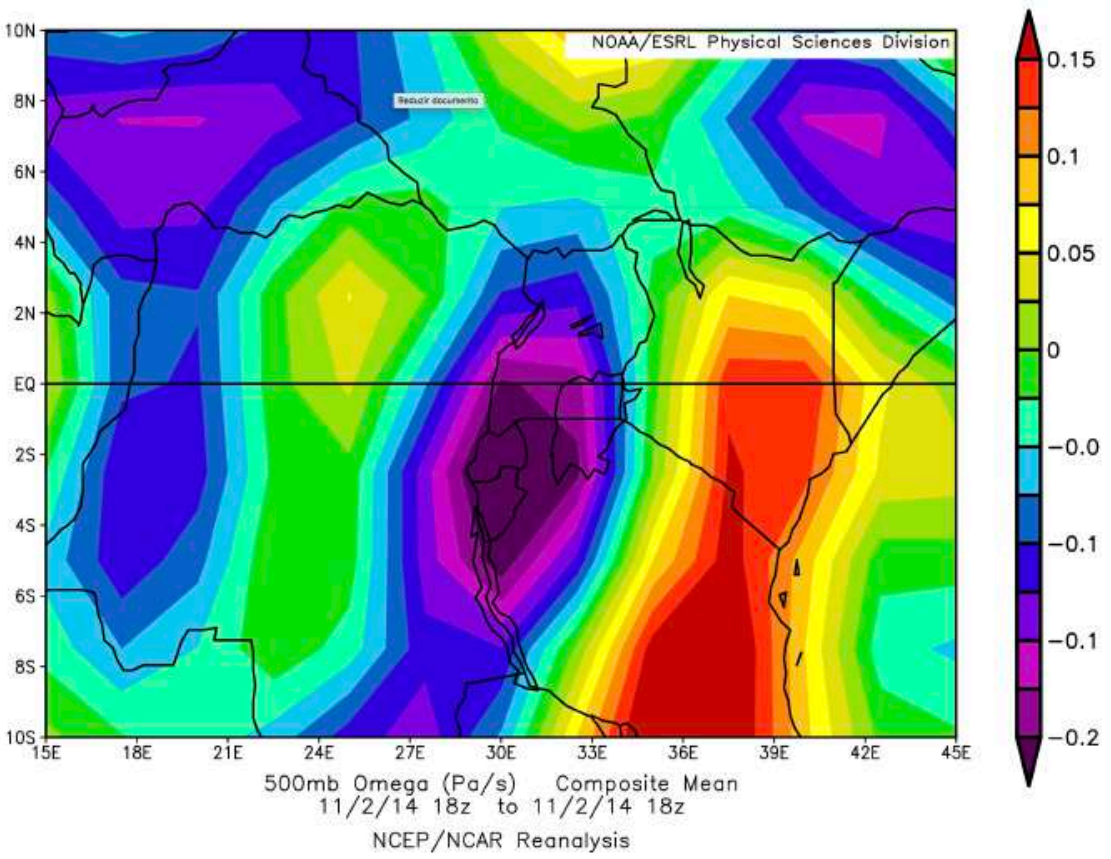

Figura 2.5: Velocidade vertical omega média, para o período da tarde anterior (02/11/2014) ao disparo da convecção noturna sobre o LV para o nível de $500 \mathrm{hPa}$. Contornos geopolíticos e do LV estão indicados. Barra de cores indica omega em $\mathrm{Pa} \mathrm{s}^{-1}$. Fonte: Reanálise do NCEP.

O segundo evento, de $03 / 11 / 2014$, estava embebido em uma atmosfera muito mais instável com convecção intensa no entorno do LV, no período da tarde anterior ao evento da madrugada sobre o LV. As formações que ocorreram a tarde dispararam frentes de rajadas de sul e de leste que se acoplaram com a circulação local de brisa lacustre. Na confluência de ambas, houve convecção intensa no período da noite e madrugada. Esse experimento apresentou sensibilidade 
a variações na TSL muito menor, ou seja, mesmo com redução na TSL, ocorria o disparo da convecção na confluência entre as linhas de frente de rajada, no entanto, com menor intensidade. A figura 2.5 mostra a velocidade vertical ômega $\left(\mathrm{Pa} \mathrm{s}^{-1}\right) \mathrm{em} 500 \mathrm{hPa}$ no período da tarde anterior a convecção noturna do dia 03/11/2014, nota-se movimentos convectivos intensos na região no entorno do LV, além disso, nota-se um trem de ondas de movimentos de subsidência e convecção em torno de $2{ }^{\circ} \mathrm{S}$ de latitude. Este trem de ondas deixou o ambiente favorável a convecção o que justifica a menor sensibilidade da TSL na convecção noturna sobre o LV.

\subsubsection{Experimentos com e sem topografia}

Os experimentos controles foram realizados com os dados topográficos SRTM com 90 metros de resolução e que foram interpolados para resoluções menores. Na região da África equatorial, predominam os ventos alísios de leste durante todo o ano, com menor ou maior intensidade. A leste do LV montanhas com altitude acima dos 3000 metros estão presentes e certamente influenciam na redução ou mesmo no bloqueio dos ventos alísios. Para verificar a influência desse bloqueio proveniente das montanhas realizou-se experimentos numéricos para o evento de 01/11/2010 para avaliação do impacto nas circulações de brisa lacustre para esse tipo de evento. 


\section{Capítulo 3}

\section{Resultados}

\subsection{Análise climatológica}

As figuras 2.1 e 3.1 apresentam a climatologia anual e mensal sobre a África equatorial. O domínio pode ser dividido em 2 regiões em $30^{\circ} \mathrm{E}$ com acumulação superior a $4000 \mathrm{~mm}$ ano ${ }^{-1}$ na floresta do Congo e acumulação inferior a leste do Vale do Rift e sobre as montanhas que, segundo as estimativas, é inferior a $200 \mathrm{~mm} \mathrm{ano}^{-1}$.

A influência dos lagos fica nítida tanto para lagos pequenos como para lagos tão grandes quanto o LV. Na maior parte deles o acumulado total de precipitação é quase 2 vezes superior ao que foi estimado no entorno e indicam a forte influência das circulações locais em produzir grande variabilidade espacial da precipitação no clima local. Sobre a floresta do Congo, os acumulados são maiores e estão associados a convecção vespertina, enquanto que sobre o LV a maior parte da precipitação ocorre no período da madrugada.
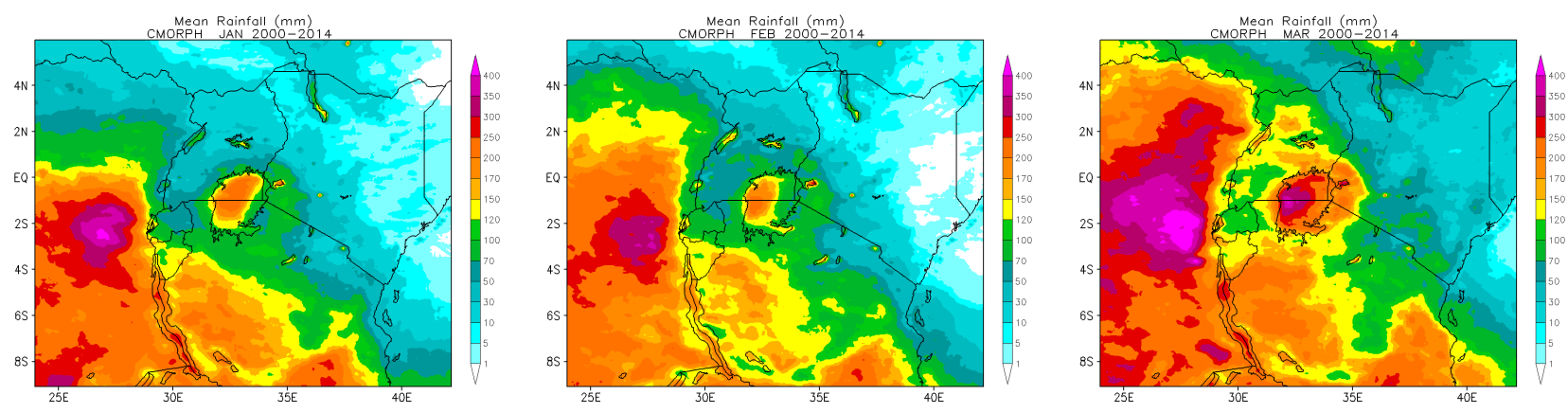

Figura 3.1: Campo médio mensal da precipitação com estimativa CMORPH (mm) sobre a África Equatorial para o período entre 2000 e 2014. Longitudes, latitudes, contornos geográficos e geopolíticos estão indicados. Escala de cores indica precipitação acumulada média mensal em mm mês ${ }^{-1}$. 

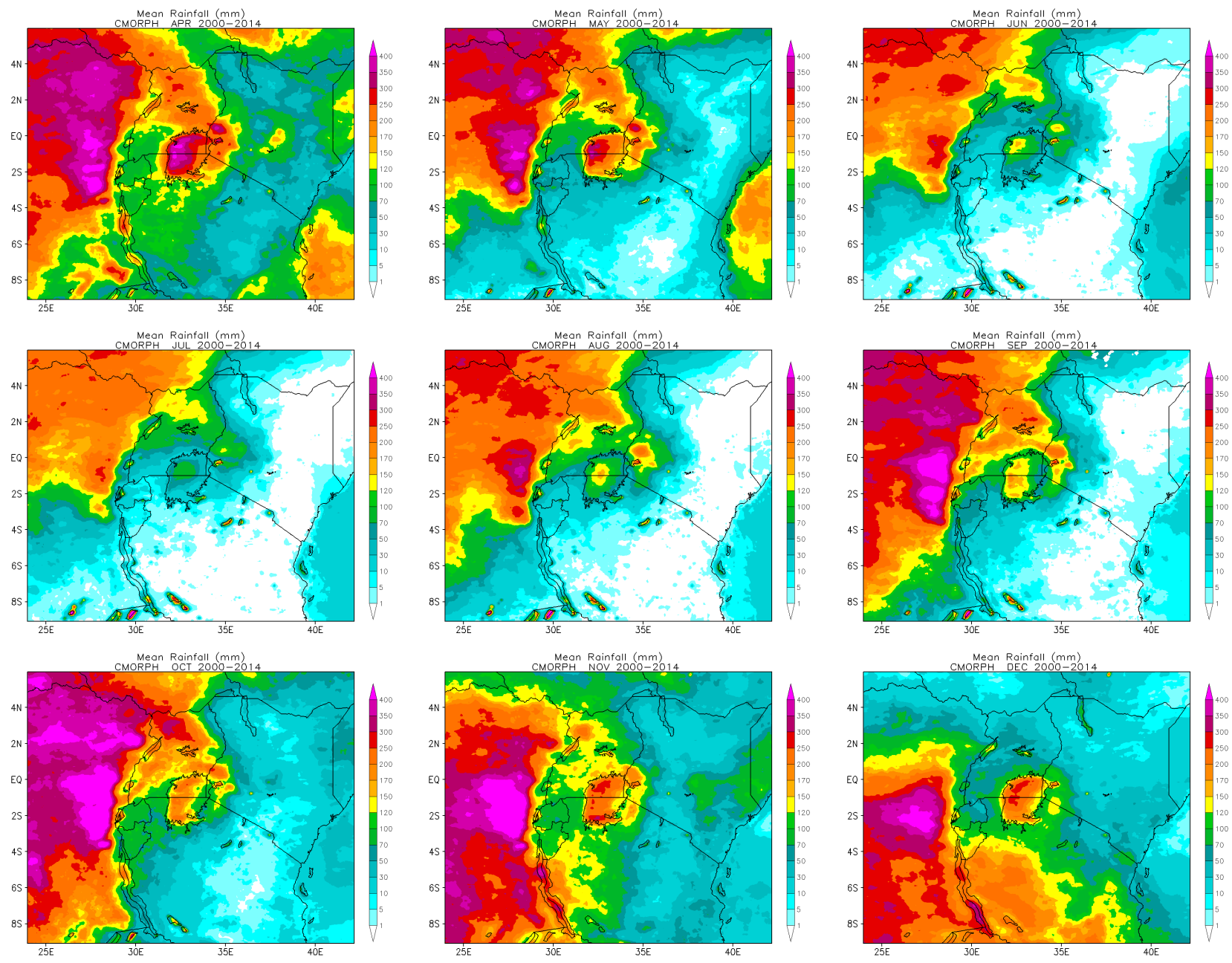

Figura 3.1: Continuação...

A figura 3.1 mostra máximos secundários de precipitação acumulada anual sobre o LV em torno de $3000 \mathrm{~mm}^{\mathrm{ano}} \mathrm{o}^{-1}$ e sobre os lagos Tanganyika $\left(6.3^{\circ} \mathrm{S}, 29.6^{\circ} \mathrm{E}\right)$, Rukwa $\left(7.9^{\circ} \mathrm{S}, 32.3^{\circ} \mathrm{E}\right)$, Mweru $\left(8.9^{\circ} \mathrm{S}, 28.8^{\circ} \mathrm{E}\right)$, Kivu $\left(2.0^{\circ} \mathrm{S}, 29.2^{\circ} \mathrm{E}\right)$, Edward $\left(0.3^{\circ} \mathrm{S}, 29.6^{\circ} \mathrm{E}\right)$, Albert $\left(1.7^{\circ} \mathrm{N}, 30.9^{\circ} \mathrm{E}\right)$, Kwanja $\left(1.8^{\circ} \mathrm{N}, 32.8^{\circ} \mathrm{E}\right)$, Kyoga $\left(1.5^{\circ} \mathrm{N}, 32.9^{\circ} \mathrm{E}\right)$, Kojweri $\left(1.6^{\circ} \mathrm{N}, 33.2^{\circ} \mathrm{E}\right)$ e outros lagos menores. Particularmente, sobre os lagos, nota-se os máximos locais que ocorrem devido a convergência da frente de brisa lacustre-terrestre sobre os mesmos [Laing et al., 2011; Anyah et al., 2006]. Os ventos de lestes tendem a deslocar a máxima precipitação para a metade oeste do lago Vitória. Sobre a floresta do Congo ocorrem os maiores acumulados devido ao disparo da convecção no período da tarde. Para essa região, os maiores acumulados ocorrem entre os meses de setembro e dezembro e a menor acumulação ocorre no período de junho a agosto, período na qual o LV também produz os menores acumulados, e está associado a subsidência de compensação da zona de convergência intertropical (ZCIT) posicionada centena de quilômetros a norte da linha do equador. Sobre o LV os maiores índices pluviométricos acontecem nos meses de março, abril, maio, novembro e dezembro. 
A frequência de chuva horária foi obtida para os limiares de $1.0 \mathrm{~mm}, 2.0 \mathrm{~mm}, 5.0 \mathrm{~mm}, 10.0$ $\mathrm{mm}$ e $20.0 \mathrm{~mm}$ foram obtidas das estimativas CMORPH no período entre 2000 e 2014. A figura 3.2 mostra o ciclo diurno da precipitação horária maior que $1.0 \mathrm{~mm}$ para o mês com máxima acumulação sobre o lago Vitória (abril). Para os outros meses do ano, o ciclo diurno da convecção noturna é similar para essa frequência (não mostrado). A área mais ampla com alta frequência sobre o lago ocorre as 0500 UTC $(0800 \mathrm{HL})$ sobre a metade oeste do lago. Outros lagos menores na região apresentam alta frequência entre 0400 UTC e 0500 UTC no período da madrugada. A frequência de precipitação horária é mínima entre 1600 UTC (1900 HL) e 1700 UTC (2000 HL) na qual coincide com a máxima frequência fora do LV, a leste do mesmo e parte leste da floresta do Congo. Nota-se máxima frequência na chuva na longitude $35^{\circ} \mathrm{E}$ no período vespertino. Em geral, esse sistema convectivo desenvolve-se sobre as montanhas a leste-nordeste do LV, entre período da tarde e início da noite, esse sistema perde intensidade enquanto desloca-se para oeste, mas as frentes de rajadas geradas pelo mesmo acoplam-se a CBVM e a CBL e deslocam-se sobre o LV.

Ar mais frio e seco proveniente das montanhas se desloca sobre o LV e aumenta os fluxos de calor sensível e latente, que instabilizam a CLP e posteriormente disparam novas células convectivas e se propagam para oeste. O comportamento dos sistemas convectivos obtidos com o CMORPH está de acordo com o obtido pelas estimavas com o TRMM por Omondi, [2017].

As células convectivas avançam e sua máxima intensidade ocorre ainda sobre o lago (metade oeste). O processo de dissipação se inicia antes delas alcançarem a borda do lago. Esse sistema gera frentes de rajadas que se propagam para oeste ao longo do dia. As perturbações geradas sobre o LV podem, de algum modo, contribuir com a convecção vespertina que ocorre sobre a floresta do Congo, no entanto, é necessária uma análise mais detalhada com modelagem numérica e observações de superfície para avaliação do mesmo.

No período entre 1400 UTC e 1800 UTC nota-se a máxima divergência em superfície produzida pela convecção a leste e oeste do LV, essa onda de divergência/convergência em superfície e altitude se propaga para oeste.

A figura 3.3, similar a figura 3.2, mostra a frequência para o horário/mês $0600 \mathrm{UTC} / \mathrm{julho,}$ 0700 UTC/julho, 0500 UTC/maio e 0600 UTC/novembro, respectivamente. Pela mesma, notase a máxima convecção sobre o LV para o mês mais seco e os meses mais chuvosos sobre o LV. 

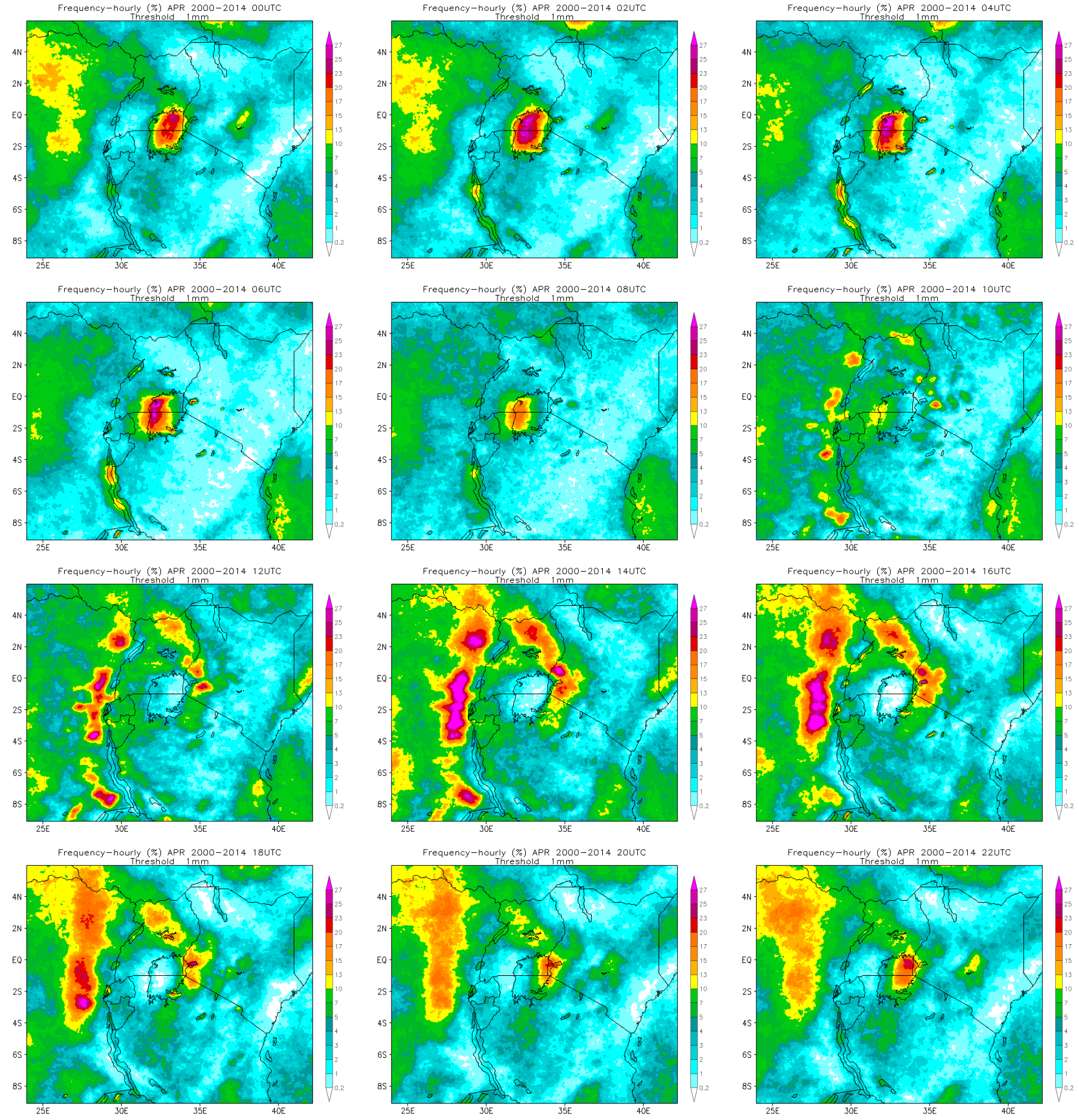

Figura 3.2: Frequência de precipitação horária superior a $1 \mathrm{~mm} \mathrm{~h}^{-1}$ obtida com CMORPH sobre a África Equatorial para o período entre 2000 e 2014. Titulo da figura indica abreviação de mês e hora UTC de referência para o calculo da frequência horária. Longitudes, latitudes, contornos geográficos e geopolíticos estão indicados. Escala de cores indica frequência de precipitação horária em \%. 

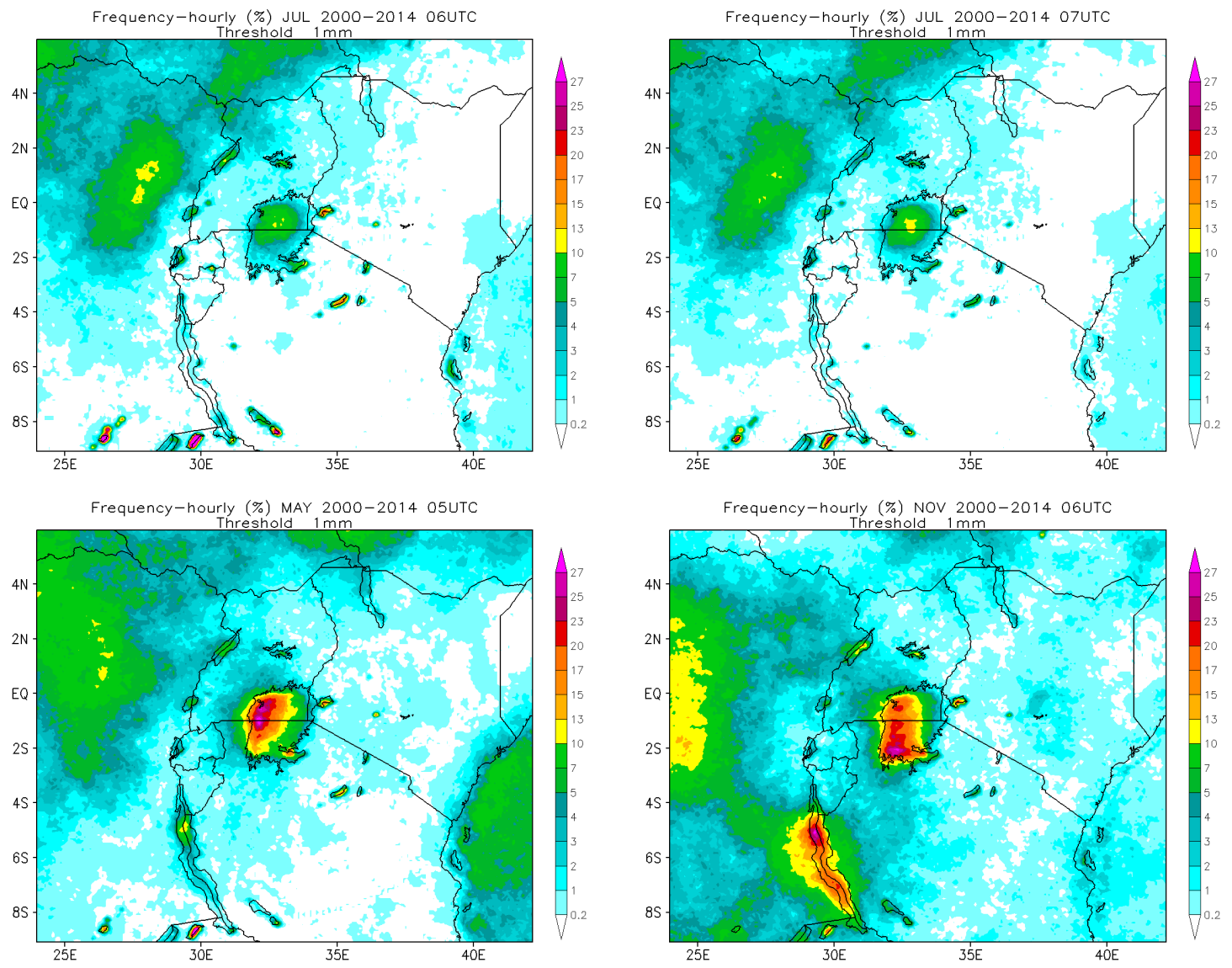

Figura 3.3: Similar a figura 3.2 mas para horários específicos nos meses de maio, julho e novembro. Longitudes, latitudes, contornos geográficos e escala de cores (\%) estão indicados.

A figura 3.4 mostra a frequência de chuva horária para o limiar de $20 \mathrm{~mm} \mathrm{~h}^{-1}$, utilizado para identificar chuvas mais intensas, dado a resolução espacial e o método utilizado, para os meses de abril e novembro, os horários de máxima frequência de chuvas mais intensas sobre o LV ocorrem entre 0300 UTC e 0400 UTC. Os episódios mais intensos sobre o LV ocorrem nos meses de março, abril, maio, outubro e novembro, com maior frequência na borda oeste nos meses de março a maio e na borda sul nos meses de outubro e novembro. O mesmo pode ser notado na figura 3.3 mas, para o limiar de $1 \mathrm{~mm} \mathrm{~h}^{-1}$. O mês de julho é o que apresenta o menor pico de frequência de chuva (entre 10\% e 13\%) entre 0600 UTC e 0700 UTC, aproximadamente 1 evento a cada 9 dias, enquanto ocorre 1 evento de precipitação acima de $1 \mathrm{~mm} \mathrm{~h}^{-1}$ a cada 3 dias nos meses de convecção mais intensa, maio e novembro. Sobre a região do lago Tanganyika, o menor pico ocorre no mês de julho e o maior pico em novembro, no mesmo horário que o LV e com frequência similar, o que indica que o tamanho do lago, neste caso, tem pouca ou quase nenhuma influência na frequência e no horário de máxima precipitação sobre os lagos. 
A constatação anterior está de acordo com alguns estudos de relação entre intensidade e duração da circulação de brisa lacustre e o tamanho do lago, nos quais chegaram à conclusão que para lagos com distância entre as bordas maior que $50 \mathrm{~km}$, a circulação de brisa lacustre se comporta como a circulação de brisa marítima [Crosman e Horel, 2012, Segal et al., 1997, Laird et al., 2001, 2003].
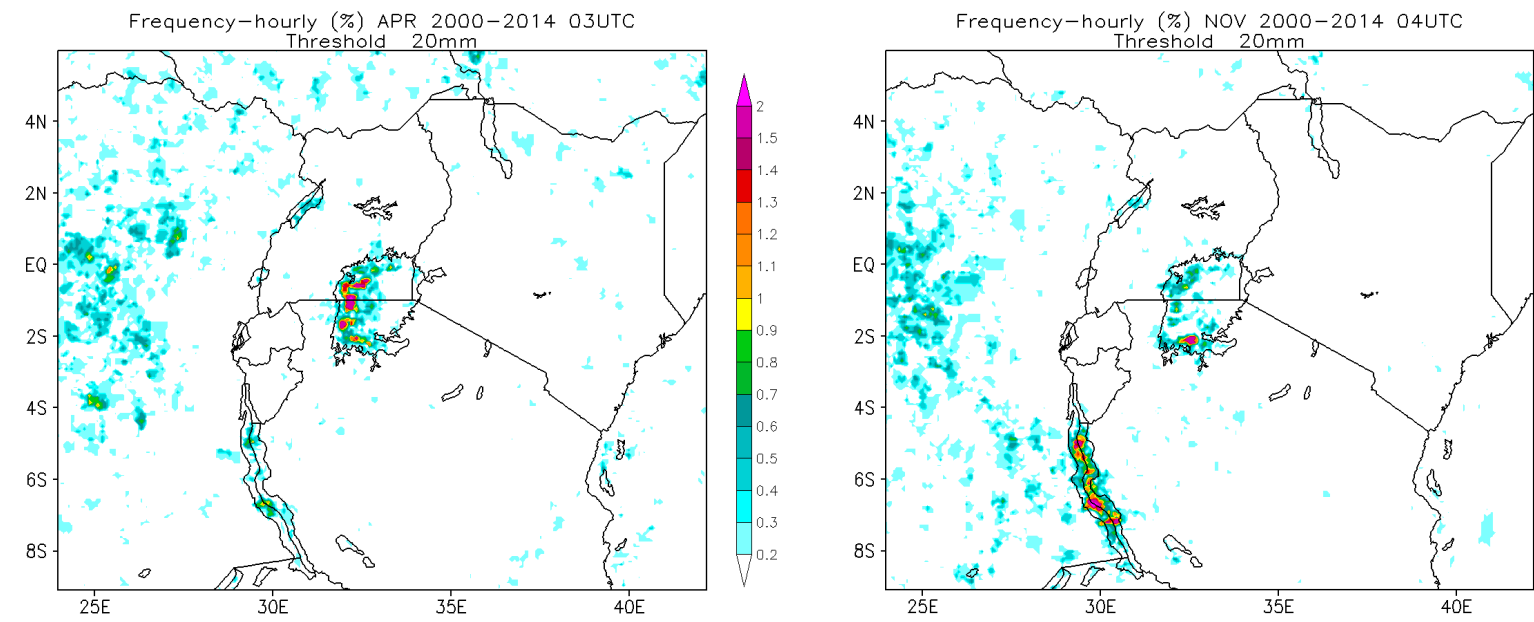

Figura 3.4: Similar a figura 3.3, mas para limiar de $20 \mathrm{~mm}$. Latitudes, longitudes e limites geográficos estão indicados. Escala de cores indica frequência (\%).

Diagramas Hovmoller indicam os eventos e suas respectivas características espaciais e temporais que auxiliaram no entendimento da dinâmica climatológica associadas a esses eventos. De maneira geral, nota-se que o posicionamento da banda de máxima frequência ocorre seguindo o posicionamento da zona de convergência intertropical (ZCIT), com a máxima convecção sobre o Vale do Rift no período da tarde e sobre os lagos durante a madrugada. As circulações locais de brisa lacustre e vale-montanha induzem a convergência sobre a água quente dos lagos [Sun et al., 2014].

A convecção organizada tende a se propagar para oeste ao longo do ano na região da África equatorial. Alguns episódios duram mais que 50 horas sobre essa região. Eles tendem a perdurar por mais tempo nos meses de março, abril, outubro e novembro como verificado pelas estatísticas com o diagrama Hovmoller. Eventos de curta duração e chuva mais intensa ocorrem a oeste/sudoeste do LV e seu pico ocorre entre a metade da madrugada e início da manhã nos meses citados acima. Sobre a floresta do Congo a convecção ocorre em uma área muito maior a partir do início da tarde e segue o ciclo diurno típico de região tropical. A figura 3.5, apresenta alguns eventos típicos de convecção ampla sobre a África equatorial começando a leste do LV sobre região montanhosa e movendo para oeste com o pico no começo da manhã sobre o LV. 
Posteriormente, o sistema tende a decair e reintensificar no limite oeste do vale do Rift e com propagação sobre a floresta do Congo.

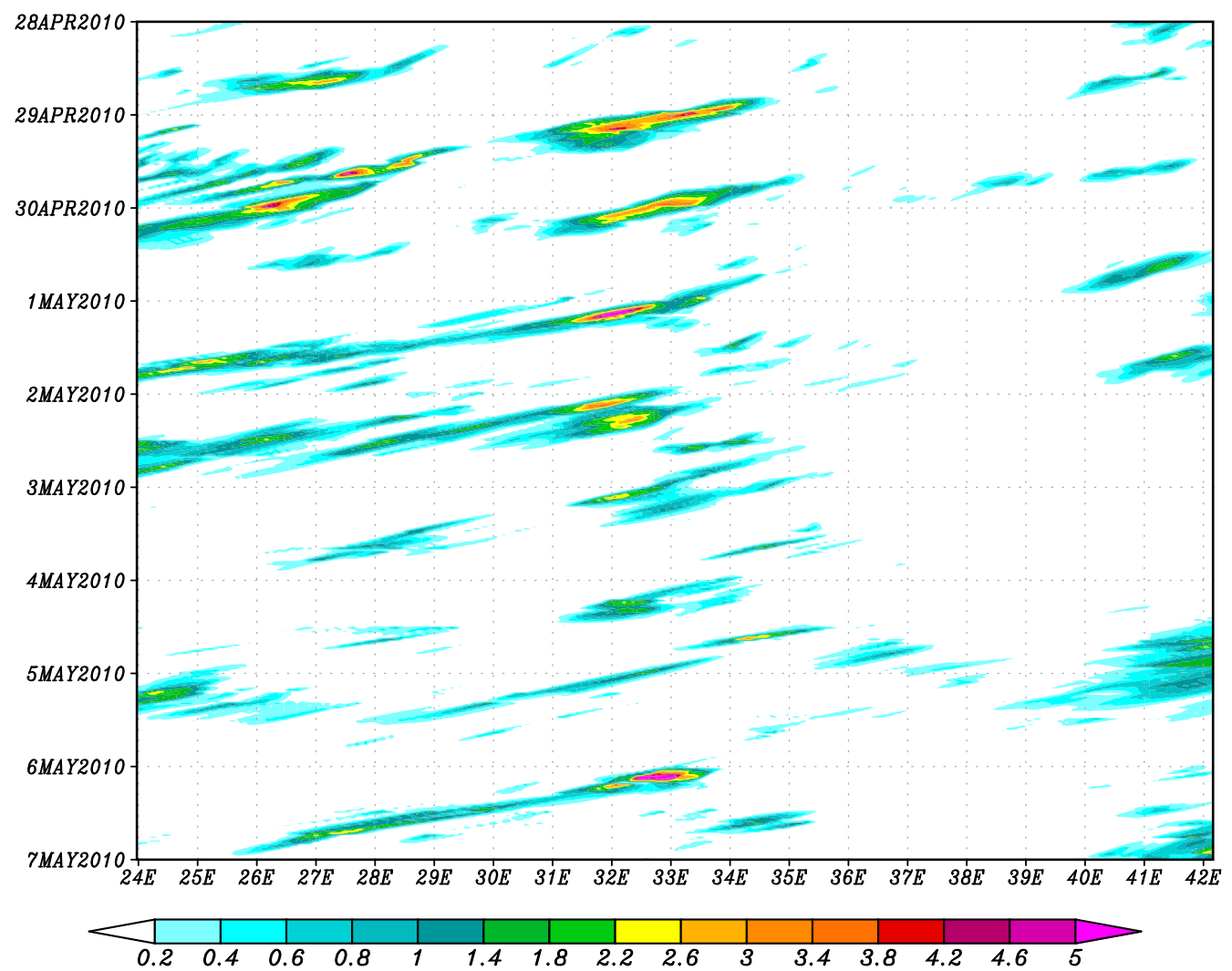

Figura 3.5: Diagrama hovmoller de chuva média horária entre $3^{\circ} \mathrm{S}$ e $1^{\circ} \mathrm{N}$ entre 28 de Abril de 2010 e 7 de Maio de 2010. Eixo x indica longitude da média de precipitação e eixo y indica a data. Barra de cores indica taxa de precipitação média na latitude $\left(\mathrm{mm} \mathrm{hr}^{-1}\right)$.

Os sistemas convectivos disparam a leste do LV devido ao aquecimento diferencial sobre as montanhas e propagam-se para oeste com intensidade variável no tempo e espaço. O pico na intensidade chega a $5 \mathrm{~mm} \mathrm{hr}^{-1}$ entre $34^{\circ} \mathrm{E}$ e $32^{\circ} \mathrm{E}(\mathrm{LV})$ e entre $25^{\circ} \mathrm{E}$ e $28^{\circ} \mathrm{E}$ no período da madrugada e tarde, respectivamente. Esses sistemas se intensificam sobre o LV devido à convergência da brisa terrestre e a evaporação e tendem a decair entre $32^{\circ} \mathrm{E}$ e $29^{\circ} \mathrm{E}$ durante a manhã antes do aumento do aquecimento diabático. $\mathrm{O}$ aquecimento diferencial sobre as montanhas dispara convecção profunda rapidamente no limite oeste do vale do Rift no começo da tarde e sugere-se haver um impacto de deslocamento de ar mais frio proveniente das tempestades que ocorreram sobre o lago e deslocaram-se até a floresta do Congo. Essas características podem explicar os elevados acumulados anuais sobre a floresta do Congo. A atividade convectiva na região é influenciada pela passagem de ondas equatoriais [Diaz e Aiyyer, 2013; Alaka e Maloney, 2014]. Nessa região, o aquecimento diabático e a 
evapotranspiração são as maiores forçantes afetadas pela passagem das ondas equatoriais como ondas de Kelvin e Rossby [Li et al., 2015].

A fonte de umidade para o vale do Rift é o oceano índico e a evaporação do LV e da floresta contribui por reciclar a umidade. Todos esses diferentes mecanismos agem em diferentes escalas de tempo e espaço e são secundários em relação ao ciclo diurno do aquecimento diabático e umidade fornecidos principalmente pelo LV. As ondas equatoriais podem estar em fase com a convecção organizada assim como os fluxos na camada limite pelos ventos de leste. As características topográficas também afetam o máximo e mínimo local. As ondas de Kelvin podem aumentar a convecção sobre a região. Sua passagem é precedida nos baixos níveis por anomalias de vento de leste seguidas por anomalias de vento de oeste que aumentam a convergência e favorece a convecção generalizada sobre a bacia do Congo [Sinclaire et al., 2015].

A convecção organizada apresenta alta variabilidade em termos de duração, velocidade de fase e propagação longitudinal. Algumas são intermitentes com velocidade de fase e distância percorrida variáveis. Outras propagam-se transversalmente para leste, sentido contrário ao movimento prevalecente de leste para oeste, como por exemplo as ondas de Kelvin que se movem por uma região e interagem construtivamente com o ciclo diurno sobre a África equatorial, incluindo a convecção sobre o lago vitória. Elas são muito menos frequentes que as ondas de Rossby [Mekonnen et al., 2008]. Wang [2002] e Kiladis et al., [2009] indicaram ondas equatoriais de Kelvin com propagação rápida para leste com correntes ascendente sobre as fontes de calor e movimentos de subsidência na direção leste. O ciclo diurno se torna menos aparente durante a passagem de trens de ondas de Kelvin que tendem a secar o ambiente na sua esquerda e a direita dentro de uma região influenciada por essa onda. Os sistemas convectivos aparentemente caóticos na África equatorial se tornam mais estruturados pelas ondas equatoriais e pelas ondas de leste, no entanto, poucas ondas de oeste se movem sobre a África equatorial. Algumas ondas barotrópicas de leste são intensas e de longa duração como é verificado na assinatura de uma na figura 3.5 , a mesma começou em $34.5^{\circ} \mathrm{E}$ no dia 30 de abril e percorreu mais de 1,000 km entre todo o Vale do Rift até a floresta do Congo. Esse tipo de onda pode estar associado com uma onda de Rossby de longa duração [King et al., 2015]. A cadeia de montanhas a leste do LV favorece a intensificação das ondas de Rossby. Ondas de oeste como Kelvin e Madden-Julian oscilation (MJO) podem intensificar as ondas de Rossby pela modificação da estabilidade e aumento da convergência na baixa troposfera [Berhane et al., 2015]. Na figura 3.6, nota-se o ciclo diurno médio da convecção com a máxima precipitação no oeste do vale do Rift, e outros 2 máximos locais, um a leste do LV e outro sobre o LV 
confinado entre as latitudes $3{ }^{\circ} \mathrm{S}$ e $1^{\circ} \mathrm{N}$. Entre o LV e a floresta do Congo, a convecção é menos intensa ou quase não ocorre. No entanto, ela intensifica logo a oeste do vale do Rift e segue o ciclo diurno de máximo aquecimento.

Basicamente existem 3 regiões nas quais o ciclo diurno da precipitação é predominante: o primeiro nas montanhas a leste do LV com máxima amplitude no período da tarde, o segundo sobre o lago com máxima acumulação no oeste do lago entre o meio da madrugada e início da manhã e o terceiro a oeste do vale do Rift sobre a floresta do Congo, com máxima acumulação entre a tarde e início da noite. A leste do vale do Rift há o ciclo diurno, com maior amplitude nos meses de março, abril, outubro e novembro (fig. 3.7), o mesmo é praticamente inexistente em outras épocas do ano devido ao clima seco do local, basicamente devido ao posicionamento de ZCIT mais a norte no verão do hemisfério norte e mais ao sul no verão do hemisfério sul, o que deixa a região equatorial sobre o ramo de subsidência.

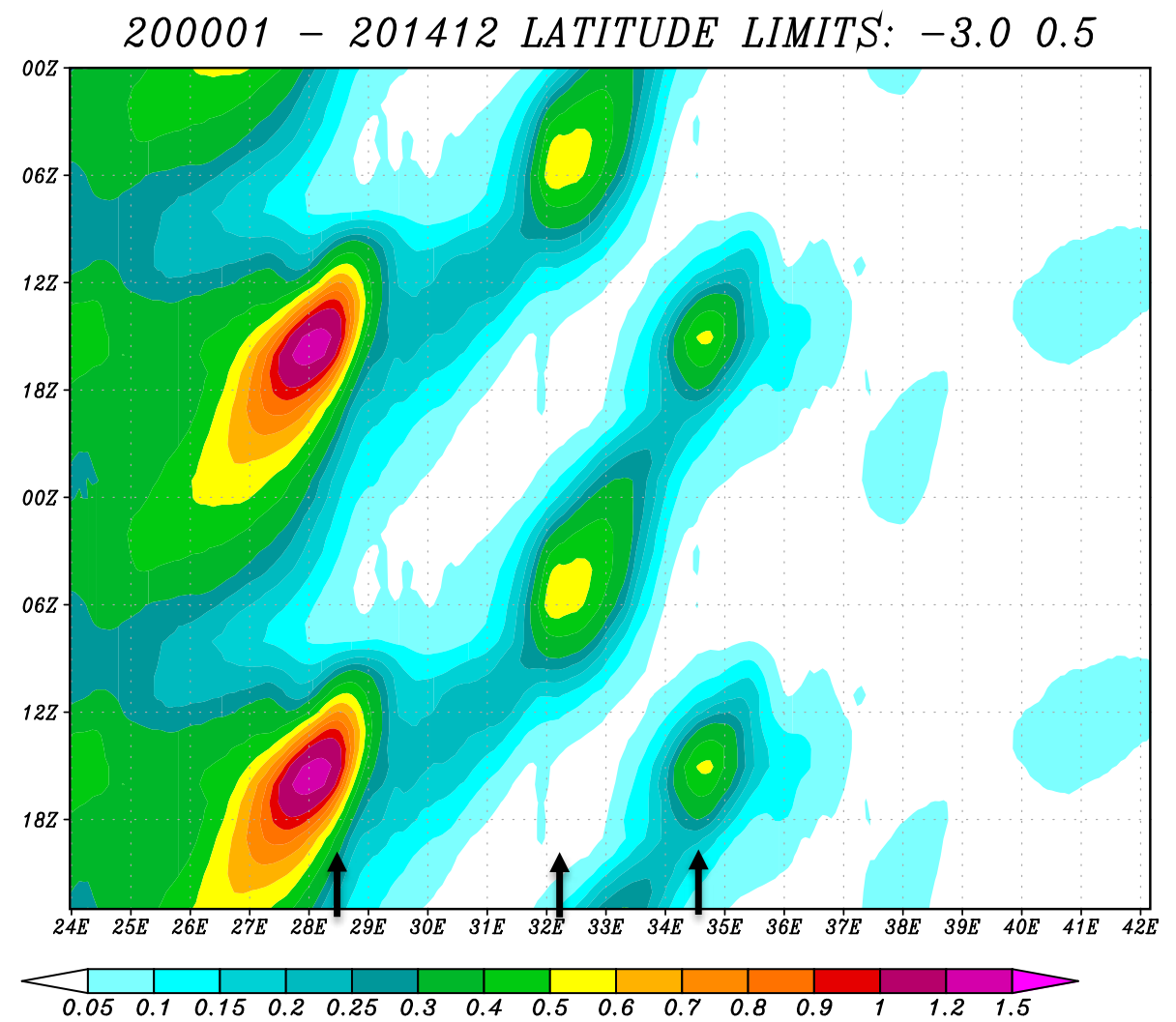

Figura 3.6: Diagrama hovmoller do ciclo diurno médio da precipitação entre $3^{\circ} \mathrm{S}$ e $1^{\circ} \mathrm{N}$ para o período entre 2000 e 2014. As 3 setas da esquerda para direita indicam, floresta do Congo, LV e motanhas a leste do LV, respectivamente. Eixo $\mathrm{x}$ indica longitude e y indica horário UTC. Barra de cores indica taxa de chuva média $\left(\mathrm{mm} \mathrm{hr}^{-1}\right)$. 
2000JAN - 2014JAN LATITUDE LIMITS: -3.00 .5$

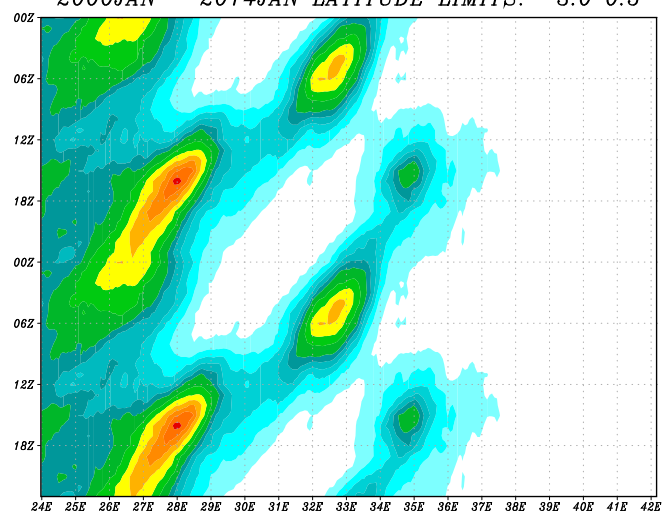

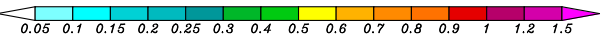
2000MAR - 2014MAR LATITUDE LIMITS: $-3.0 \quad 0.5$

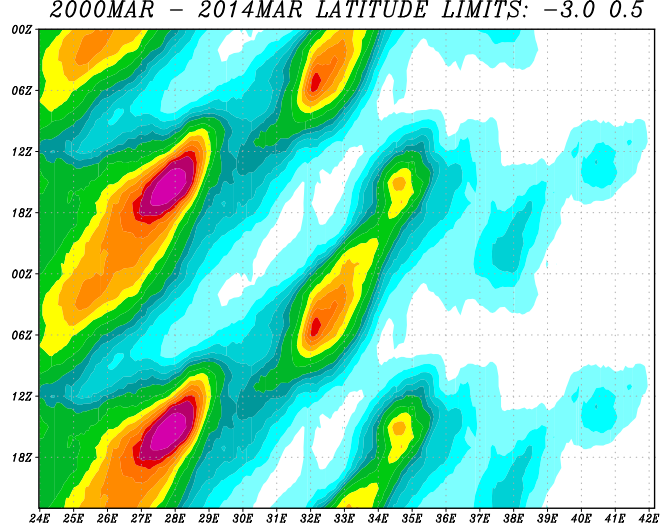

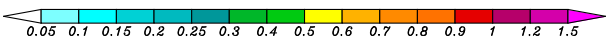
2000MAY - 2014MAY LATITUDE LIMITS: $-3.0 \quad 0.5$

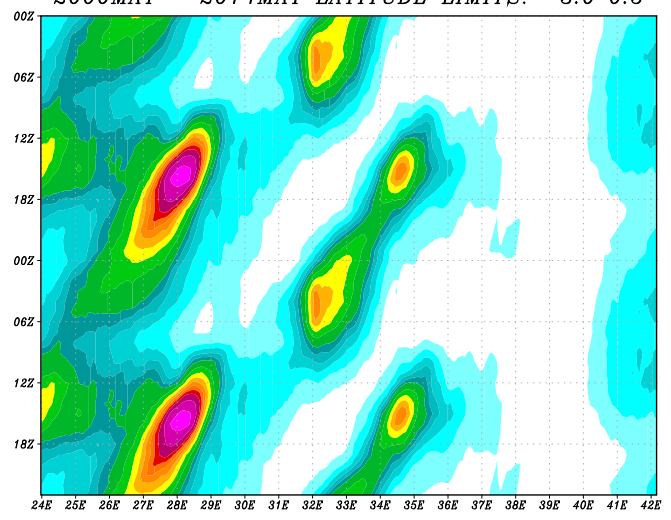

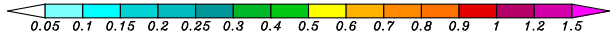
2000JUL - 2014JUL LATITUDE LIMITS: $-3.0 \quad 0.5$

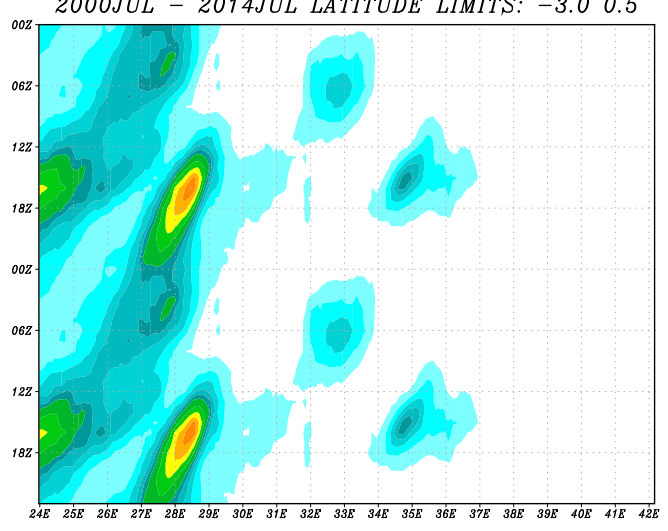

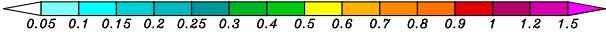

200OFEB - 2014FEB LATITUDE LIMITS: -3.00 .5$

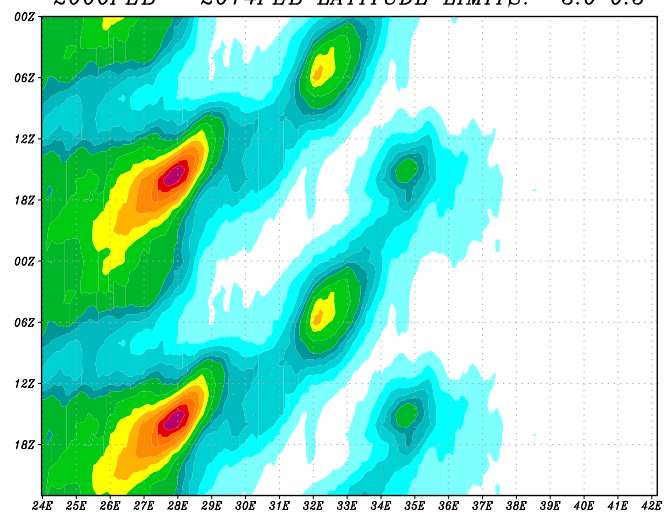

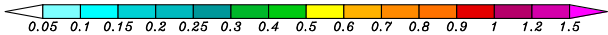
2000APR - 2014APR LATITUDE LIMITS: $-3.0 \quad 0.5$

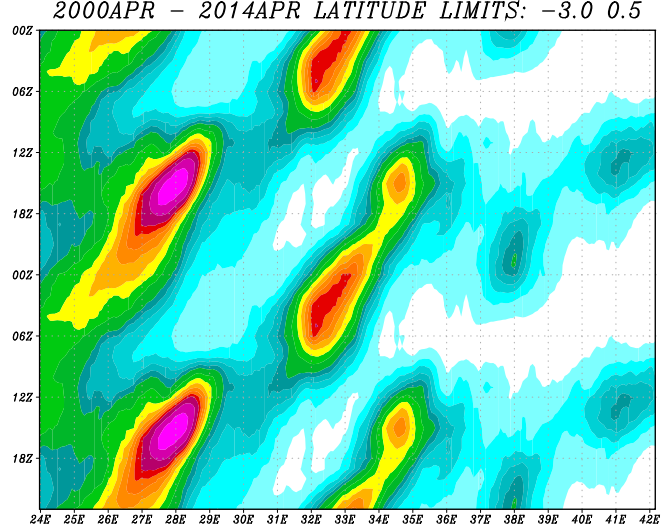

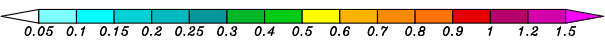
2000JUN - 2014JUN LATITUDE LIMITS: -3.00 .5$

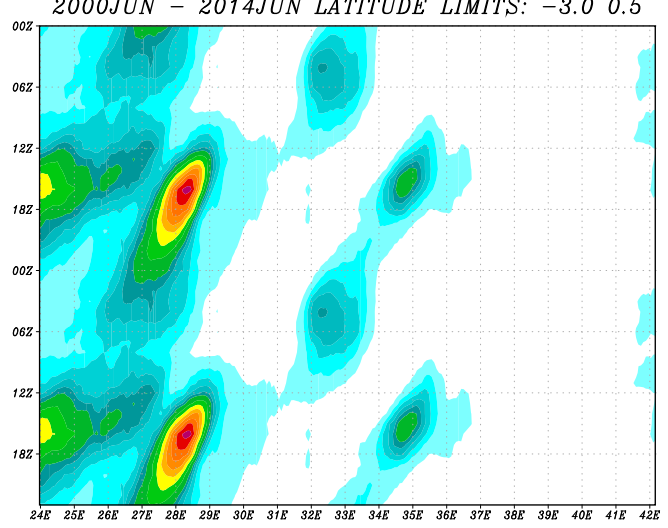

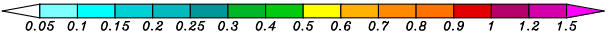

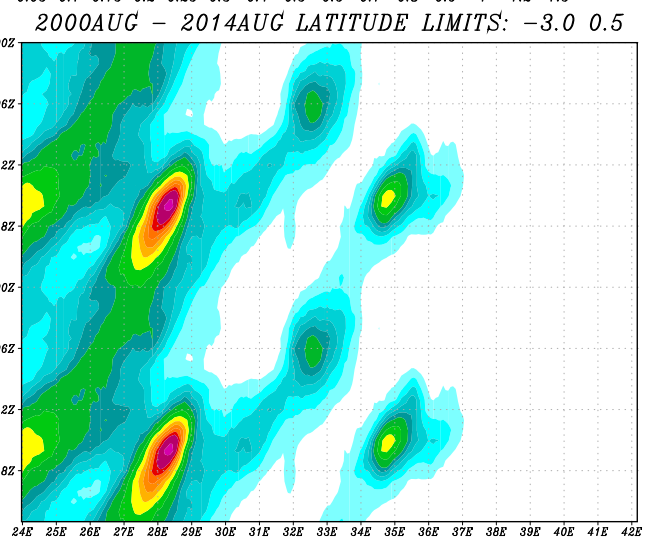

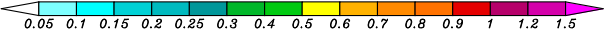

Figura 3.7: Similar a figura 3.6, mas média horária para cada mês do ano. Barra de cores indica taxa de chuva média $\left(\mathrm{mm} \mathrm{hr}^{-1}\right)$. 

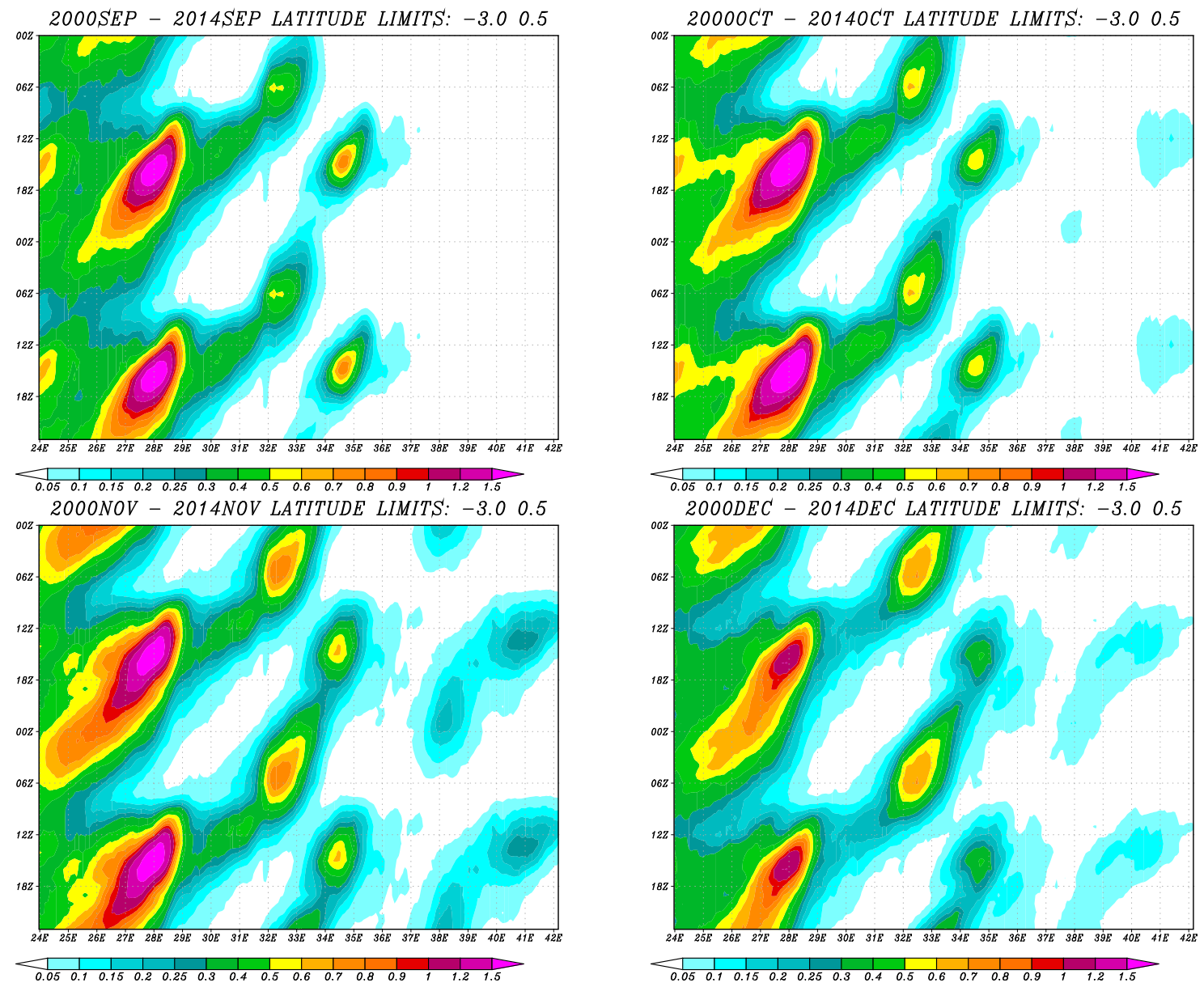

Figura 3.7: Continuação.

Lagos tão pequenos quanto $10 \mathrm{~km}$ de diâmetro podem mudar a distribuição espacial da precipitação sobre e no entorno dele [Crosman e Horel, 2012]. O forte ciclo diurno mostra a máxima atividade convectiva por volta de $28^{\circ} \mathrm{E}$. As máximas ocorrem no fim da tarde associada às ondas de leste em $850 \mathrm{hPa}$. $\mathrm{O}$ campo médio de vento no nível de $850 \mathrm{hPa}$ mostra uma ampla área de ventos de leste através de todo o domínio latitudinal e permanece durante todo o ano com intensidade variável com padrão similar ao da figura 1.6, onde nota-se um freio dos alísios pela cadeia de montanhas a leste do LV. A área de máxima precipitação a oeste do vale do Rift coincide com as elevações mais baixas na topografia. As variações sazonais são nítidas ao longo do ano em amplitude, no entanto, quase não existe diferença na fase. A frequência de chuva horária maior que $1 \mathrm{~mm} \mathrm{hr}^{-1}$ é máxima com 50\% (30\%) de frequência no outono e primavera do hemisfério sul a oeste do vale do Rift (LV). A leste de $36^{\circ} \mathrm{E}$ o clima é mais seco com frequência de chuva muito baixa no decorrer do ano. Similarmente, o ciclo diurno de atividade elétrica apresenta máxima ocorrência entre 0500 UTC e 0800 UTC no LV, conforme figura 3.8. Nota-se que o locacional da máxima atividade elétrica coincide com o máximo de precipitação horária anual estimados com o CMORPH. O máximo na estimativa de queda de 
raios é ligeiramente a leste do máximo de precipitação. No período da tarde o máximo na densidade de descargas atmosférica ocorre sobre a floresta do Congo [Soula et al., 2016]. Vale notar, que a suavização dos dados do LIS pode ser a fonte desse pequeno deslocamento entre a máxima queda de raios e a máxima precipitação. As características mais predominantes dos sistemas convectivos sobre a África equatorial já foram estudadas por outros autores, mas com o uso de outras fontes de dado como o TRMM por exemplo [Omondi, 2017].
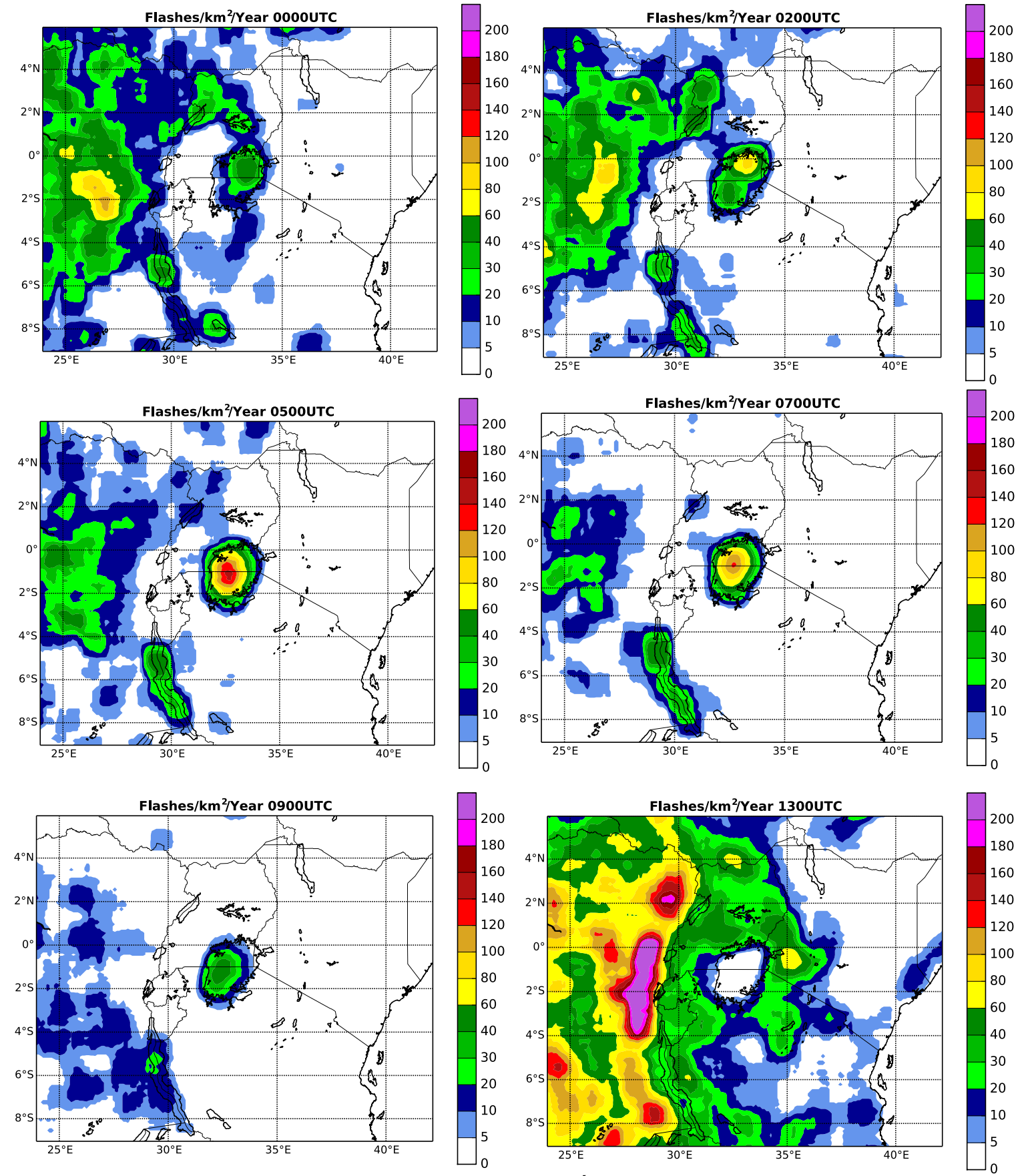

Figura 3.8: Densidade média de descarga atmosférica sobre a África equatorial para o período de 2000 a 2013. Longitude, latitude e limites geográficos estão indicados. A escala de cores indica densidade de raios (número de raios $\mathrm{km}^{-2} \mathrm{ano}^{-1}$ ). Horário em UTC. Fonte dos dados brutos: NASA, http://lightning.nsstc.nasa.gov/data/data_lis-vhr-climatology.html 

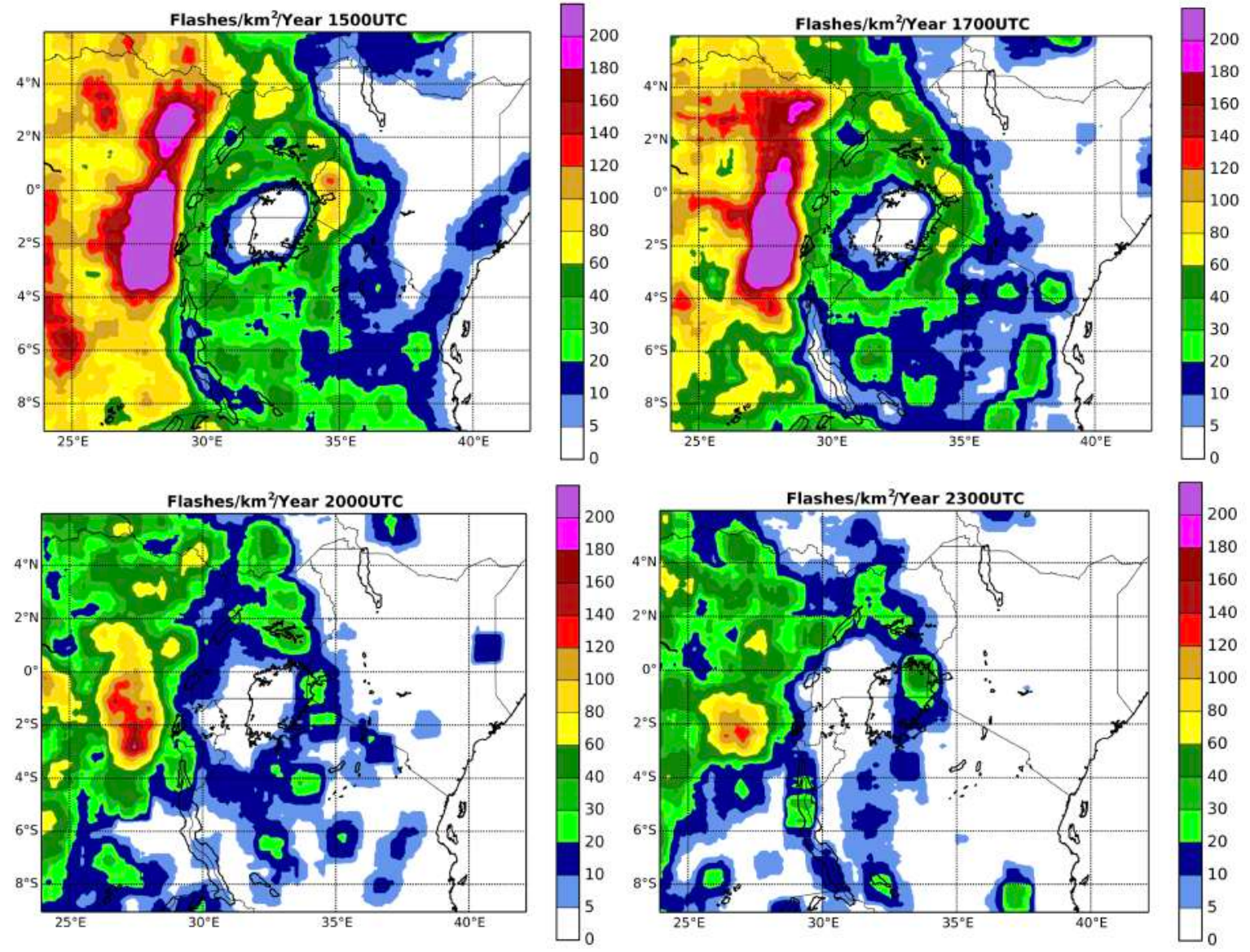

Figura 3.8: Continuação.

Foi obtido um total de 33,189 episódios de convecção com propagação de leste para oeste no período entre 2000 e 2014 tal que a máxima frequência ocorre entre março e maio e nos meses de outubro e novembro e a mínima frequência ocorre nos meses julho e agosto. A frequência está em acordo com o posicionamento latitudinal da ZCIT. A figura 3.9 mostra a frequência na distribuição da duração, velocidade de fase e distancia de propagada. A distância, velocidade de fase e duração média desses episódios são de $332 \mathrm{~km}, 10.3 \mathrm{~m} \mathrm{~s}^{-1}$ e 10.7 horas, respectivamente. Aproximadamente, $40 \%$ tem velocidade de fase entre 6 e $10 \mathrm{~m} \mathrm{~s}^{-1}, 17 \%$ menos que $6 \mathrm{~m} \mathrm{~s}^{-1}$ e $0.5 \%$ dos eventos mais que $30 \mathrm{~m} \mathrm{~s}^{-1}$. Aproximadamente $48 \%$ propagam-se menos que $300 \mathrm{~km}$ e $6 \%$ mais que $500 \mathrm{~km}$, tal que $50 \%$ deles duram entre 8 e 16 horas, enquanto $5 \%$ duram mais que 20 horas e $8 \%$ menos que 5 horas.

Quando se considera apenas os episódios que percorrem mais que $600 \mathrm{~km}$ foram identificados 3515 episódios. Neste caso, quase 5 vezes mais episódios maiores que $600 \mathrm{~km}$ que obtidos anteriormente (Fig 3.10d). Isso ocorre devido à junção de episódios menores, mas que juntos, ainda mantém correlação superior a 0.35 com a função retangular cosseno, o que mostra que a convecção pode desaparecer em determinado momento do gráfico, mas a perturbação inicial gerada pela mesma favorece novas células convectivas com a mesma 
velocidade de fase. Esses episódios mais longos podem ser gerados por ondas que deslocam-se pela região equatorial e disparam convecção e mantém um ciclo de dissipação e regeneração da convecção. A velocidade média de fase e duração é de $12.1 \mathrm{~m} \mathrm{~s}^{-1}$ e 19 horas, respectivamente. Esses episódios longos propagam-se entre o leste do LV e a floresta do Congo e sua reintensificação está associada a circulação local sobre o LV em um primeiro momento e posteriormente, ao aquecimento diabático do ciclo diurno a oeste do LV. Os eventos que se propagam por uma distancia inferior a $500 \mathrm{~km}$ tendem a se propagar mais rápido do que os que se propagam por longas distancias. $\mathrm{O}$ oposto depende das condições dinâmicas e termodinâmicas, embora a velocidade de fase dos episódios com propagação superior a $600 \mathrm{~km}$ é maior que aqueles com propagação inferior a $500 \mathrm{~km}$. O espalhamento da velocidade de fase tende a ser mais amplo (estreito) para maiores (menores) durações e distância propagada, mas existem alguns eventos de longa propagação e duração com alta velocidade de fase.

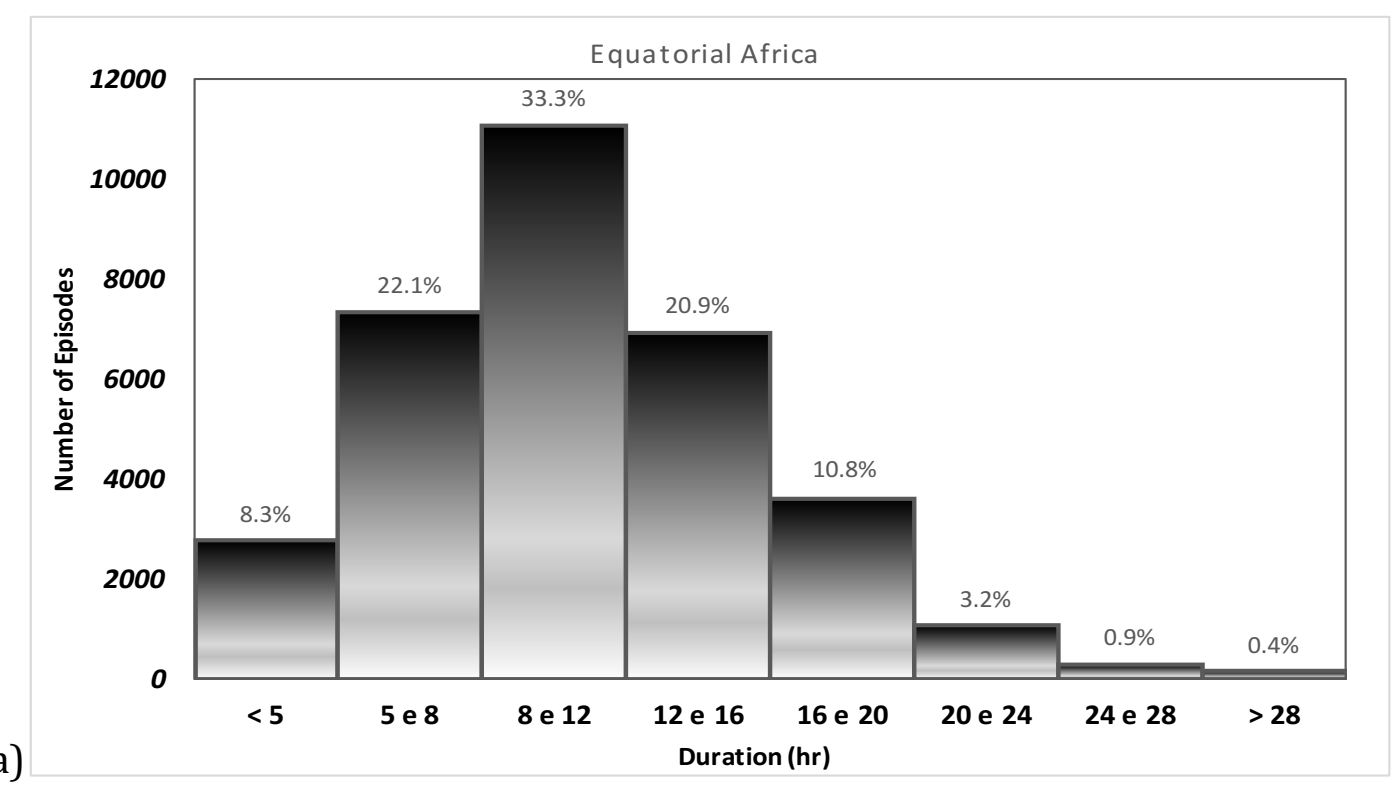

Figura 3.9: Frequência da distribuição de duração (a), velocidade de fase (b) e propagação longitudinal (c) dos eventos de leste de convecção organizada sobre a África equatorial entre $1^{\circ} \mathrm{N}$ e $3^{\circ} \mathrm{S}$ para 33,189 eventos no período 2000 a 2014. Eixo x indica (a) duração dos episódios, (b) velocidade de fase e (c) distância propagada e o eixo y indica número de episódios. As unidades estão indicadas. 
(b)
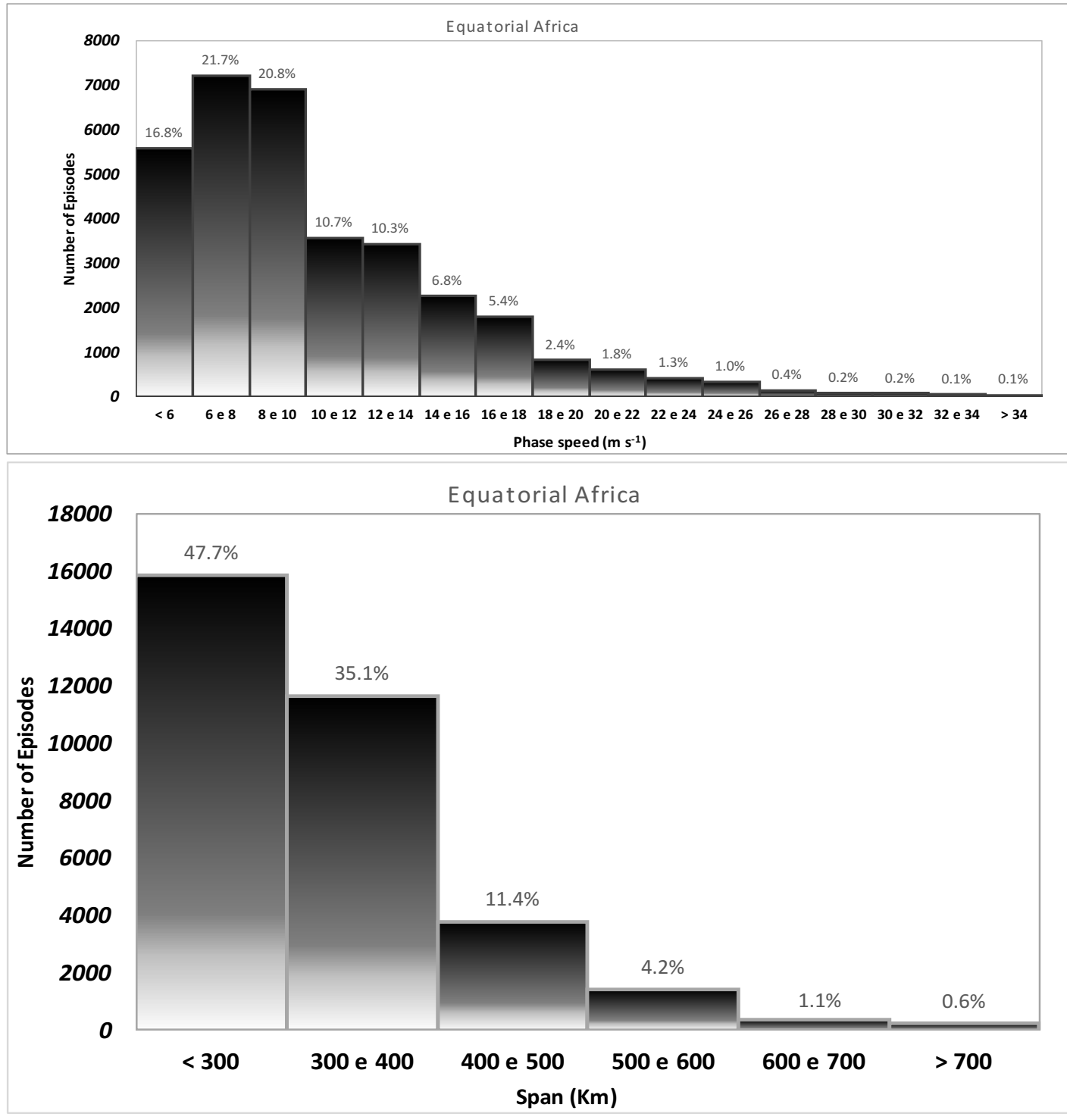

(c)

Span (Km)

Figura 3.9: Continuação. 


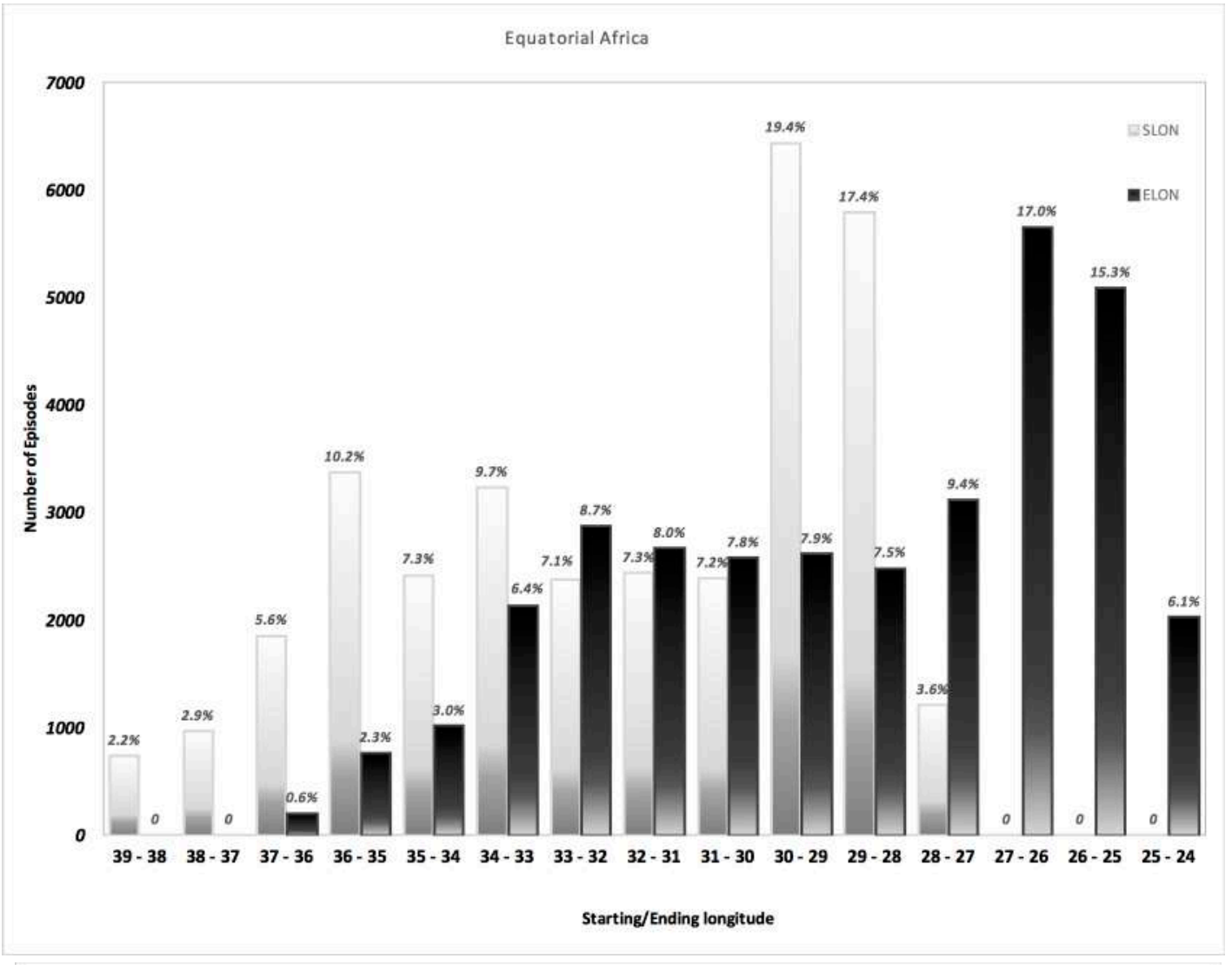

(a)

Equatorial Africa

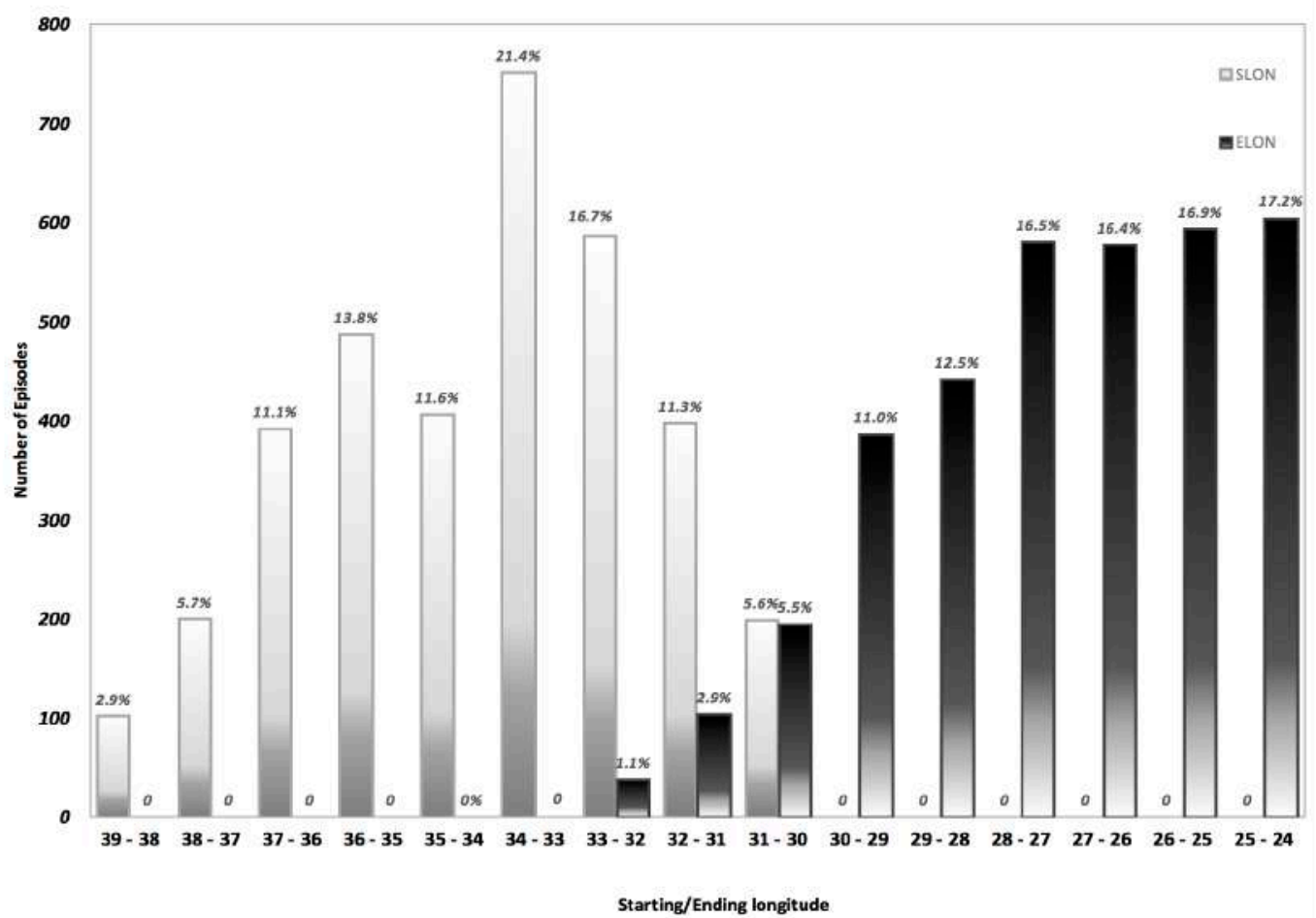

(b)

Figura 3.10: Frequência da distribuição de longitude inicial e final para todos os eventos (a) de leste da convecção organizada entre as latitudes $1^{\circ} \mathrm{S}$ e $3^{\circ} \mathrm{N}$ para os eventos com propagação superior a $600 \mathrm{~km}$ (b) e respectiva hora de início (c) e distribuição de frequência de propagação (d). Eixo x indica longitude

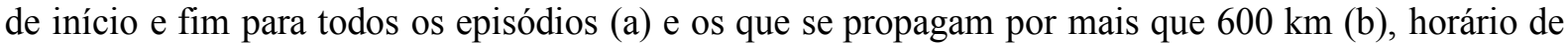
início para todos os episódios (c) e distância propagada dos episódios que se propagam por mais que $600 \mathrm{~km}$ (d). Eixo y indica número de episódios. Unidade de tempo está em (x100) UTC. 


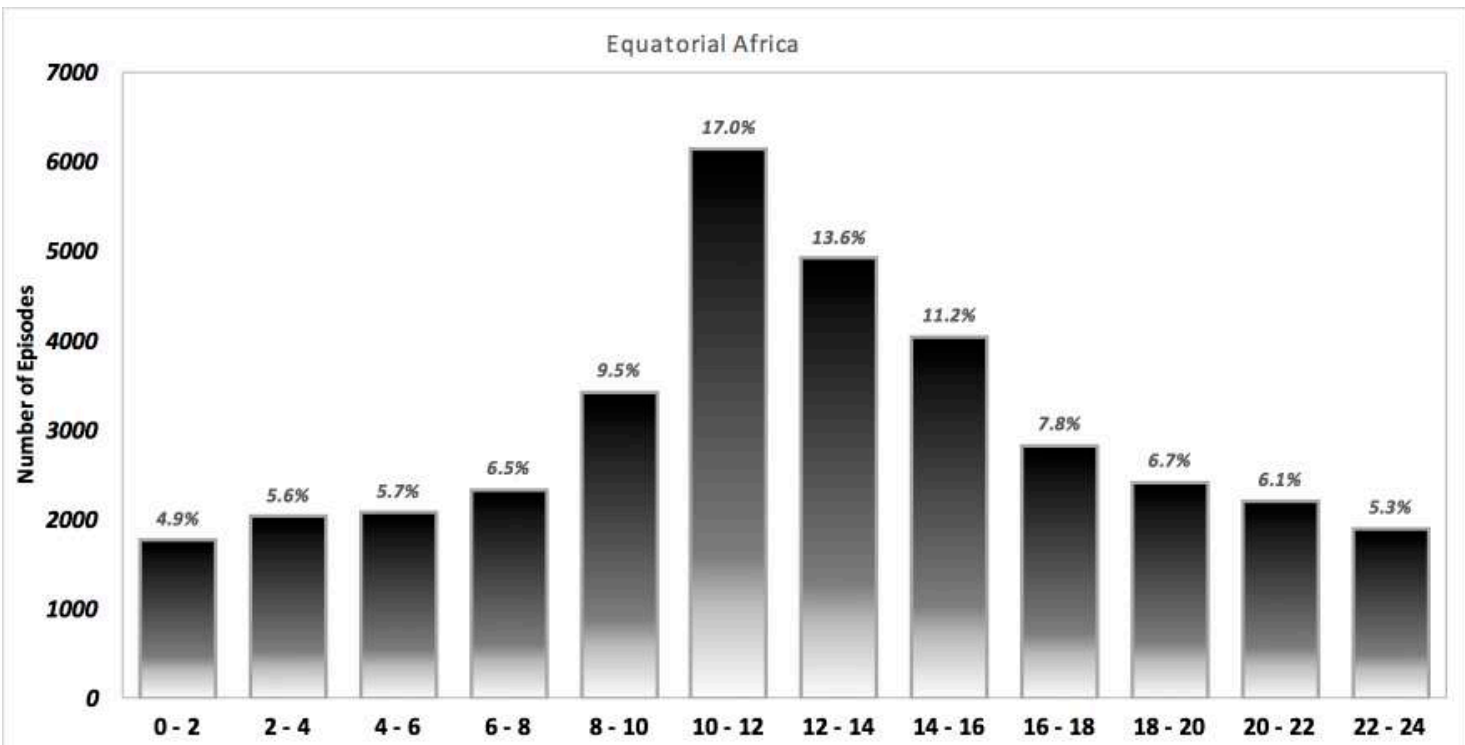

(c) Starting Time (UTC)

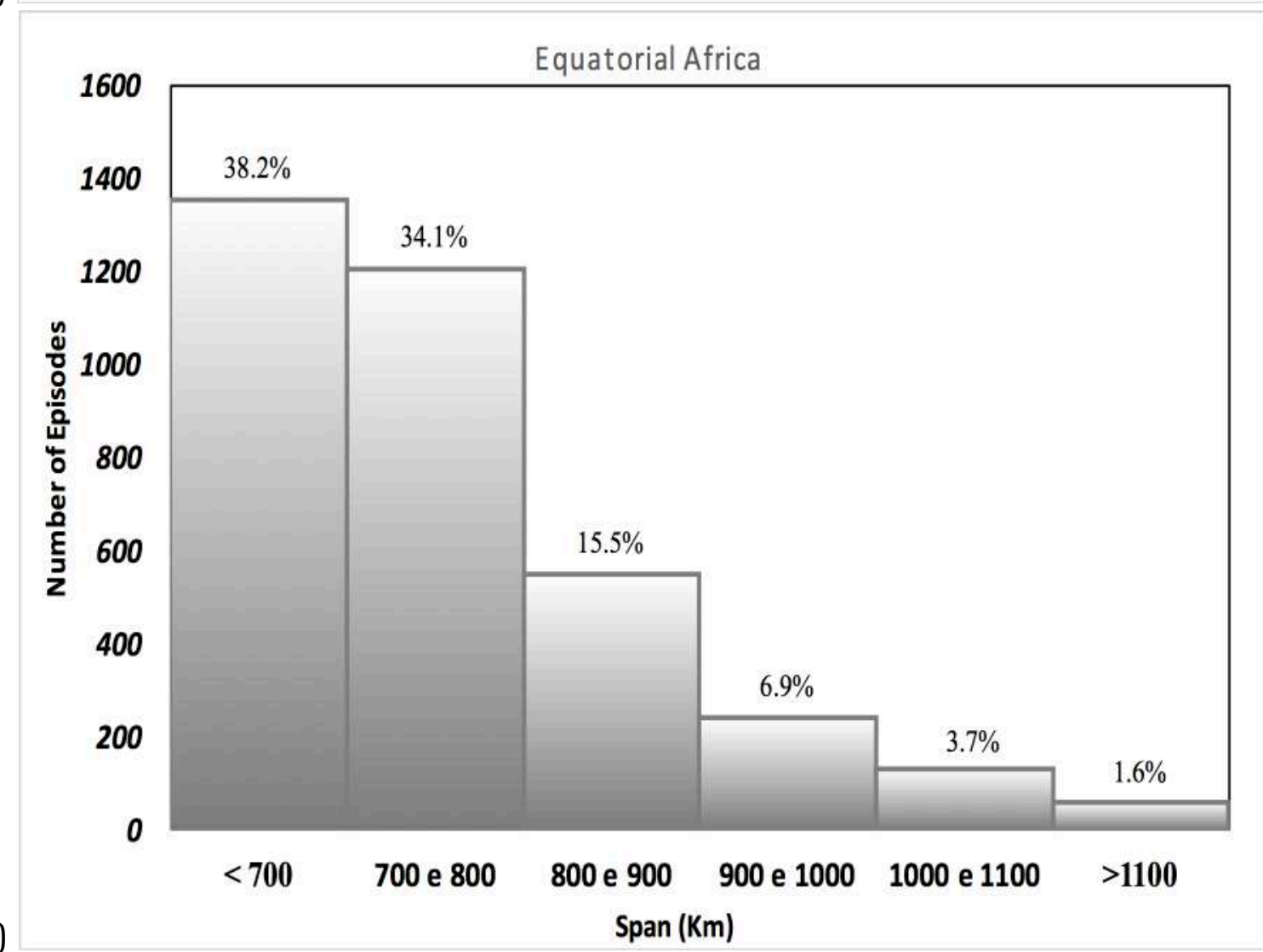

Figura 3.10: Continuação.

Episódios de oeste que começam no fim da tarde a leste do LV se intensificam no período da madrugada sobre o lago e disparam convecção a oeste do lago Kivu durante o período da tarde. Sobre o LV e a oeste do vale do Rift, os episódios aceleram dado a grande superfície de água com baixa fricção e terreno quase plano a oeste do lago Kivu. A evaporação sobre o LV 
é advectada para oeste e pode contribuir para o aumento da chuva sobre a floresta do Congo durante o período da tarde, devido ao acoplamento das ondas equatoriais [Kiladis et al., 2009] e as perturbações geradas pela convecção sobre o LV [Lenouo et al., 2016]. A região de máxima precipitação sobre a floresta do Congo é na mesma latitude do LV, os acumulados decrescem fora desta banda de latitude para aproximadamente metade do pico nos valores estimados sobre a floresta do Congo. Assim, a umidade fornecida pelo LV e a convecção prévia sobre o lago, pode estar associada a intensificação das ondas equatoriais e de maiores índices pluviométricos sobre a floresta.

Muitos episódios curtos começam a oeste do LV, se reintensificam sobre ele e aparentemente se dissipam a oeste do LV. A piscina de ar frio gerada pelas tempestades alcança o limite oeste do vale do Rift entre o fim da manhã e meio da tarde, conforme discutido anteriormente, e pode intensificar a convecção local. Esses episódios estão separados no diagrama Hovmoller porque ele se dissipa entre o LV e oeste do vale do Rift, embora um esteja relacionado ao outro. Por outro lado, quando são considerados apenas episódios com propagação superior a $600 \mathrm{~km}$, aproximadamente a distancia entre o meio do LV e a floresta do Congo, $50 \%$ dos eventos que começaram sobre o LV e por volta de $30 \%$ daqueles que se iniciaram a leste do LV dispararam convecção também sobre a floresta do Congo logo, podese inferir significante associação entre a chuva sobre o LV e a floresta do Congo por meio das ondas equatoriais de Rossby como mostrado na figura 3.10d com a distribuição de episódios superior a $600 \mathrm{~km}$. A convecção que se inicia sobre o LV (24\%) influência as chuvas a oeste do lago Kivu indiretamente por meio das ondas equatoriais de oeste (Fig. 3.5). Há uma área com baixa precipitação entre o LV (32E) e leste da floresta do Congo (29E) como mostrado na figura 2.1. Outras evidências que mostram que episódios que são disparados sobre o LV têm impacto sobre a floresta do Congo durante a tarde, é a velocidade de fase e o tempo que a propagação demora para chegar na floresta. A perturbação previamente gerada ou intensificada sobre o LV alcança a floresta do Congo pouco depois do início da convecção vespertina.

Considerando os eventos com propagação superior a $600 \mathrm{~km}$, nota-se que a correlação entre os eventos sobre o LV e a parte leste da floresta do Congo permanece acima dos 0.35. De todos os episódios que se iniciaram durante a tarde a leste do LV, 30\% intensificaram a brisa valemontanha a leste do LV e mais tarde disparam tempestades sobre o LV no período da madrugada. Assim, é razoável inferir que a circulação local dispara 30\% dos episódios de leste com alguma influência nas tempestades disparadas sobre a floresta do Congo, uma interessante estimativa que mostra como grandes lagos como o LV pode influenciar o padrão de chuvas a centenas de quilômetros distante dele. 
Os mapas de distribuição de frequência horária na região da África equatorial na área descrita pelo retângulo da figura 2.1 mostram meses preferencias das tempestades noturnas e meses em que sua frequência é baixa (figura 3.11 e 3.12).

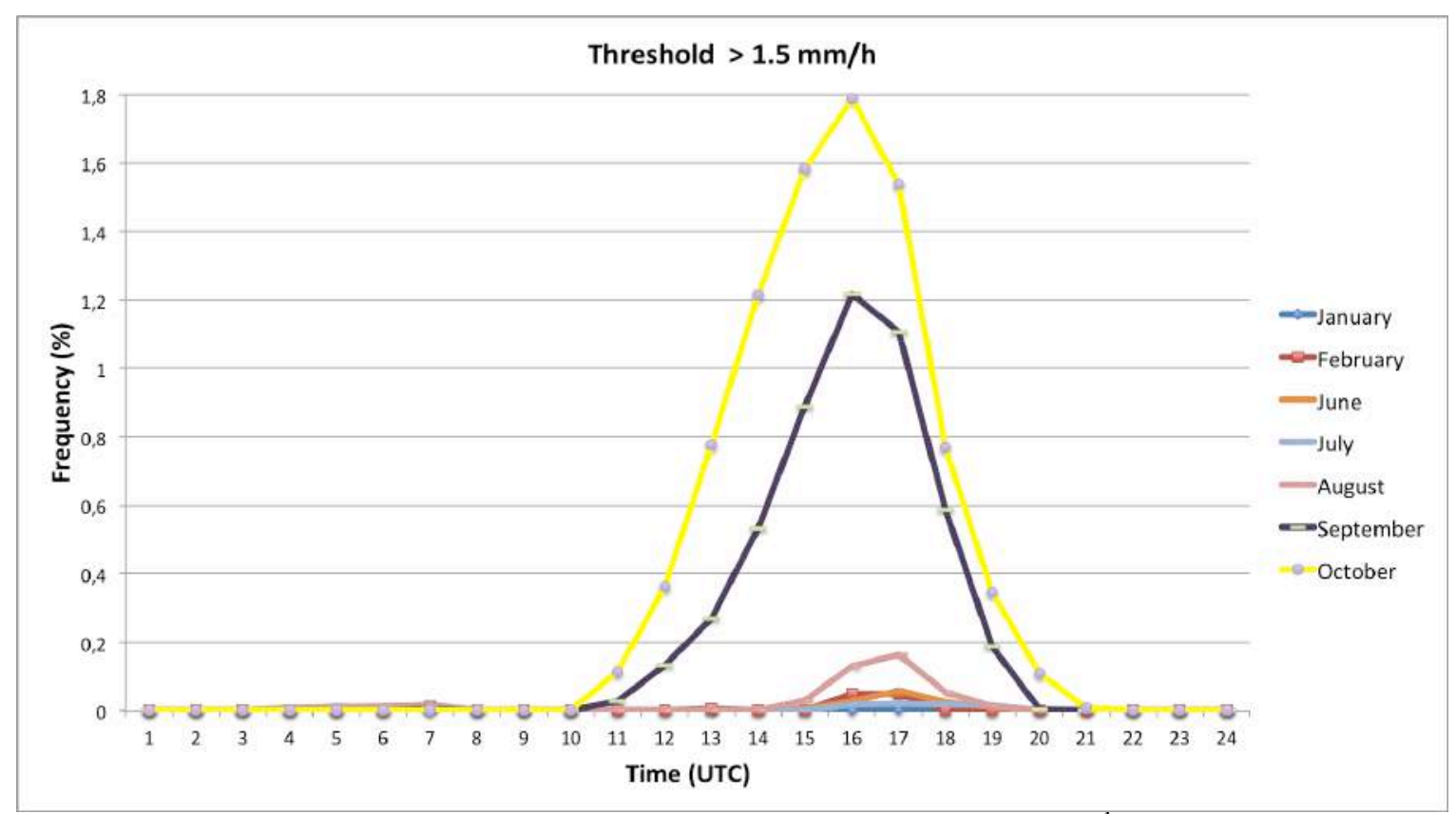

Figura 3.11: Frequência horária de precipitação com limiar superior a $1.5 \mathrm{~mm} \mathrm{~h}^{-1}$ sobre a na área descrita pelo retângulo da figura 2.1. Eixo x representa hora UTCx100 e eixo y frequência de pontos de grade média horária para cada mês.

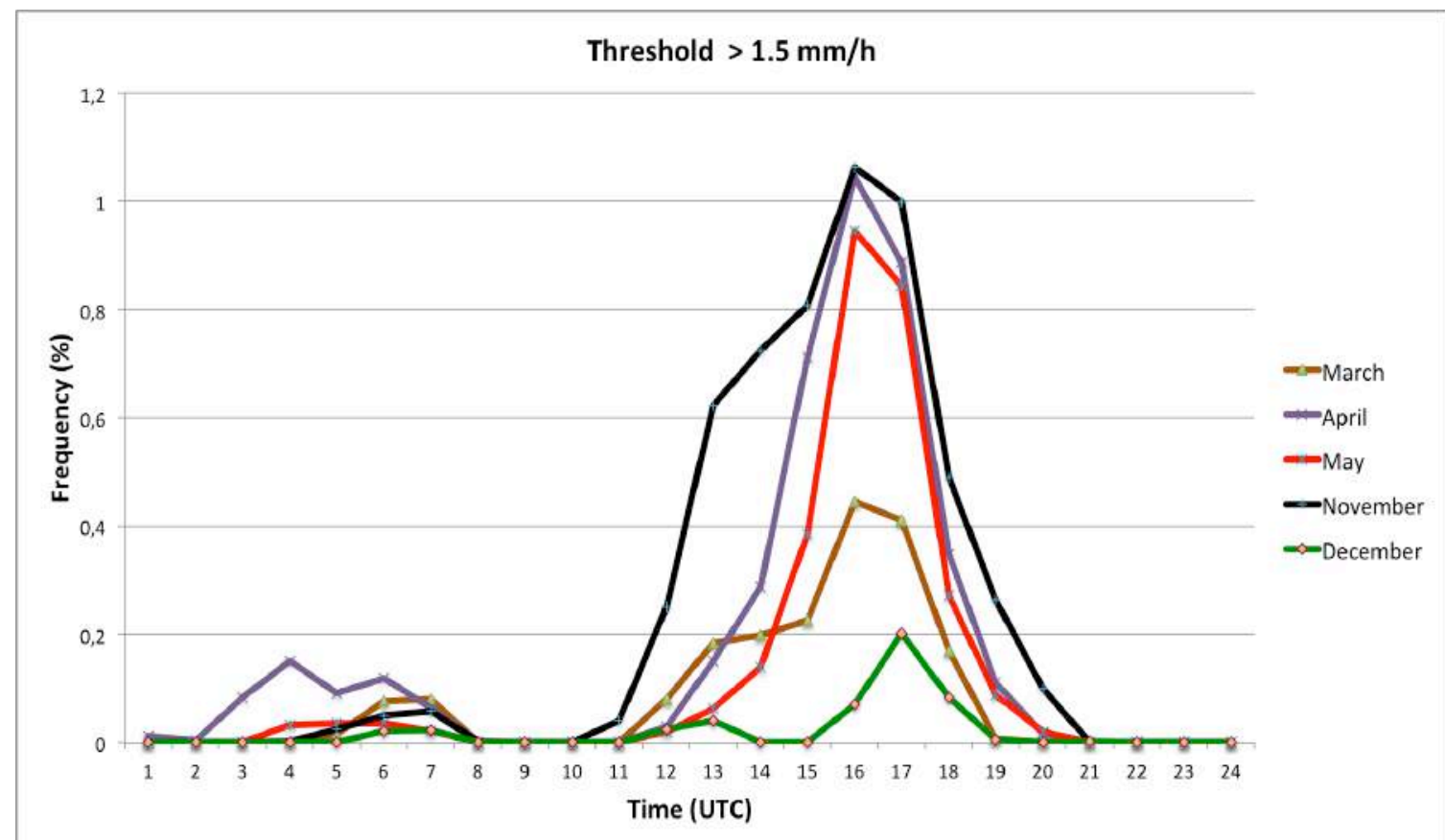

Figura 3.12: Frequência horária de precipitação com limiar superior a $1.5 \mathrm{~mm} \mathrm{~h}^{-1}$ sobre a na área descrita pelo retângulo da figura 2.1. Eixo x representa hora UTCx100 e eixo y frequência de pontos de grade média horária para cada mês. 
A figura 3.11 representa os meses de janeiro, fevereiro, junho, julho, agosto, setembro e outubro. Nota-se que no período da madrugada e início da manhã, entre 2100 UTC e 0500 UTC, a frequência de eventos são quase nulas, período esse em que normalmente ocorrem os eventos sobre o LV, e as chuvas ocorrem quase que exclusivamente no período da tarde e início da noite, entre 1100 UTC e 2000 UTC basicamente devido à convecção no período da tarde associada ao ciclo diurno de aquecimento a leste do LV e sobre a floresta do Congo. Para os meses de março, abril, maio, novembro e dezembro (figura 3.12) valores significativos de frequência ocorrem no período da madrugada e inicio da manhã na região da África equatorial e basicamente estão associadas à convecção do período noturno sobre o LV pela CBL e CBVM. Ressalta-se que a frequência é relativa a toda a área descrita pela figura 2.1 e o LV representa aproximadamente $11 \%$ de toda essa área logo, frequências entre $0.1 \%$ e $0.2 \%$ de área com precipitação superior a $1.5 \mathrm{~mm} \mathrm{~h}^{-1}$ é extremamente relevante sobre a região para um determinado horário.

\subsection{Análise sinótica dos eventos selecionados}

Nesse trabalho foram escolhidos 2 eventos de tempestade para análise mais detalhada, o primeiro evento ocorreu dia 01/11/2010 e o disparo da convecção ocorreu no período da madrugada de forma mais localizada sem convecção significativa na maior parte do vale do Rift. O segundo evento analisado foi o de convecção noturna do dia 03/11/2014 e esteve associado a uma atmosfera mais instável em toda a região do Vale do Rift.
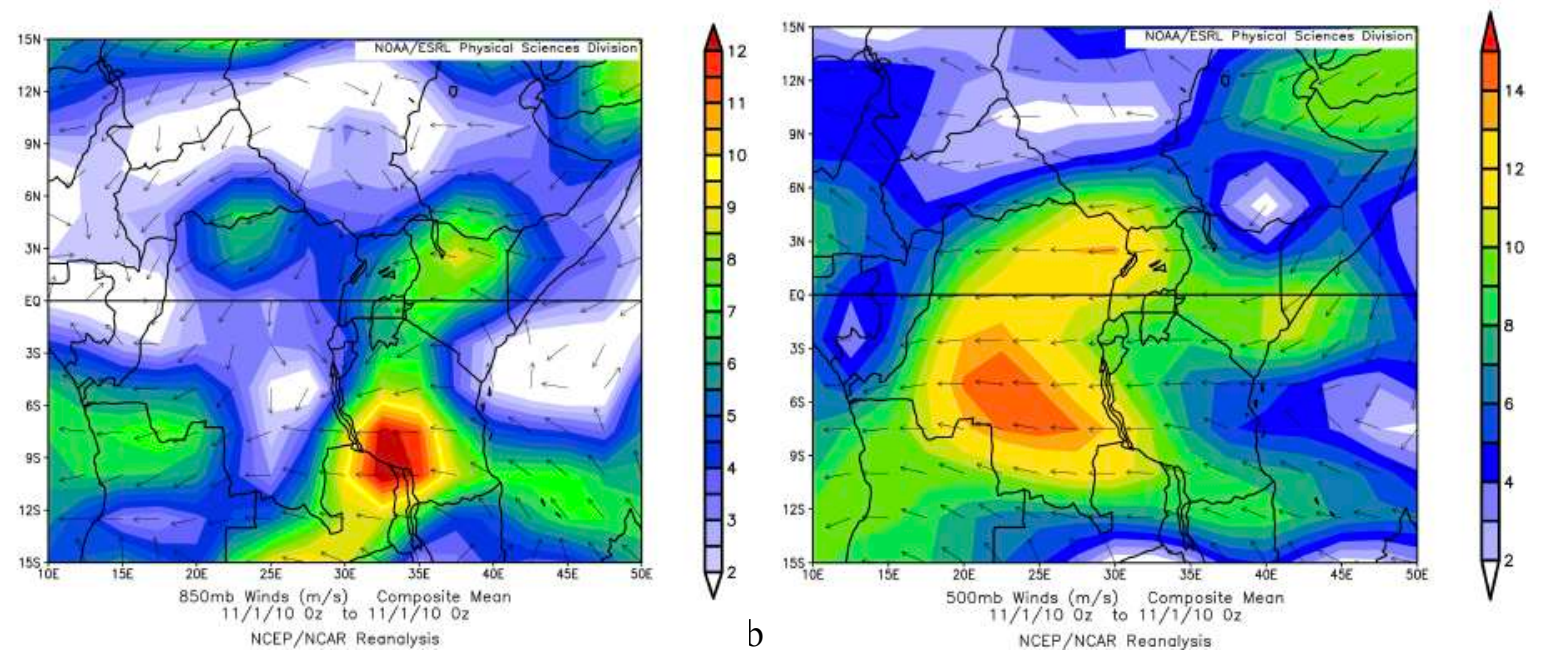

Figura 3.13: Campo de direção e intensidade do vento no nível de $850 \mathrm{hPa}$ (a) e $500 \mathrm{hPa}$ (b). Contornos geopolíticos e do LV estão indicados. Barra de cores indica intensidade do vento $\mathrm{em} \mathrm{m} \mathrm{s}^{-1}$ as 0000 UTC do dia $01 / 11 / 2010$. 
A figura 3.13 mostra o campo sinótico dos ventos nos baixos e médios níveis no dia 01/11/2010, nota-se ventos de leste na baixa e média atmosfera. Na baixa atmosfera, nota-se o efeito da desaceleração dos ventos alísios devido a topografia a leste do LV e os ventos tendem a contornar o LV. No nível de 500 hPa (fig. 3.13b), ocorre aceleração dos ventos entre o LV e oeste do lago. Essa aceleração produz divergência nos médios níveis sobre o LV e movimentos de subsidência nessa região, conforme figura 3.14 b, ou seja, a tempestade que se formou pouco tempo depois sobre o LV estava embebida em um ambiente mais estável. Nos altos níveis (fig. 3.14a), nota-se uma leve divergência a sudoeste do LV, com pouca influência sobre a convecção que ocorreu, posteriormente na região. A análise sinótica desse evento conclui-se que houve baixa influência da grande escala na formação desse sistema e as condições locais, como TSL elevada, CBL e CBVM foram significativos para o disparo da convecção noturna.
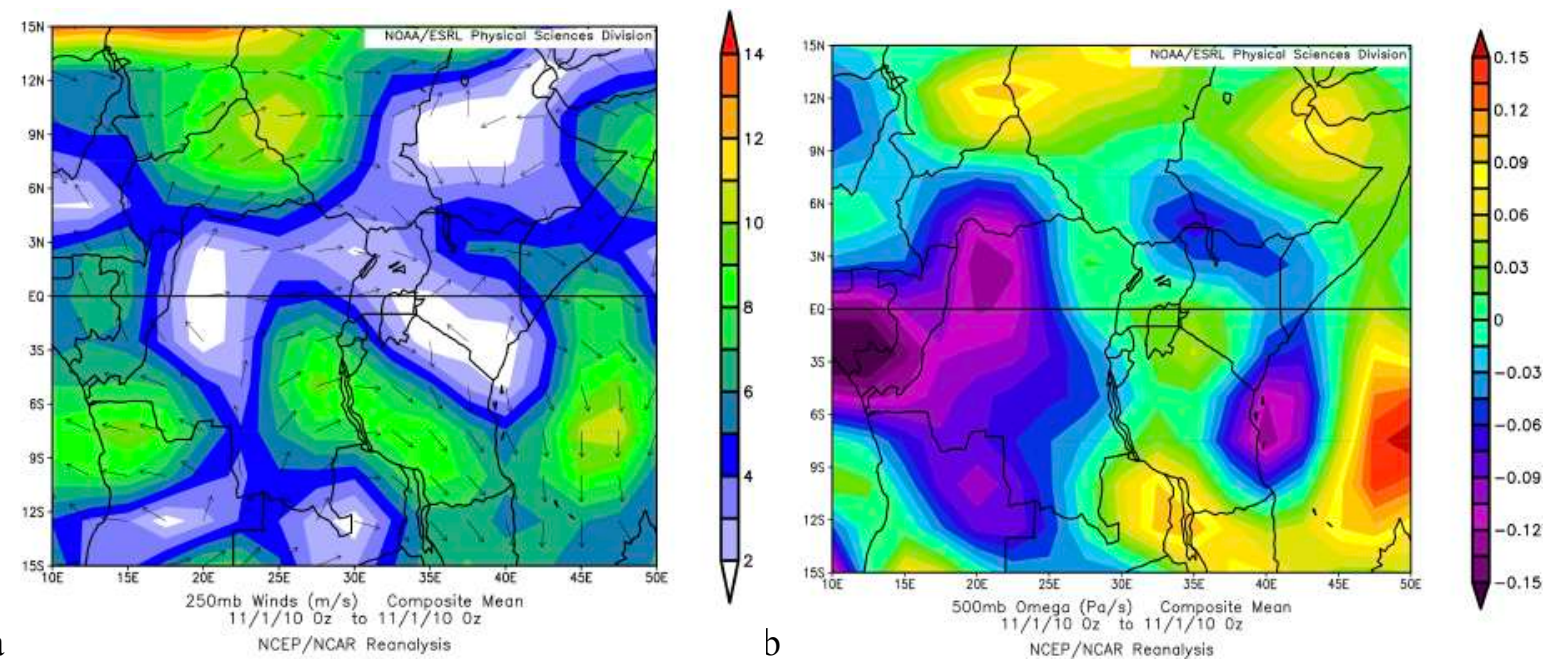

Figura 3.14: Campo de direção e intensidade do vento no nível de $250 \mathrm{hPa}$ (a) e velocidade vertical ômega em $500 \mathrm{hPa}$ (b). Contornos geopolíticos e do LV estão indicados. Barra de cores indica intensidade do vento em $\mathrm{m} \mathrm{s}^{-1}$ (a) e velocidade vertical omega em $\mathrm{Pa} \mathrm{s}^{-1}$ (b) as 0000 UTC do dia 01/11/2010.

A figura 3.15 mostra o campo sinótico dos ventos nos baixos e médios níveis no dia 03/11/2014. Os ventos alísios sobre a região do LV estão aproximadamente entre 3 e $4 \mathrm{~m} \mathrm{~s}^{-1}$, enquanto que para o evento do dia 01/11/2010 os ventos estavam entre 6 e $7 \mathrm{~m} \mathrm{~s}^{-1}$. Por outro lado, no nível de $500 \mathrm{hPa}$ nota-se a desaceleração dos ventos entre o leste do LV e o lago, que produz convergência nos médios níveis e favorece movimentos convectivos sobre o LV, conforme figura 3.16b. Ainda, ligeiramente a sul do LV se observa ventos de sudeste, que favoreceu o deslocamento da convecção do período vespertino a sul do LV em direção ao lago.

De maneira geral, o evento do dia 03/11/2014 esteve embebido em uma atmosfera mais instável com influência significativa do nível de $500 \mathrm{hPa}$, com convergência em fase com a convergência da baixa atmosfera produzida pelas montanhas. Neste caso, os eventos de 
convecção noturna foram menos sensíveis a variação da TSL, devido a maior influência da grande escala no disparo da convecção, conforme será mostrado posteriormente.
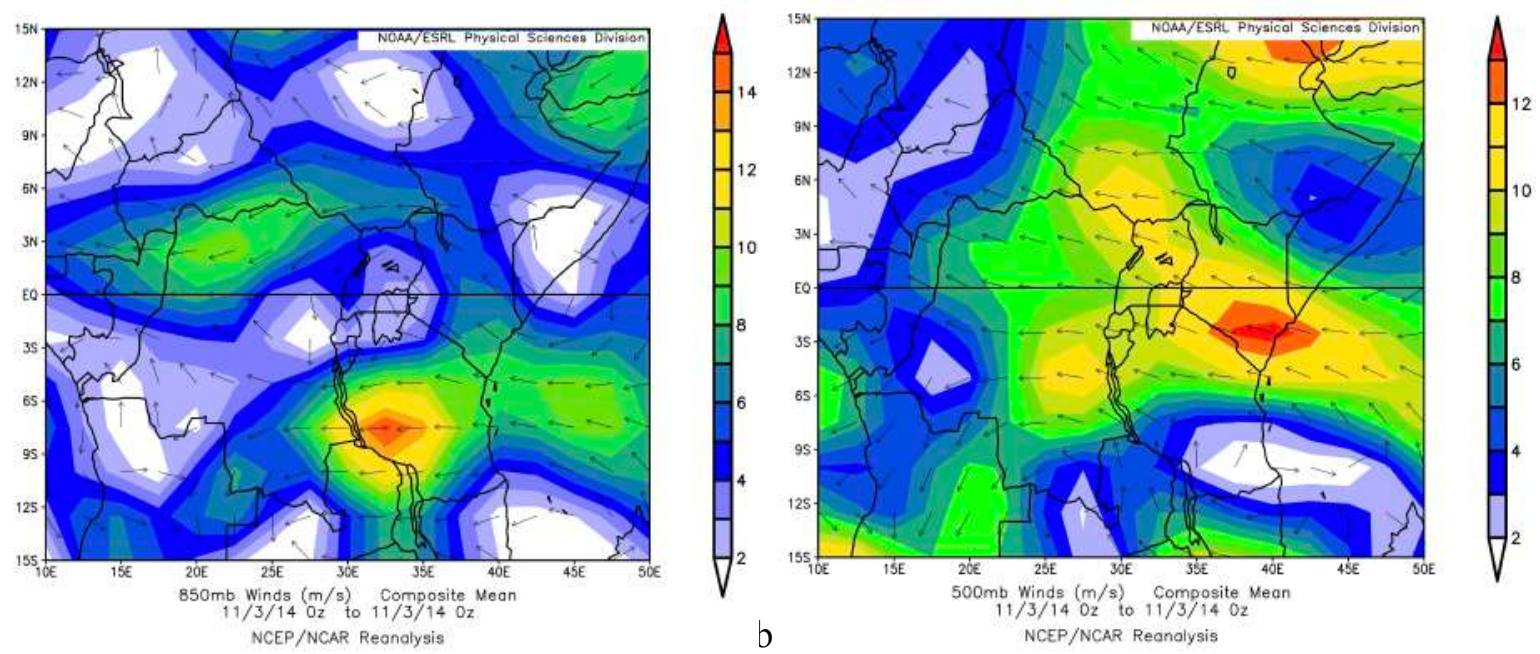

Figura 3.15: Campo de direção e intensidade do vento no nível de $850 \mathrm{hPa}$ (a) e $500 \mathrm{hPa}$ (b). Contornos geopolíticos e do LV estão indicados. Barra de cores indica intensidade do vento em $\mathrm{m} \mathrm{s}^{-1}$ as 0000 UTC do dia $03 / 11 / 2014$.
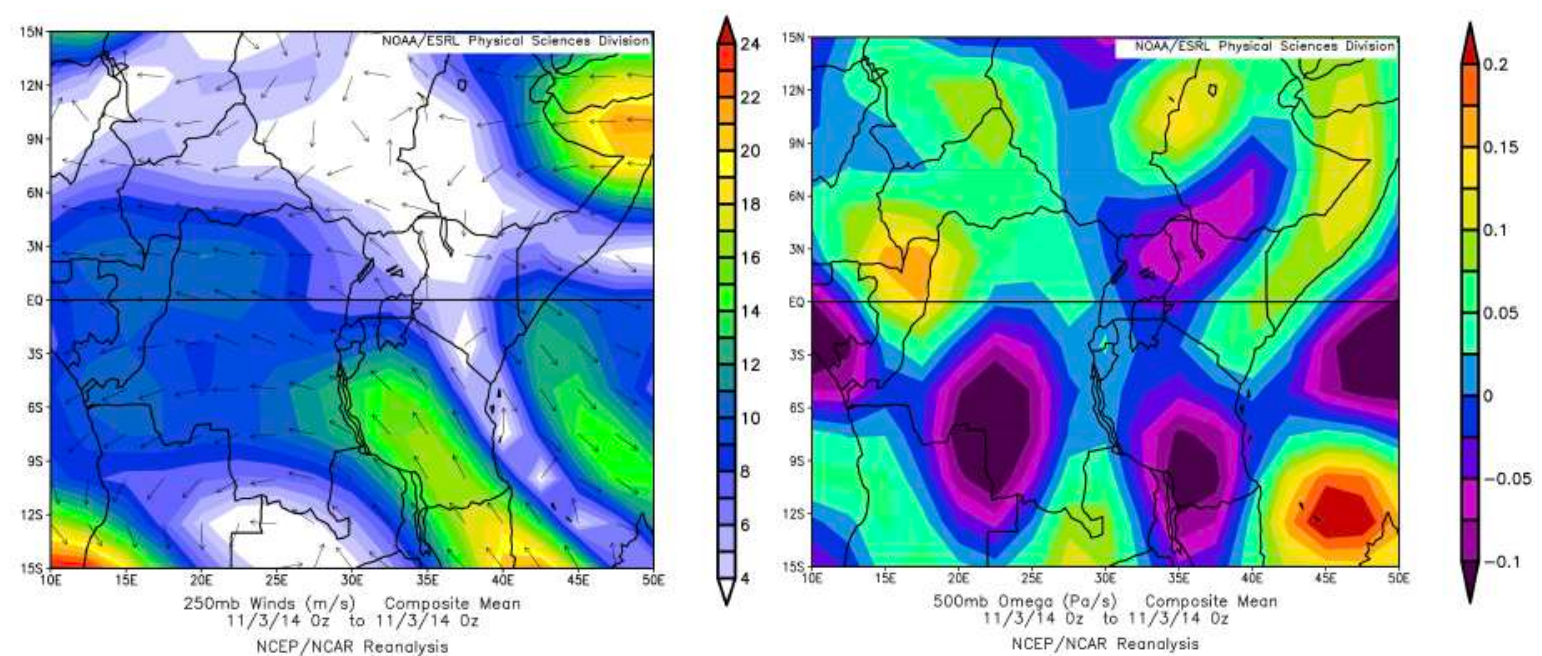

Figura 3.16: Campo de direção e intensidade do vento no nível de $250 \mathrm{hPa}$ (a) e velocidade vertical ômega em $500 \mathrm{hPa}$ (b). Contornos geopolíticos e do LV estão indicados. Barra de cores indica intensidade do vento em $\mathrm{m} \mathrm{s}^{-1}$ (a) e velocidade vertical omega em $\mathrm{Pa} \mathrm{s}^{-1}$ (b) as 0000 UTC do dia 03/11/2014.

\subsection{Simulações com o ARPS}

As simulações com o sistema ARPS foram realizadas de acordo com as grades descritas na figura 1.2, tal que do retângulo maior para o menor, as resoluções horizontais utilizadas foram de $12 \mathrm{~km}, 4 \mathrm{~km}$ e $500 \mathrm{~m}$, respectivamente. O mesmo possui alta eficiência em simular a formação e o desenvolvimento da circulação de brisa em regiões com topografia complexa 
[Vemado, 2012; Vemado e Pereira filho, 2016; Pereira filho et al., 2018]. Testes iniciais com o ARPS, mostraram forte correlação entre a TSL e a formação de tempestades sobre o LV. Variações na TSL média em torno de $2^{\circ} \mathrm{C}$ foram o suficiente entre uma condição com disparo da convecção noturna e outra condição sem nenhuma precipitação.
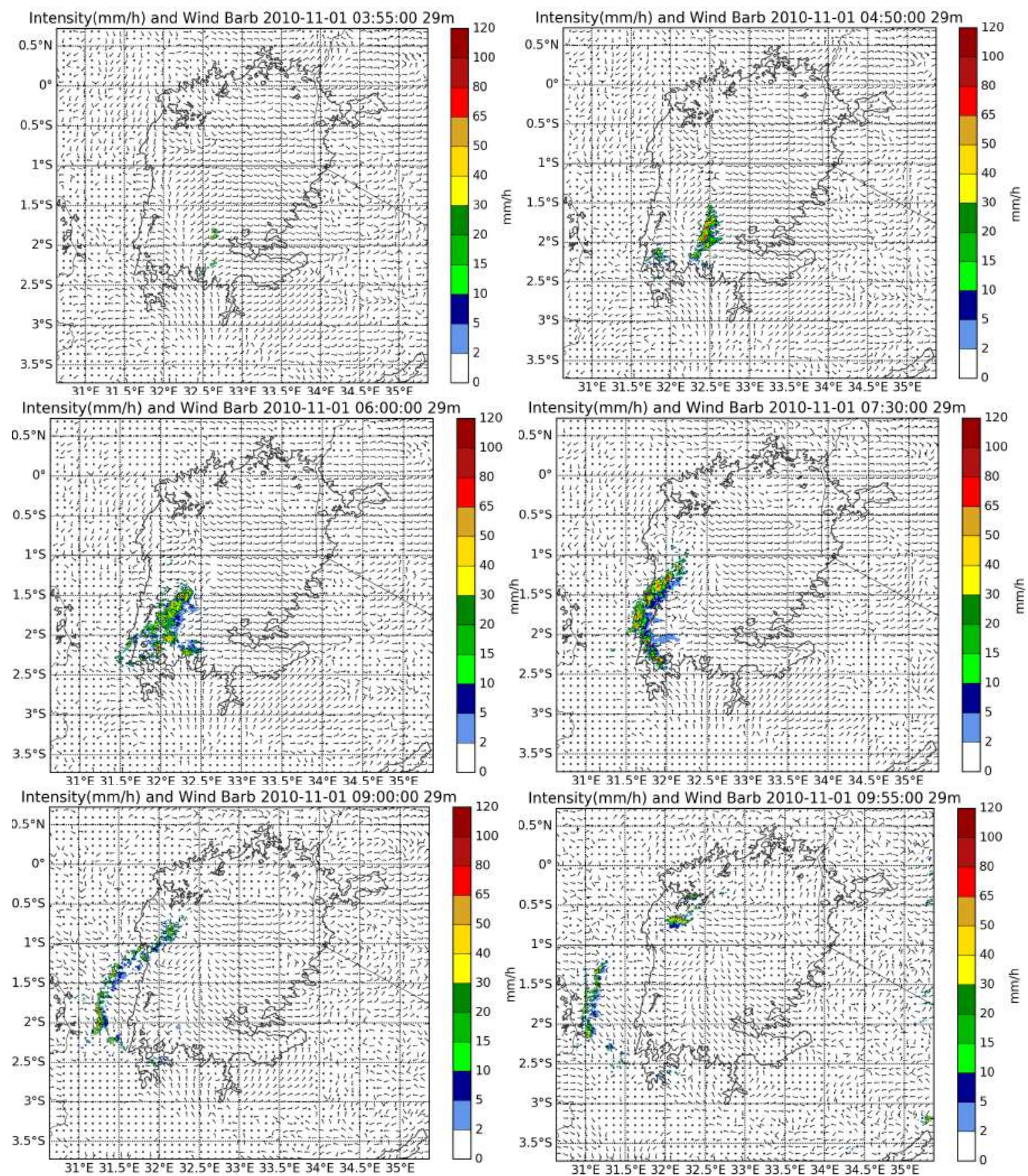

Figura 3.17: Simulação numérica com o sistema ARPS para o evento convectivo de 01 de novembro de 2010. Barbela de vento indica direção e intensidade do vento $\mathrm{em} \mathrm{m} \mathrm{s}^{-1} \mathrm{e}$ barra de cores indica intensidade da chuva em $\mathrm{mm} \mathrm{h}^{-1}$. Resolução espacial da simulação com 500 metros. Contorno do LV e horário estão indicados. 
As simulações realizadas foram centradas no centro do LV para o dia 01 de novembro de 2010. A condição inicial e de contorno utilizadas em ambas, foram provenientes do modelo global GFS (Global Forecast System). Uma das simulações foi realizada com temperatura média do lago em torno de $23.5^{\circ} \mathrm{C}$, proveniente direto do GFS e a outra, com configuração de TSL similar à figura 2.2 (climatologia). Em ambas as simulações, notou-se o desenvolvimento da brisa lacustre noturna, no entanto, sem o disparo de convecção na simulação com TSL 2 ${ }^{\circ} \mathrm{C}$ inferior. No entanto, para a simulação com a TSL da figura 2.2, houve disparo da convecção seguindo a linha de brisa terral noturna, conforme figura 3.17. A TSL maior aumenta a disponibilidade de umidade específica devido ao aumento no fluxo de calor latente entre o LV e a atmosfera no ar e torna a CLP mais instável, conforme será mostrado na posteriormente.

As simulações conseguiram capturar o disparo da convecção de tempestades mais a sudoeste do lago, embora não tenha conseguido simular com precisão as células de tempestades mais a norte que apareceram nas imagens do canal infravermelho do MSG (fig. 3.18) entre 3 a 4 horas antes do indicado pelas simulações. O disparo da convecção mais a sul do LV também ocorreu antes do observado pelas imagens de satélite. As incertezas na estimativa da TSL podem estar relacionadas à menor acurácia no horário de disparo das células convectivas

Na figura 3.19, nota-se advecção de ar frio que desce as montanhas em direção ao LV pela borda leste do mesmo. O maior resfriamento noturno no entorno do LV favorece a formação da CBL, que no leste do LV acopla-se com a CBVM. No decorrer da madrugada, a temperatura do ar sobre o $\mathrm{LV}$, superior a $25^{\circ} \mathrm{C}$, diminui devido a entrada de ar mais frio pela lateral do mesmo, com redução para valores entre $22{ }^{\circ} \mathrm{C}$ e $23{ }^{\circ} \mathrm{C}$ e o deslocamento da frente de brisa sobre o lago aumenta os fluxos de calor sensível e latente. O desenvolvimento de células de tempestades organiza uma linha formada por suas respectivas frentes de rajada que acoplam-se com a CBT com temperatura em torno de $5{ }^{\circ} \mathrm{C}$ inferior à temperatura do ar na sua dianteira. A frente de brisa desloca-se rapidamente em direção à costa oeste e forma novas células de tempestades. Pelo campo de fluxo de umidade (fig. 3.20) do solo para atmosfera, verifica-se que um aumento de $2{ }^{\circ} \mathrm{C}$ na TSL intensifica o fluxo em alguns pontos entre 6 a 8 vezes o fluxo de umidade obtido para a simulação com TSL de $23.5^{\circ} \mathrm{C}$ (não mostrado).

Os resultados encontrados estão em acordo com o verificado por Sun et al., [2014] que indica forte sensibilidade das condições atmosféricas na região com pouca variação na TSL. Os resultados iniciais encontrados por essa simulação, deram origem ao interesse em estudar o comportamento climatológico das tempestades sobre essa região que ocorrem, preferencialmente, no período da madrugada. 

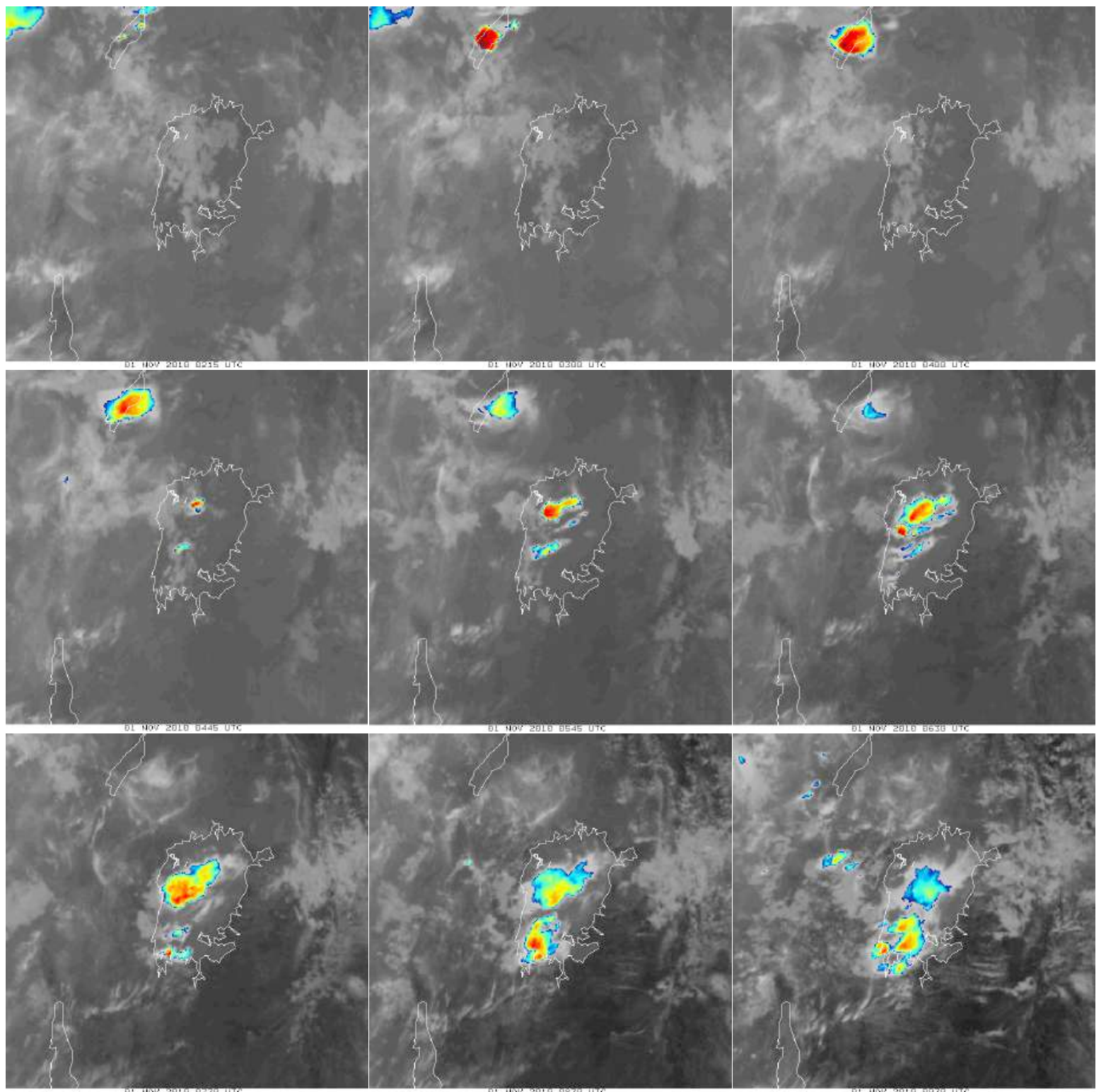

Figura 3.18: Imagens do Satélite METEOSAT realçada do canal infravermelho, para o evento de tempestade de 01 de novembro de 2010, com início no meio da madrugada. Horário UTC está indicado no canto inferior da figura. Está indicado contorno do LV.

Na figura 3.21, nota-se a evolução da circulação de brisa e a formação de frentes de rajada, associadas às tempestades, com intensidade pontual em torno de $110 \mathrm{~km} \mathrm{~h}^{-1}$ em algumas células, já próximo à borda oeste do lago. A área com intensidade do vento em torno de 100 $\mathrm{km} \mathrm{h}^{-1}$ é de $\sim 3 \mathrm{~km}^{2}$. As frentes de rajadas das primeiras células convectivas, contribuem para um aumento da evaporação por onde passa e favorece a formação de novas células (feedback positivo), que se organizam na forma de linha de instabilidade e só perdem intensidade quando atingem terra e o fluxo de umidade superficial cessa. 

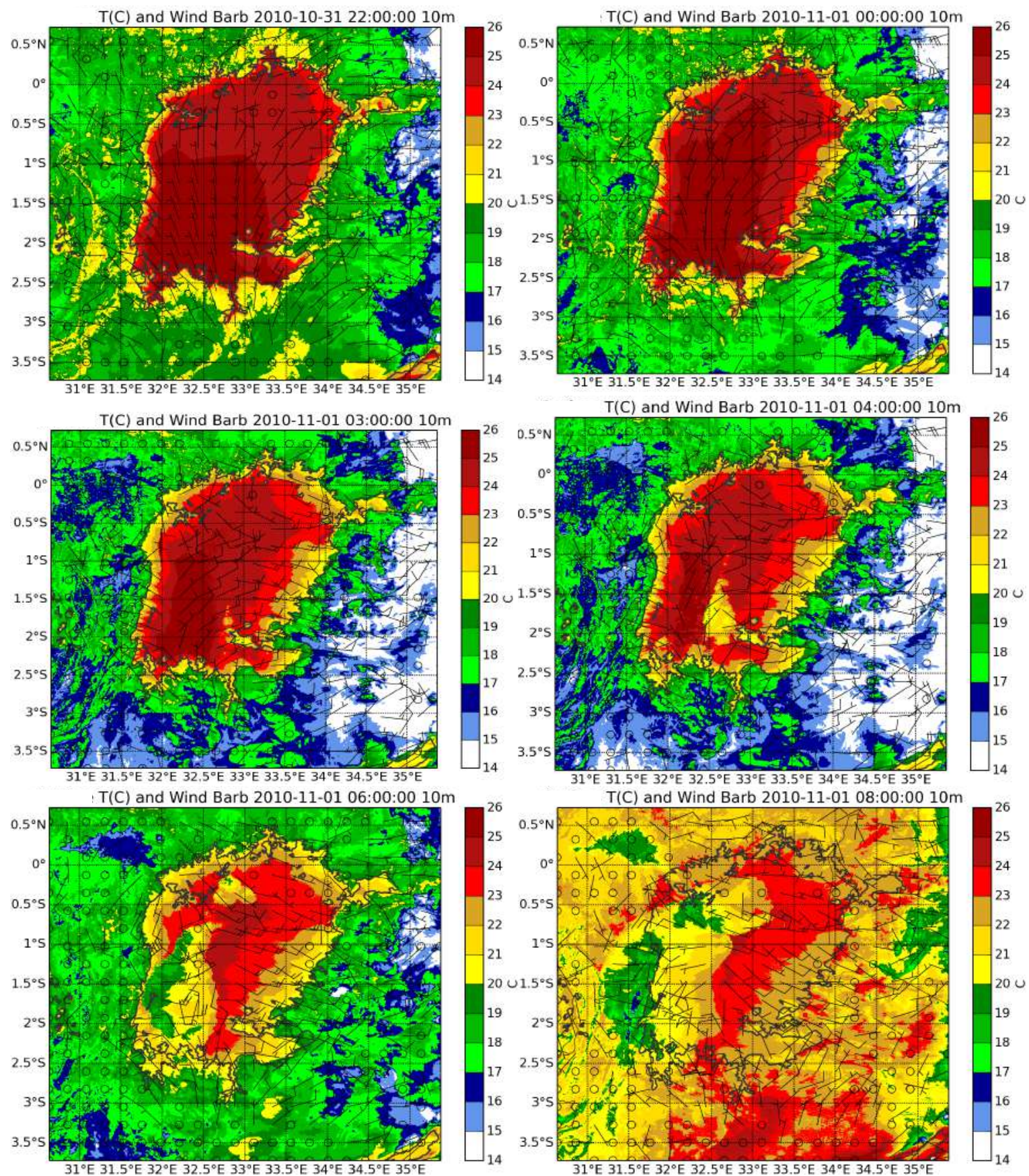

Figura 3.19: Simulação numérica com o modelo ARPS para o evento de 01 de novembro de 2010. Barbelas indicam direção e intensidade do vento (10 m da superfície) e barra de cores indica temperatura do ar em ${ }^{\circ} \mathrm{C}$ no mesmo nível. Resolução espacial da simulação é de $500 \mathrm{~m}$. Título da figura indica horário UTC. Contorno do LV está indicado.

Na figura 3.22, observa-se a temperatura potencial equivalente, calculada da forma:

$\theta_{e}=\theta \exp \left(\frac{L W_{s}}{C_{p} T}\right)$, onde:

$\theta_{e}$ - Temperatura potencial equivalente;

$\theta$ - Temperatura potencial; 
L - Calor latente de condensação;

$\mathrm{W}_{\mathrm{s}}$ - razão de mistura de saturação;

$\mathrm{c}_{\mathrm{p}}$ - Calor específico do ar a pressão constante;

$\mathrm{T}$ - Temperatura do ar para que chegue a saturação;
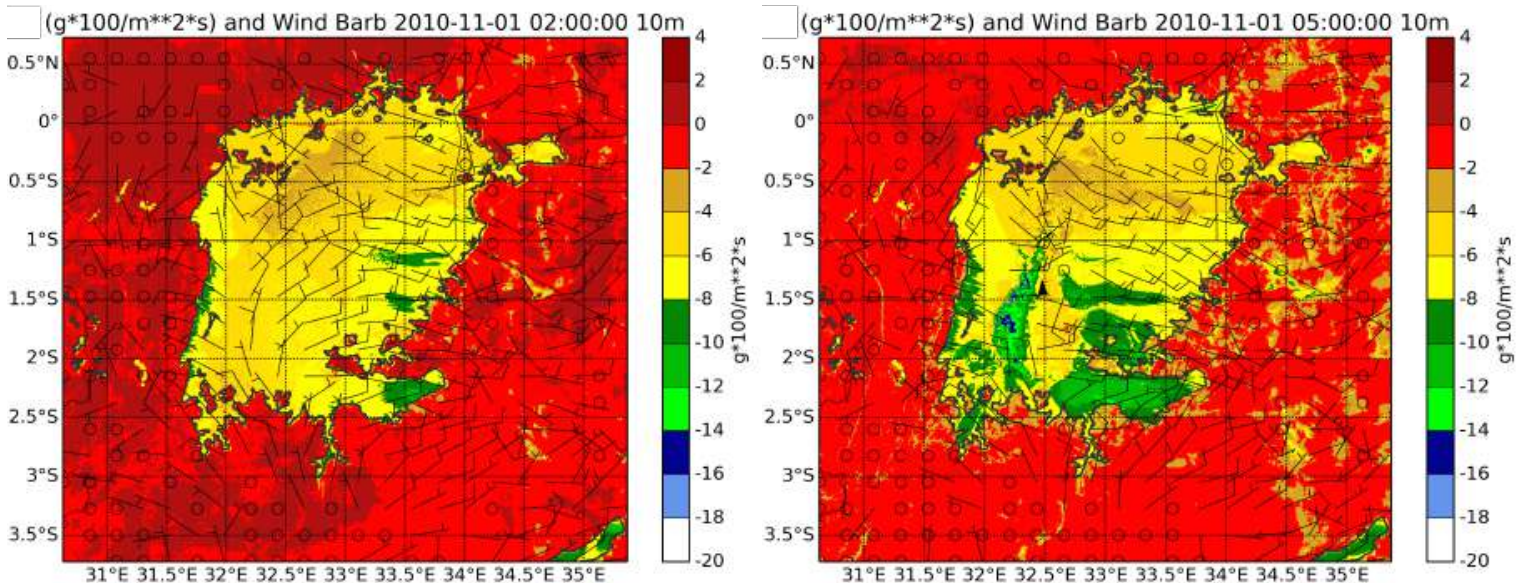

Figura 3.20: Simulação numérica com o modelo ARPS para o evento de 01 de novembro de 2010. Barbelas indicam direção e intensidade do vento (10 m da superfície) e barra de cores indica fluxo de umidade em $\mathrm{g}^{*} 100 / \mathrm{m}^{2} \mathrm{~s}$. A letra g indica grama de vapor de água. Resolução espacial da simulação é de $500 \mathrm{~m}$. Título da figura indica horário UTC. Contorno do LV está indicado.
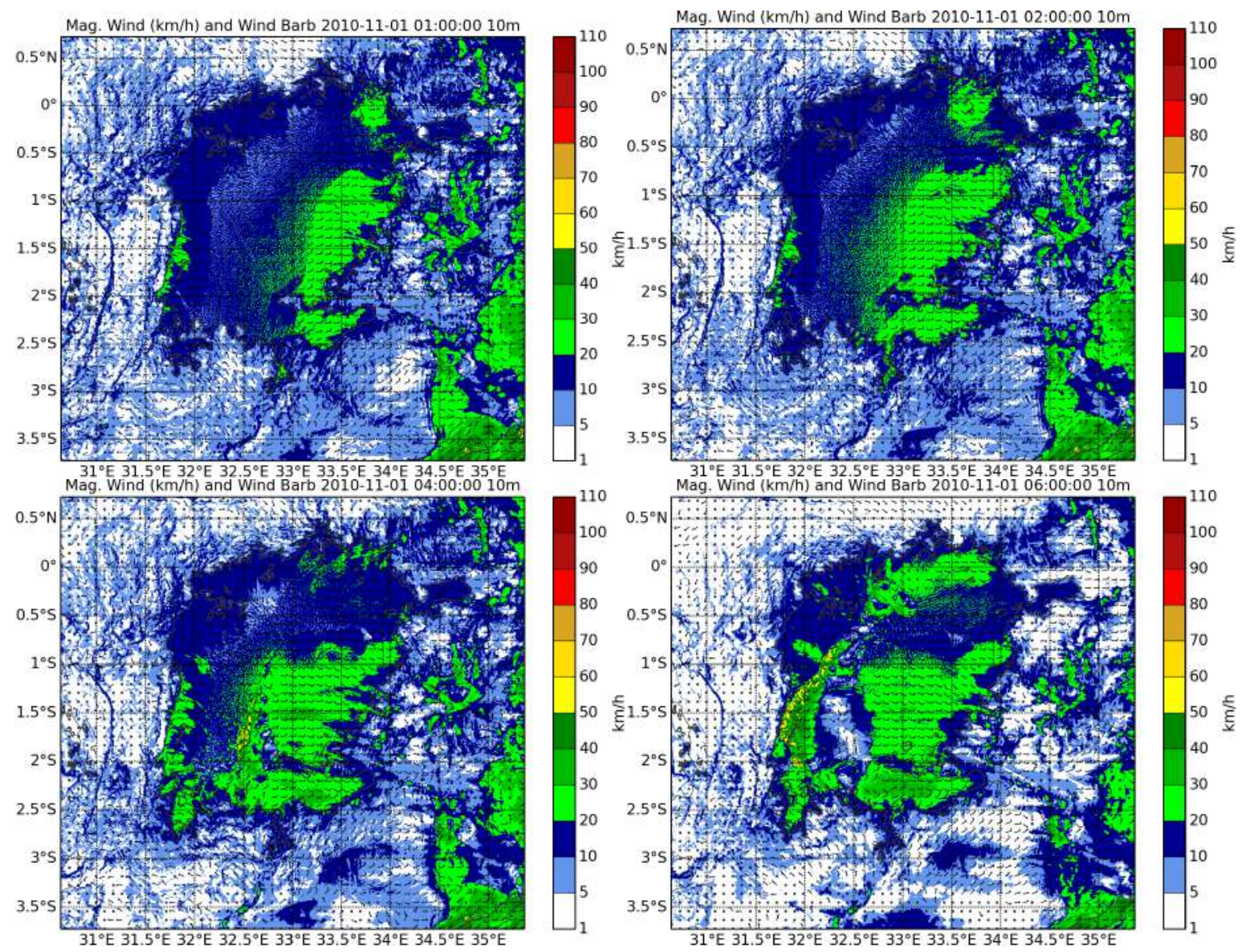

Figura 3.21: Simulação numérica com o modelo ARPS para o evento de 01 de novembro de 2010. Barbelas indicam direção e intensidade do vento ( $10 \mathrm{~m}$ da superfície) e barra de cores indica intensidade $\mathrm{em} \mathrm{km} \mathrm{h}^{-1}$. Resolução espacial da simulação é de $500 \mathrm{~m}$. Título da figura indica horário UTC. 

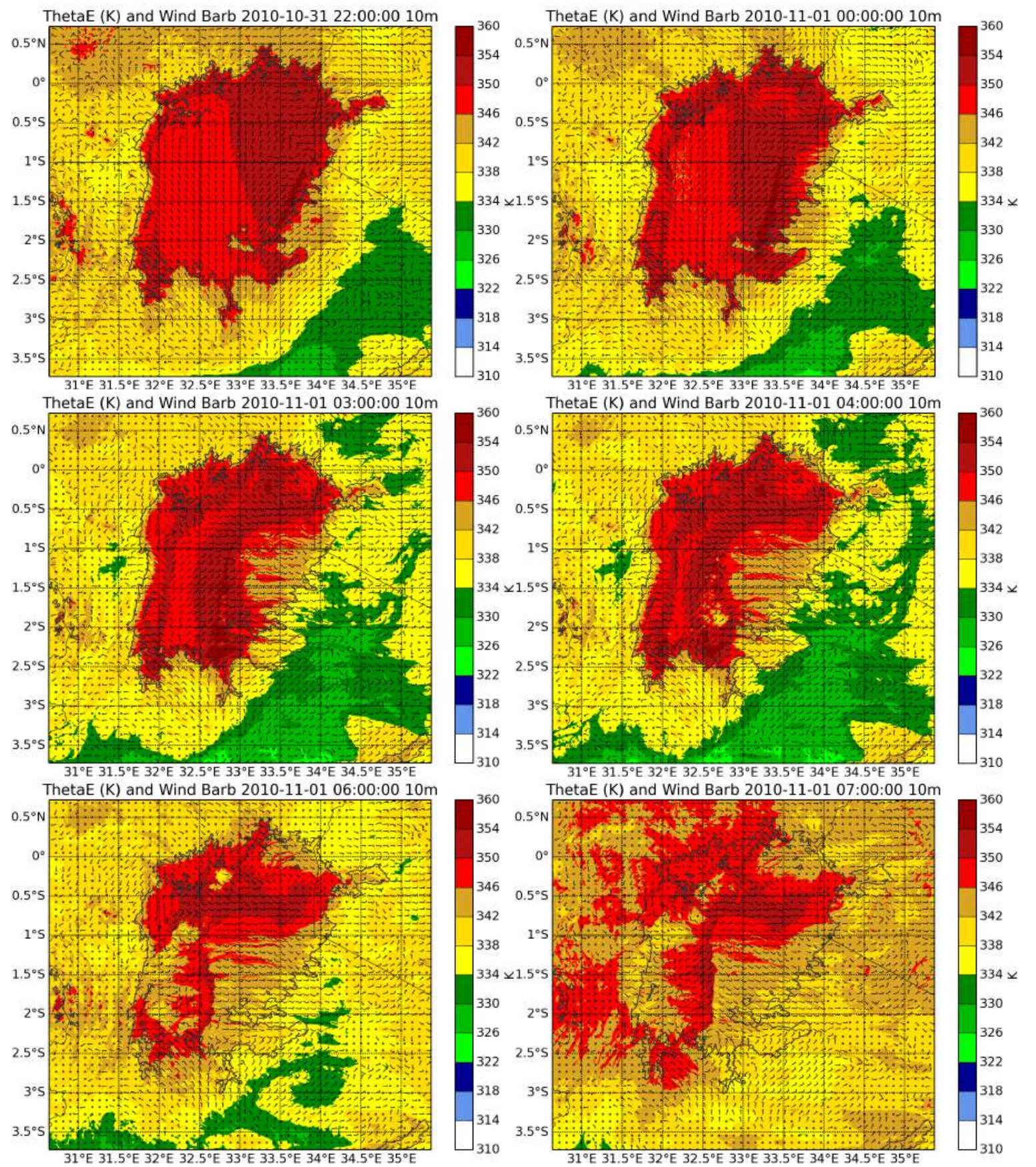

Figura 3.22: Simulação numérica com o modelo ARPS para o evento de 01 de novembro de 2010. Barbelas indicam direção e intensidade do vento (10 $\mathrm{m}$ da superfície) e barra de cores indica temperatura potencial equivalente (K). Resolução espacial da simulação é de $500 \mathrm{~m}$. Título da figura indica horário UTC. Contorno do LV está indicado.

A temperatura potencial equivalente $\left(\theta_{\mathrm{e}}\right)$ é uma variável que combina temperatura do ar e a umidade específica, nessa combinação temos pela figura 3.22 que, cores quentes indicam ar quente e úmido e cores frias indicam ar mais frio e com menor disponibilidade de umidade. A TSL do LV mais aquecido, além de prover maior fluxo de umidade para os níveis mais próximos da superfície, também aumenta a temperatura do ar sobre o mesmo, e fica nítido que, 
a temperatura potencial equivalente no início da madrugada tem a forma do lago, com valores $\theta_{\mathrm{e}}$ em torno de $16 \mathrm{~K}$ acima do simulado no entorno do LV, $350 \mathrm{~K}$ e $334 \mathrm{~K}$, respectivamente.

A circulação de brisa lacustre remove calor e umidade principalmente da borda leste do lago, com convergência da mesma. A frente de brisa, "acumula" mais calor e umidade à sua dianteira, até que seja suficiente para disparar o processo de convecção, que se inicia na interação entre essa frente com maior disponibilidade de umidade e a topografia da ilha situada no sudeste do LV. O processo convectivo se retroalimenta até a borda oeste do LV, com redução de $\theta_{\mathrm{e}}$. O perfil vertical de $\theta_{\mathrm{e}}$ será mostrado posteriormente.

O campo da componente vertical da vorticidade relativa (fig. 3.23) calculado pela equação (2) a 29 metros de altura acima indica o valor da rotação pontual do fluido em torno do eixo $\mathrm{z}$.

$$
\zeta_{z}=\frac{\partial v}{\partial x}-\frac{\partial u}{\partial y}
$$

Notam-se estruturas finas na forma de linha que se propagam desde a borda leste do LV, tal que a mesma, separa uma região com valores próximos de 0 de vorticidade vertical de uma região com valores em módulo acima de $10^{-4} \mathrm{~s}^{-1}$. Essa linha se propaga para oeste, e acompanha a frente de brisa lacustre. A sua fronteira, é uma região de turbulência, que separa ar mais frio que anteriormente desceu das montanhas de ar mais quente e úmido. Em um determinado momento, essa fronteira de vorticidade relativa converge com outra gerada por uma pequena linha no sul do lago, na posição $2^{\circ} \mathrm{S}$ e $33^{\circ} \mathrm{E}$ as $0300 \mathrm{UTC}$, essa interação geram as primeiras células convectivas da simulação. As células convectivas, geram frentes de rajada que se acoplam com a CBT e aumentam a vorticidade vertical da frente de brisa e novas células convectivas. Por volta das 0600 UTC, a estrutura fina de máxima vorticidade vertical chega à costa oeste do lago mais intensa do que inicialmente. Também, nesse campo, fica evidente que a CBL de oeste fica confinada na borda oeste do lago e não se propaga para leste. Visualmente, fica mais nítido a identificação das frentes de rajada e de brisa por meio do campo de vorticidade relativa em alta resolução espacial $(500 \mathrm{~m})$.

Fica evidente que, mesmo no decorrer do período da manhã, essa linha tênue com máxima vorticidade vertical se propaga para longe do lago a uma velocidade média de aproximadamente $10 \mathrm{~m} \mathrm{~s}^{-1}$, ou seja, supondo velocidade constante, o deslocamento de ar mais frio relacionado a esta tempestade chegaria à floresta do Congo entre 1200 UTC e 1300 UTC ou 1500 HL e 1600 HL e pode intensificar a convecção vespertina sobre a floresta do Congo, a $300 \mathrm{~km}$ de distancia da borda oeste do LV. 

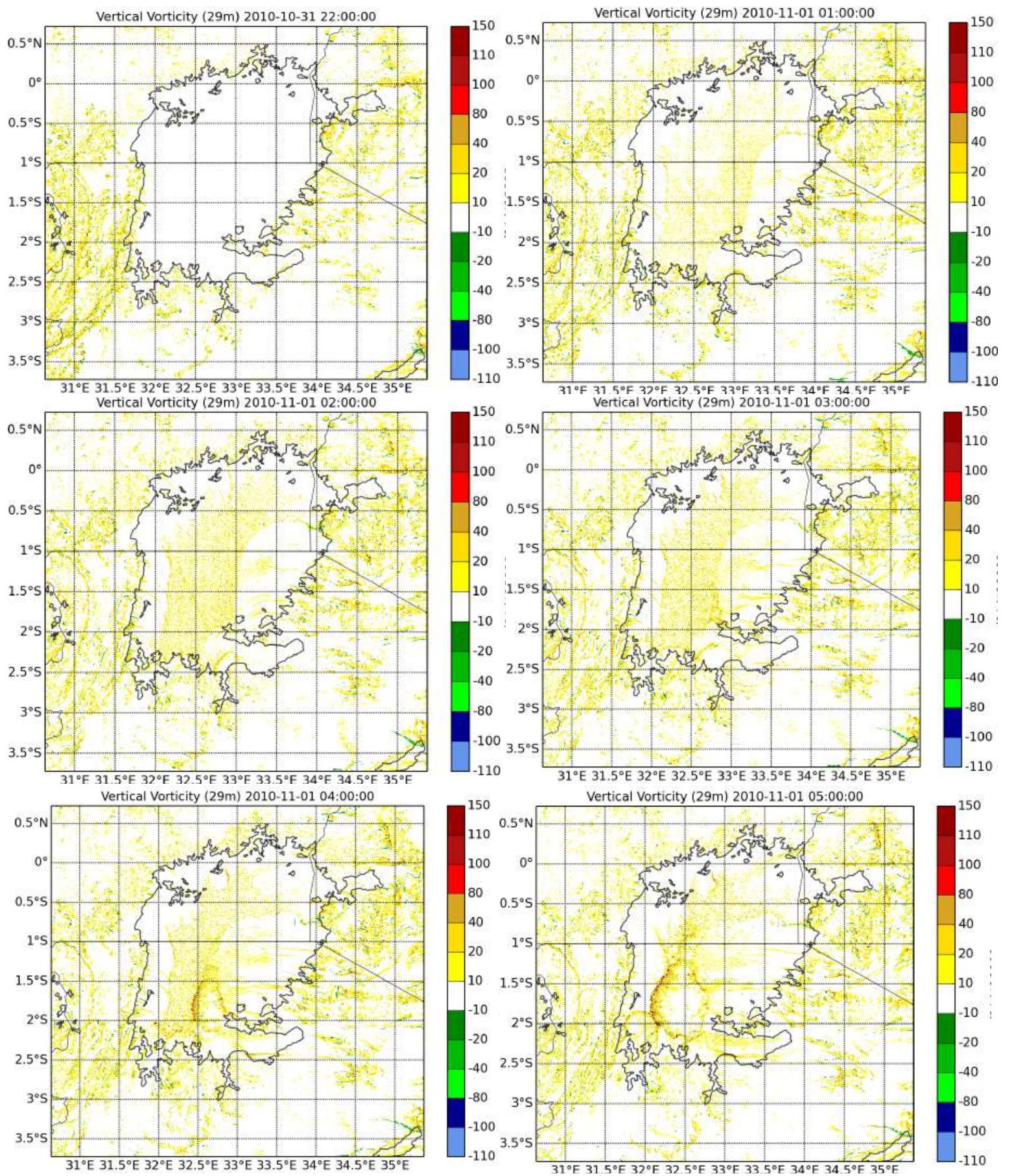

Figura 3.23: Campo de vorticidade vertical da simulação numérica com o modelo ARPS para o evento de 01 de novembro de 2010. Resolução espacial da simulação é de $500 \mathrm{~m}$. Barra de cores indica vorticidade relativa $\mathrm{em} \mathrm{s}^{-1} 10^{-5}$. Título da figura indica horário UTC. 

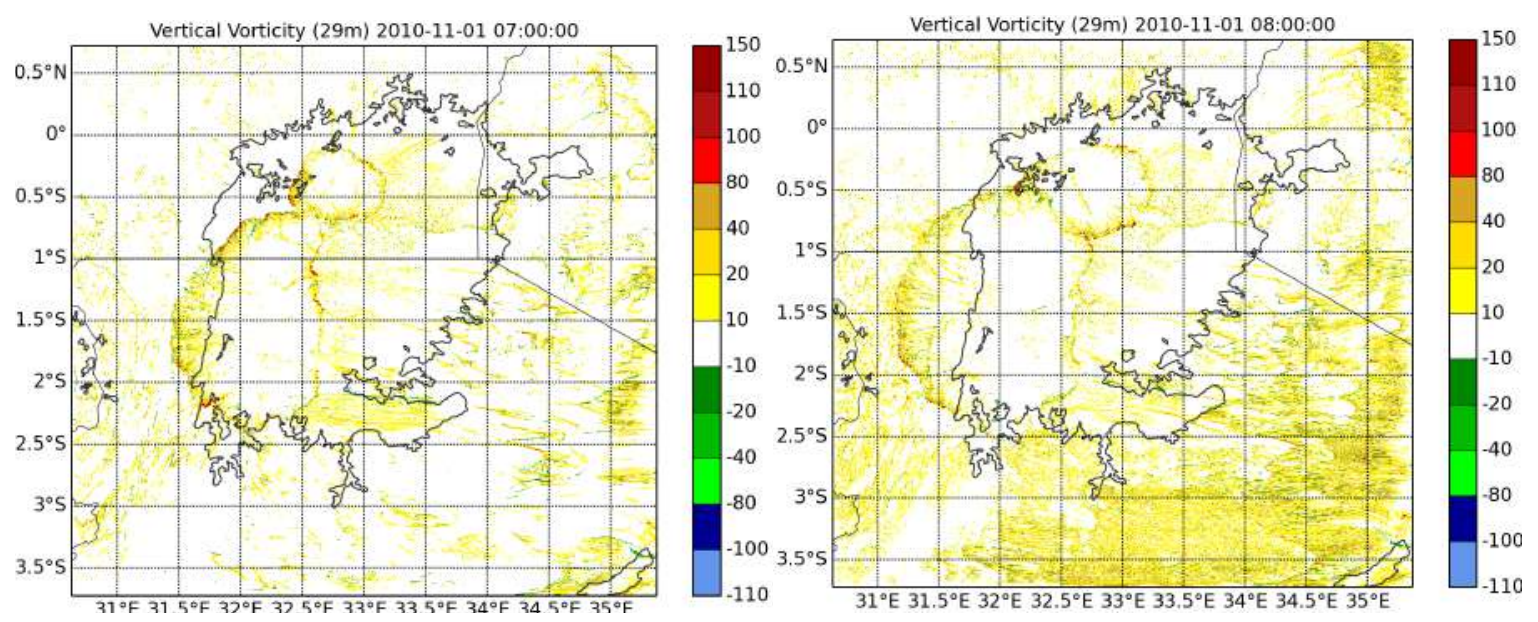

Figura 3.23: Continuação.

A espessura da CBL na borda oeste do lago é de $\sim 500 \mathrm{~m}$, enquanto que a proveniente da borda leste foi estimada em aproximadamente $1500 \mathrm{~m}$, conforme será mostrado posteriormente. A CBL de leste atua no mesmo sentido da circulação sinótica predominante nessa região que é de leste para oeste e favorece uma CBL mais espessa. Por outro lado, a CBL da borda oeste fica confinada nessa região do lago já que se desloca contra a circulação sinótica. A máxima velocidade vertical simulada na tempestade produzida sobre o LV pela interação das circulações locais chega a $35 \mathrm{~m} \mathrm{~s}^{-1}$ (figura 3.24) e é condizente com o tipo de fenômeno que é relatado em superfície associado a fortes rajadas de vento e até mesmo à formação de ondas sobre o LV.
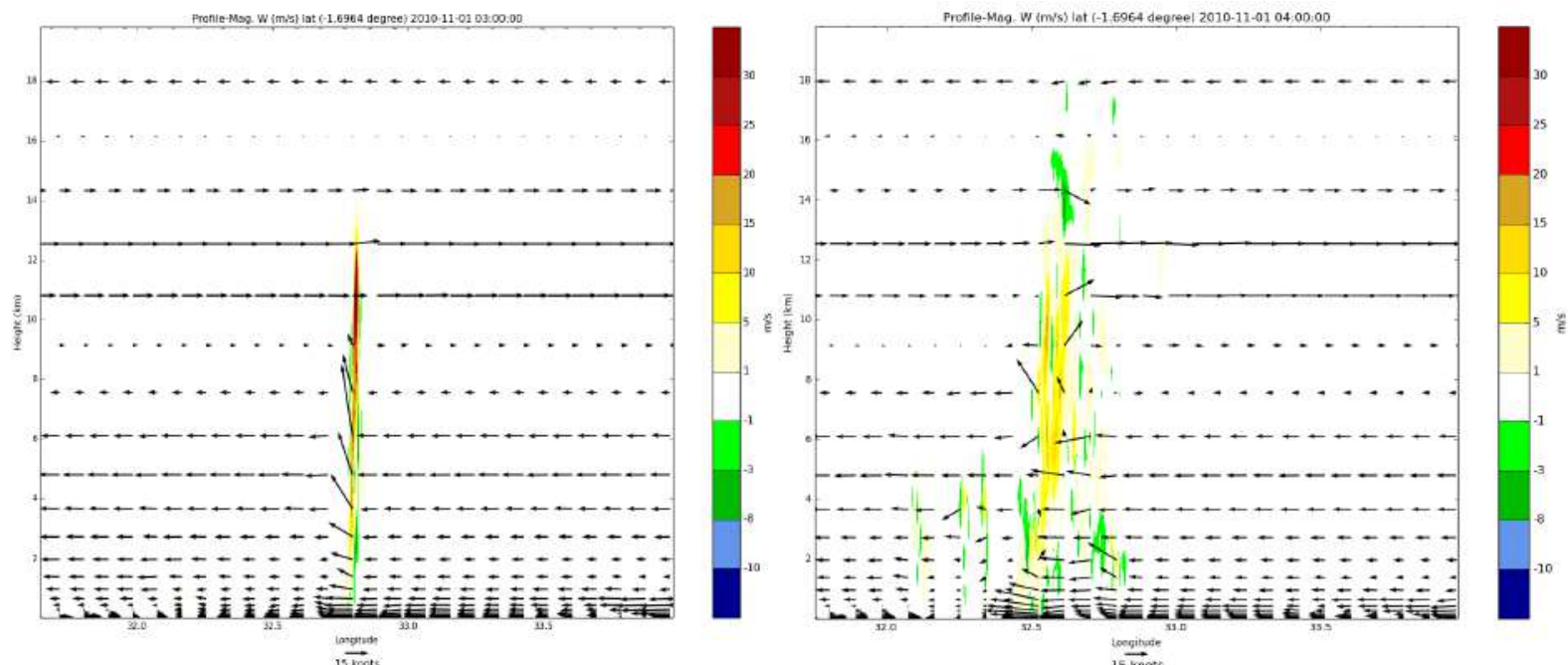

Figura 3.24: Secção vertical de componente zonal e vertical do vento e magnitude para a simulação numérica com o modelo ARPS do evento de 01 de novembro de 2010. Vetor indica direção e intensidade do vento e a barra de cores indica intensidade do vento vertical $\mathrm{em} \mathrm{m} \mathrm{s}^{-1}$. Corte vertical foi feito em 1.7 ${ }^{\circ} \mathrm{S}$ de latitude. Da esquerda para a direita, o horário do corte foi as 0300 e $0400 \mathrm{UTC}$, respectivamente, 


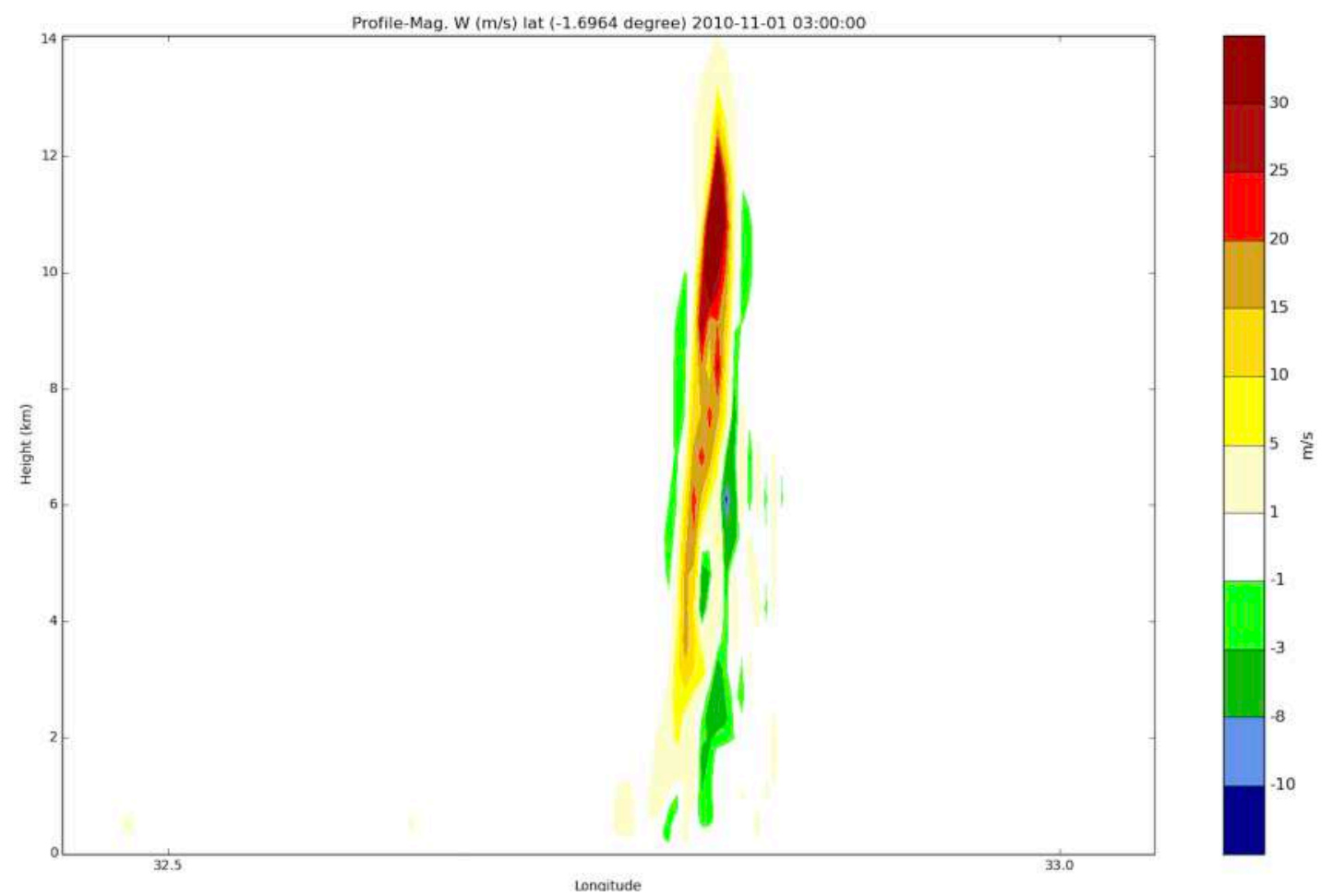

Figura 3.25: Similar a figura 3.24, mas com zoom sobre a região de máxima velocidade vertical da tempestade. Barra de cores indica intensidade da componente vertical do vento $\mathrm{em} \mathrm{m} \mathrm{s}^{-1}$ as 0300 UTC.

A figura 3.25, mostra um zoom no horário de máxima intensidade das correntes ascendentes no interior da tempestade. No centro da mesma, nota-se velocidade vertical máxima de até 35 $\mathrm{m} \mathrm{s}^{-1}$ a aproximadamente $10 \mathrm{~km}$ acima da superfície. A leste deste centro, os movimentos descendentes chegam a $8 \mathrm{~m} \mathrm{~s}^{-1}$ e estão associados a chuvas intensas e a formação das frentes de rajada que se acoplam com a CBL em superfície. O sentido de propagação da tempestade, é de leste para oeste e conforme nota-se na figura, na CLP, na dianteira do sistema encontra-se os movimentos ascendentes e na traseira os movimentos de subsidência que alimentam as rajadas de vento.

A circulação de brisa cria rolos horizontais [Xue e Martin, 2002] que tendem a estirar junto com os movimentos de convecção. Eles geram a estrutura fina de vorticidade vertical da figura 3.23 proveniente da conversão de vorticidade horizontal em vertical. As frentes de rajada que alimentam o processo de convecção ao longo da frente de brisa, criam rolos horizontais com maior vorticidade horizontal e que, como consequência, se convertem em vorticidade vertical maior, que explica o aumento em módulo dos valores de vorticidade vertical da figura 3.23. 

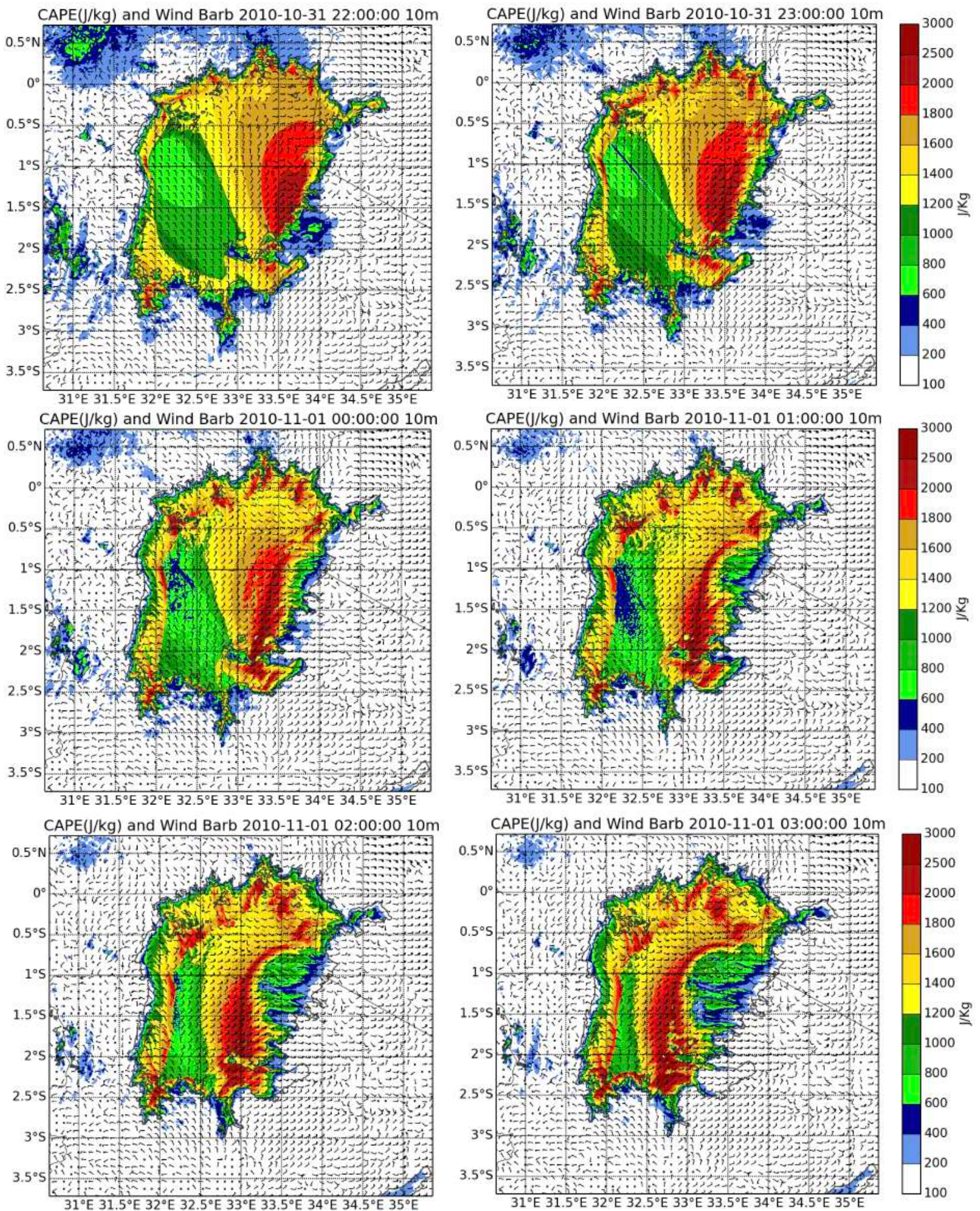

Figura 3.26: Campo de CAPE e vento para a simulação numérica com o modelo ARPS para o evento de 01 de novembro de 2010. A barbela indica direção e intensidade do vento e a barra de cores indica energia disponível para a convecção (CAPE) em $\mathrm{J} \mathrm{kg}^{-1}$. Simulação realizada com 500 metros de resolução. Título da figura indica horário UTC. 

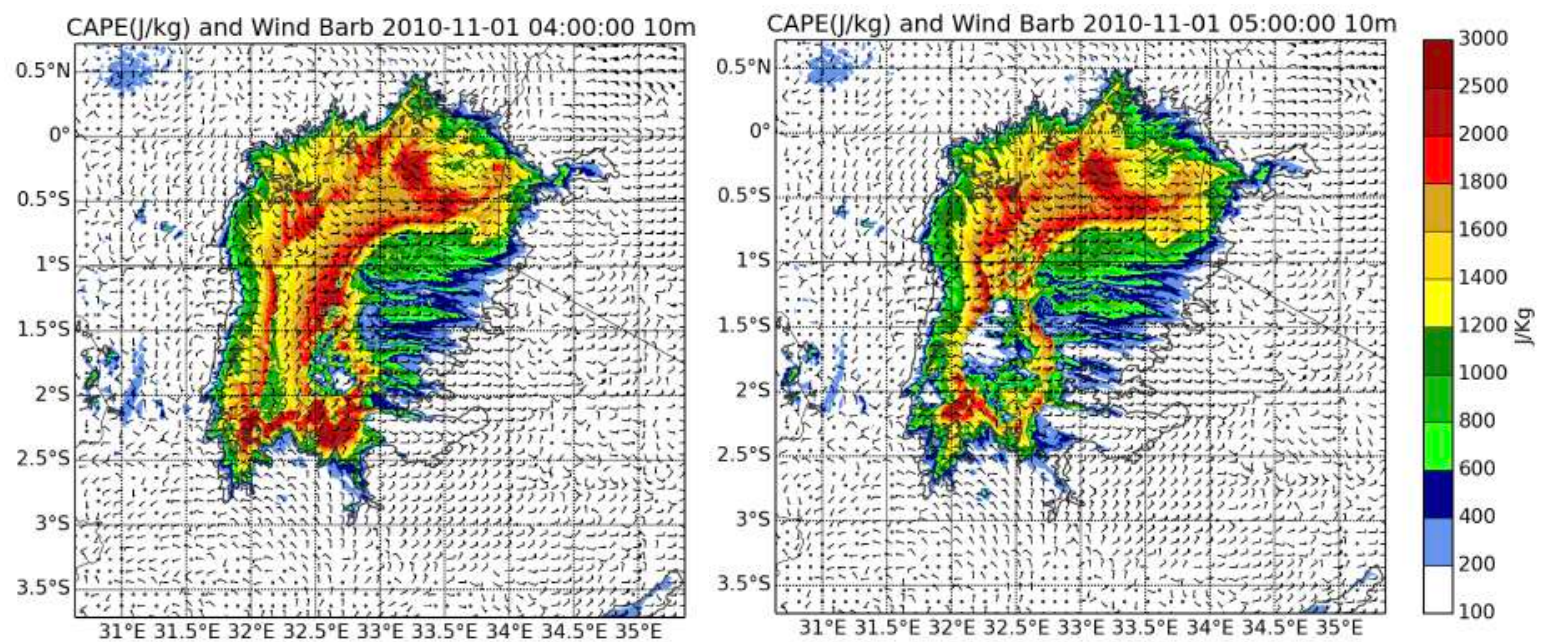

Figura 3.26: Continuação.

A frente de brisa que se propaga de leste para oeste, tende a criar uma região com máximo local de CAPE (fig. 3.26) que aumenta junto com a mesma, conforme se desloca pelo LV e se alimenta do fluxo de calor latente entre o lago e o ar. Durante sua propagação, nota-se aumento da CAPE na forma de linha que chega a atingir valores acima dos $2500 \mathrm{~J} \mathrm{~kg}^{-1}$ e coincide com a linha tênue de máximo local da vorticidade vertical (3.23), suficiente para instabilizar a atmosfera e disparar a convecção.

Os primeiros resultados mostraram alta performance do ARPS em estimar as principais variáveis que dão origem às tempestades noturnas sobre o LV. O mesmo simulou o acoplamento das interações entre as circulações locais de CBL e CBVM no aumento dos fluxos de calor latente e sensível sobre o lago que deram origem ao processo convectivo noturno próximo à borda oeste do LV. Nota-se, que a convecção se inicia antes mesmo da convergência entre as 2 frentes de CBL das 2 bordas do lago e isso se dá basicamente devido à instabilização da CLP por meio da advecção de ar mais frio e seco da borda leste do lago sobre a superfície aquecida do LV. Os fluxos de calor latente e sensível aumentam a temperatura e a umidade específica no primeiro nível acima do solo, na frente de brisa, esse aumento ocorre gradualmente e é transferido para os níveis acima, conforme ocorre o deslocamento da CBL o que, em determinado momento, torna o ambiente suficiente instável e propício ao disparo da convecção. $\mathrm{O}$ encontro entre as 2 frentes de CBL amplifica a convecção formada previamente. Além disso, conforme ficou demonstrado na figura 3.23, as frentes de rajadas também são disparadas durante esse processo e a interação das mesmas entre si e com a própria CBL formam outras áreas de convecção em um processo bastante complexo. Assim, o monitoramento dessas linhas tênues, que representam a separação entre massas de ar com diferentes densidades é 
importante na identificação de áreas onde pode ocorrer a formação de novas células convectivas [Atkins e Wakimoto, 1997].

Em suma, as configurações das grades ARPS foram baseadas nos resultados desse primeiro experimento e com base nos estudos de Chamberlain et al., [2013] onde se definiram as 3 grades de simulação para todos os estudos posteriores $(12 \mathrm{~km}, 4 \mathrm{~km}$ e $500 \mathrm{~m})$. Outros testes foram realizados para grade com configuração de $32 \mathrm{~km}, 8 \mathrm{~km}, 2 \mathrm{~km}$ e $500 \mathrm{~m}$, no entanto, essa última configuração demanda mais tempo de máquina, além de ter produzido resultados semelhantes logo, optou-se pelo conjunto menos dispendioso em termos de custo computacional.

\subsubsection{Análise da convecção noturna de 01/11/2010}

As simulações com o ARPS indicam a sensibilidade na formação das tempestades convectivas com relação à TSL do LV. Os experimentos foram realizados com padrão espacial de TSL similares aos obtidos por Anyah [2005], com TSL menor no leste do lago e maior a oeste. A figuras 2.3 indicam as 3 configurações de TSL utilizadas nas simulações.

De modo geral, a configuração da TSL altera basicamente a amplitude dos acumulados, mas o posicionamento da formação das tempestades pouco se altera, conforme indicado na figura 3.27 .

Para o padrão da figura $2.3 \mathrm{a}$ e $2.3 \mathrm{~b}$, mesmo com diferenças no padrão espacial da TSL, notou-se que a máxima amplitude da precipitação ficou concentrada basicamente na mesma região, no setor sudoeste do lago. Para essas 2 primeiras simulações a temperatura média do lago foi similar e de $24.5^{\circ} \mathrm{C}$ enquanto, na terceira simulação, diminuiu-se a TSL média do lago para $23.5^{\circ} \mathrm{C}$ e concentrou-se os maiores valores na região com a máxima acumulação estimada pelo CMORPH. O último padrão (fig. 2.3c) diminuiu a amplitude dos núcleos de máxima acumulação em basicamente toda a região do lago atingida pela precipitação, embora o posicionamento da mesma não tenha se alterado.

Os resultados obtidos confirmam Sun et al., [2015], que afirma que a distribuição espacial da TSL, quase não altera a amplitude e o posicionamento da chuva das chuvas e a TSL média do LV é mais importante do que propriamente sua distribuição pelo LV.

A evolução temporal do perfil vertical de $\theta_{\mathrm{e}}$ (fig. 3.28) para uma das simulações indica que basicamente os efeitos físicos associados ao disparo da convecção estão associados ao deslocamento da frente de brisa terrestre, que ao propagar-se sobre o lago aquecido aumenta a evaporação sobre o mesmo, com aumento do fluxo de calor latente e consequente aumento de 
$\theta_{\mathrm{e}}$. Conforme a frente de brisa se propaga, gera-se uma onda de $\theta_{\mathrm{e}}$, que aumenta sua altura com o tempo. Em determinado momento, os fluxos associados a essa onda de $\theta_{\mathrm{e}}$ atingem o nível de convecção espontânea (NCE) e então inicia-se o processo de disparo convectivo com formação de tempestades. As correntes descendentes das primeiras células convectivas estabilizam o nível abaixo e a onda se divide em 2, sendo que uma permanece semi-estacionária e a outra propaga-se em direção a costa oeste do lago e alimenta a linha de tempestade formada até atingir a borda oeste do lago, onde inicia-se o processo de desintensificação.

Os processos físicos associados às tempestades explicam o fato de que a TSL média influencia muito mais a fase e a amplitude da precipitação do que a própria distribuição de TSL em si, isso porque como a frente de brisa se propaga de leste para oeste, ela passa pela maior parte do lago e o montante do fluxo de calor latente associado ao seu deslocamento fica mais diretamente relacionado com a TSL média por onde a frente de brisa se deslocou.

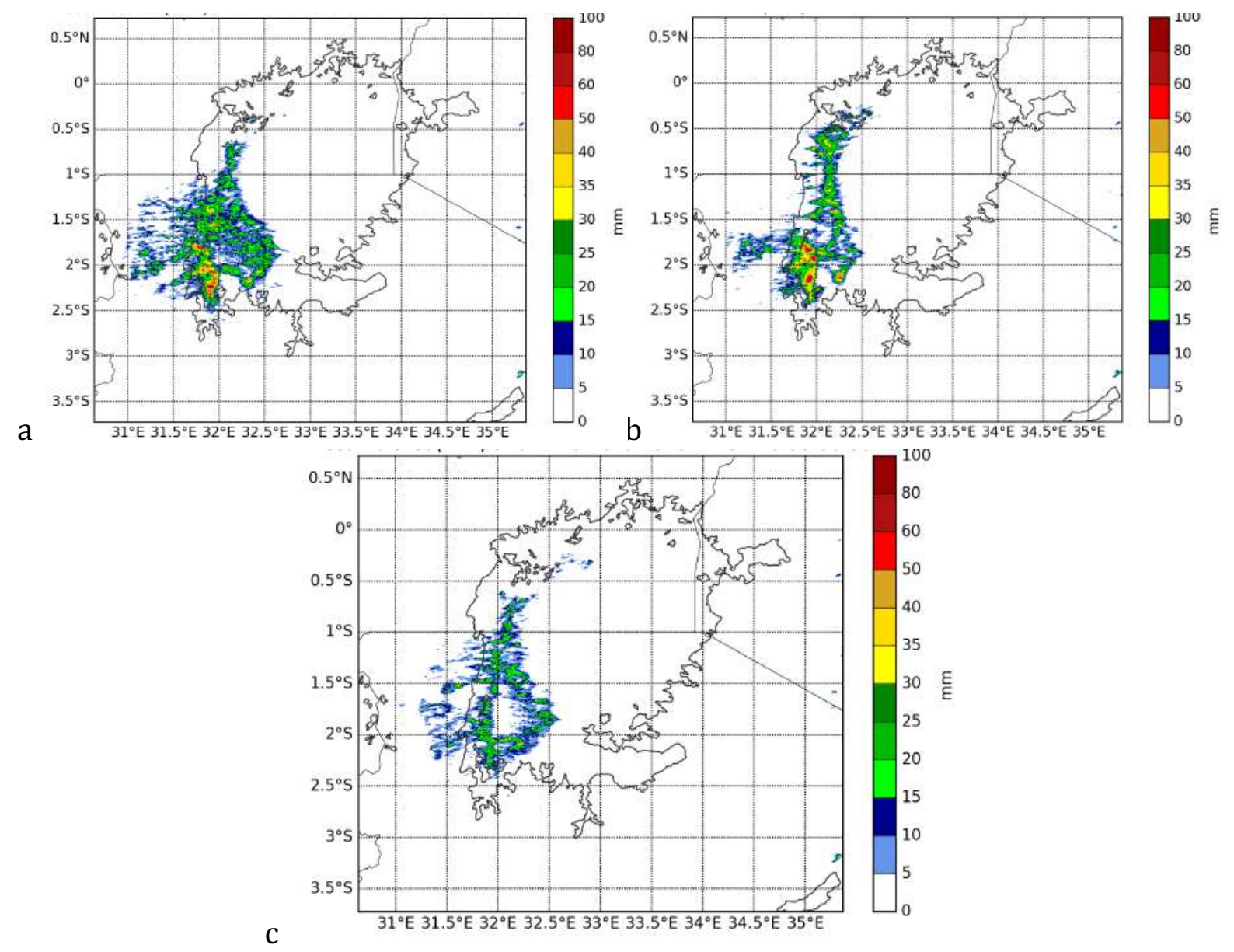

Figura 3.27: Chuva acumulada para o período entre 0000 e 0900 HL (hora local) para as configurações de TSL da figura 2.3a, b e c com a, b e c, respectivamente. Simulação com 500 metros de resolução espacial. Contorno do LV está indicado. Barra de cores indica chuva acumulada em $\mathrm{mm}$. 
Assim, explica-se o fato de que alterar a temperatura na costa oeste do lago, pouco alterou a fase da precipitação, já que o disparo da convecção ocorreu antes da frente de brisa de leste atingir essa região. As maiores diferenças referem-se a amplitude da chuva.
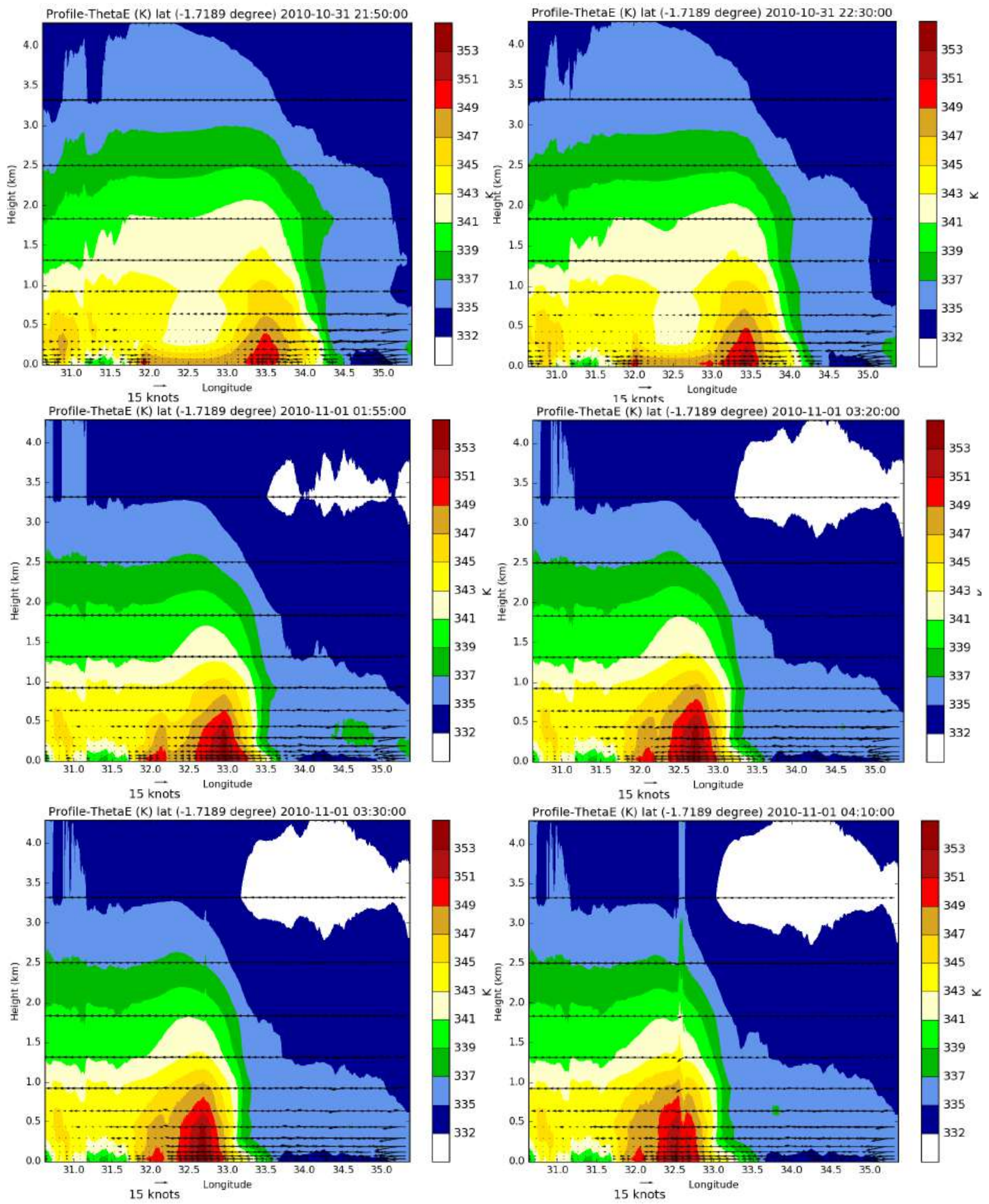

Figura 3.28: Perfil vertical de $\theta_{\mathrm{e}}$ para a latitude de $1.7^{\circ} \mathrm{S}$. Utilizou-se a média dos 50 cortes mais a norte e mais a sul para remoção de ruído ocasionado por células convectivas muito localizadas. Simulação com 500 metros de resolução espacial. Barra de cores indica $\theta_{\mathrm{e}} \mathrm{em} \mathrm{K}$. 

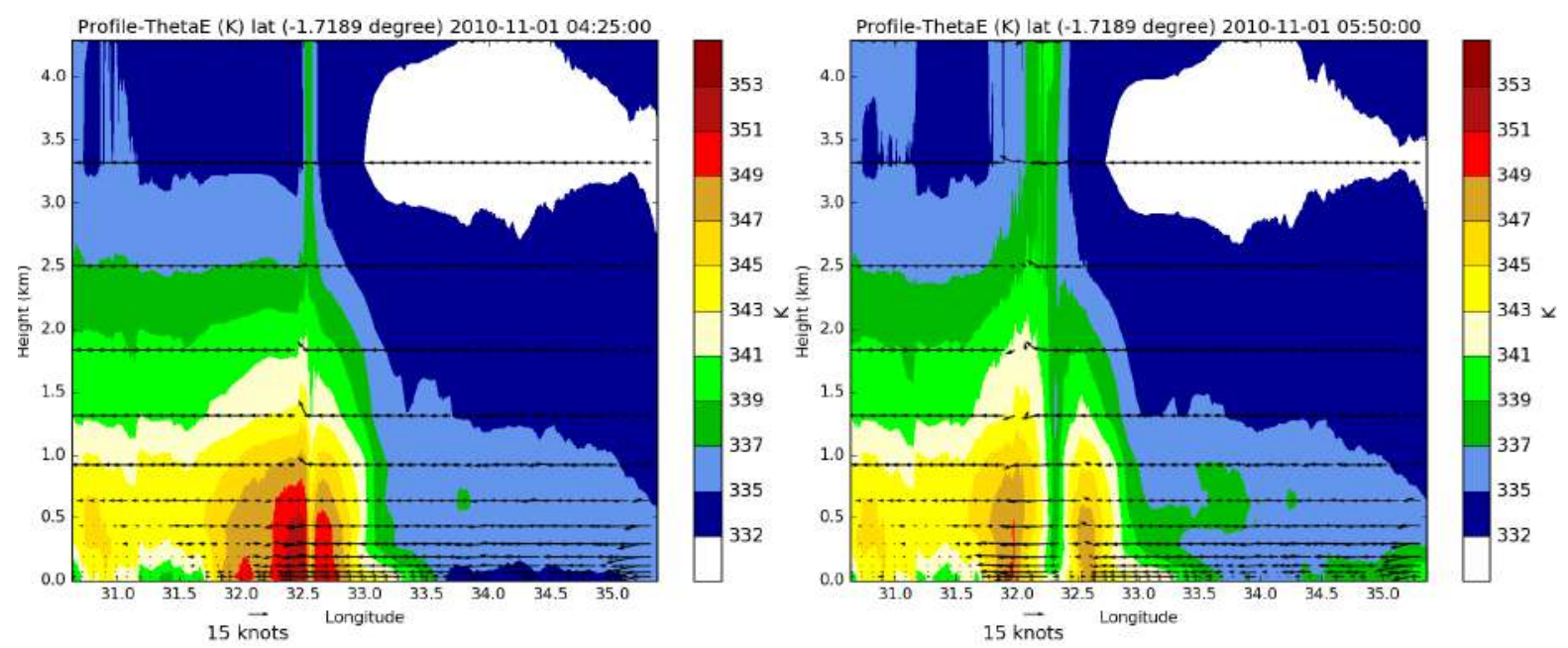

Figura 3.28: Continuação.
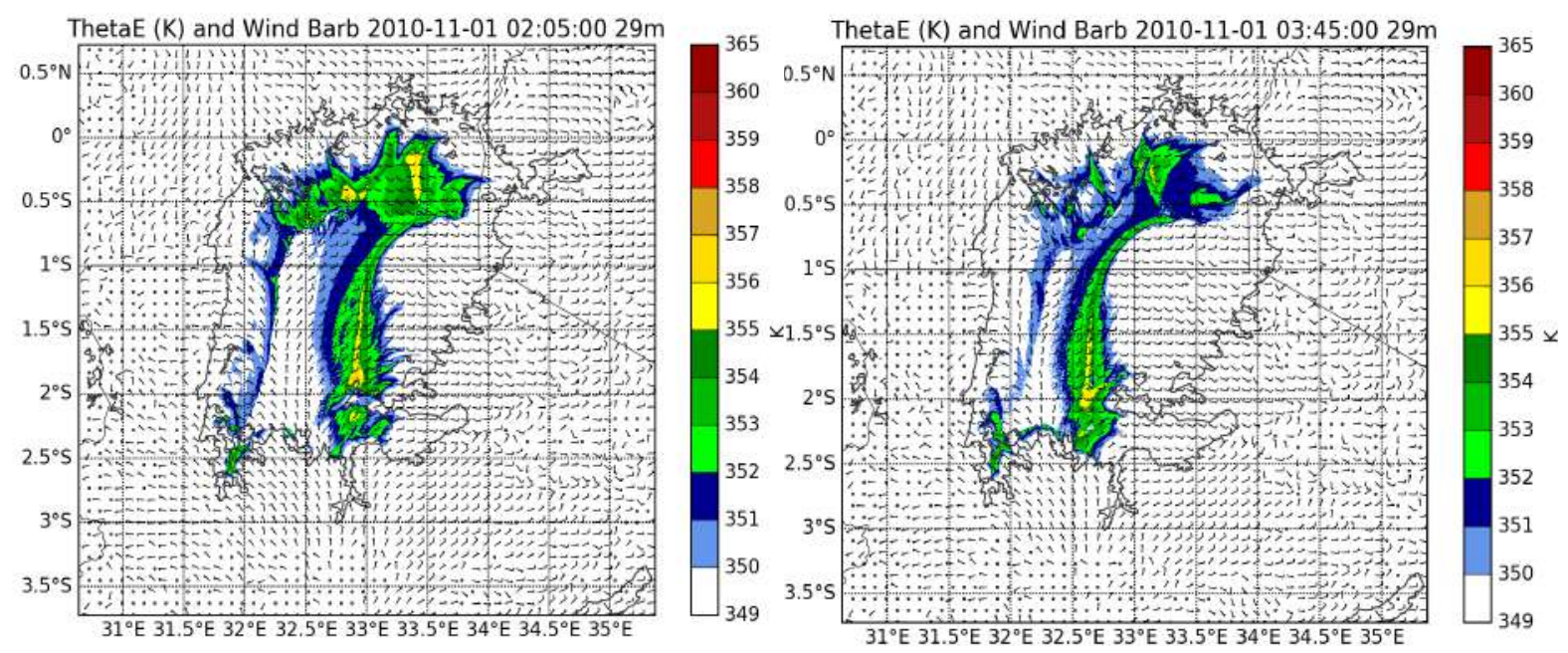

Figura 3.29: Distribuição horizontal de $\theta_{\mathrm{e}}$ à 29 metros acima da superfície. Contorno do LV está indicado. Simulação numérica realizada com 500 metros de resolução espacial. Barra de cores indica $\theta_{\mathrm{e}}$ em K.

A figura 3.29 indica que existe um máximo de $\theta_{\mathrm{e}}$ próximo à superfície e que está associado a CBL que avança de leste. Enquanto na metade sul do LV a frente de brisa se propaga com orientação mais linear em latitude, no norte do lago a mesma se propaga de modo difluente, ou seja, parte da CBL inclina para norte, isso acaba influenciando em menores valores de $\theta_{\mathrm{e}}$ embora a TSL do lago nessas 2 regiões do lago sejam iguais. A difluência dos ventos nessa região favorece subsidência atmosférica com transporte de ar seco de níveis mais altos para próximo da superfície, que resulta em menores valores de $\theta_{\mathrm{e}}$ e baixa ou nenhuma acumulação. Pela borda oeste do lago, também se observa uma linha com máximo $\theta_{\mathrm{e}}$ local associado à frente terrestre de oeste. Porém, dado que a intensidade da mesma é muito menor que a frente proveniente de leste os valores máximos são até $5 \mathrm{~K}$ menores que o observado na CBL de leste. Além disso, essa frente fica bloqueada nessa região devido a circulação sinótica de leste nos 
níveis acima (contra a frente de brisa) associado aos alísios de leste e limitam a propagação da frente de brisa terrestre.

O efeito de cadeia de montanhas a leste do lago para a geração da CBVM foi importante e pode ser verificado nas simulações que indicam que o ar mais frio, que desce a cadeia de montanhas no período noturno, gera uma frente de brisa terrestre de leste que posteriormente dispara a convecção na metade oeste do lago. No entanto, é nítido que enquanto a frente de brisa de leste se propaga por todo o lago, a de oeste fica "confinada" muito próximo à borda leste do LV. Parte disso, ocorre devido à própria cadeia de montanhas a leste apresentar altitudes menores e mais distantes do lago das que estão no oeste e isso, por si só, gera uma circulação local mais enfraquecida, dado que a declividade entre a costa do lago e a região montanhosa é menor. No entanto, isso por si só não explica uma frente de brisa tão fraca e rasa como verificado na figura 3.28, com a frente de brisa de oeste a uma altitude inferior a 150 metros. Nessa região da África equatorial os ventos predominantes são os alísios que sopram de leste para oeste e que atuam durante todo o ano, com menor ou maior intensidade, sempre na mesma direção. Até os médios níveis, verifica-se essa configuração no padrão dos ventos sinóticos.

A figura 3.30 mostra o perfil vertical médio entre $1.6^{\circ} \mathrm{S}$ e $1.8^{\circ} \mathrm{S}$ da somatória de água de nuvem (Qc), água de chuva (Qr) e gelo de nuvem (Qi) e indica a evolução da convecção sobre o LV, desde a formação das primeiras células convectivas até a dissipação da mesma sobre o lago. Entre 0150 UTC e 0425 UTC, observa-se o deslocamento da CBL de oeste na somatória de Qc+Qr+Qi com valores entre 0.1 e $0.3 \mathrm{~g} \mathrm{~kg}^{-1}$ e espessura entre $150 \mathrm{~m}$ e $300 \mathrm{~m}$. As primeiras nuvens convectivas surgem por volta das 0430 UTC, acima dessa camada da CBL, a uma altura entre $2 \mathrm{~km}$ e $5 \mathrm{~km}$ acima da superfície. Esse deslocamento da CBL de oeste parece ser importante para o aparecimento das primeiras células. A CBL de leste já atua na região, nesse mesmo horário, conforme figura 3.29, embora não seja perceptível no aumento dos valores de Qc+Qr+Qi. Em aproximadamente 10 minutos, a convecção evoluí e as nuvens mais desenvolvidas apresentam base a $1 \mathrm{~km}$ com topo em $6.5 \mathrm{~km}$ acima da superfície. As 0445 UTC, surgem as primeiras Cumulus-Nimbus $(\mathrm{Cb})$ com topo acima dos $16 \mathrm{~km}$ com intensa precipitação em superfície. A convecção evoluí na próxima hora e as 0550 UTC, o centro de massa dos Cb's que antes situava-se entre 2 e $3 \mathrm{~km}$ acima da superfície, chega a $4 \mathrm{~km}$ nas nuvens mais desenvolvidas verticalmente. Sobre o LV, a evolução da convecção continua até as 0600UTC, com o centro de massa dos Cb's próximo a $5 \mathrm{~km}$ de altura. A partir daí, nota-se chuva mais intensa em superfície com o centro de massa da tempestade caindo rapidamente em direção ao solo. Entre as 0600 UTC e 0600 UTC o centro de massa caí quase $3 \mathrm{~km}$ (para 
aproximadamente $2 \mathrm{~km}$ acima da superfície) e na hora seguinte a linha de tempestades avança rapidamente para oeste.
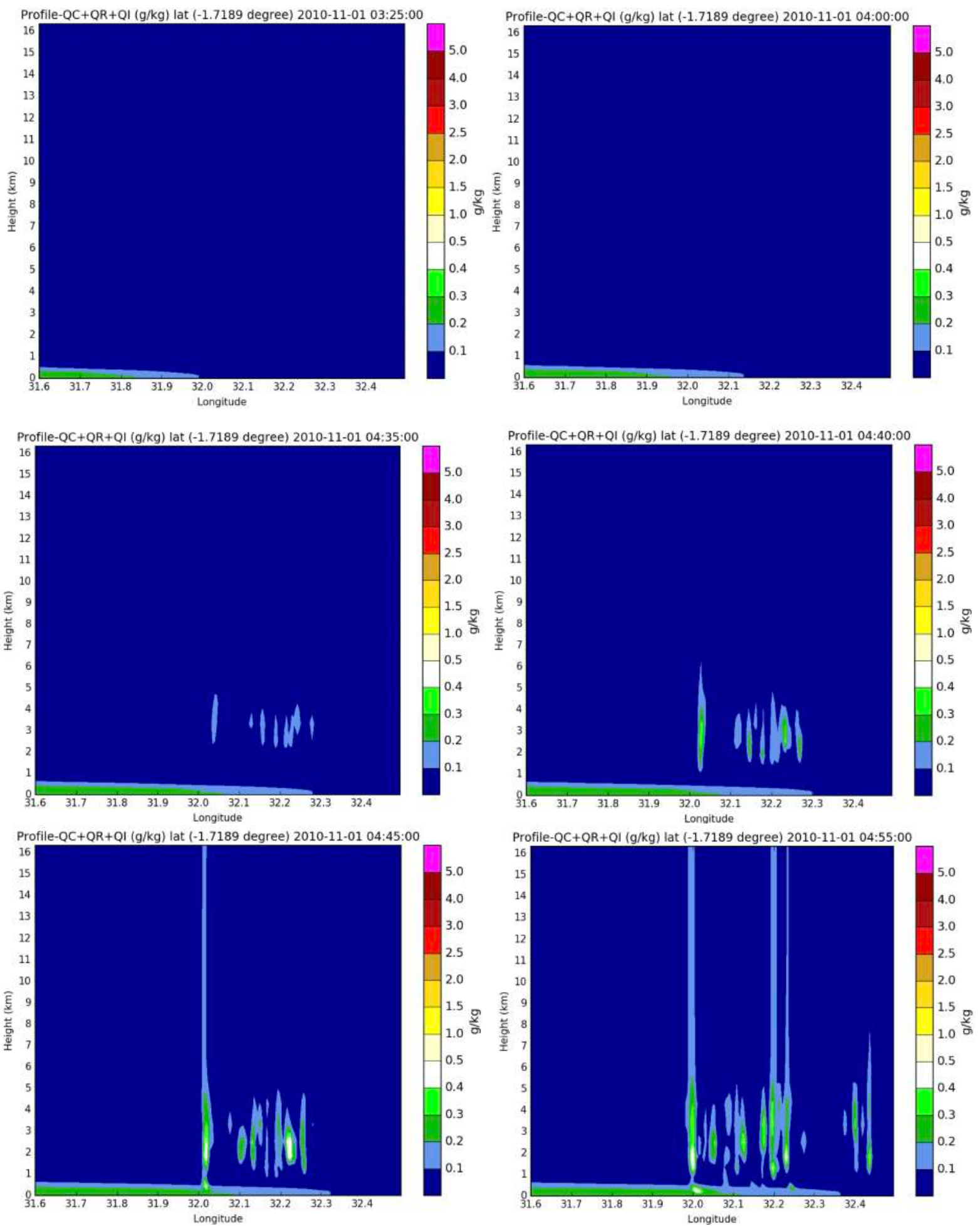

Figura 3.30: Perfil vertical médio entre as latitudes $1.6^{\circ} \mathrm{S}$ e $1.8^{\circ} \mathrm{S}$ da somatória de Qc+Qr+Qi (água de nuvem + água de chuva + gelo em $\mathrm{g} \mathrm{kg}^{-1}$, respectivamente). Simulação com 500 metros de resolução espacial, com corte entre as longitudes $31.6^{\circ} \mathrm{E}$ e $32.5^{\circ} \mathrm{E}$. Barra de cores em $\mathrm{g} \mathrm{kg}^{-1}$. 

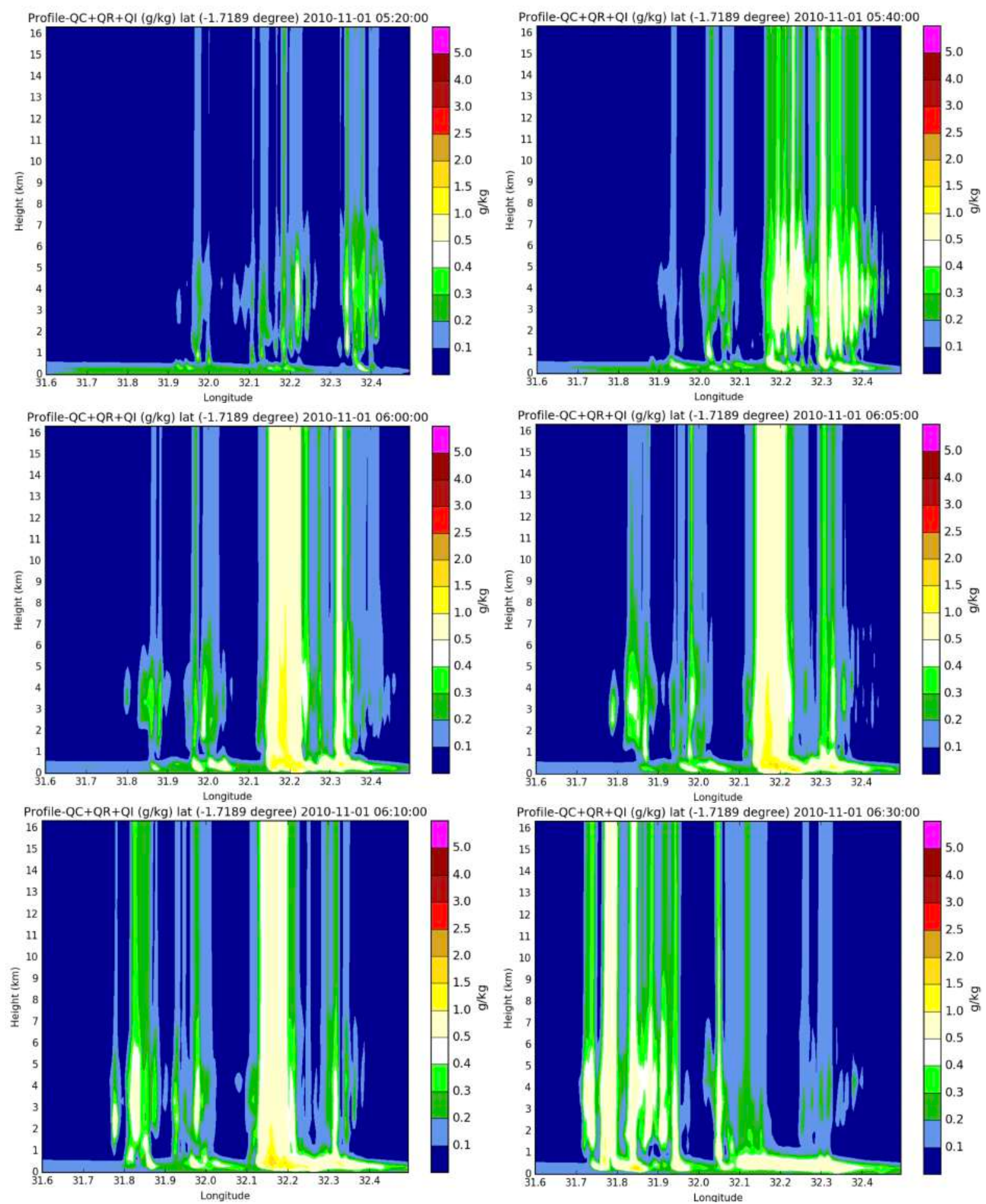

Figura 3.30: Continuação.

Por trás da evolução da convecção mostrada na figura 3.30, existem processos dinâmicos complexos associados a advecção e geração de vorticidade vertical. Esses processos podem ser calculados por meio dos termos da equação de tendência de vorticidade vertical. Os termos foram calculados nas simulações com 500 metros de resolução de acordo com a equação 3 : 


$$
\begin{gathered}
\frac{\partial \zeta_{z}}{\partial t}=\left(-u \frac{\partial \zeta_{z}}{\partial x}-v \frac{\partial \zeta_{z}}{\partial y}\right)+\left(-w \frac{\partial \zeta_{z}}{\partial z}\right)+\left(-v \frac{\partial f}{\partial y}\right)+\left(-(\zeta+f)\left(\frac{\partial u}{\partial x}+\frac{\partial v}{\partial y}\right)\right)+ \\
\left(\frac{\partial w}{\partial y} \frac{\partial u}{\partial z}-\frac{\partial w}{\partial x} \frac{\partial v}{\partial z}\right) \\
\text { (3), onde: }
\end{gathered}
$$

$\zeta_{z}-$ Vorticidade vertical em s${ }^{-1}$

$u$ - Componente zonal do vento em $\mathrm{m} \mathrm{s}^{-1}$;

$v$ - Componente meridional do vento em $\mathrm{m} \mathrm{s}^{-1}$;

$w$ - Componente vertical do vento em $\mathrm{m} \mathrm{s}^{-1}$;

$f$ - Vorticidade planetária em s $\mathrm{s}^{-1}$;

O termo sombreado em amarelo e verde é a contribuição para o aumento da vorticidade vertical local com o tempo, dado pela advecção horizontal e vertical, respectivamente. O termo sombreado em vermelho refere-se ao aumento da advecção de vorticidade vertical dado pela advecção de vorticidade planetária. Dado que a área de estudo se localiza na região equatorial ( $\mathrm{f} \sim 0$ ), é possível negligenciar esse termo. Em cinza, temos o termo de divergência, ou de estiramento. Basicamente, a vorticidade local ciclônica, diminui (aumenta) se há divergência (convergência) local. Por último, temos o termo de inclinação sombreado em azul claro, que se refere a conversão de vorticidade horizontal em vorticidade vertical, conforme esquema da figura 3.31 .

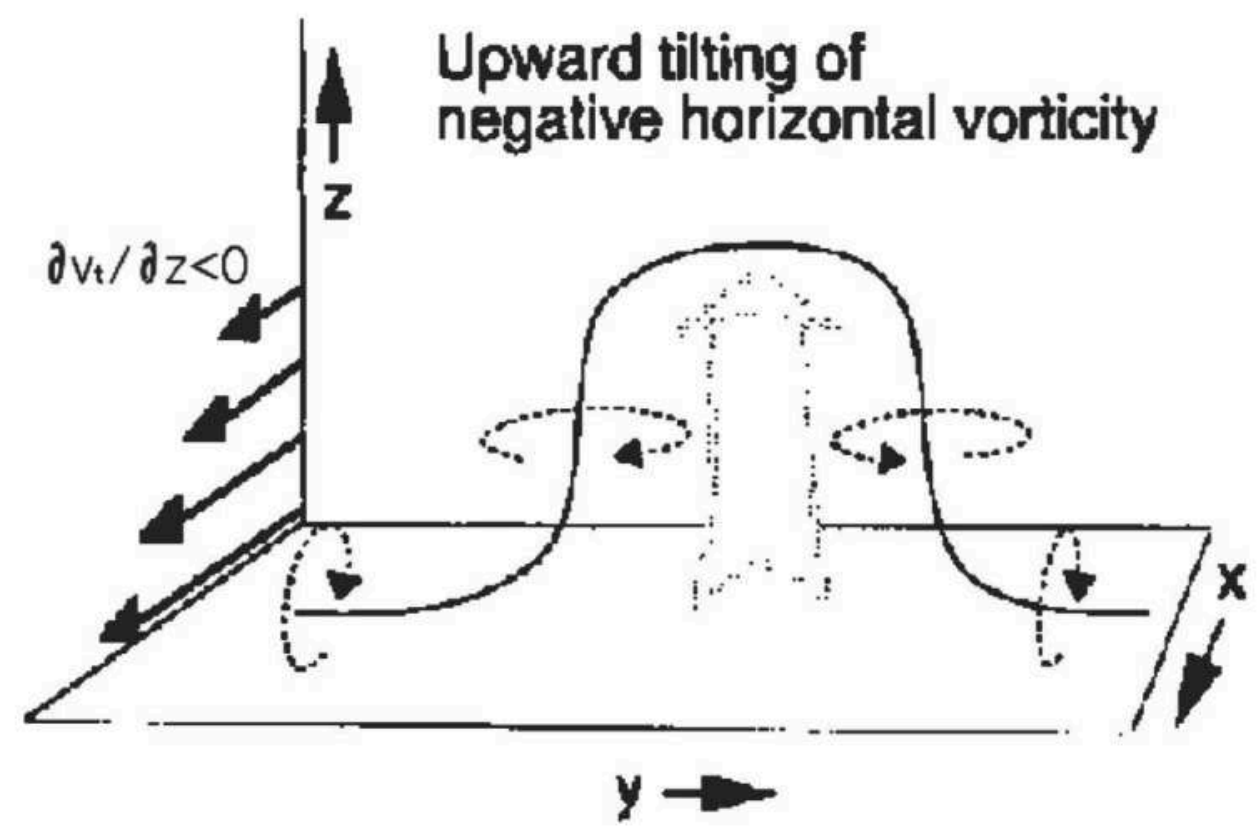

Figura 3.31: Esquema da geração de vorticidade vertical através da inclinação de vórtice horizontal. O eixo X representa direção tangencial e y a radial. Movimentos ascendentes inclinam o rolo em ambos os lados e produz rotação ciclônica de um lado e anticiclônica do outro. Fonte: Franklin et al., [2006]. 

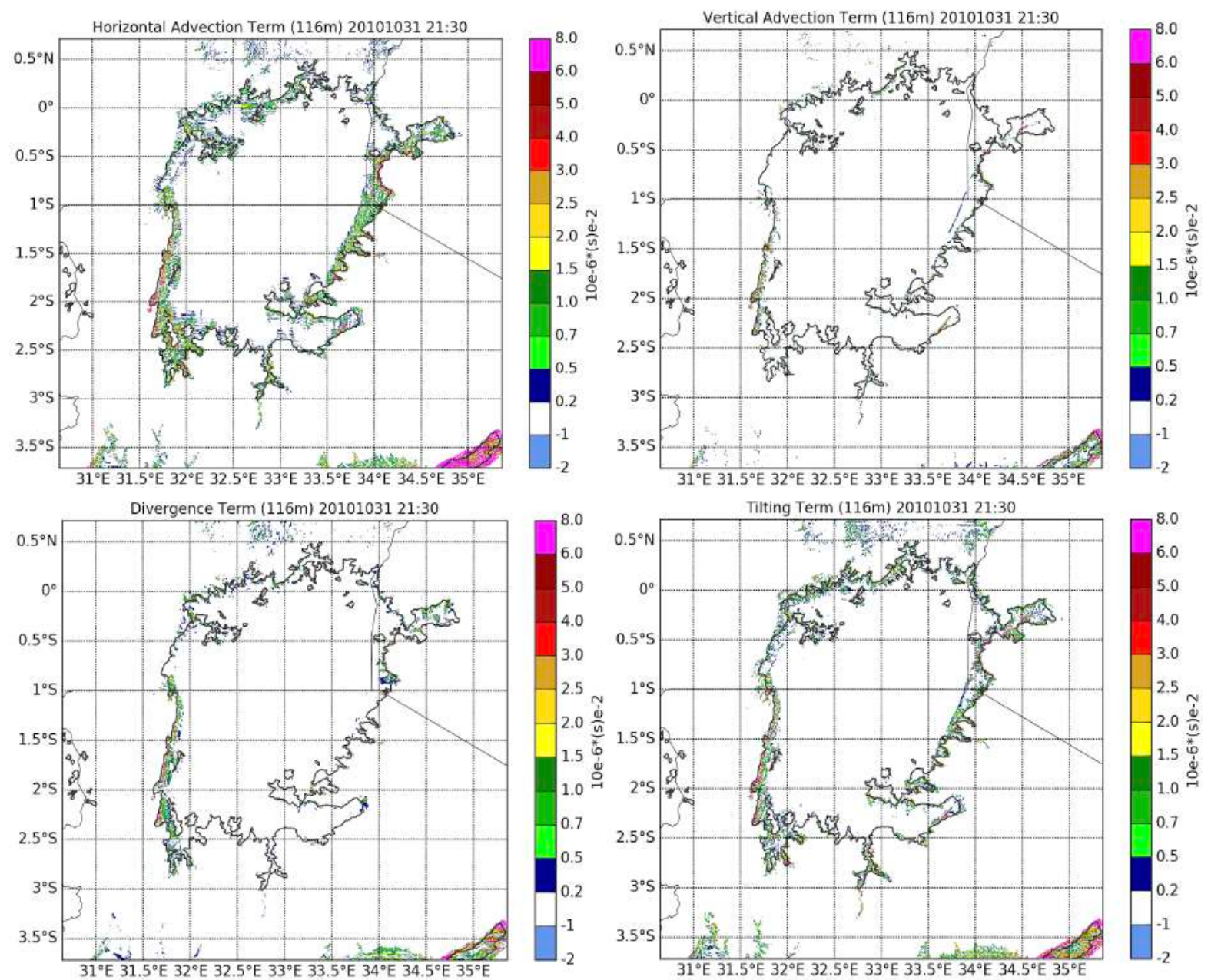

Figura 3.32: Campo horizontal dos termos da equação de tendência da vorticidade vertical (3) à 116 metros acima da superfície às 2130 UTC. Os termos calculados foram os de advecção horizontal e vertical, termo de divergência e inclinação, indicados no titulo da figura. Contorno do LV está indicado. Simulação numérica realizada com 500 metros de resolução espacial. Barra de cores indica contribuição de cada termo em s- ${ }^{2} 10^{-6}$.

De acordo com o indicado na figura 3.32, nota-se o efeito do descolamento das frentes de brisa nas bordas leste e oeste do LV. As 2130 UTC, na dianteira da CBL, nota-se que a maior contribuição para o aumento da vorticidade vertical ocorre pelo termo de inclinação $\left(\sim 10^{-6} \mathrm{~s}^{-2}\right)$ ou seja, conversão de rolos horizontais em vórtices com rotação no eixo z, seguido pelo termo de advecção horizontal $\left(\sim 0.5^{*} 10^{-6} \mathrm{~s}^{-2}\right)$, vertical $\left(\sim 0.2 * 10^{-6} \mathrm{~s}^{-2}\right)$ e o termo de divergência (< $\left.0.1^{*} 10^{-6} \mathrm{~S}^{-2}\right)$ é o que apresenta a menor contribuição para o aumento da vorticidade na dianteira da frente de brisa. Na traseira da CBL, o termo de advecção horizontal aumenta e passa a apresentar a maior contribuição na equação 3, embora com valores próximos ao termo de inclinação. O mesmo comportamento é verificado na CBL proveniente de oeste. 

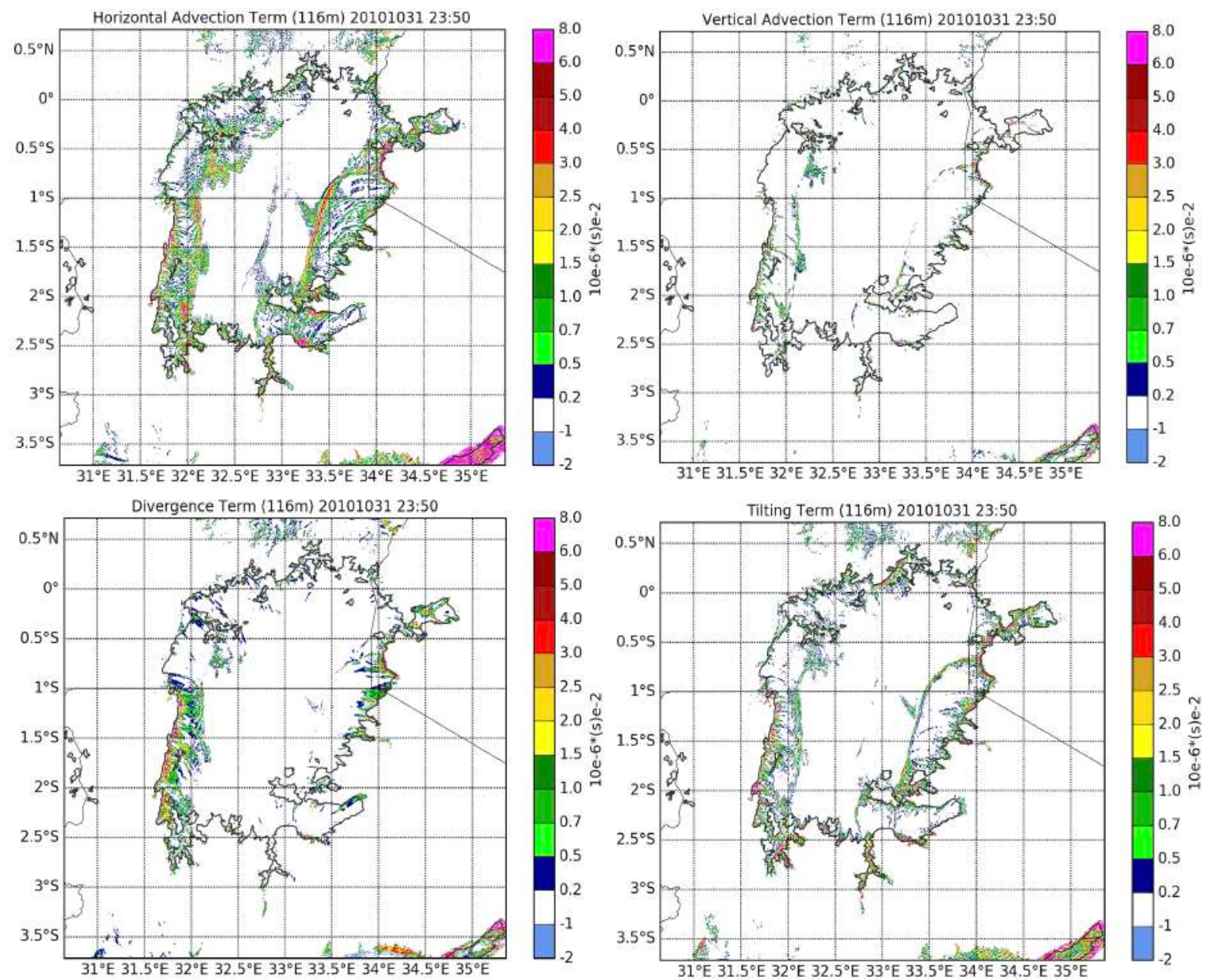

Figura 3.33: Similar a figura 3.32, mas para o horário das 2350 UTC.

As 2350 UTC (Fig. 3.32), o termo de advecção horizontal domina na dianteira na CBL precedido pelo termo de inclinação com valores de $\sim 3^{*} 10^{-6} \mathrm{~s}^{-2}$ e $1 * 10^{-6} \mathrm{~s}^{-2}$, respectivamente. Os termos de divergência e advecção vertical apresentam baixa valores $<0.2 * 10^{-6} \mathrm{~s}^{-2}$.

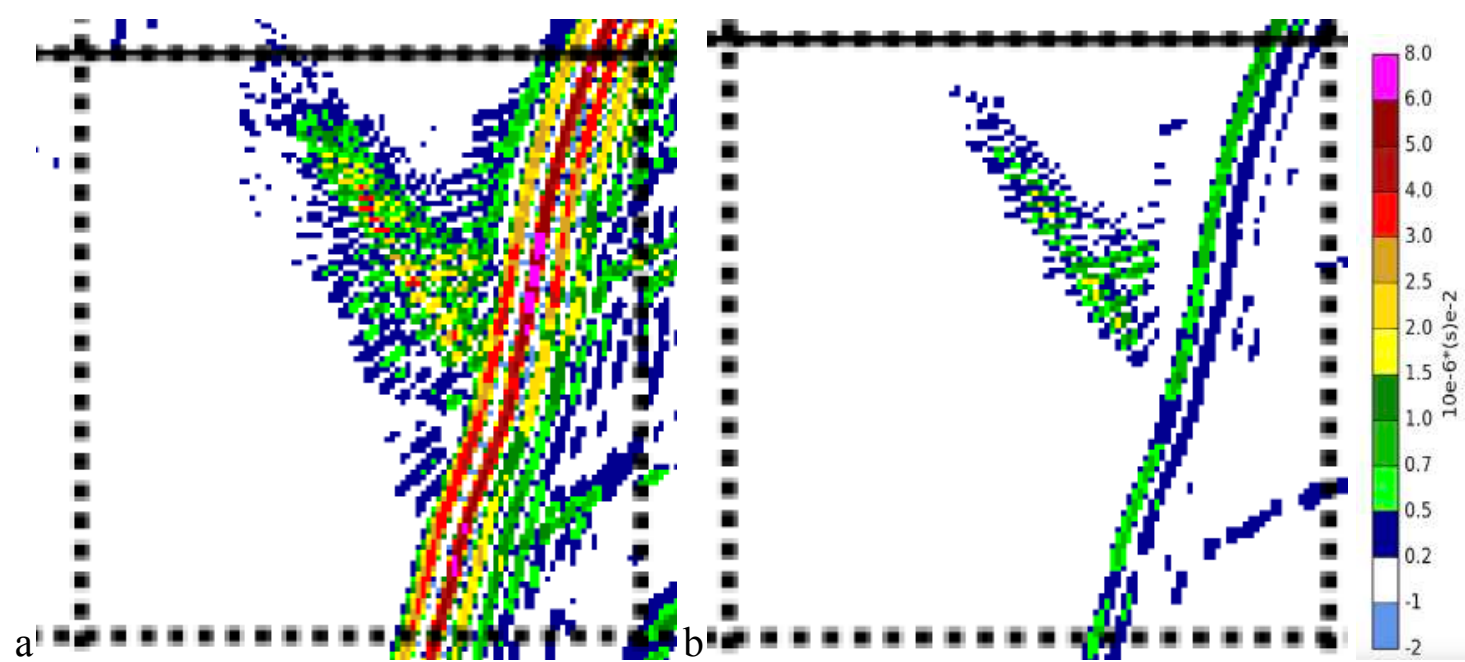

Figura 3.34: Similar a figura 3.33, com zoom na região da CBL para os termos de advecção horizontal e de inclinação. 
Um zoom na figura 3.33, nos termos de advecção horizontal e inclinação (Fig. 3.34), indica que existe um trem de ondas no calculo dos termos de advecção horizontal de vorticidade vertical e no termo de inclinação, com comprimento de onda entre 2000 e 2500 metros, ou seja, os vórtices simulados pelo sistema ARPS apresentam diâmetro em torno desses valores. Ainda, nota-se que as ondas estão $180^{\circ}$ fora de fase com as ondas produzidas pelo termo de inclinação. Isso indica que, inicialmente o cisalhamento vertical do vento produz rolos na horizontal que são convertidos em vórtices verticais pelos movimentos de ascensão na região da CBL, esses vórtices verticais são produzidos nos níveis abaixo do campo da figura e são advectados pelos ventos acima que são mais intensos logo, a região a frente da CBL passa a ser dominada pelo termo de advecção horizontal já que com o tempo, mais vórtices são produzidos na inclinação dos rolos horizontais com aumento na contribuição do termo de advecção horizontal.
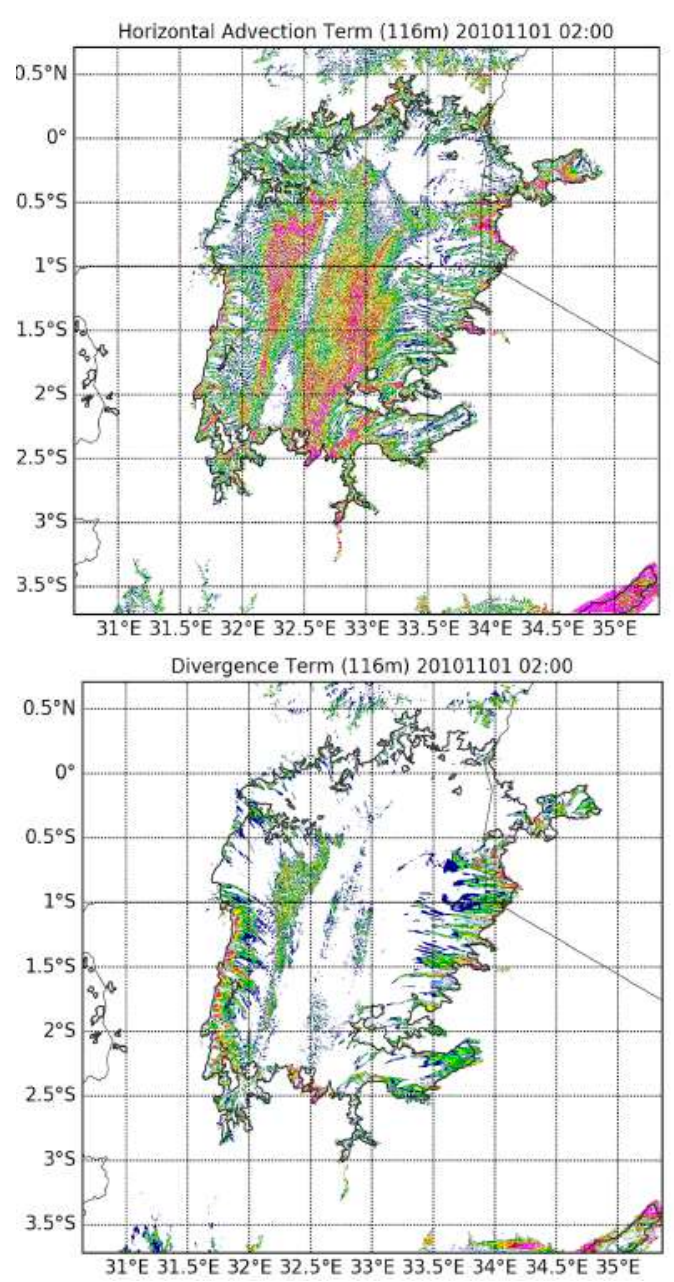
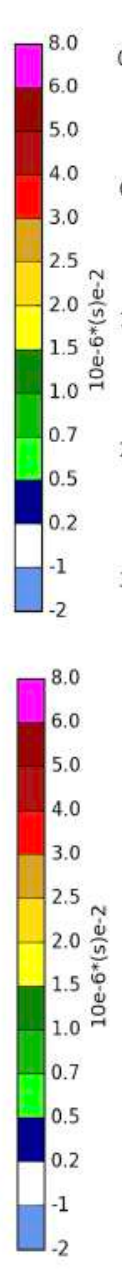

Figura 3.35: Similar a figura 3.32, mas para o horário das 0200 UTC.

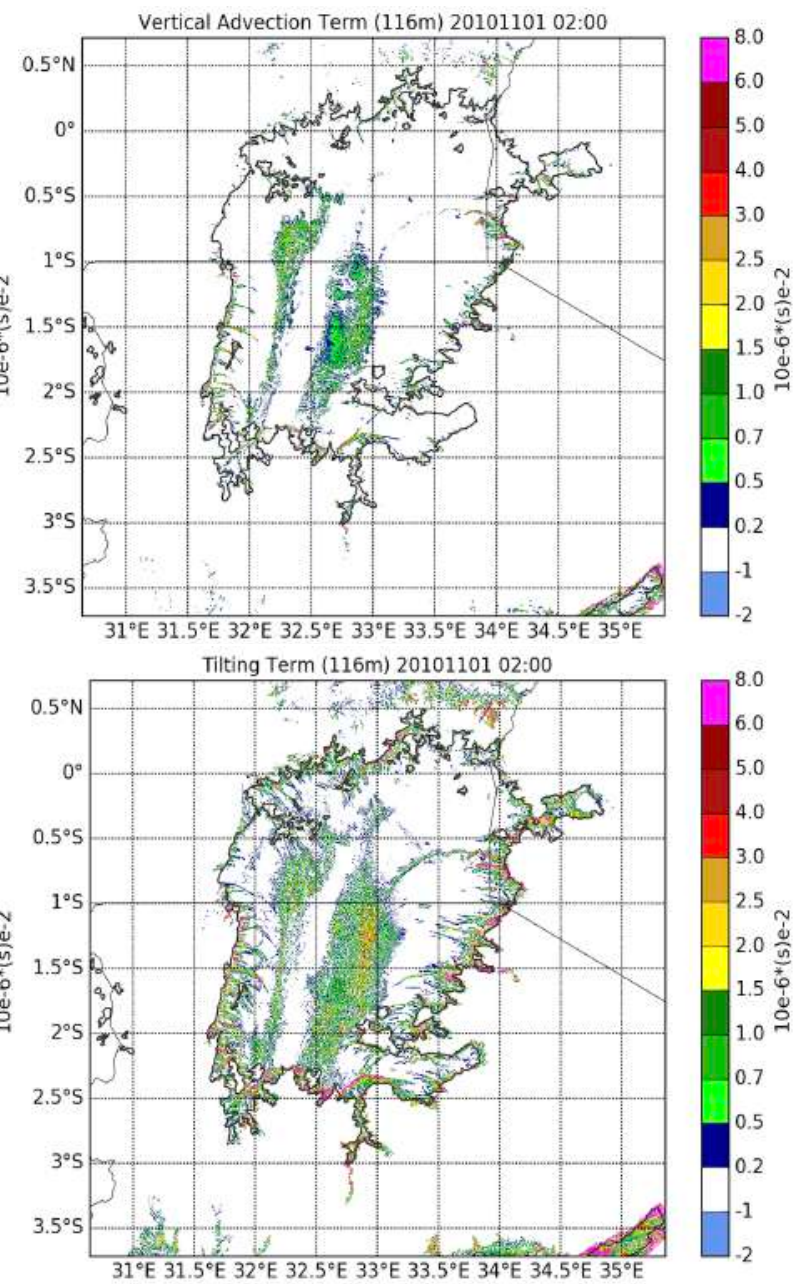

As 0200 UTC (Fig. 3.35), aumenta a contribuição do termo de advecção vertical, no entanto, o mesmo ainda apresenta valores entre 3 vezes abaixo do termo de inclinação e mais de 5 vezes 
abaixo da contribuição dada pelo termo de advecção horizontal. O mesmo vale para o termo de divergência, que apresenta maiores valores, mas é o que mostra a menor contribuição de todos os termos da equação 3. Na frente de brisa de oeste, todos os termos passam a produzir contribuição de igual magnitude na produção de vorticidade vertical. Nesse caso, os termos de advecção vertical e de divergência são maiores, pois a CBL de leste atua contra a circulação sinótica e aumenta a divergência/convergência e os movimentos verticais nos níveis mais baixos.
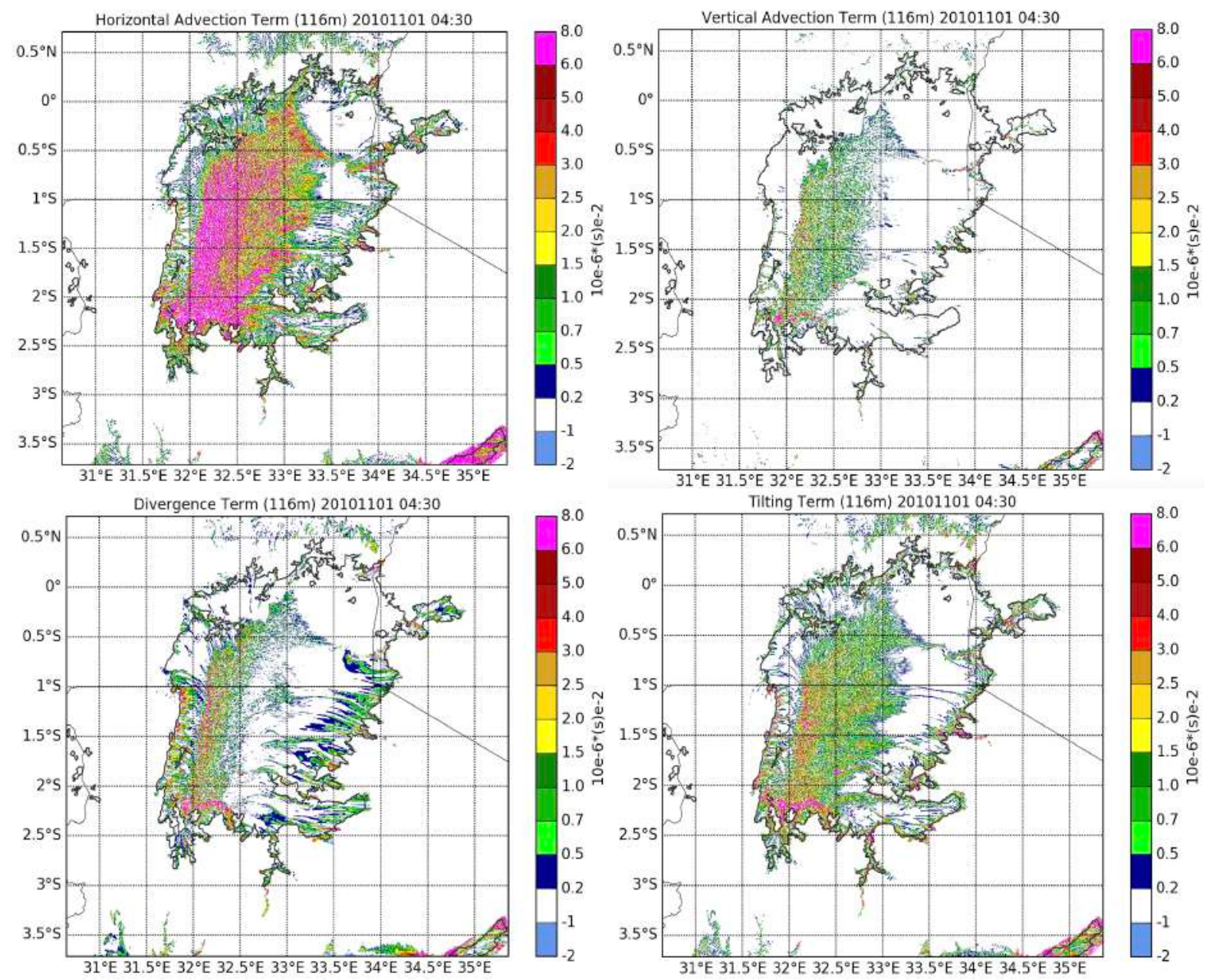

Figura 3.36: Similar a figura 3.32, mas para o horário das 0430 UTC, pouco antes do disparo das primeiras células convectivas.

As 0430 UTC, os termos de inclinação, divergência e advecção vertical de vorticidade passam a ter contribuição similares na região da CBL, embora o termo de inclinação ainda atue sobre uma área maior. Neste ponto, o termo de advecção horizontal já está bastante elevado, mas ele basicamente, transporta a vorticidade vertical produzida pelos termos anteriores e acumula toda a vorticidade vertical gerada durante todo o período de deslocamento da CBL. A principal fonte de produção de vorticidade vertical foi via termo de inclinação, com os termos 
de divergência e advecção vertical aumentando sua contribuição para valores próximos do termo de inclinação apenas as no início da formação das primeiras células de convecção.

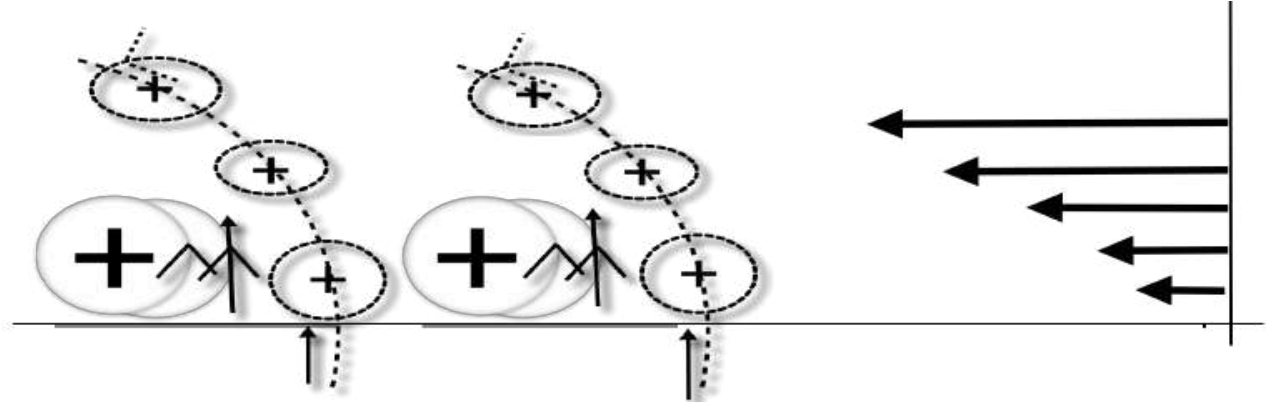

Figura 3.37: Esquema de atuação do termo de inclinação na produção de vorticidade vertical. As setas horizontais representam a variação da velocidade do vento com a altura. O símbolo + representa vorticidade vertical positiva. Setas verticais indicam regiões onde se produzem movimentos de ascensão do ar e inclinação dos rolos horizontais.

A figura 3.37, mostra um esquema da atuação do termo de inclinação na conversão de rolos horizontais, produzidos pela circulação da frente de brisa, em vorticidade vertical. Na região da frente de brisa, os ventos são mais intensos, com intensidade que reduz na traseira do sistema, isso produz rolos horizontais mais intensos na dianteira e mais fracos na traseira. Esses rolos horizontais na dianteira possuem circulação mais intensa e inclina o rolo logo atrás dele, que possui circulação mais fraca. Isso ocorre sucessivamente, com rolos cada vez mais fracos conforme a distancia do rolo principal da frente de brisa. Esse processo, colabora com a conversão de vorticidade horizontal em vertical nos níveis acima. Os ventos nos níveis acima da superfície são mais intensos e a vorticidade vertical produzida é advectada para a frente da CBL em superfície, que posteriormente, dispara a convecção na sua dianteira. Nos níveis acima de $2 \mathrm{~km}$ de altura, temos vorticidade relativa positiva produzida pela circulação sinótica, e que favorece o surgimento de muito mais vórtices positivos em detrimento da formação de vórtices com vorticidade negativa no decorrer do deslocamento da CBL na CLP.

Para tentar inferir a atuação dos ventos alísios sem a presença da cadeia de montanhas, removeu-se toda a região montanhosa no entorno do lago, utilizando-se de uma grade flat a 1133 metros, a altitude do LV, e com a TSL da figura 2.3c.

A figura 3.38 mostra o campo de chuva acumulada simulada para o evento de 01/11/2010 sem a presença da cadeira de montanhas no entorno. Nota-se, de maneira geral, que a chuva se espalha por uma área muito maior com acumulados pontuais próximos dos $100 \mathrm{~mm}$, enquanto que para a mesma configuração de TSL, mas com topografia (3.6c), os acumulados são menores, sobre uma área menor e ainda com máximos pontuais entre 30 e $40 \mathrm{~mm}, 3$ vezes menor. 


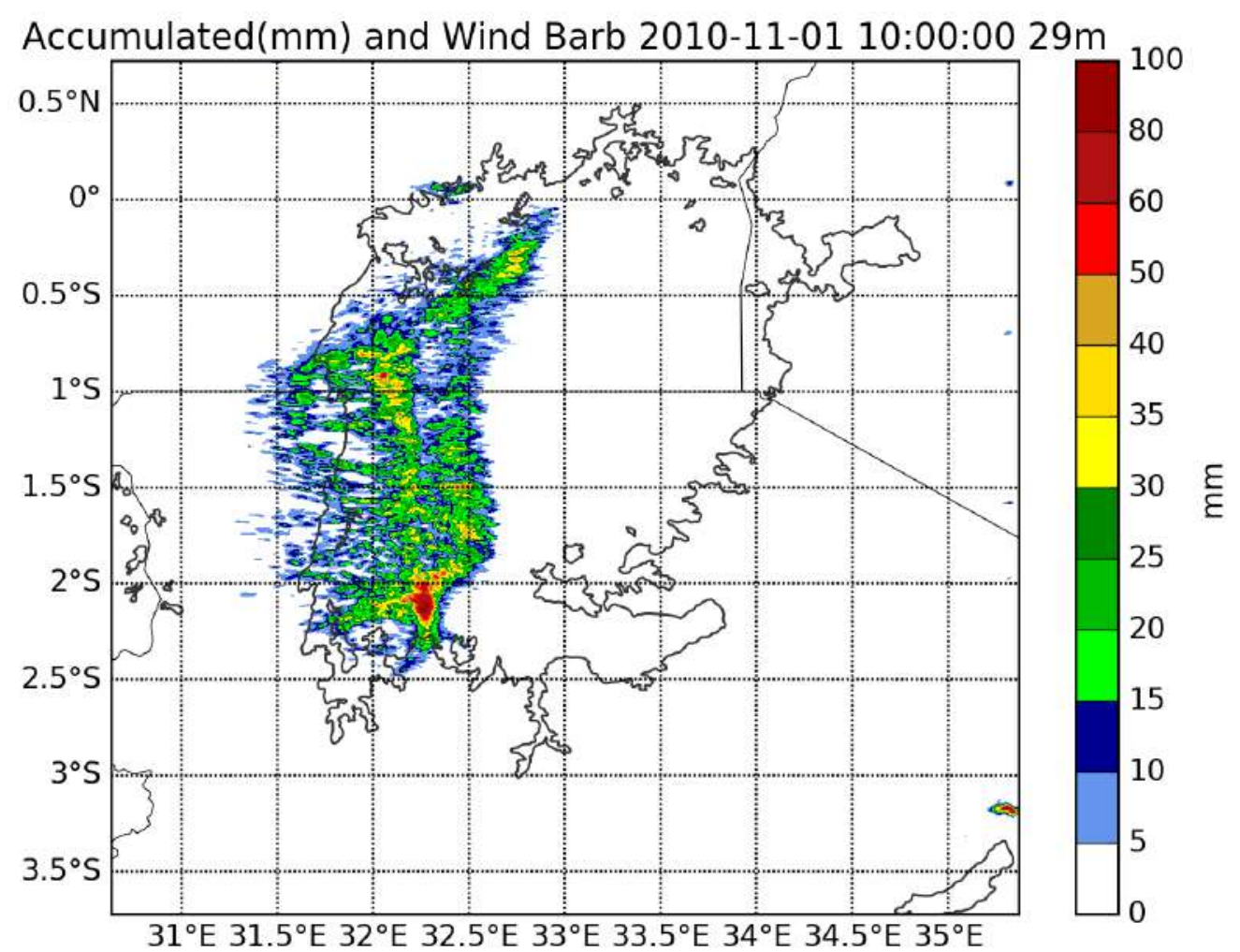

Figura 3.38: Campo de precipitação acumulada para o período da madrugada com a configuração de TSL da figura $2.3 \mathrm{c}$ e remoção das montanhas no entorno do lago Vitória. Simulação numérica com 500 metros de resolução horizontal. Contorno do LV está indicado. Barra de cores indica chuva acumulada em $\mathrm{mm}$.

A primeira diferença básica que se observa nos campos para a simulação com a região montanhosa no entorno e a simulação sem a topografia e altitude constante em 1133 metros, é observada na magnitude do vento próximo a superfície. Nota-se que, sem a região montanhosa, os ventos de leste para oeste é entre 3 a $5 \mathrm{~m} \mathrm{~s}^{-1}$ mais intenso (fig. 3.38), com o deslocamento da CBL mais rápido sobre o lago. A diferença na magnitude e direção do vento é perceptível até por volta de 700 metros acima da superfície acima disso, não há diferenças nos campos de vento antes do disparo da convecção. Apenas após o disparo da convecção, que ocorre entre 0250 UTC e 0300 UTC e entre 0420 UTC e 0430 UTC para as grades sem e com topografia, respectivamente, próximo a longitude $32.5^{\circ} \mathrm{E}$, ocorre a transferência de momento para os médios e altos níveis por meio da convecção e liberação de calor latente com diferenças consideráveis nesses níveis. 

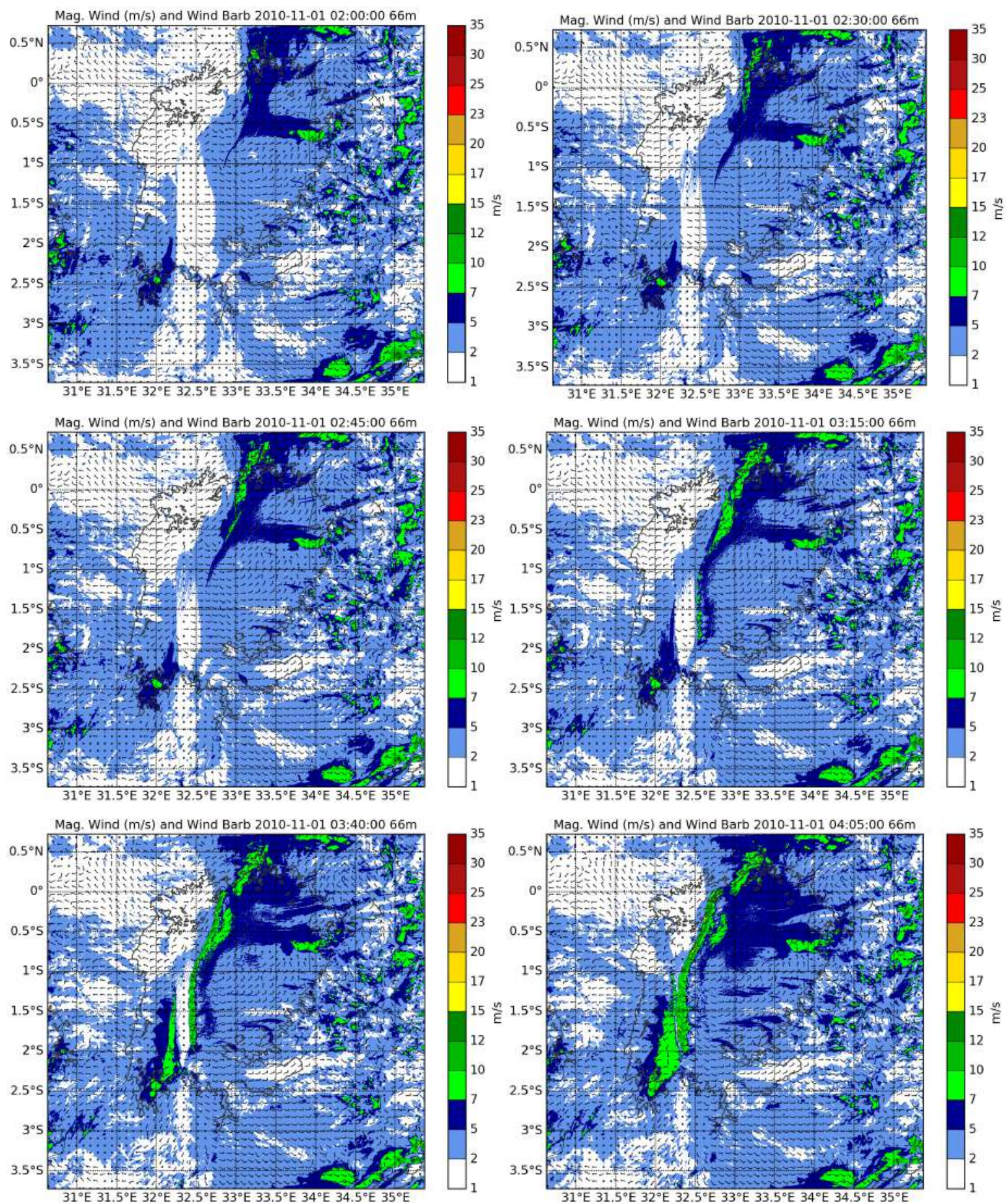

Figura 3.39: Campo de diferença de direção e magnitude do vento para as simulações com e sem topografia no entorno. Simulações com 500 metros de resolução horizontal. Contorno do LV está indicado. A barra de cores indica diferença de magnitude em $\mathrm{m} \mathrm{s}^{-1}$.

A figura 3.40 mostra a intensidade da precipitação para as 2 grades em diferentes instantes de tempo, isso porque o disparo da convecção ocorre mais de 1 hora mais cedo na grade sem topografia já que a frente de brisa lacustre se propaga mais rápido. De maneira geral, nota-se que, sem a topografia, a frente de brisa lacustre se propaga de maneira mais uniforme orientada no sentido sul-norte e por isso produz uma linha de instabilidade que atua em quase toda a 
porção longitudinal do lago a leste de $33^{\circ} \mathrm{E}$, enquanto que, no outro caso, a frente de brisa lacustre é mais lenta e se propaga de maneira não uniforme devido à irregularidade na cadeia de montanhas a leste que a originou, com menor intensidade da precipitação e acumulação muito menor. Embora para a condição real de topografia a região montanhosa a leste do lago seja importante no sentido da CBVM contribuir para a frente de brisa lacustre, nota-se que para essa região, que apresenta forte componente dos ventos alísios de leste para oeste, a cadeia de montanhas a leste do lago age no sentido de frear os alísios que chegam mais fracos sobre o lago. Sem a cadeia de montanhas, os alísios aceleram ainda mais a frente de brisa lacustre e aumentam os fluxos de calor latente entre o LV e a atmosfera com a formação de chuvas mais intensas.
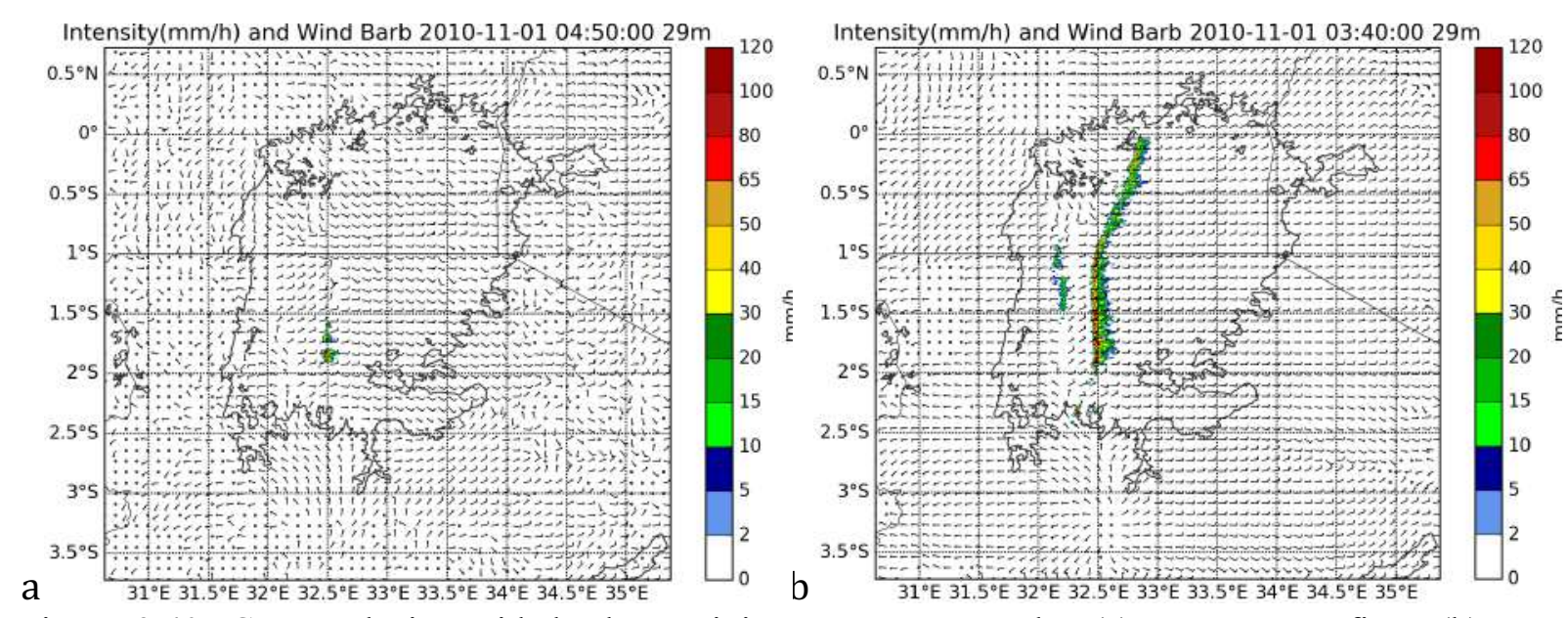

Figura 3.40: Campo de intensidade da precipitação para as grades (a) com topografia e (b) sem topografia. Para a grade (a), início da ocorrência das chuvas e para a grade (b) 40 minutos após o disparo das primeiras células convectivas. Simulações com 500 metros de resolução horizontal. A barra de cores indica intensidade da precipitação $\left(\mathrm{mm} \mathrm{h}^{-1}\right)$.

Do exposto acima, conclui-se que nem sempre o fato de haver uma cadeia de montanhas no entorno de um lago resulta em contribuir para CBL's mais intensas. Particularmente, nesse caso, a cadeia de montanhas a leste age no sentido de barrar os alísios em boa parte da camada limite planetária e reduzir a intensidade da precipitação sobre o LV. Por outro lado, essa avaliação não é valida para concluir sobre como seria o clima sobre o LV sem as montanhas, já que ventos mais intensos e constantes sobre o lago durante todo o ano poderiam contribuir significativamente para temperaturas consideravelmente inferiores ao longo do tempo. 


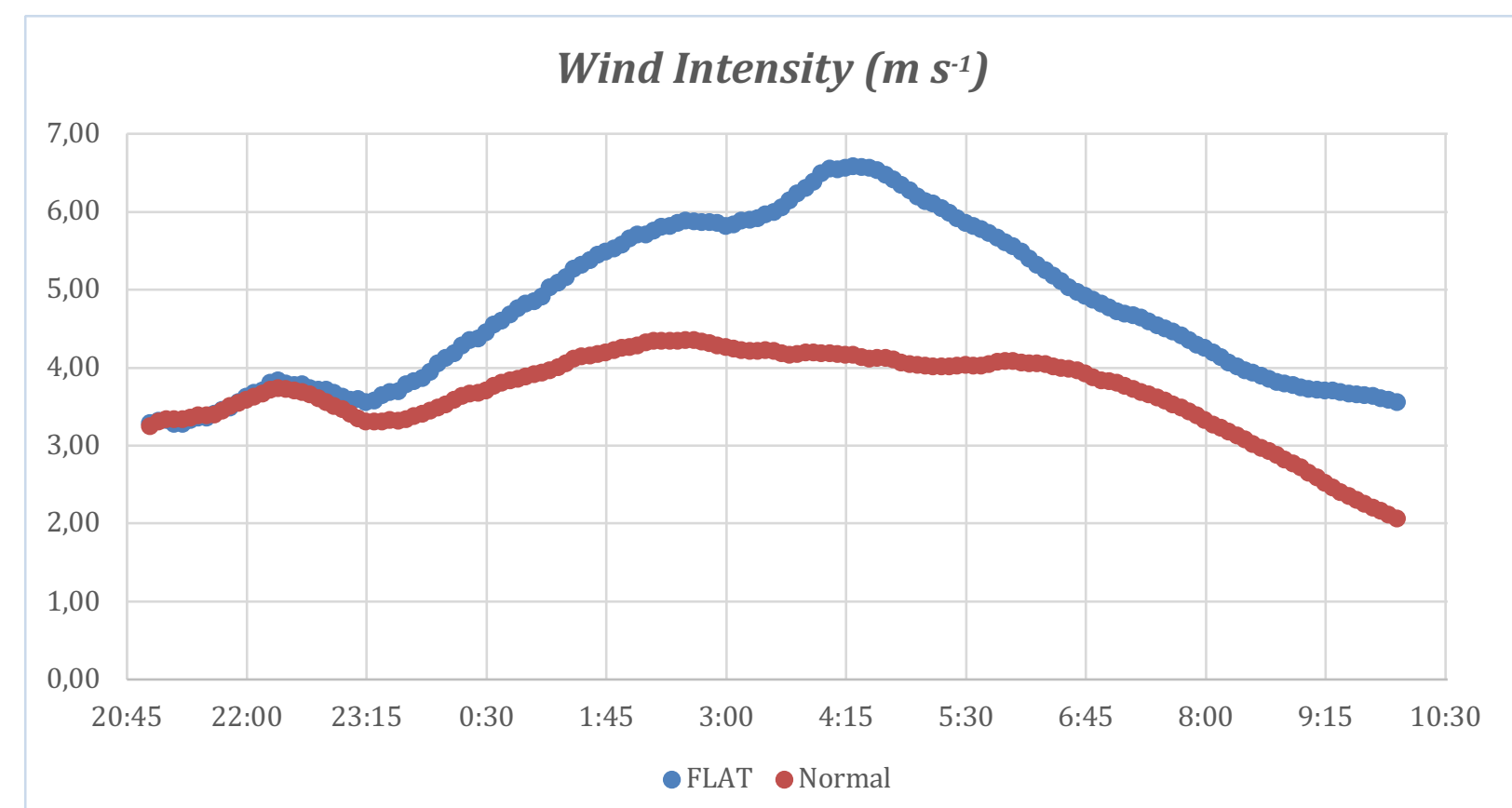

Figura 3.41: Intensidade média do vento sobre o LV para as simulações com o sistema ARPS com topografia (vermelho) e sem topografia (azul) no entorno para o evento de $01 / 11 / 2010$. Eixo x representa o horário e eixo y vento médio sobre a área do lago $\mathrm{em} \mathrm{m} \mathrm{s}^{-1}$.

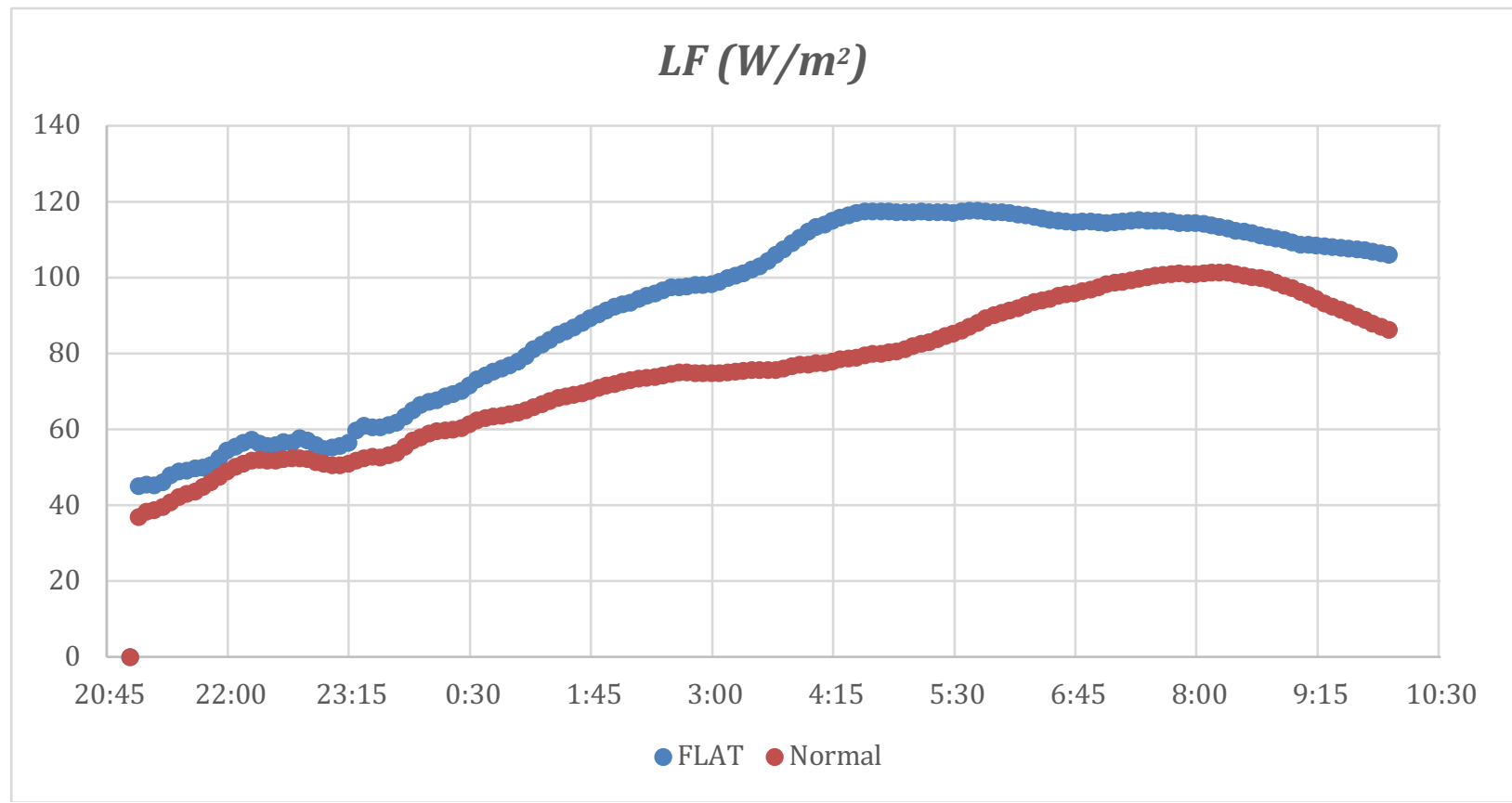

Figura 3.42: Fluxo de calor latente médio sobre o LV para as simulações com (vermelho) e sem topografia (azul) no entorno do LV para o evento de 01/11/2010. Eixo x representa o horário e eixo y o vento fluxo de calor latente $\mathrm{em}_{\mathrm{W} \mathrm{m}}^{-2}$.

Na figura 3.41 nota-se que após as 2300 UTC os ventos são mais intensos sobre o lago durante toda a madrugada. Essa diferença na magnitude média do vento sobre o lago produz uma diferença máxima de até $40 \mathrm{~W} \mathrm{~m}^{-2}$ no fluxo de calor latente por volta das 0400 UTC. No entanto, na maior parte do tempo essa diferença fica em $\sim 20 \mathrm{~W} \mathrm{~m}^{-2}$ (fig. 3.42), o suficiente para 
produzir acumulados pontuais até 3 vezes acima do simulado com a topografia real e na média entre 2 a 2.5 vezes maior. Ressalta-se que, dado que a área do LV é de $\sim 68800 \mathrm{~km}^{2}$, isso representa $1.376 \times 10^{6} \mathrm{MW}$ de fluxo de calor latente entre o lago e a atmosfera, o que explica a produção de um volume de chuva 2 vezes superior nesse caso. Mesmo após o evento, já no período da manhã do dia seguinte, é nítido que a intensidade média do vento permanece quase $2 \mathrm{~m} \mathrm{~s}^{-1}$ acima na simulação sem a região montanhosa, já que sem as montanhas, os ventos alísios tendem a contribuir para ventos de leste mais intenso sobre o LV ao longo de todo o dia.
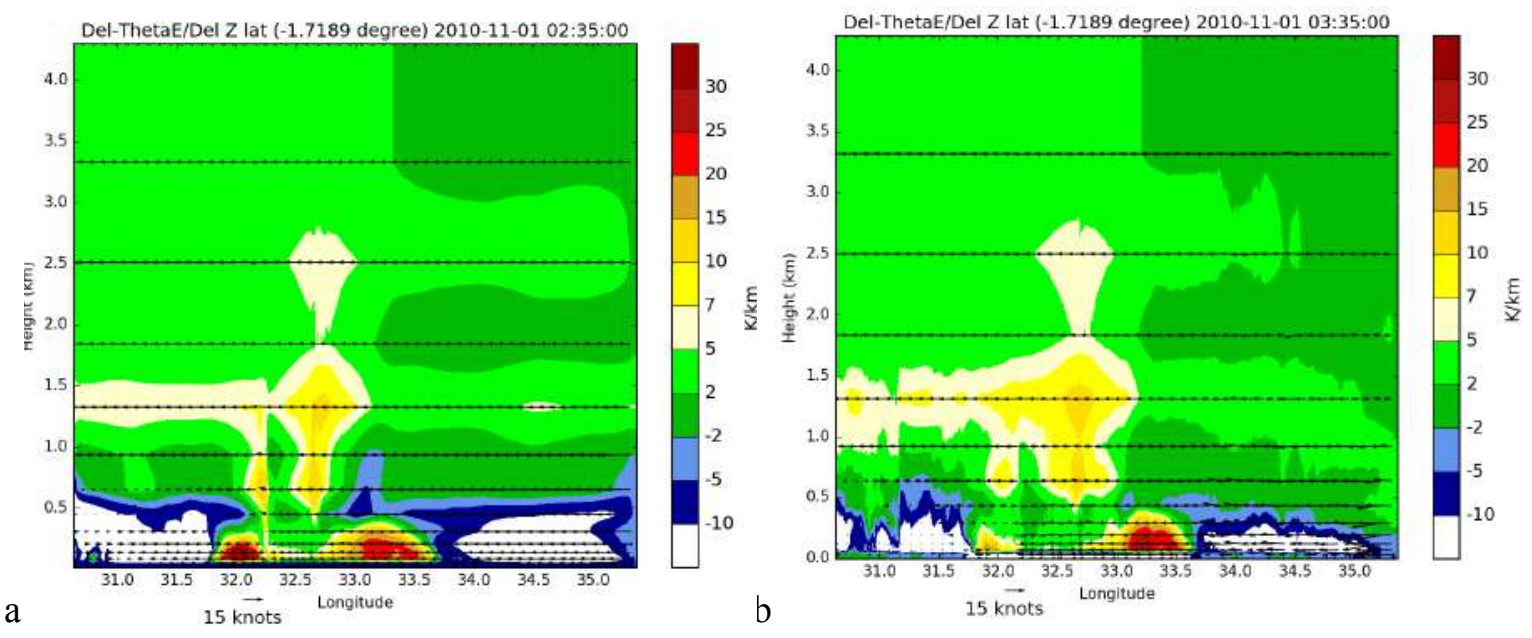

Figura 3.43: Perfil vertical do gradiente vertical de temperatura potencial equivalente para a latitude central de $1.7^{\circ} \mathrm{S}$ em (a) grade sem topografia (terreno plano) e (b) grade com topografia normal. Utilizou-se a média dos 50 cortes mais a norte e 50 cortes mais a sul para remoção de ruído, ocasionado por células convectivas localizadas.

O perfil vertical do gradiente vertical de temperatura potencial equivalente (Fig. 3.43) para as grades sem e com topografia, alguns minutos antes do disparo da convecção, apresentam diferença de horário em torno de 1 hora, já que o disparo da convecção ocorre mais cedo para a grade (a) devido ao rápido deslocamento da $\mathrm{CBL}$ de leste. De maneira geral, o perfil vertical é similar em ambas as grades com gradiente de $\theta_{\mathrm{e}}$ de $7 \mathrm{~K}$ entre 1.7 e $1.8 \mathrm{~km}$ acima da superfície, situação em que a CLP se torna instável e dispara o processo convectivo, no entanto, esse gradiente é atingido 1 hora antes na grade plana. Ainda, devido ao vento mais intenso, nota-se que a região na traseira da frente de brisa entre $32.5^{\circ} \mathrm{E}$ e $33.5^{\circ} \mathrm{E}$, nos primeiros 300 metros acima da superfície com gradiente superior a $15 \mathrm{~K}$ é mais ampla do que na grade com topografia, o que sugere uma região com maior instabilidade na camada de mistura e está associada a ventos mais intensos em superfície e consequente maior fluxo de calor latente e $\theta_{\mathrm{e}}$ próximo a superfície, com instabilização da camada limite planetária (CLP). 

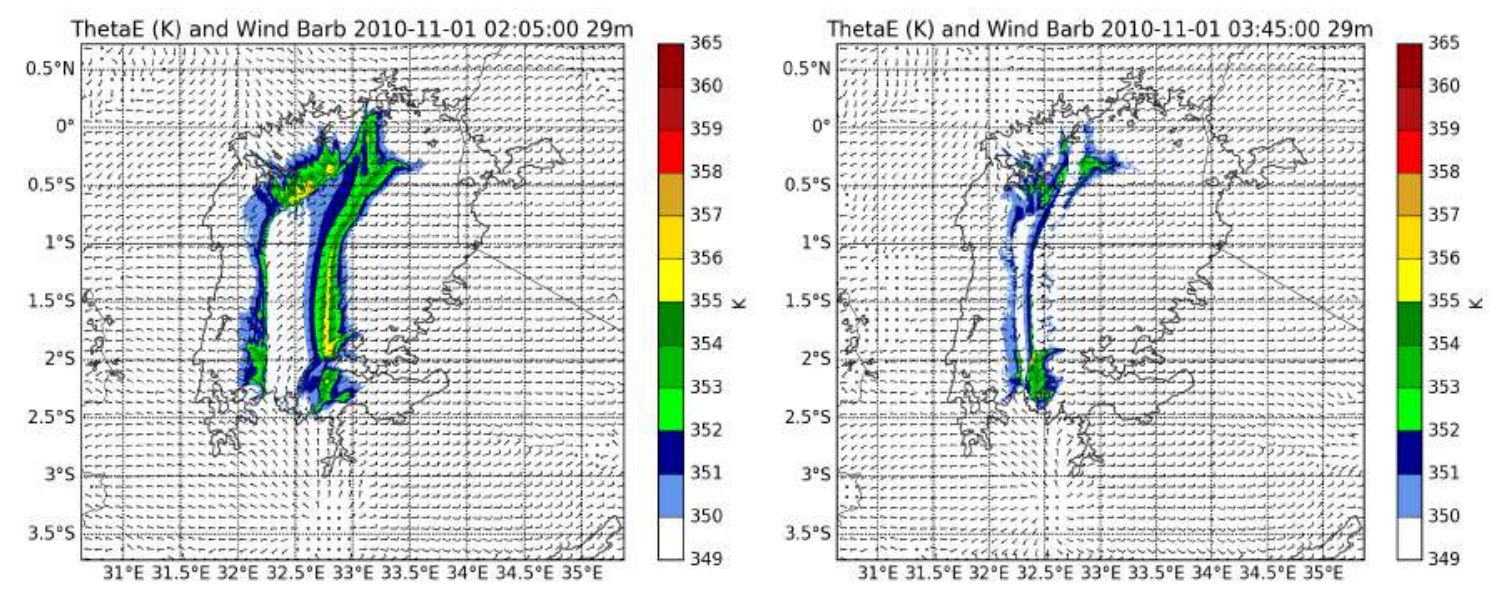

a
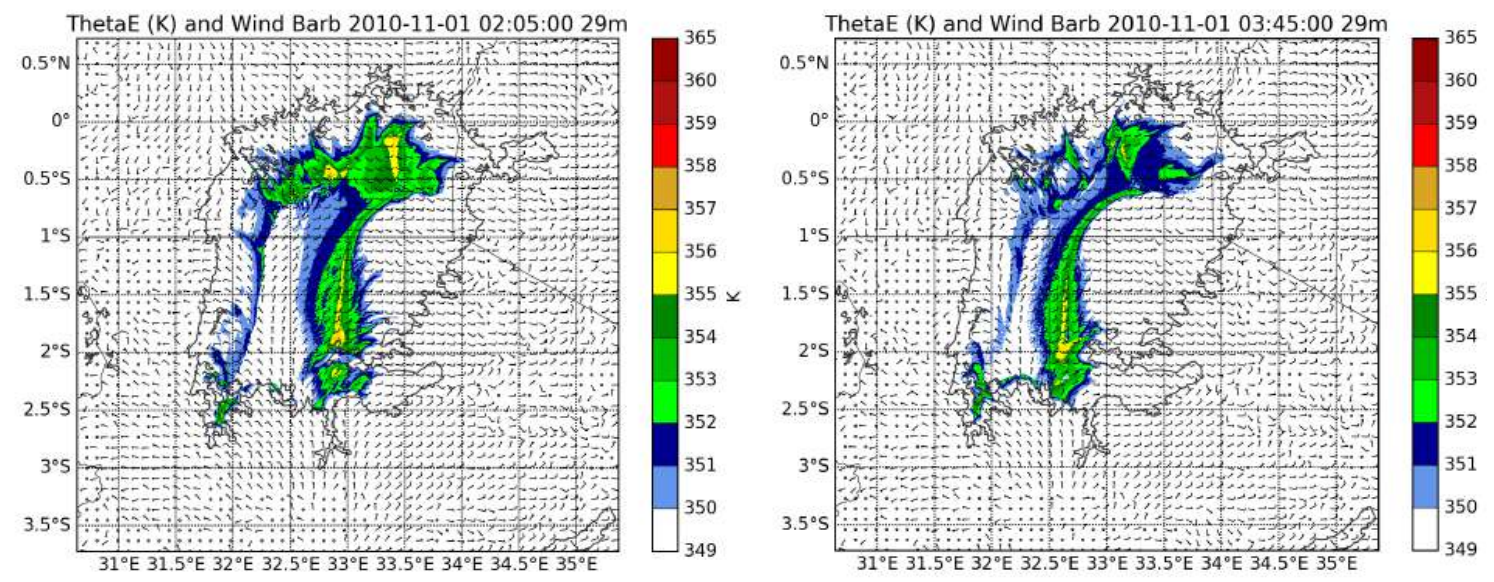

b

Figura 3.44: Campo horizontal de $\theta_{\mathrm{e}}$ a 29 metros acima da superfície para a grade (a) terreno plano e (b) com topografia real para o evento de 01/11/2010. Contorno do LV e horário está indicado. Barra de cores indica temperatura potencial equivalente em $\mathrm{K}$.

Nota-se na figura 3.44, a CBL para as grades com terreno plano (a) e grade com topografia real (b). Para a grade (a), o transporte de $\theta_{\mathrm{e}}$ é mais homogêneo. Os ventos mais intensos de leste aumentam $\theta_{\mathrm{e}}$ pelo fluxo de calor latente na formação da convecção profunda com maior precipitação na grade (a). As 0345 UTC, nota-se valores de $\theta_{\mathrm{e}}$ maiores na grade (b), do que na grade (a), já que boa parte do $\theta_{\mathrm{e}}$ da grade (a) foi utilizado pela convecção na formação de chuva.

Em suma, conclui-se que as montanhas a leste agem no sentido de diminuir a intensidade dos ventos ao frear os ventos alísios, embora a cadeia montanhosa contribua na intensificação da frente de brisa de leste no decorrer da madrugada por meio da circulação vale-montanha. A contribuição gerada pelos ventos alísios é por volta de $2 \mathrm{~m} \mathrm{~s}^{-1}$ superior à gerada pela CBVM. Em outras simulações foi possível observar que até mesmo para configurações de TSL menor ( $\sim 22{ }^{\circ} \mathrm{C}$ em média), onde a grade com topografia não produz precipitação, a grade plana produziu precipitação, ou seja, em uma condição sem cadeia de montanhas a leste as condições 
sinóticas responsáveis pela intensificação/desintensificação dos alísios seriam muito maiores do que a TSL do lago, já que a diminuição na evaporação devido a menor TSL é compensada por ventos mais intensos que aumentam a taxa de evaporação do LV para a atmosfera. Por outro lado, não é possível afirmar no longo prazo qual seria o impacto no clima local por meio de estudos de caso, já que a permanência de ventos mais constantes pode contribuir significativamente para a redução da TSL.

\subsubsection{Análise da convecção noturna de $03 / 11 / 2014$}

Para o evento de 03/11/2014 realizou-se simulações com TSL média do lago em $21.5^{\circ} \mathrm{C}$ e $24.5{ }^{\circ} \mathrm{C}$, respectivamente. A primeira foi estimada das análises do modelo global GFS; a segunda foi utilizada TSL maior da figura 2.3b. O evento do dia 03/11/2014 foi mais generalizado e teve atuação em quase toda a área do lago.
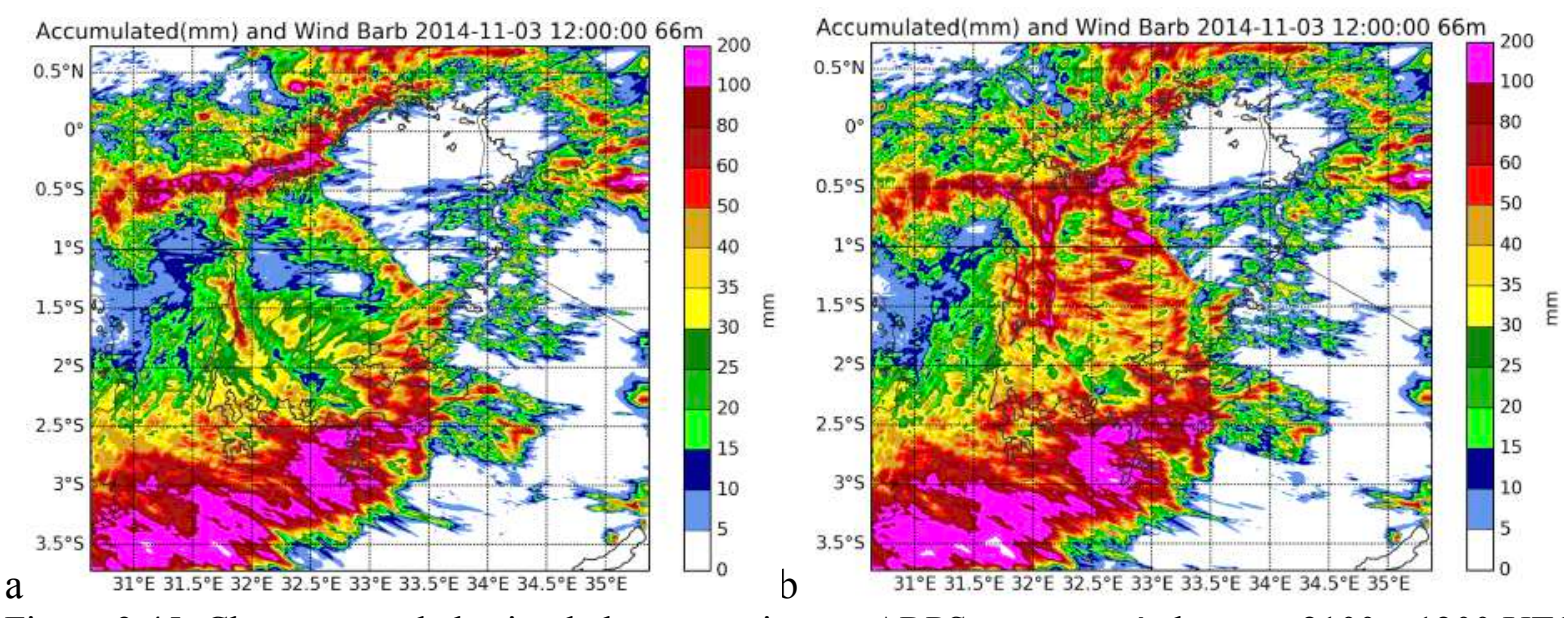

Figura 3.45: Chuva acumulada simulada com o sistema ARPS para o período entre 2100 e 1200 UTC do evento do dia 03/11/2014 com a TSL do GFS que de $\sim 21.5^{\circ} \mathrm{C}$ (a) e TSL da figura $2.3 \mathrm{~b}$ (b). que apresenta média aproximada sobre o LV de $24.5^{\circ} \mathrm{C}$. Simulação numérica realizada com 500 metros de resolução. Barra de cores indica precipitação acumulada em $\mathrm{mm}$.

Para a simulação com TSL maior (Fig 3.45b), nota-se acumulados acima dos $60 \mathrm{~mm}$ em uma área mais abrangente sobre o LV e com amplitude mais de 2 vezes superior a grade com TSL menor. Isso indica que o efeito da TSL é muito relevante mesmo nos casos de convecção mais generalizada. Para esse evento, tempestades se originaram no fim da tarde sobre a cadeia de montanhas a leste e a sul do LV; as frentes de rajadas associadas a essa região de tempestade desenvolveram-se ao longo do período noturno devido a piscinas de ar frio originadas pelo ar descendente de diversas células convectivas. Essas frentes de rajadas se acoplaram com a CBVM e no decorrer da madrugada deslocaram-se sobre o LV de sul e de leste. A confluência 
entre essas frentes de rajadas disparou novas células de tempestades no decorrer do deslocamento do sistema pelo LV. Outra frente de rajadas se originou na borda norte do LV associada a chuvas pré-existentes e que se acoplaram com a CBVM deslocando-se sobre o LV e confluindo com as outras 2 frentes de rajadas. A mesma originou uma linha de precipitação acumulada acima dos $100 \mathrm{~mm} / 24$ horas. A figura 3.46 refere-se a direção e intensidade do vento para a simulação com TSL do GFS em $21.5^{\circ} \mathrm{C}$.

A figura 3.46, indica a intensidade da precipitação para o evento de $03 / 11 / 2014$, onde se nota o pré-desenvolvimento das áreas de chuva a leste e sul do LV que por meio de suas frentes de rajadas deslocam-se por todo o LV. Esse deslocamento aumenta o fluxo de calor latente do LV para a atmosfera e favorece o processo de disparo e continuidade da convecção.

O fluxo de vapor de água (calor latente) entre a superfície e a atmosfera (fig. 3.48) basicamente segue a propagação das frentes de brisa de leste e sul, dado que quanto maior a velocidade do vento maior é o fluxo. A confluência dessas linhas de fluxo favorece o desenvolvimento das chuvas sobre o LV. Ao longo da propagação das frentes de brisa o fluxo de vapor de água aumenta de $\sim 30 \mathrm{~g} \mathrm{~m}^{-2} \mathrm{~s}^{-1}$ para $\sim 300 \mathrm{~g} \mathrm{~m}^{-2} \mathrm{~s}^{-1} \mathrm{e}$ fornece umidade para as tempestades que se formam.
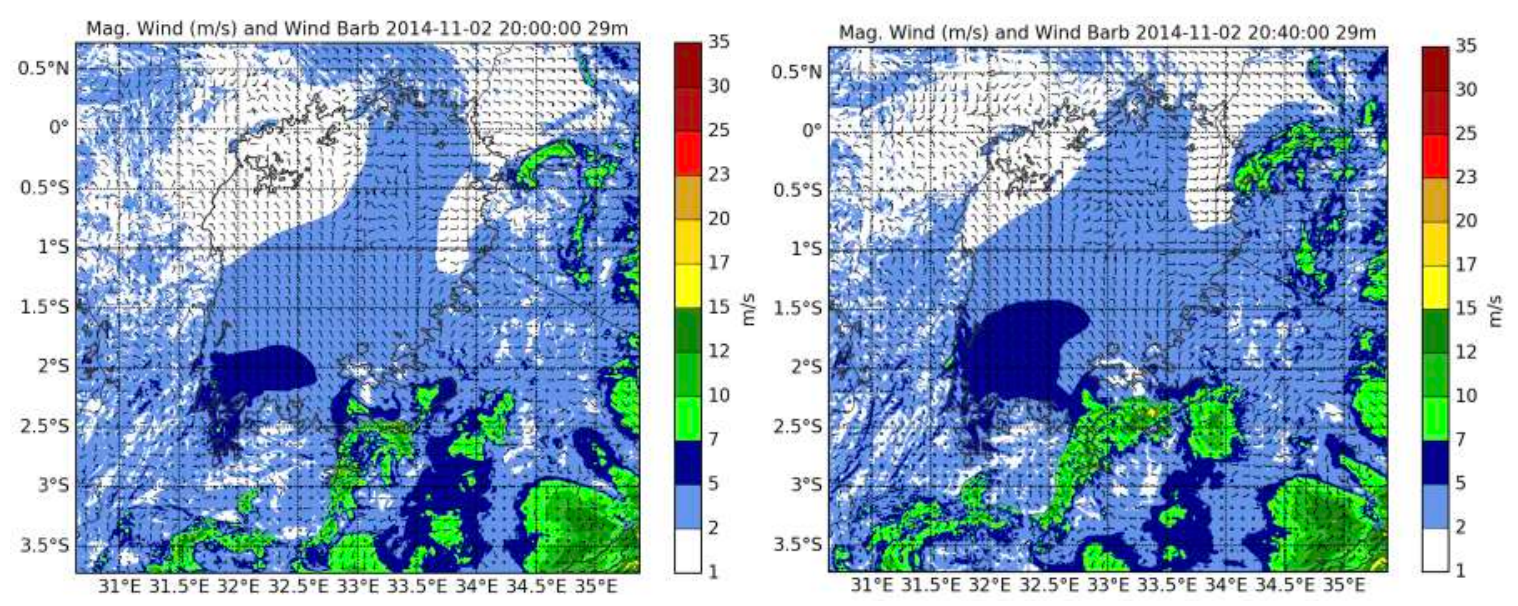

Figura 3.46: Campo de direção e magnitude do vento para a simulação com o ARPS para o evento de 03/11/2014 com TSL de $21.5^{\circ} \mathrm{C}$. Contorno do LV e hora UTC está indicado. Simulação com $500 \mathrm{~m}$ de resolução horizontal. Barra de cores indica velocidade do vento em $\mathrm{m} \mathrm{s}^{-1}$. 

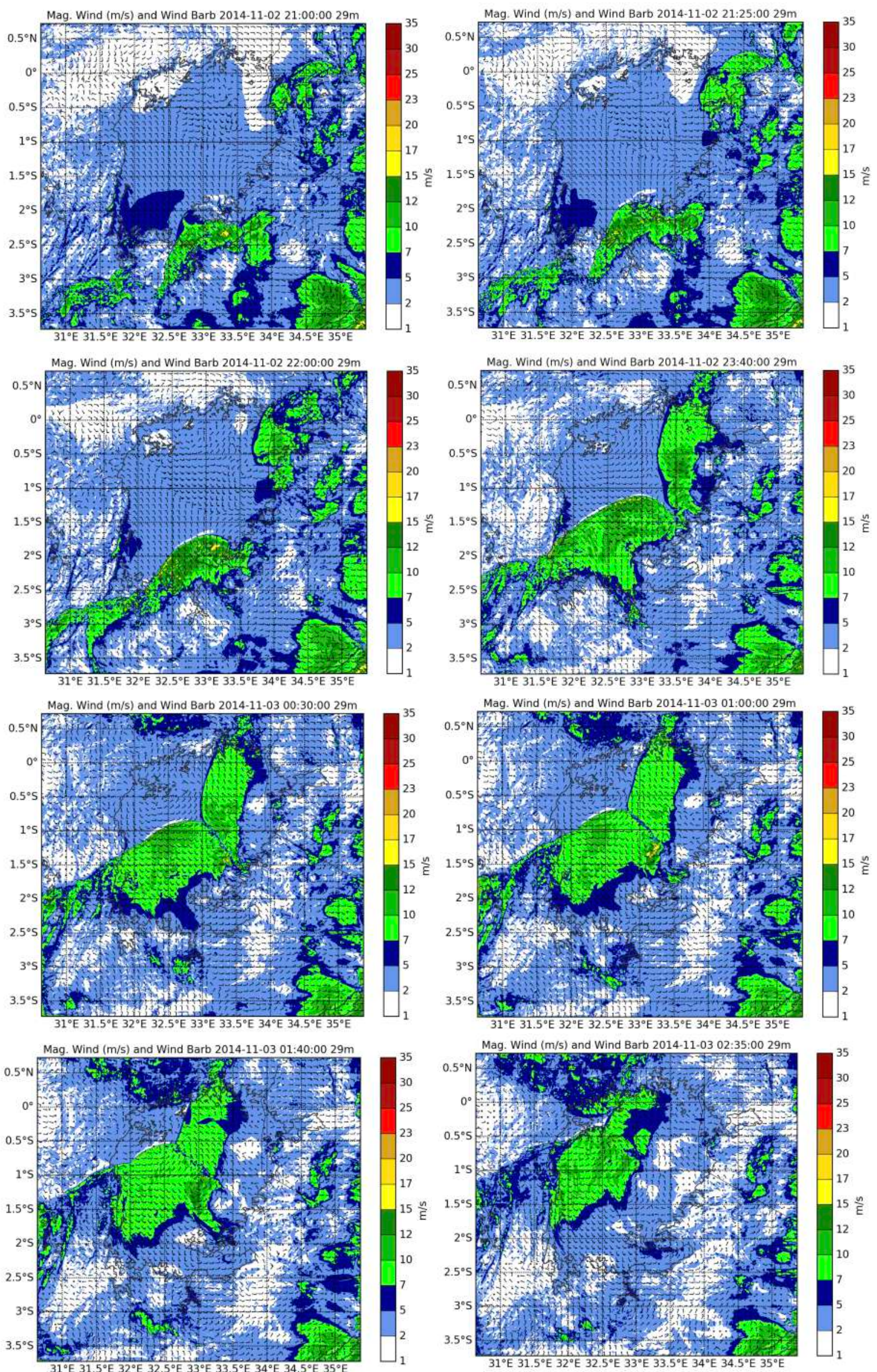

Figura 3.46: Continuação. 


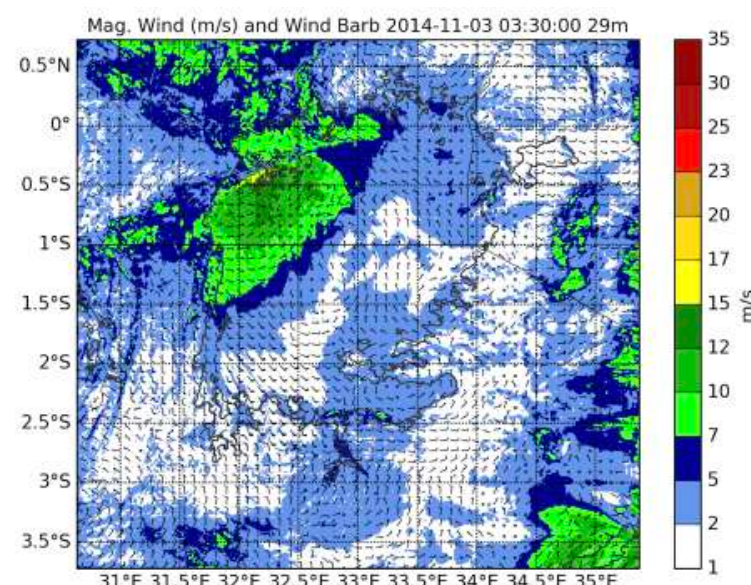

Figura 3.46: Continuação.
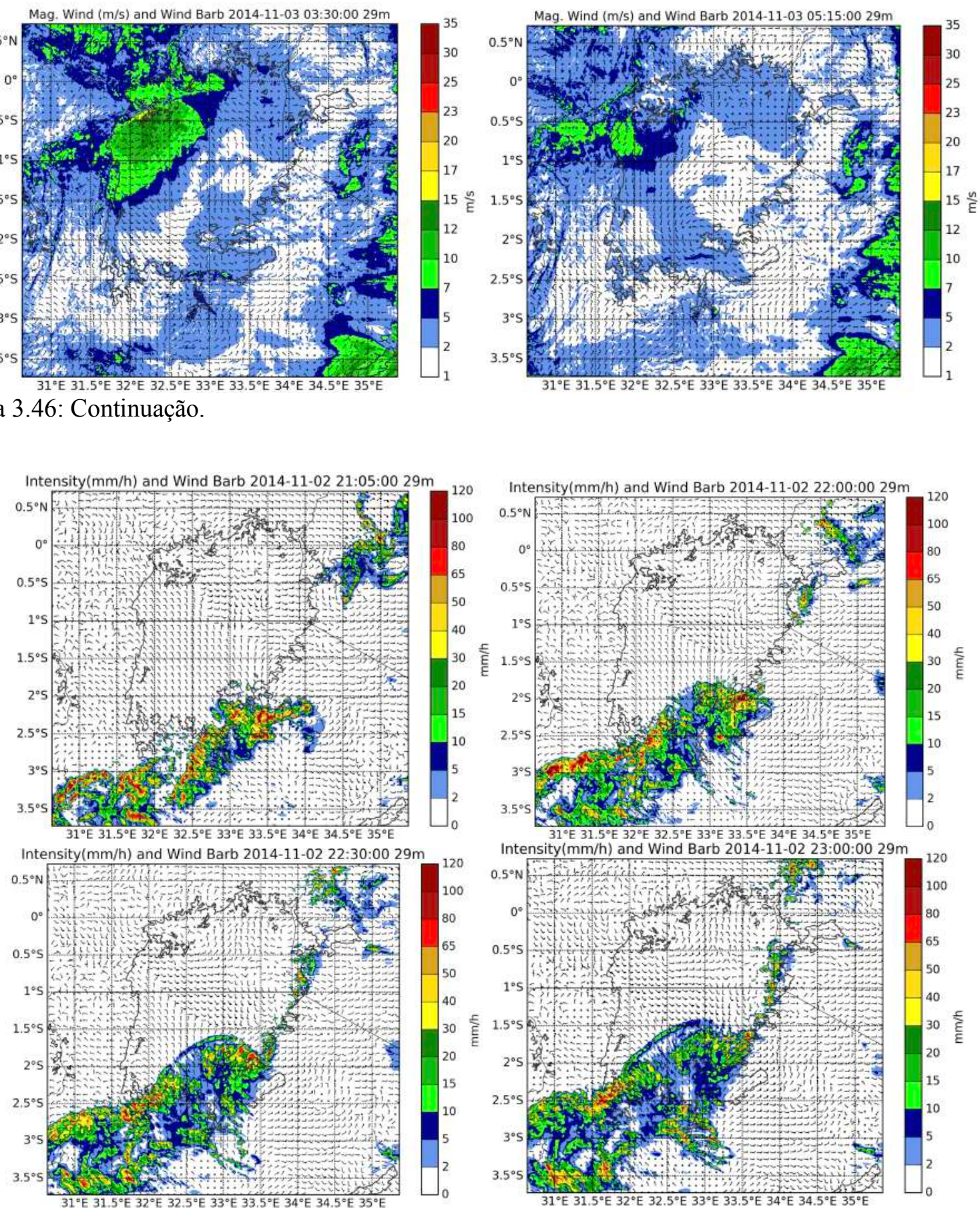

Figura 3.47: Campo de intensidade da precipitação para o evento de 03/11/2014 com TSL de $21.5^{\circ} \mathrm{C}$ simulada com o modelo ARPS. Contorno do LV e hora UTC está indicado. Simulação realizada com $500 \mathrm{~m}$ de resolução horizontal. Barra de cores indica intensidade em $\mathrm{mm} \mathrm{h}^{-1}$. 

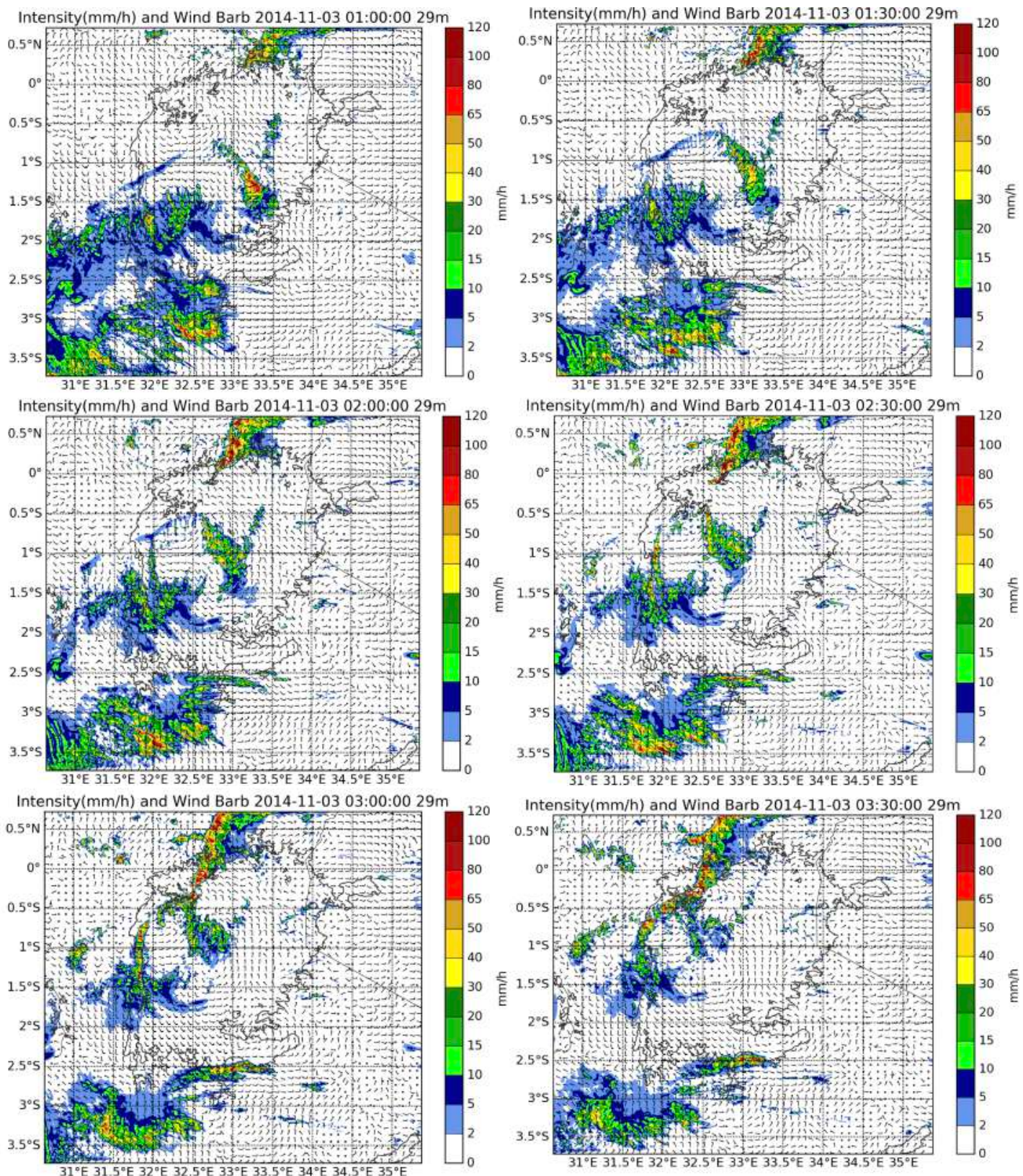

Intensity $(\mathrm{mm} / \mathrm{h})$ and Wind Barb 2014-11-03 04:00:00 29m
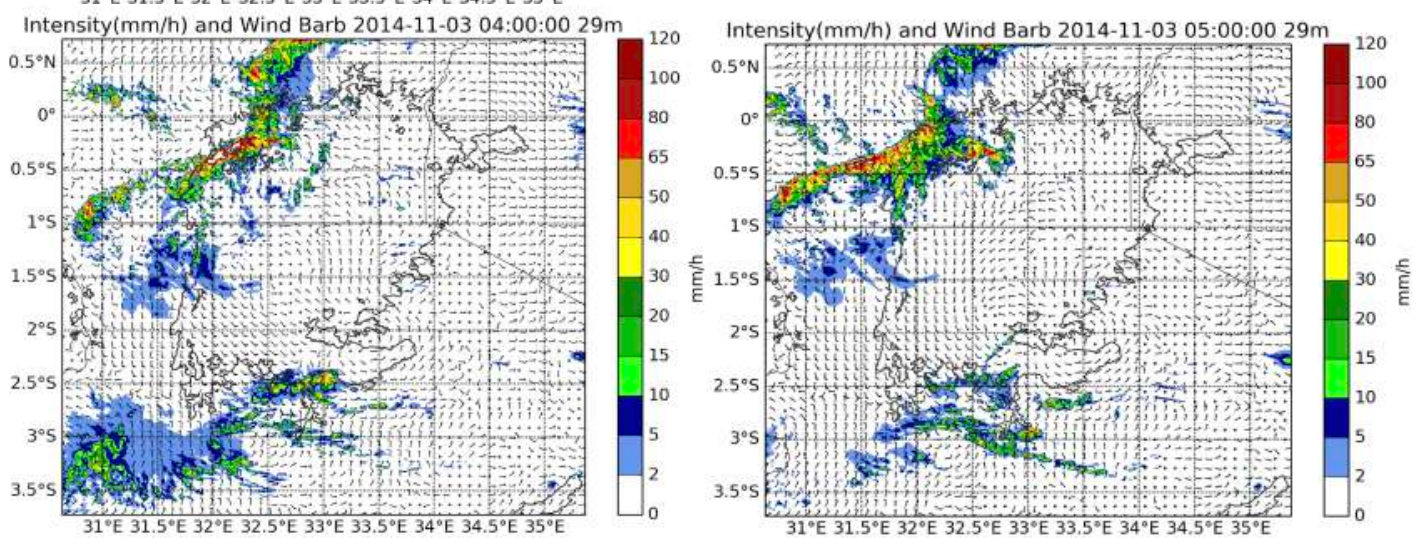

Figura 3.47: Continuação. 

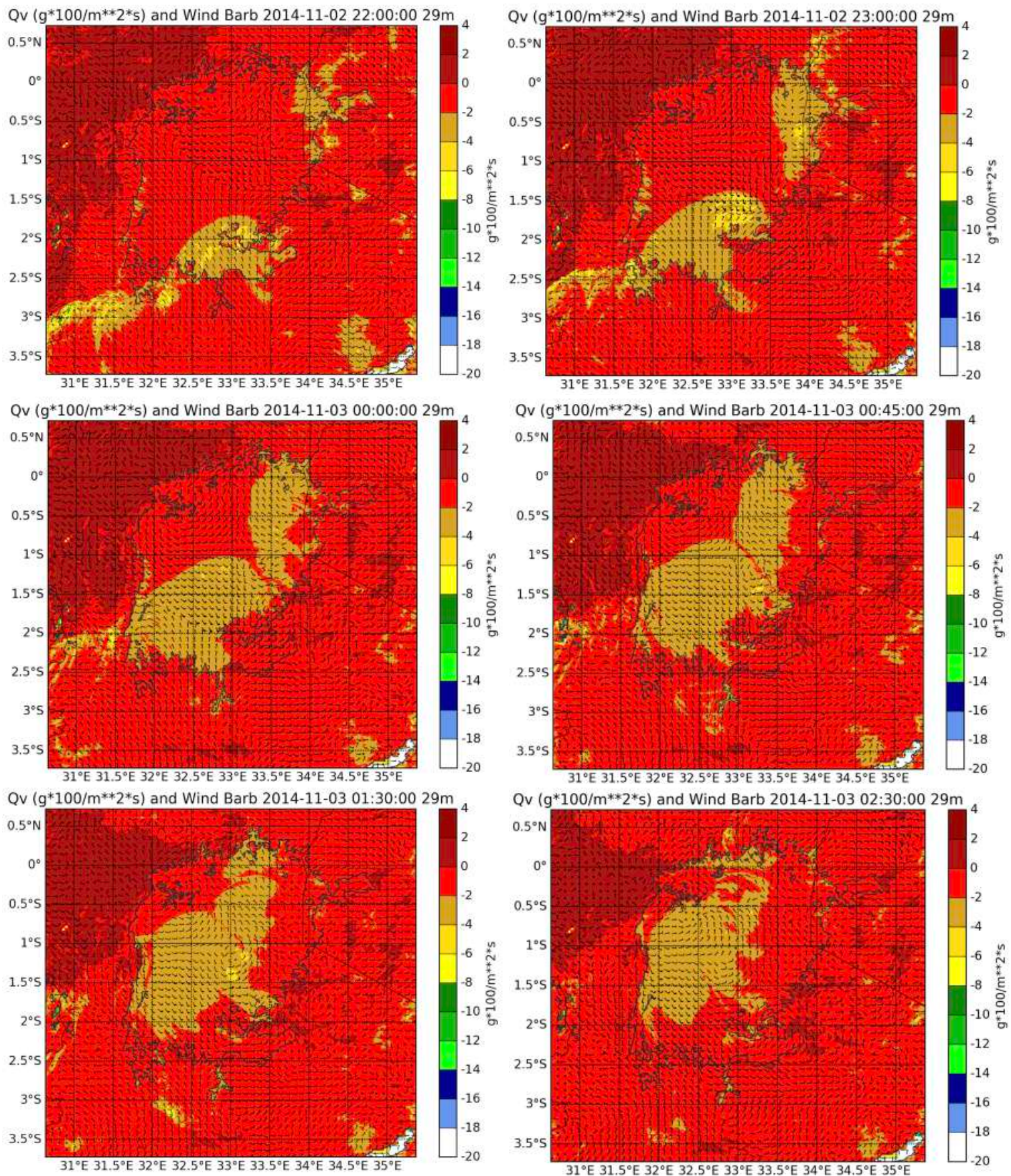

Figura 3.48: Campo de fluxo de vapor de água entre a superfície e o ar acima para o evento de 03/11/2014 com TSL de $21.5^{\circ} \mathrm{C}$ simulada com o ARPS. Simulação realizada com $500 \mathrm{~m}$ de resolução horizontal. Contorno do LV e hora UTC está indicado. Barra de cores indica intensidade fluxo em $\mathrm{g} * 100$ $\mathrm{m}^{-2} \mathrm{~s}^{-1}$. 

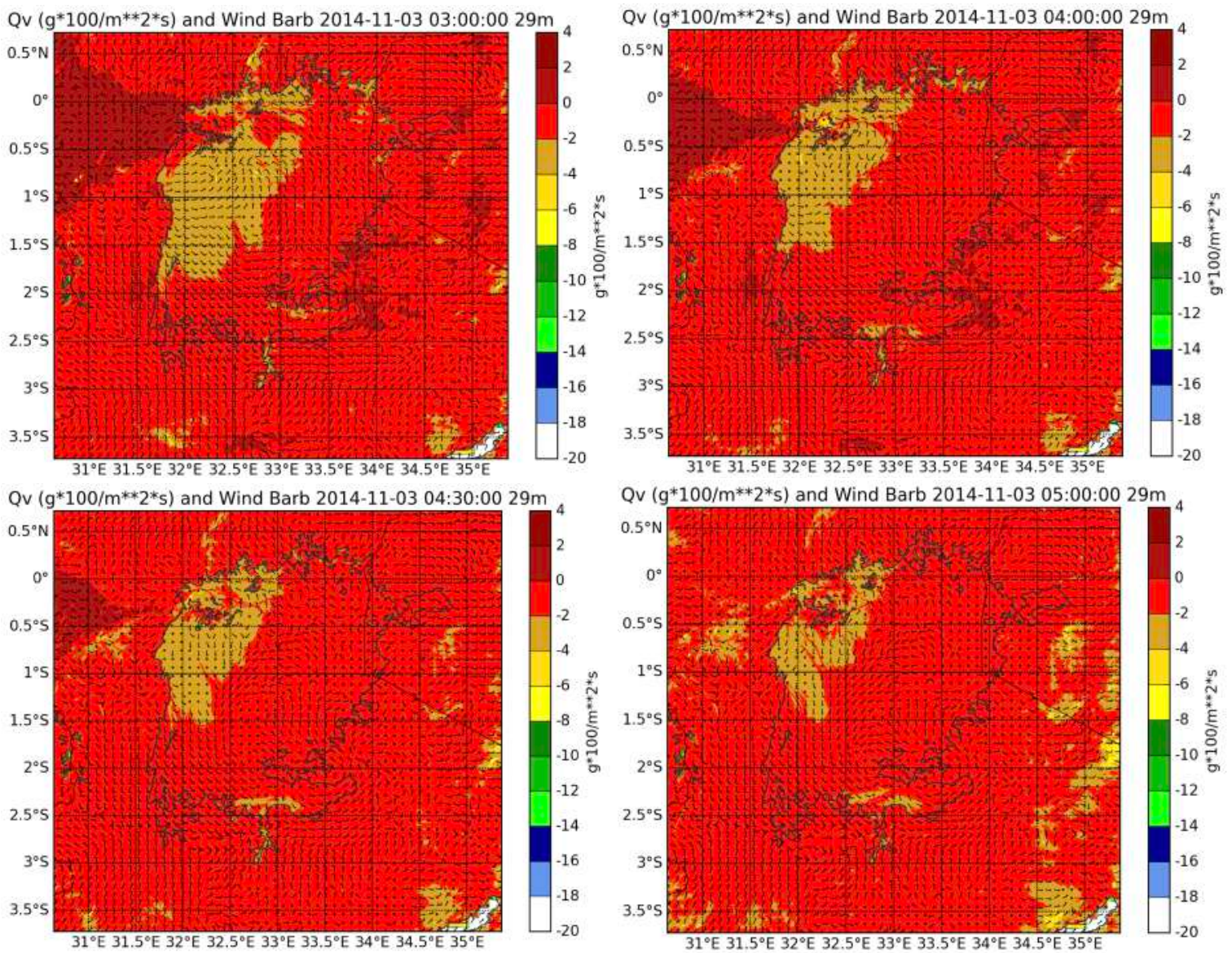

Figura 3.48: Continuação.
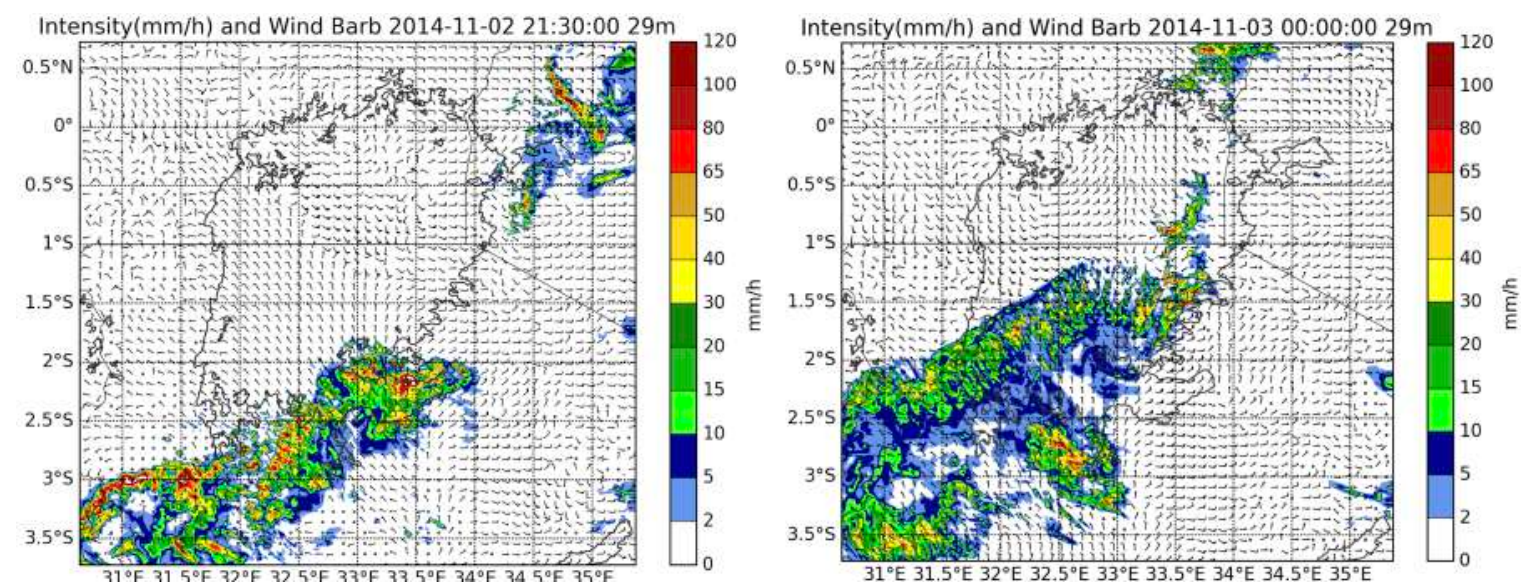

Figura 3.49: Campo de intensidade da precipitação para o evento de $03 / 11 / 2014 \mathrm{com}$ TSL de $24.5^{\circ} \mathrm{C}$ da simulação com o ARPS com $500 \mathrm{~m}$ de resolução espacial. Contorno do LV e hora UTC está indicado. Barra de cores indica chuva em $\mathrm{mm} \mathrm{h}^{-1}$. 

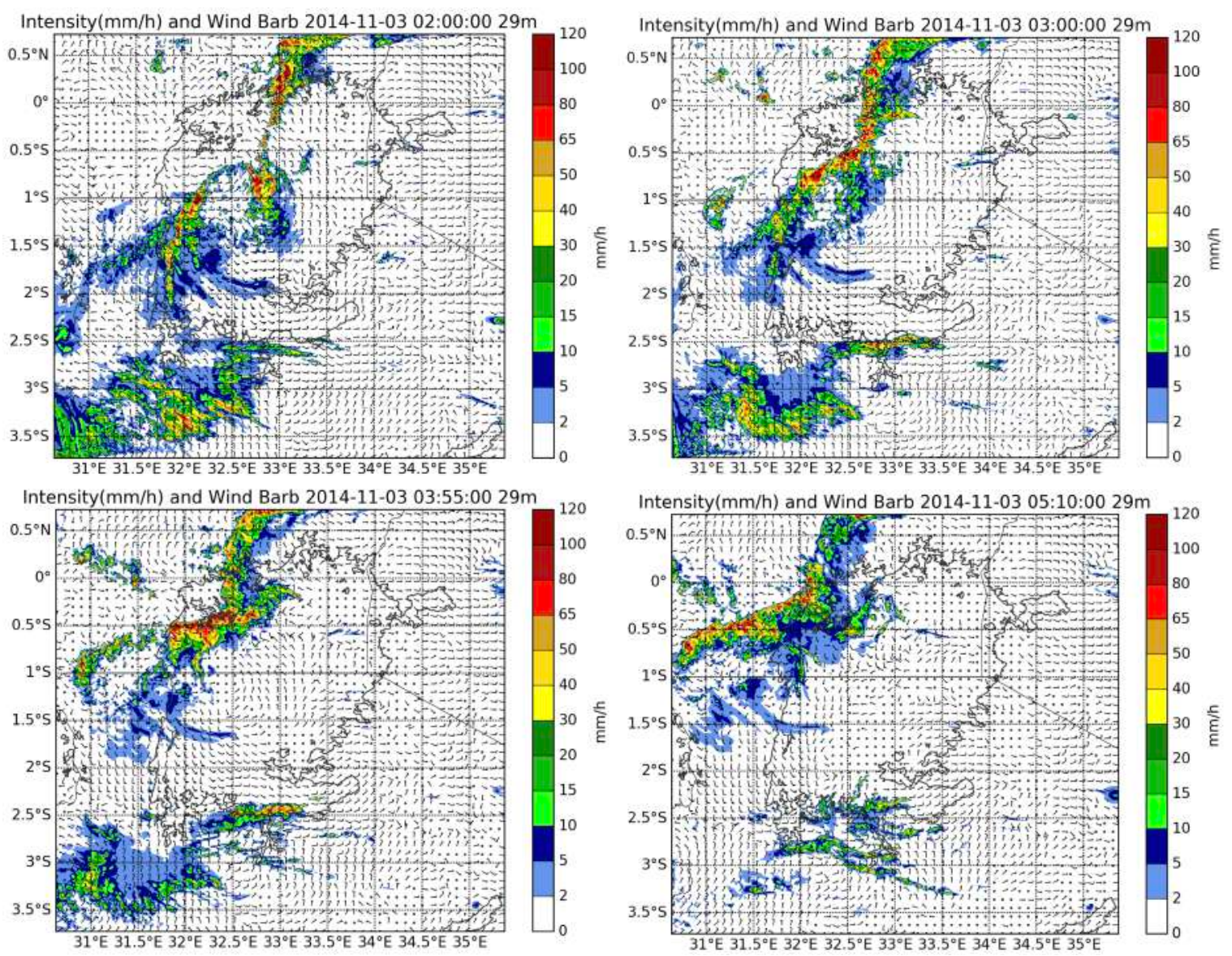

Figura 3.49: Continuação.

A figura 3.49 indica a intensidade da chuva para a simulação do evento do dia 03/11/2014 com a TSL da figura $2.3 \mathrm{c},\left(24.5^{\circ} \mathrm{C}\right)$. Basicamente, nota-se a mesma propagação dos sistemas, no entanto, dado ao LV mais aquecido, a CBL e a frente de rajada que passa sobre o mesmo gera células convectivas mais intensas do que na condição com TSL menor (Fig. 3.47). Em alguns pontos, nota-se até mesmo redução local da precipitação fora do lago devido a subsidência de compensação (Fig. 3.45). 

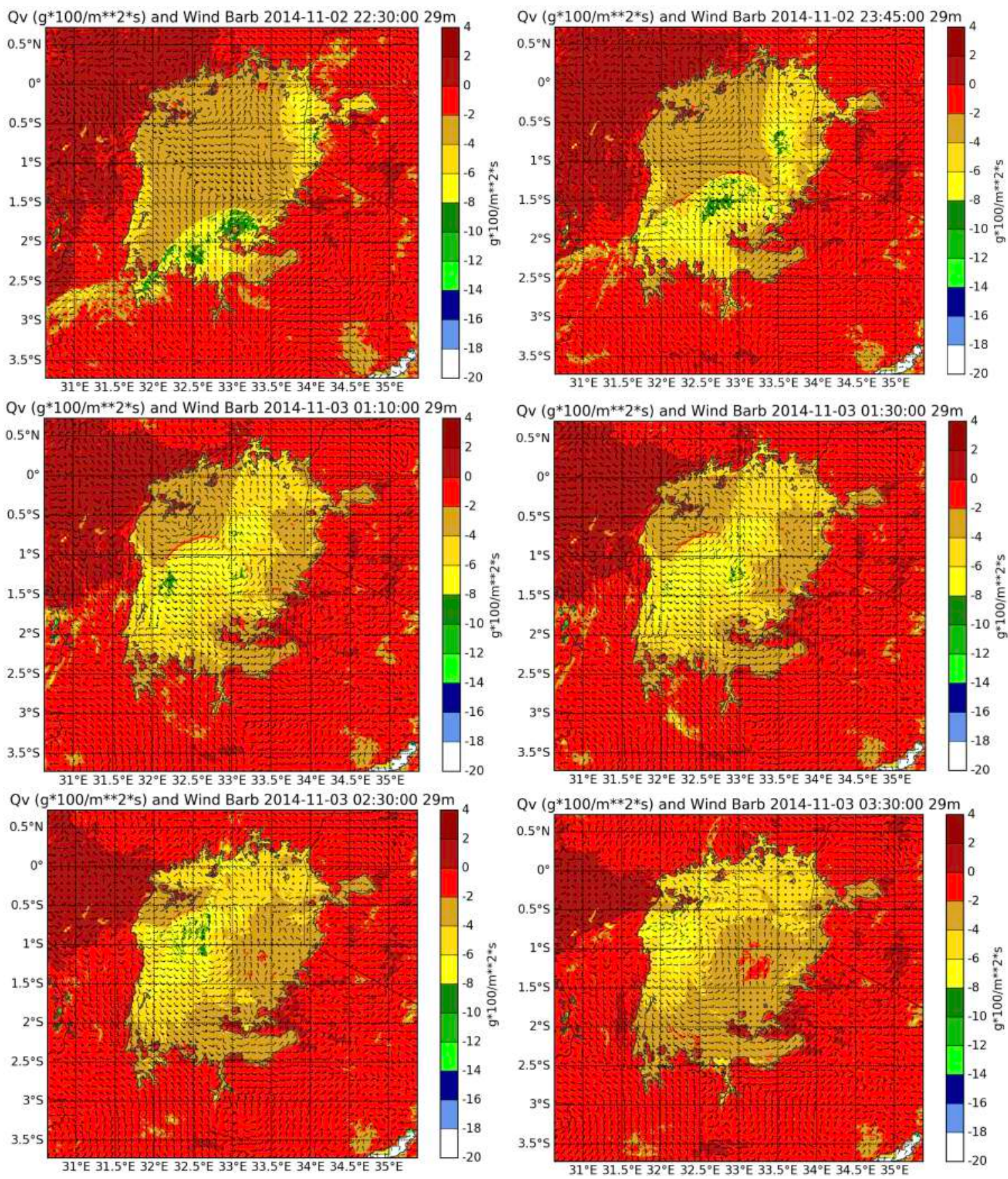

Figura 3.50: Campo do fluxo de vapor de água entre a superfície e o ar acima para o evento de 03/11/2014 com TSL de $24.5^{\circ} \mathrm{C}$ (Fig. 2.3b) simulado com o ARPS. Contorno do LV e hora UTC está indicado. Simulação realizada com $500 \mathrm{~m}$ de resolução horizontal. Barra de cores indica intensidade do fluxo em $\mathrm{g}^{*} 100 \mathrm{~m}^{-2} \mathrm{~s}^{-1}$. 

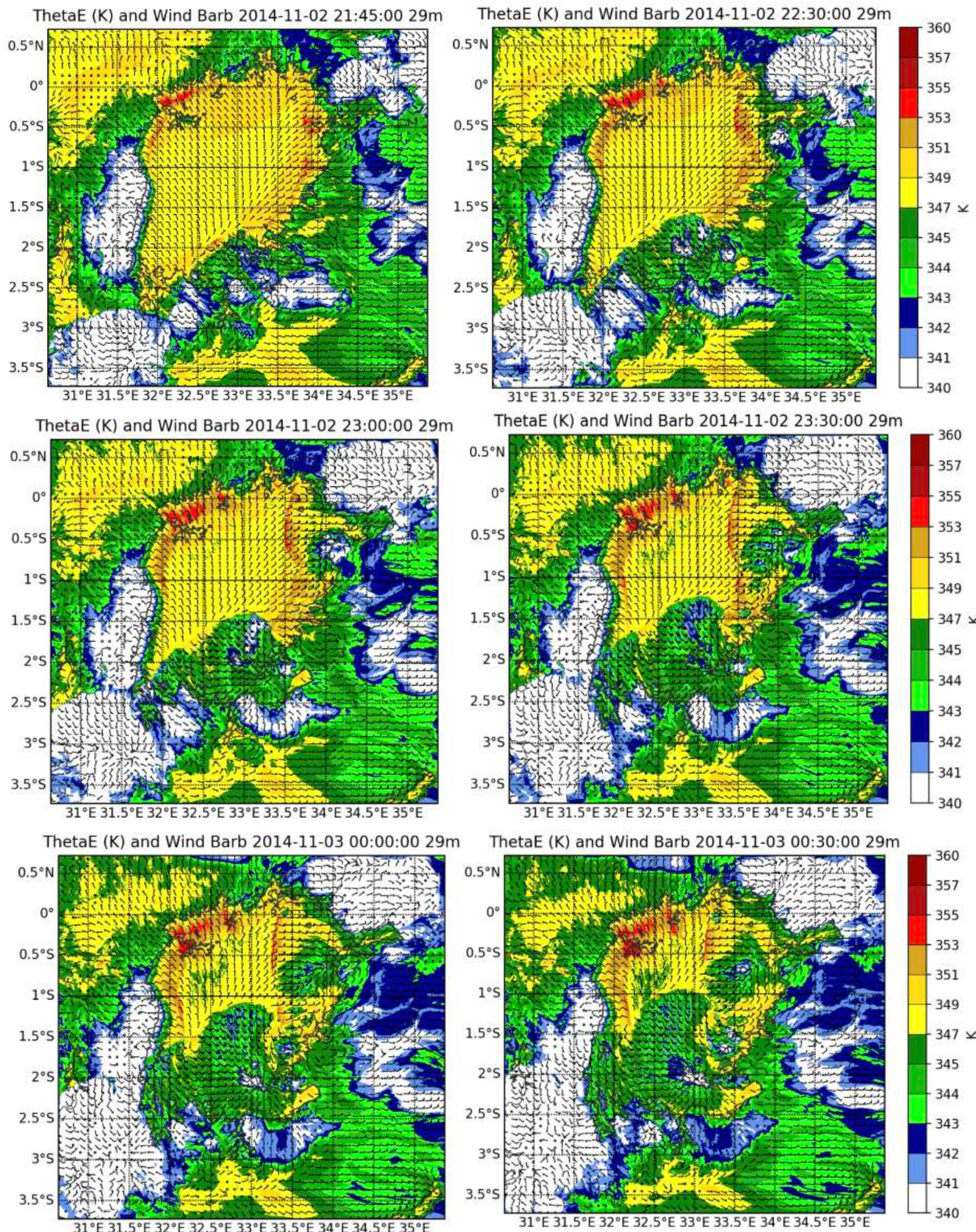

Figura 3.51: Campo de $\theta_{\mathrm{e}}$ para o evento de $03 / 11 / 2014$ com TSL de $24.5^{\circ} \mathrm{C}$ (Fig. 2.3b). Barra de cores indica ThetaE em K. Simulação realizada com $500 \mathrm{~m}$ de resolução horizontal. Contorno do LV e hora UTC está indicado. 

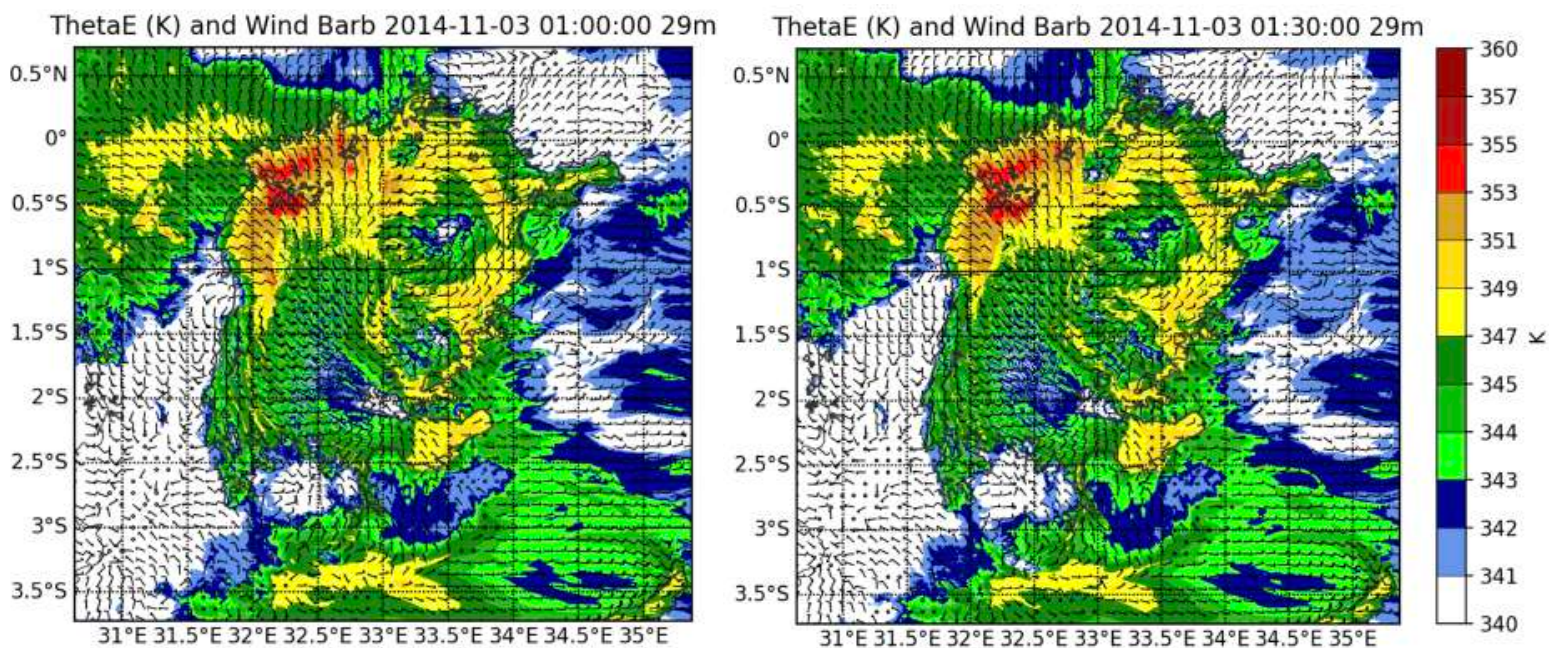

ThetaE (K) and Wind Barb 2014-11-03 02:00:00 29m
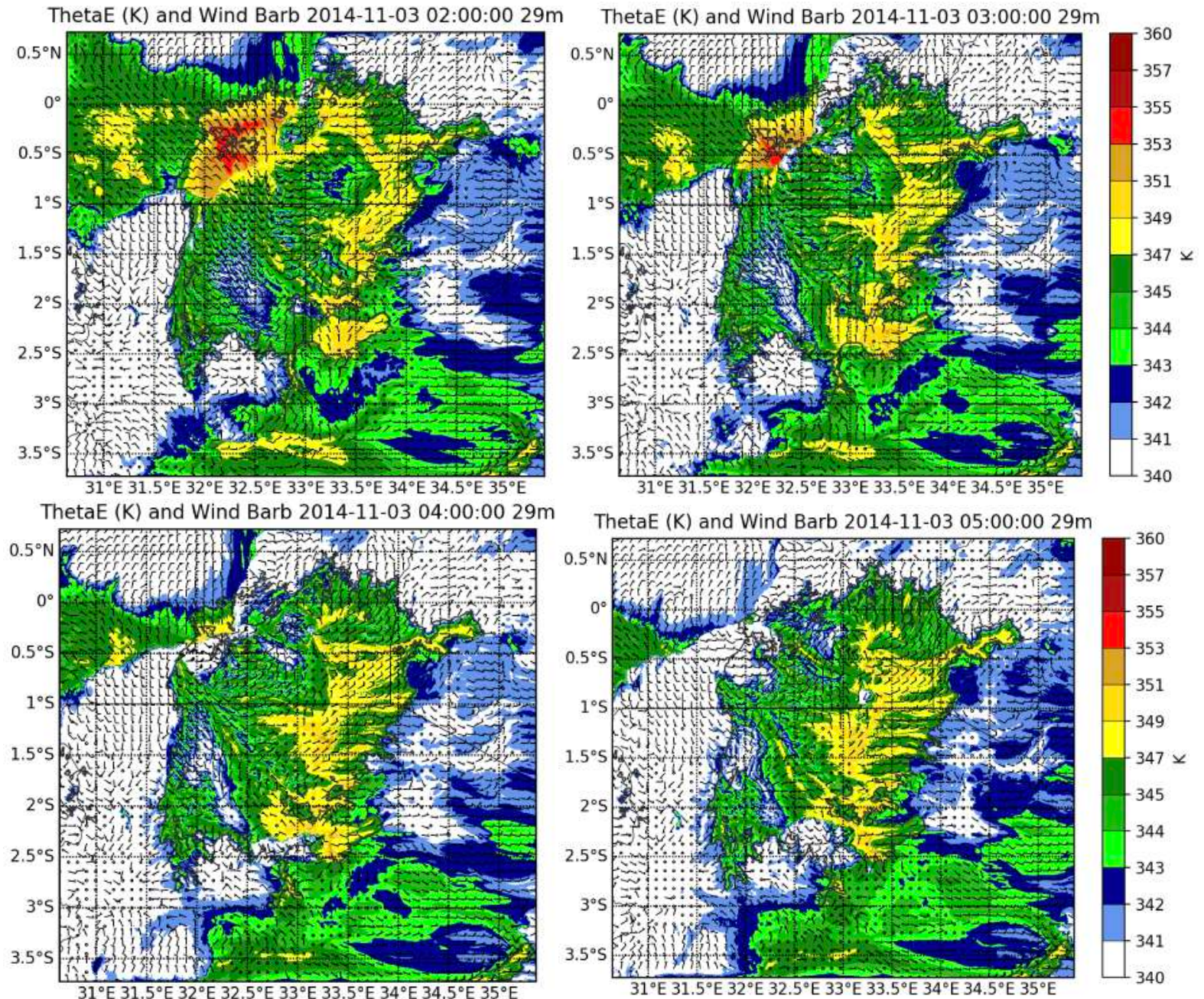

Figura 3.51: Continuação

A diferença no fluxo de vapor de água entre o LV e a atmosfera é aproximadamente 3 vezes maior para o lago com TSL em $24.5^{\circ} \mathrm{C}$ nas regiões de frente de brisa, ou seja, para um aumento de apenas $3^{\circ} \mathrm{C}$ tem-se uma diferença muito intensa no fluxo. $\mathrm{O}$ máximo simulado na condição com TSL em $21.5^{\circ} \mathrm{C}$ é por volta de $400 \mathrm{~g} \mathrm{~m}^{-2} \mathrm{~s}^{-1}$ (fig. 3.48), enquanto o máximo para a TSL de $24.5^{\circ} \mathrm{C}$ é de até $900 \mathrm{~g} \mathrm{~m}^{-2} \mathrm{~s}^{-1}$ (fig. 3.50). Para uma região em que as estimativas de temperatura 
do lago variam mais de $2^{\circ} \mathrm{C}$, se torna imprescindível uma rede de medição da TSL já que erros relativamente pequenos resultam em diferenças muito grandes nos fluxos de superfície e consequentemente no volume de chuva simulado.

Para este evento de convecção mais generalizada comparado ao evento do dia 03/11/2010, nota-se que no período da tarde do dia 02/11/2014 houve intensa convecção vespertina ao sul do lago com a formação de intensas frentes de rajadas. No decorrer do período noturno, essas frentes de rajadas entraram no LV pela borda sul. Nota-se na figura 3.51, que há uma redução de $\theta_{\mathrm{e}}$ (vapor de água) conforme essa frente de brisa se propaga e as chuvas vão estabilizando o a CLP. Paralelamente, a CBVM com a CBT se desenvolve na borda leste do lago e se desloca sobre o mesmo com a origem de uma linha tênue de máximo local de $\theta_{\mathrm{e}}$ associado a ventos mais intensos em superfície com maior fluxo de calor latente. Entre 0000 e 0030 UTC nota-se que no ponto de confluência entre essas 2 circulações, há o disparo de convecção profunda localizada com intensa precipitação que segue a região de confluência até chegar próximo à parte nordeste no lago. Nesse ponto de convergência entre a frente de rajada de sul, CBT de leste e CBT de norte é o local onde há a área mais abrangente com acumulados acima dos 100 mm. O desenvolvimento das células de tempestades sobre o lago consome CAPE com diminuição dos mesmos ao longo da madrugada. Toda a dinâmica de tempestades sobre o lago está associada à confluência de circulações locais entre si ou com outras frentes de rajadas originadas de tempestades pré-existente. Essa condição é valida mesmo na situação de convecção mais generalizada, pois a área de chuva mais intensa vai depender da região de convergência dessas linhas de frente de rajada e a CBL. Muitas vezes essas tempestades se originam no período da tarde no entorno do lago, que vai disparar convecção profunda sobre o LV apenas no período da madrugada devido ao tempo de deslocamento sobre o mesmo. Com $\mathrm{o}$ auxilio de um radar meteorológico banda $\mathrm{X}$ seria possível monitorar essas linhas finas associadas a essas frentes e estimar o ponto em que se dará o inicio do disparo da convecção. Além disso, seria possível um estudo mais detalhado da interação entre as frentes de brisa e frentes de rajadas, já que após a interação inicial entre 2 frentes, novas células convectivas se formam dando origem a novas frentes de rajadas e dá-se inicio a uma complexa interação dinâmica e termodinâmica.

Os volumes de precipitação estimados com o CMORPH são inferiores aos simulados com o ARPS. No entanto, vale ressaltar que a resolução horizontal do primeiro é de $8 \mathrm{~km}$, enquanto a do segundo é de apenas 500 metros. Uma análise mais detalhada sobre sub ou superestimavas de precipitação nesse contexto só seria possível por meio de estimativas de precipitação obtidas com radar meteorológico. 
Em suma, as conclusões para as simulações de outros eventos foram no mesmo sentido, mesmo na situação de convecção mais generalizada e indicam que uma rede de medições e monitoramento nessa área é de extrema importância para a simulação e a identificação de dias potencias com risco de chuva muito forte e intensas rajadas de vento. Mesmo em condições de convecção mais ampla um pequeno aumento na TSL resultou em tempestades com rajadas de vento em torno de $100 \mathrm{~km} \mathrm{~h}^{-1}$, enquanto que, para eventos mais localizados, esses eventos são ainda mais sensíveis a uma pequena diferença na TSL, no sentido de alterar-se de uma condição sem qualquer formação significativa de precipitação para outra com formação de tempo severo. 


\section{Capítulo 4}

\section{Conclusões}

O presente estudo começou por simulações iniciais de sensibilidade na TSL a fim de entender se sistema ARPS era capaz de simular as condições particulares do lago Vitória na formação das tempestades que ocorrem naquela região. Concluiu-se com esses testes que, o modelo simulou adequadamente as circulações locais de brisa lacustre e vale-montanha, assim como o disparo da convecção noturna. Após isso, objetivou-se nesse estudo entender o comportamento climatológico dos sistemas convectivos que atuam na região da África equatorial e no LV para isso, utilizou-se da base de estimativas de precipitação do CMORPH entre 2000-2014. Obteve-se a climatologia de chuva horária, mensal, anual, frequência de eventos precipitantes acima de limiares definidos (1, 5, 10 e $\left.20 \mathrm{~mm} \mathrm{hr}^{-1}\right)$ e estatísticas dos eventos atuantes com base no diagrama hovmoller e estudo de correlação das faixas de precipitação do diagrama. Os principais resultados encontrados com o CMORPH foram:

- Não somente o lago Vitória exerce forte influência na climatologia da precipitação, como também outros lagos nessa região da África. É nítido um máximo de precipitação sobre os lagos da região e principalmente sobre o LV, tal que o pico de máxima acumulação ocorre entre março e maio, e um pico secundário entre outubro e dezembro.

- Os mapas de chuva horária indicam que a maior da precipitação sobre o LV ocorre preferencialmente no período noturno, já que o LV fica mais aquecido que o seu entorno nesse período, e favorece o surgimento da circulação de brisa lacustre-terrestre, principalmente na borda leste, devido à circulação sinótica predominante de leste, que segue a propagação preferencial dos sistemas ao longo do ano e ficam evidentes pelo diagrama Hovmoller de ciclo diurno.

- A diferença de precipitação acumulada sobre o LV chega a $1000 \mathrm{~mm}$ ano-1 entre a borda leste e oeste do lago, com a máxima acumulação localizada na borda oeste. O pico de 
máxima acumulação na metade oeste chega a $3000 \mathrm{~mm}^{\mathrm{ano}}{ }^{-1}$ e na metade leste atinge um mínimo de $1200 \mathrm{~mm}^{2} \mathrm{ano}^{-1}$, basicamente porque devido aos ventos mais intensos de leste até o disparo da convecção a chuva se concentra na parte oeste do lago.

- As estatísticas obtidas com os diagramas hovmoller para todos os 33189 eventos entre 2000 e 2014 mostram que lago Vitória é fonte de 1/5 de todos os episódios que se originam na África equatorial entre as longitudes $24^{\circ} \mathrm{E}$ e $42^{\circ} \mathrm{E}$, o que implica que o lago não somente produz um alto impacto no volume de chuva localmente sobre ele, como também os episódios originados sobre ele podem contribuir para um aumento de precipitação a $500 \mathrm{~km}$ a oeste dele, sobre a floresta do Congo, seja por meio das ondas de gravidade produzidas por esses eventos de tempestades sobre o lago, seja por meio indireto pelas frentes de rajadas que produzem "piscinas de ar frio" que chegam até a borda leste da floresta do Congo no início da tarde.

- A distancia zonal, velocidade de fase e duração média dos eventos foram de $332 \mathrm{~km}$, $10.3 \mathrm{~m} \mathrm{~s}^{-1}$ e 10.7 horas, respectivamente. A maior parte dos eventos apresenta duração entre 8 e 12 horas (33.3\%), com distribuição quase gaussiana. Poucos eventos duraram menos de 5 horas (8.3\%) e mais de 20 horas (4.4\%) e aproximadamente $1 / 3$ dos eventos tiveram entre 12 e 20 horas de duração. $21.7 \%$ dos eventos apresentaram velocidade de fase entre 6 e $8 \mathrm{~m} \mathrm{~s}^{-1}, 20.8 \%$ entre 8 e $10 \mathrm{~m} \mathrm{~s}^{-1}, 5 \%$ apresentaram velocidade de fase superior a $20 \mathrm{~m} \mathrm{~s}^{-1}$ e $0.1 \%$ velocidade superior a $34 \mathrm{~m} \mathrm{~s}^{-1}$. A velocidade média de fase dos eventos que atuam na África equatorial foram ligeiramente mais lentos que os que atuam na região da Amazônia (12 $\mathrm{m} \mathrm{s}^{-1}$ ) [Pereira Filho et al., 2015]. A complexidade topográfica na região da África é maior que a da Amazônia, que é uma planície, logo, já se esperavam velocidades menores em média.

- $47.7 \%$ dos eventos percorreram menos que $300 \mathrm{~km}$ em longitude, $35 \%$ entre 300 e 400 $\mathrm{km}$ e menos que $1 \%$ mais que $700 \mathrm{~km}$. Episódios maiores que $600 \mathrm{~km}$ apresentam velocidade de fase média de $12 \mathrm{~m} \mathrm{~s}^{-1}$, ou seja, maior que os $10.3 \mathrm{~m} \mathrm{~s}^{-1}$ quando considerado todos os eventos. $50 \%$ dos episódios maiores que $600 \mathrm{~km}$ iniciam-se sobre o lago e influenciam a região da floresta do Congo, região que apresenta máximos anuais totais superiores a $4000 \mathrm{~mm} \mathrm{ano}^{-1}$.

Posteriormente aos resultados encontrados acima, objetivou-se estudar a dinâmica da complexa interação entre a circulação da brisa lacustre, circulação vale-montanha basicamente 
induzida pela cadeia de montanhas muito próxima do lago e a diferença de temperatura próximo a superfície causada pelo lago aquecido para o evento de 01/11/2010. As condições sinóticas predominantes na região são basicamente ventos de leste desde os baixos até os médios níveis sem nenhum evento transiente de latitude subtropicais na região. As simulações foram realizadas com o modelo ARPS utilizando condição inicial e de contorno do modelo "Global Forecast System” (GFS) para 3 grades centradas sobre o LV com 12 km, 4 km e $500 \mathrm{~m}$ de resolução espacial. Os resultados indicaram:

- Alta sensibilidade da formação da precipitação a pequenas diferenças na TSL do lago. Para uma temperatura média de $23.5^{\circ} \mathrm{C}$ nenhum evento se formou sobre o lago, embora tenha-se organizado o padrão de frente de brisa terrestre acoplada com a circulação de vale-montanha em ambas as bordas do lago, enquanto que, para uma TSL média de $25.5^{\circ} \mathrm{C}$, tempestades convectivas foram disparadas quando a frente de brisa de leste atinge a metade oeste do lago. Os fluxos de umidade associados a uma TSL $2^{\circ} \mathrm{C}$ superior aumentaram localmente o fluxo entre 6 a 8 vezes, quase 1 ordem de grandeza. As tempestades geradas apresentaram rajadas de vento entre 100 a $110 \mathrm{~km} \mathrm{~h}^{-1}$ na simulação.

- O padrão espacial de TSL do lago altera muito menos a amplitude e a fase da chuva do que a temperatura média do lago em si, ou seja, para uma mesma TSL média com um padrão espacial diferente não se esperam mudanças muito significativas no posicionamento e amplitude das tempestades.

- A frente de brisa terrestre de leste propaga-se por todo o lago, enquanto que a de oeste fica confinada muito próxima à borda do lago. Devido ao escoamento sinótico de leste, a propagação da primeira é na direção do escoamento sinótico, enquanto que a segunda é contra o escoamento. Deste modo, a espessura da frente de brisa de leste atinge quase o topo da camada limite planetária $(\sim 1500 \mathrm{~m})$ e a segunda uma espessura $\sim 500 \mathrm{~m}$, e mostra o importante acoplamento entre circulação local e sinótica.

- Os fluxos de calor latente na superfície se intensificam na frente de brisa conforme ela se propaga para oeste criando um máximo $\theta_{\mathrm{e}}$ local que aumenta de altura conforme propaga-se sobre o lago. Em determinando momento, a mesma atinge o 
nível de convecção espontânea (NCE) e inicia-se a formação das tempestades com propagação para oeste.

- Independente da TSL média utilizada, verificou-se que o disparo das tempestades ocorre quando o gradiente vertical de $\theta_{\mathrm{e}}$ de $-7 \mathrm{~K} / \mathrm{km}$ atinge o nível entre 1.7 e $1.8 \mathrm{~km}$ acima da superfície. Basicamente nesse limiar, a atmosfera se torna localmente muito instável com disparo da convecção.

- Com o calculo dos termos da equação de tendência de vorticidade vertical foi possível identificar que o principal termo na sua produção, foi o termo de inclinação, ou seja, o termo que converte os rolos horizontais produzidos pela CBL em vorticidade vertical. Basicamente, os rolos na dianteira da CBL são mais intensos e favorecem o levantamento dos rolos horizontais na traseira da CBL que são mais fraco. Esse processo, produz vorticidade vertical no nível logo acima, que é advectado para oeste. Ao longo da madrugada, o termo de inclinação produz continuamente vorticidade vertical que posteriormente vai favorecer o disparo da convecção profunda.

Com o entendimento de como é a interação entre a complexa topografia do lago na geração das circulações de brisa e vale-montanha e como ocorre o acoplamento entre as circulações locais e o escoamento sinótico, removeu-se a cadeia de montanhas no entorno do lago para efeito de remoção da circulação vale-montanha e o quanto a mesma influencia para desacelerar os ventos sinóticos de leste e obteve-se:

- Sem a cadeira de montanhas no entorno as simulações indicam uma frente terrestre mais intensa de leste. Embora não exista a circulação de vale-montanha sem a cadeia de montanhas a leste, a frente de brisa terrestre é gerada pela diferença de temperatura sobre o lago e o ar sobre a terra. Além disso, sem a existência da cadeia de montanhas a circulação sinótica de leste (alísios) não perde intensidade na barreira topográfica e intensifica o deslocamento da CBL para oeste, mais do que a CBVM gerada pela topografia.

- A velocidade média do vento de leste para a grade sem topografia é entre 1.5 e 2.0 $\mathrm{m} \mathrm{s}^{-1}$ superior à condição real, o que gera um fluxo de calor latente $\sim 20 \mathrm{~W} \mathrm{~m}^{-2}$ 
superior e favorece o disparo da linha de tempestades 1 hora antes quando comparado à grade realística.

- O nível de instabilidade atingido em ambas as simulações é similar, no entanto, ocorre antes na grade com terreno plano. Nesse caso, a instabilidade gerada é maior e produz acumulados pontuais máximos em torno de 3 vezes acima dos que ocorrem na grade com topografia realística. Além disso, a área com chuva é muito maior nessa condição.

- A diferença máxima no fluxo de calor latente chega a $\sim 40 \mathrm{~W} \mathrm{~m}^{-2}$ no fluxo de calor latente por volta das 0400 UTC, embora a maior parte do tempo seja a metade disso. Como a área do lago é de $68800 \mathrm{~km}^{2}$, isso representa $1,376 \times 10^{6} \mathrm{MW}$ no fluxo de calor latente entre o lago e a atmosfera, o que explica a produção de um volume de chuva entre 2 a 3 vezes maiores.

- A frente de brisa de oeste propaga-se por volta de $50 \mathrm{~km}$ lago adentro em ambas as simulações e indica que a cadeia de montanhas desse lado exerce menor influência no acoplamento com a circulação local. A cadeia de montanhas nesse lado do lago está consideravelmente mais distante e possui baixa declividade. Com as grades com ou sem a topografia nessa região, dada a baixa declividade da mesma, há pouca influencia na frente de brisa deste lado do LV, que basicamente tem como única forçante a diferença de aquecimento/resfriamento superficial entre o LV e o solo. Ressalta-se que, para a obtenção de uma simulação realística de como seria o comportamento climático das chuvas nessa região e da própria TSL do LV, seriam necessárias simulações de longo prazo sem a cadeia de montanhas e com modelagem hidrodinâmica do lago, já que a predominância de ventos mais intensos nessa região certamente reduziria a TSL no longo prazo. 


\section{Capítulo 5}

\section{Sugestões para trabalhos futuros}

Sugere-se para trabalhos futuros a possibilidade da continuidade e aprimoramento dos estudos aqui desenvolvidos:

- Realizar experimentos com rede de pluviômetros e medições da temperatura da superfície do lago para simulações com TSL medidas in locu, isso permitirá um estudo da eficácia do modelo ARPS em simular tempestades na região do LV com dados mais confiáveis de condição inicial, já que foi mostrado no decorrer da pesquisa que pequenas diferenças na TSL produzem diferenças significativas na intensidade das tempestades.

- As estimativas utilizadas aqui, foram as efetuadas por meio de sensoriamento remoto com satélite. Seria interessante a instalação de radar meteorológico para obter medições na região do LV pois apresentam fundamental importância para estudo das tempestades e até mesmo das estruturas finais associadas as frentes de brisa e de rajada para avaliação dos dados simulados com o modelo numérico. Além de permitir monitoramento e estudo desses sistemas, seria possível melhorar a previsibilidade da região por meio da modelagem numérica. Mesmo com o uso apenas do radar meteorológico é possível antever situações nas quais há risco para o disparo de tempestades apenas identificando pontos de confluência entre 2 frentes de brisa ou frente de rajadas.

- O experimento de campo poderia contar com uma rede de monitoramento de mesosescala com sensores de temperatura, direção e intensidade do vento e umidade no entorno do lago para assimilação com o modelo e também para estudo da intensidade das frentes de brisa lacustre e vale-montanha. A 
assimilação com o modelo melhoraria a previsibilidade do posicionamento das tempestades iniciais e as observações ajudariam a identificar padrões em superfícies horas antes do disparo da convecção profunda sobre o LV.

- Todas as sugestões anteriores, referem-se a instalação de equipamentos que podem não ser viáveis em vários pontos da região. Deste modo, com o que há disponível atualmente sugere-se obter estimativas do campo de direção e intensidade do vento por meio de dados de satélite para assimilação com modelagem numérica. Espera-se melhora nas simulações dos eventos. A TSL também pode ser assimilada por meio de sensoriamento remoto, mas suas estimativas divergem consideravelmente de uma estimativa para outra.

- Realizar simulações ao longo de 1 ano ou mais com diferentes configurações de TSL para identificação do quanto cada aumento de $1^{\circ} \mathrm{C}$ na TSL impacta no clima local e no seu entorno. Isso pode dar uma ideia a questões de como as mudanças climáticas podem alterar as condições na região da África equatorial. Nesse trabalho foi demonstrado que as frentes de rajada das tempestades formadas sobre o lago têm impacto inclusive no disparo das tempestades a centenas de quilômetros a oeste do LV, sobre a floresta do Congo. Portanto certamente haverá um impacto nas chuvas daquela região. 


\section{Referências Bibliográficas}

Alaka G J., Maloney E D., The Intraseasonal Variability of African Easterly Wave Energetics. Journal of climate, 2014, Vol. 27, p. 65596580

Albrecht, S., Goodman D., Buechler R, Blakeslee C., LIS 0.1 Degree Very High Resolution Gridded Lightning Diurnal Climatology (VHRAC). Dataset available online from the NASA global Hydrology Resource Center DAAC, 2016, Huntsville, Alabama, USA, doi: http://dx.doi.org/10.5067/LIS/LIS/DATA303

Alusa A L., The occurrence and nature of hailstorms in Kericho, Kenya. Preprints, Second WMO Scientific Conference on Weather Modification. Boulder, Colorado, August, WMO Geneva, 1976, p. 249256

Antonelli M., Rotunno R., Large-eddy simulation of the onset of the sea breeze. Journal Atmos. Sci., 2007, Vol. 64, p. 44454457

Anyah R., Modeling the variability of the climate system over Lake Victoria Basin $[\mathrm{Ph} . \mathrm{D}$. dissertation], North Carolina State University, 2005

Anyah R., Semazzi F., Xie L., Simulated physical mechanisms associated with climate variability over Lake Victoria in East Africa. Monthly Weather Review, 2006, Vol. 134, p. 35883609

Arrit R., Effects of the Large-Scale Flow on Characteristic Features of the Sea Breeze. Journal of Applied Meteorology, 1993, Vol. 32, p. 116125

Asefi-Najafabady S., Knupp K., Mecikalski R., Welch R., Philips D., Ground-based measurements and dual-Doppler analysis of 3-D wind fields and atmospheric circulations induced by a meso-scale inland lake. Journal Geophysical Research, 2010, Vol. 115, doi:10.1029/2010JD014022 
Asefi-Najafabady S., Knupp K., Mecikalski J R., Welch R M., Radar observation of mesoscale circulations induced by small lake under varying synoptic-scale flows. Journal of Geophysical Research, 2012, D01106, doi:10.1029/2011JD016194

Asnani G., Kinuthia J., Diurnal variation of precipitation in East Africa. East Africa Meteorology Dept. Memo, 1979, Vol 8, p. 58

Atkins T., Wakimoto R., Influence of the synoptic-scale flow on sea breezes observed during CaPE. Monthly Weather Review, 1997, Vol. 125, p. 21122130

Ba M B., Nicholson S E., Analysis of convective activity and its relationship to the rainfall over the Rift Valley lakes of East Africa during 1983-1990 using the METEOSAT infrared Channel. Journal of Climatology Applied Meteorology, 1998, Vol. 10, p. 12501264

Bechtold P., Pinty P., Mascart P., A numerical investigation of the influence of large-scale winds on sea-breeze and inland-breeze-type circulations. Journal of Applied Meteorology, 1991, Vol. 30, p. 12681279

Berhane F., Zaitchik B., Badr H S., The Madden-Julian Oscilation's influence on Spring Rainy Season Precipitation over Equatorial West Africa. Journal of Climate, 2015, Vol. 28, p. 8653 8672. DOI: 10.1175/JCLI-D-14-00510.1

Birkett C., Murtugudde R., Allan T., Indian Ocean Climate event brings floods to East Africa's lakes and the Sudd Marsh. Geophysical Research Letters, 1999, DOI:10.1029/1999GL900165

Cairns M., Collins R., Cylke T., Deutschendorf M., Mercer D., A lake effect snowfall in Western Nevada - Part I: Synoptic setting and observations. 18 ${ }^{\text {th }}$ Conf. On Weather Analysis and Forecasting, 2001, Fort Lauderdale, FL, Amer. Meteor. Society, p. 329332

Carbone R E., Tuttle J D., Ahijevych D A., Trier S B., Inferences of Predictability Associated with Warm Season Precipitation Episodes. Journal of the Atmospheric Sciences, 2002, Vol. 59, p. 20332056 
Chamberlain J., Bain L., Boyd D., McCourt K., Butcher T., Palmer S., Forecasting storms over Lake Victoria using a high resolution model. Meteorol Appl., 2013, doi:10.1002/met.1403

Cheng F., Byun D., Application of high resolution land use and land cover data for atmospheric modelling in the Houston-Galveston metropolitan area. Part I: meteorological simulation results. Atmos. Environ., 2008, Vol. 42, p. 77957811

Courault D., Drobinski P., Brunet Y., Lacarrere P., Talbot C., Impact of surface heterogeneity on a buoyancy-driven convective boundary layer in light winds. Boundary-Layer Meteorol, 2007, Vol. 124, p. 383403

Crosman E T., Horel J. D., Idealized Large-Eddy Simulations of Sea and Lake breezes; Sensitivity to lake Diameter, Heat flux and Stability. Boundary-Layer Meteorol., 2012, Doi: 10.1007/s10546-012-9721-x

Dandou A., Tombrou M., Soulakellis N., The influence of the city of Athens on the evolution of the sea-breeze front. Boundary-Layer Meteorol., 2009, Vol. 131, p. 3551

Datta R., Certain aspects of monsoonal precipitation dynamics over Lake Victoria. Monsoon Dynamics, J. Lighthill, and R. P. Pearce, Eds., 1981, Cambridge University Press, 333349

Diaz, M., Aiyyer, A. (2013) The Genesis of African Easterly Waves by Upstream Development. Journal of the Atmospheric Sciences, 2013, Vol. 70, p. 3492 3512. DOI: 10.1175/JAS-D-120342.1

Estoque M., A theoretical investigation of the sea breeze. Quarterly Journal Roy. Met. Soc., 1961, Vol. 87, p. 136146

Estoque M., The Sea breeze as a function of the prevailing synoptic situation. Journal of Atmospheric Science, 1962, Vol. 19, p. 244250 
Ferraro R., SSM/I derived global rainfall estimates for climatological applications. Journal Geophysics Research, 1997, Vol. 102, p. 1671516735

Ferraro R., Weng F., Grody N C., Zhao L., Precipitation characteristics over land from NOAA15 AMSU Sensor, Geophys. Res. Lett, 2000, Vol. 27(17), 26692672

Flohn H., Fraedrich K., Tagesperiodische Zirkulation und Nierderschlagsverteilung am Victoria-see, Ostafrika (Diurnal circulation and rainfall distribution on Lake Victoria, East Africa, in German). Meteorol. Rundschau., 1966, Vol. 19, p. 157165

Flohn H., East African rains of 1961/1962 and the abrupt changes of the White Nile discharge. Paleoclimatology of Africa, 1987, Vol. 18, p. 318

Flores J., Modelagem da camada limite planetária urbana com o Sistema ARPS - tTEB tese edn. Universidade de São Paulo - IAG - USP, 2017

Flores J., Pereira Filho A., Karam A., Vemado F., Masson V., Effects of Explicit Urban-Canopy Representation on Local circulation Above a Tropical Mega-City. Boundary Layer, 2018, Vol. 166, p. 83111

Freitas E., Rozoff C., Cotton W., Silva Dias P., Interactions of an urban heat island and sea breeze circulations during winter over the metropolitan area of São Paulo, Brazil. Boundary-Layer Meteorol., 2007, Vol. 122, p. 4365

Hallak R., Simulações numéricas de tempestades severas na RMSP tese edn. Universidade de São Paulo - IAG - USP, 2007

Harman J., Hebr J., Lake breezes and summer rainfall, Annual Associated America Geography, 1972, Vol. 62, p. 375387

Hickling F. Tropical Inland Fisheries. Longman \& CO, London, 1961 
Honda T., Kawano T., How does mid-tropospheric dry air affect the evolution of supercellular convection?, Atmospheric Research, 2015, vol. 157, p. 116

Hovmoller, E., The Trough-and-Ridge diagram, Tellus 1 (2), pp. 62-66, DOI:10.1111/j.21533490.tb01260.x

Huffman G., Adler R., Stocker E., Bolvin D., Nelkin E., Analysis of TRMM 3-hourly multisatellite precipitation estimates computed in both real and post-real time. $12^{\text {th }}$ Conf. on Satellite Meteorology and Oceanography, 2003, Long Beach, CA

Indeje M., Anyamba K., Sensitivity of mesoescale system over Kenya to changes roughness lenght. Journal of the African Meteorological Society, 1998, Vol. 3, p. 1933

Janowiak J E., Kousky V E., Joyce R J., Diurnal Cycle of Precipitation Determined from the CMORPH High Spatial and Temporal Resolution Global Precipitation Analyses. Journal of Geophysical Research, 2005, D23105. http://dx.doi.org/10.1029/2005JD006156.

Jehn H., A sea breeze bibliography. Atmospheric Science Group, The university of Texas, 1973, Vol. 37, p. 16641972

Joyce R J., Janowiak J E., Arkin P A., Xie P., A method that produces global precipitation estimates from passive microwave and infrared data at high spatial and temporal resolution. Journal Hydrometeorology, 2004 , Vol. 5, p. 487503

Kala J., Lyons T., Nair U., Numerical simulations of the impacts of land-cover change on a southern sea breeze in south-west western Australia. Boundary-Layer Meteorol., 2010, Vol. 135, p. 485503

Karam H., Pereira Filho A., Masson V., Noilhan J., Marques Filho E., Formulation of a tropical town energy budget (t-TEB) scheme. Theor. Appl. Climatol., 2010, vol. 101, p. 109120

Karina W., Chamberlain J., Buontempo C., Bain C., Regional climate model performance in the Lake Victoria basin. Climate Dynamics, 2015, Vol. 44, p. 16991713 
Kiladis G N., Wheeler M C., Haertel P T., Straub K H., Roundy P E., Convectively Coupled Equatorial Waves. Reviews of Geophysics, 2009, Vol. 47, RG2003/2009 1-42. http://dx.doi.org/10.1029/2008RG000266.

King M J., Wheeler C. M., Lane P T., Association of Convection with the 5-Day RossbyHaurwitz wave. Journal of the Atmospheric Sciences, 2015, Vol. 72, p. 3309 3321. DOI: 10.1175/JAS-D-14-0316.1.

Kizza M., Rodhe A., Xu C-Y., Ntale K H., Halldin S., Temporal rainfall variability in the lake victoria basin in east Africa during the twentieth century. Theo. Applied Clim., 2009, Vol. 98, p. 119135

Kizza M., Westerberg I., Rodhe A., Ntale K H., Estimating areal rainfall over Lake Victoria and its basin using ground-based and satellite data. Journal of Hydrology, 2012, Vol. 464-465, p. 401411

Knapp K., Ansari S., Bain C., Bourassa M., Dickinson M., Funk C., Helms C., Hennon C., Holmes C., Huffman G., Kossin J., Lee H., Loew A., Magnusdottir G., Globally gridded satellite observations for climate studies. Bull. American Meteorol. Society, 2011, Vol. 92, p. 893 907

Kousky V E., Janowiak, J E., Joyce R J., The Diurnal Cycle of Precipitation over South America Based on CMORPH. Proceedings of 8 ICSHMO, INPE, 2006, Foz do Iguaçu, 1113-1116

Kummerow C., The evolution of the Goddard profiling algorithm (GPROF) for rainfall estimation from passive microwave sensors. Journal Appl. Meteor, 2001, Vol. 39, p. 1801 1820

Laing A G., Carbone R E., Levizzani V., Tuttle J., The Propagation and Diurnal Cycle of Deep Convection in Northern Tropical Africa. Quarterly Journal of the Royal Meteorological Society, 2008, Vol. 134, p. 93109 
Laing A G., Carbone R E., Levizzani V., Cycles and Propagation of deep convection over equatorial Africa. Mon. Weather Rev, 2011, Vol. 139, 28322853

Laird F N., Kristovich A R D., Liang X-Z., Arrit W R., Labas K., Lake Michigan lake breezes: Climatology, Local Forcing and Synoptic Environment. Journal of Applied Meteorology, 2001, Vol. 40, p. 409424

Laird F N., Walsh J E., Kristovich A R D., Model Simulations Examining the Relationship of the Lake-Effect Morphology to Lake Shape, Wind Direction and Wind Speed. Monthly Weather Review, 2003, Vol. 131, p. 21022111

Laird F N., Desrochers J., Payer M., Climatology of Lake-effect precipitation Events over Lake Champlain. Journal of Applied Meteorol., 2009, Vol 48, p. 232250

Lemonsu A., Bastin S., Masson V., Drobinski P., Vertical structure of the urban boundary over Marseille under sea-breeze conditions. Boundary-Layer Meteorol., 2006, Vol. 118, p. 477 501

Lenouo A., Sall S M., Badiane D., Mkankam F K., Intense convection over West Africa during AMMA SOP3 experiment. Atmospheric Research, 2016, Vol. 180, p. 111. http://dx.doi.org/10.1016/j.atmosres.2016.05.002

Li Y., Li J., Jin F., Zhao S., Interhemispheric Propagation of Stationary Rossby Waves in a Horizontally Nonuniform Background Flow, 2015, Vol. 72, p. 3233 3256, DOI: 10.1175/JAS-D-14-0239.1

Li Q., Bou-Zeid E., Vercauteren N., Parlange M., Signatures of Air-Wave interactions Over a Large Lake, Boundary-Layer Meteorol, 2018, Vol. 167, p. 445468

Lin, Y.-L., Farley, D., Orville, H., Bulk parametrization of the snow field in a cloud model, J. Clim. Appl. Meteorol., 22, 10651092

Linch J., Lake Victoria and Invasive Species and Trade. TED Case Studies, 1997 
Liu Y., Weaver C., Avissar R., Towards a parametrization of mesoscale fluxes and moist convection induced by landscape heterogeneity. Journal of Geophysic Research, 1999, Vol. 104, p. 515533

MacCallum S., Merchant C., ARC-Lake V1.1 - Global, 1995-2009. Universidade de Edinburgh, escola de geociência/Agência espacial da Europa., 2011, http://www.geos.ed.ac.uk/arclake

Marshall C., Pielke R., Steyaert L., Willard D., The impact of anthropogenic land-cover change on the Florida peninsula sea breezes and warm season sensible weather. Mon. Weather Rev., 2004, Vol. 132, p. 2852

Mekonnen A., The role of Kelvin wave activity on convection and rainfall over tropical Africa. 27th Conference on Hurricane and Tropical Meteorology, Monterey, CA, American Meteological Society, 2006, 4D.2. http://ams.confex.com/ams/pdfpapers/108508.pdf

Mekonnen A., Thorncroft C D., Aiyyer A R., Kiladis, G N., Convectively Coupled Kelvin waves over tropical Africa during the Boreal Summer: Structure and Variability. Journal of Climate, 2008, Vol. 21, p. 66496667

Miao J., Kroon L., Arellano V., Holtslag, A., Impacts of topography and land degradation on the sea breeze over eastern Spain. Meteorol. Atmos. Phys., 2003, Vol. 84, p. 157170

Miller S., Arkin P., Joyce R., A combined microwave/infrared rain rate algorithm. Int. Journal. Remote Sen., 2001, Vol. 22, p. 32853307

Mukabana J., Pielke, R., Investigating the influence of sypnoptic-scale monsoonal winds and mesoescale circulations and diurnal weather pattern over Kenya using a mesoescala numerical model. Monthly Weather Review, 1996, Vol. 124, p. 224243

Neumann J., Savijarvi H., The sea breeze on a steep coast. Beitr. Phys. Atmos., 1986, Vol. 59, p. 375389 
Nicholson S.E., A review of climate dynamics and climate variability in Eastern Africa. The limnology, climatology, and paleoclimatology of the East African lakes. Springer, 1996, Dordrecht, pp 2526

Niziol T., Winter Weather Forecasting throughout the Eastern United States. Part IV: Lake Effect Snow, Weather and Forecasting, 1995, Vol. 10, p. 6177

Okonga J., A review of estimation of rainfall and evaporation over Lake Victoria. Directorate of Water Developmente, Water Resources Management Department, Entebbe., 2001, Paper presented at LVEMP Conference, Kisumu, Kenya.

Omondi O., Observed Diurnal Cycle of Precipitation over Lake Victoria Basin based on TRMM satellite Estimate. Dissertação edn, College of Atmospheric Science, Nanjing, Jiangsu Province - China, 2017

Orlanski I., A rational subdivision of scales for atmospheric processes. Bull. American Meteorology Society, 1975, Vol. 56, p. 527530

Pereira Filho A J., Carbone E R., Tuttle D J., Karam A. H., Convective Rainfall in Amazonia and Adjacent Tropics. Atmospheric and Climate Sciences, 2015, Vol. 5, 137161

Pereira Filho A J., Pereira J., Vemado F., Silva, I W., Operational Hydrometeorological Forecast System for Espírito Santo State, Brazil. Journal Hydrol. Eng., 2015, DOI: 10.1061/(ASCE)HE.1943-5584.0001215

Pereira Filho A J., Vemado F., Saito K., Seko H., Flores, J L F., Karam, H., ARPS simulation of Convection during TOMACS. Journal of the Meteorological Society of Japan, 2018, Vol. 96A, pp. 00 00, DOI:10.2151/jmsj.2018-030

Piper S., Plinston D., Sutcliffe J., The water balance of Lake Victoria. Hydrology Science Journal, 1986, Vol. 31, 2537 
Pielke R., A three-dimensional numerical model of the sea breezes over south Florida. Monthly Weather Review, 1974, Vol. 102, p. 115139

Porson A., Steyn D G., Schayes G., Formulation of an index for sea breeze in opposing winds. Journal Climate Applied Meteorology, 2007, Vol. 46, p. 12571263

Ramis C., Romero R., A first numerical simulation of the development and structure of the sea breeze in the island of Mallorca. Ann Geophys, 1995, Vol. 13, p. 981994

Reible D., Simpson J., Linden P., The sea breeze and gravity-current frontogenesis. Quartely Journal of the Royal Meteorological Society, 1993, Vol. 119, p. 116

Rotunno R., On the linear theory of the land and sea breeze. Journal of Atmospheric Science, 1983, Vol. 53, p. 26242651

Rudlosky S D., Shea D T., Evaluating WWLLN performance relative to TRMM/LIS. Geophysical Research Letters, 2003, Vol. 40, p. 2344 2349, doi:10.1002/grl.50428

Savijarvi H., Matthews S., Flow over small heat islands: a numerical sensitivity study. Journal Atmos. Sci., 2004, Vol. 61, p. 859868

Segal M., Leuthold M., Arrit W., Anderson C., Shen J., Small Lake Daytime breezes: Some observational and Conceptual Evaluations, American Meteorological Society, 1997, Vol. 78, p. 11351148

Sha W., Ogawa S., Iwasaki, T., A numerical study on the nocturnal frontogenesis of the sea breeze front. Journal Meteorol. Soc. Jpn., 2004, Vol. 82, p. 817823

Sharon E N., Xungang Y., Mamoudou B B., On the feasibility of using a lake water balance model to infer rainfall: an example from Lake Victoria. Hidrological Sciences Journal, 2000, Vol. 45:1, p. 7595 
Shen J., Numerical modelling of the effects of vegetation and environmental conditions on the lake breeze. Boundary-Layer Meteorol., 1998, Vol. 87, p. 481498

Sinclaire Z., Lenouo A., Tchawoua C., Janicot S., Synoptic Kelvin type perturbation waves over Congo Basin over the period 1979-2010. Journal of Atmospheric and Solar-Terrestrial Physics, 2015, Vol. 130-131, p. 43 56. http://dx.doi.org/10.1016/j.jastp.2015.04.015

Song Y., Semazzi F H M., Xie L., Ogallo L J., A coupled regional climate model for the Lake Victoria basin of East Africa. International Journal Climatology, 2004, Vol. 24, p. 5775

Soula S., Kasereka J K., Geogis J F., Barthe C., Lightning climatology in the Congo Basin. Atmospheric Research, 2016, Vol. 178-179, p. $304 \quad 319$. http://dx.doi.org/10.1016/j.atmosres.2016.04.006

Spigel R H., Coulter G W., Comparison of hydrology and physical limnology of the East African Great Lakes: Tanganyika, Malawi, Victoria, Kivu and Turkana (with reference to some North American Great Lakes). The Limnology, Climatology and Paleoclimatology of the East African Lakes (ed. by T. C. Johnson \& E. Odada), 1996, p. 103139

Steenburgh J., Halvorson S., Onton D., Climatology of Lake-Effect Snowstorms of the Great Salt Lake. Monthly Weather Review, 2000, Vol. 128, p. 709727

Stivari S M S., Oliveira A P., Karam H A., Soares J., Patterns of local circulation in the Itaipu Lake area: Numerical simulations of Lake breeze. Journal Applied Meteorology, 2003, Vol. 42(1), p. 3750

Stivari M S S., Oliveira A P., Soares J., On the climate impact of the local circulation in the ITAIPU lake área. Climate Change, 2005, Vol. 72, p. 103121

Sun L., Semazzi F., Giorgi F., Ogallo L., Application of NCAR regional climate model to eastern Africa. Part I: simulation of the autumn rains of 1988. Journal of Geophysical Research, 1999, Vol. 104, p. 65296548 
Sun X., Xie L., Semazzi, H M F., Liu B A., Numerical Investigation of the Precipitation over Lake Victoria Basin Using a Coupled Atmosphere-Lake Limited-Area Model. Hindawi Publishing Corporation, 2014, http://dx.doi.org/10.1155/2014/960924

Sun X., Xie L., Semazzi F., Liu B., Effect of Lake Surface Temperature on the Spatial Distribution and Intensity of the Precipitation over the Lake Victoria Basin. Monthly Weather Review, 2015, Vol 143, p. 11791192

Sutcliffe J V., The influence of Lake Victoria: climate change and variation in river flows. The Jonglei Canal: Impact and Opportunity (ed. by P. P. Howell, M. Lock \& S. Cobb), 1988, p. 87 99

Thompson W., Holt T., Pullen J., Investigation of a sea breeze front in an urban environment. Quartely Journal Royal Meteorol. Soc., 2007, Vol. 133, p. 579594

Tijm A., Delden A., Holtslag A., The inland penetration of sea breezes. Contrib Atmos. Phys., 1999, Vol. 72, p. 317328

Turk F., Ebert B., Sohn H., Levizzani E., Smith A., Ferraro R., Validation of a operational global precipitation analysis at short time scales. $12^{\text {th }}$ Conf. on Satellite Meteorology and Oceanography, 2003.

Vegunopal V., Virts K., Sukhatme J., Wallace J M., Chattopadhyay B., A comparison of the finescale structure of the diurnal cycle of tropical rain and lightning. Atmospheric Research, 2015, Vol. 169, p. 515 522. http://dx.doi.org/10.1016/j.atmosres.2015.09.004

Vemado F. Análise da circulação de brisa marítima e seus impactos sobre a precipitação na Região Metropolitana de São Paulo por meio do modelo ARPS. Dissertação de Mestrado (IAG-USP), 2012

Vemado F., Pereira Filho A J., Severe weather caused by heat island and sea breeze effects in the metropolitan area of São Paulo, Brazil. Advances in Meteorology, 2016, doi:10.1155/2016/8364134 
Vincente G., Hourly retrieval of precipitation rate from the combination of passive microwave and infrared satellite measurements. Universidade de Wisconsin, tese, 1994, $127 \mathrm{pp}$

Walters DN., Best MJ., Bushell AC., Copsey D., Edwards JM., Fallon PD., Harris CM., Lock AP., Manners JC., Morcrette CJ., Robberts MJ., Stratton RA., Webster S., Wilkinson JM., Willett MR., Boutle IA, Earnshaw PD., Hill., PG., MacLachlan C., Martin GM., Moufouma-Okia W., Palmer MD., Petch JC., Rooney GG., Scaife AA., Williams KD., The met office unified model global atmosphere 3.0/3.1 and JULES global land 3.0/3.1 configurations. Geoscience Model Dev., 2011, Vol. 4, p. 12131271

Wang J., Bras R., Elthair E., A stochastic linear theory of mesoscale circulation induced by the thermal heterogeneities of land surface. Journal of Atmospheric Science, 1996, Vol. 53, p. 33493366

Wang B., Kelvin Waves. Shankar, M., Ed., Elsevier Science Ltd., 7p, 2002, http://www.soest.hawaii.edu/

Weaver J., Avissar R., Atmospheric disturbances caused by human modification of the landscape. Bull. Am. Meteorol. Soc., 2001, Vol. 82, p. 269281

William K., Chamberlain J., Buontempo C., Bain C., Regional climate model performance in the Lake Victoria basin. Climate Dyamic, 2014, Vol. 44, p. 16991713

Xue M., Droegemeier K K., Wong W., Shapiro A., Brewster K., Advanced Regional Prediction System Users Guide. University of Oklahoma, USA, 1995, 380pp

Xue M., Droegemeier K K., Wong W., The Advanced Regional Prediction System (ARPS) - A multi-scale nonhydrostatic atmospheric simulation and prediction model. Part I: Model dynamics and verification. Meteorology Atmospheric Physics, 2000, Vol. 75, p. 161193 
Xue M., Droegemeier K K., Wong W., Shapiro A., Brewster K., Carr F., Weber D., Liu Y., Wang D H., The Advanced Regional Prediction System (ARPS) - A multi-scale nonhydrostatic atmospheric simulation and prediction model. Part II: Model physics and applications. Meteorology Atmospheric Physics, 2001, Vol. 76, p. 143165

Xue M., Wang D H., Gao J., Brewster K., Droegemeier K K., The Advanced Regional Prediction System (ARPS), storm-scale numerical weather prediction and data assimilation. Meteorology Atmospheric Physics, 2003, Vol. 82, p. 139170

Xue M., Martin W J., A high-resolution modeling study of the 24 May 2002 dryline case during IHOP. Part II: Horizontal Convective Rolls and Convective Initiation. Monthly Weather Review, 2006, Vol. 134, p. 172191

Yan H., Anthes R A., The effect of latitude on the sea breeze. Monthly Weather Review, 1987, Vol 115, p. 936956

Yang G., Slingo J., The diurnal Cycle in the Tropics. Monthly Weather Review, 2001, Vol. 129, p. 784801

Yin X., Nicholson S E., The water balance of Lake Victoria. Hydrology Sci. Journal, 1998, Vol. 43(5), p. 789811

Zhong S., Leone J., Takle E., Interaction of the sea breeze with a river breeze in an area of complex coastal heating. Boundary-Layer Meteorol., 1991, Vol. 56, p. 101139

Zhong S., Takle E., An Observational Study of Sea- and Land Breeze circulation in an Area of Complex Coastal Heating. Journal of Applied Meteorology, 1992, Vol. 31, p. 14261438 